\title{
A Review of the Fossil Record of Old World Turtles of the Clade Pan-Trionychidae
}

\author{
Georgios L. Georgalis ${ }^{1}$ and Walter G. Joyce ${ }^{2}$ \\ ${ }^{1}$ Corresponding author: Department of Geosciences, University of Fribourg, 1700 Fribourg, Switzerland, \\ and Dipartimento di Scienze della Terra, Università di Torino, 10125 Turin, Italy \\ -email: georgios.georgalis@unifr.ch \\ ${ }^{2}$ Department of Geosciences, University of Fribourg, 1700 Fribourg, Switzerland \\ _email: walter.joyce@unifr.ch
}

\begin{abstract}
Turtles of the clade Pan-Trionychidae have a rich fossil record in the Old World, ranging from the Early Cretaceous (Hauterivian) to the Holocene. The clade most probably originated in Asia during the Early Cretaceous but spread from there to the Americas and Europe by the Late Cretaceous, to India and Australia by the Eocene, and to Afro-Arabia by the Neogene. The presence of a single pan-cyclanorbine in the Late Cretaceous (Maastrichtian) of Asia provides a minimum estimate for the age of the trionychid crown. As preserved, diversity was relatively high in Asia during the Late Cretaceous, but the subsequent, strong decline is likely a preservational bias, as extant faunas are relatively rich, especially throughout Asia. The range of trionychids contracted southward in Europe over the course of the Neogene, and the group is now locally extirpated. The group is now similarly absent from Arabia and Australia. A taxonomic review of the 180 named Old World taxa finds 42 nomina valida, 38 nomina invalida, 88 nomina dubia, 11 nomina nuda, and 1 nomen suppressum.
\end{abstract}

KEYWORDS

Phylogeny, biogeography, Pan-Trionychidae, Pan-Cyclanorbinae, Trionyx

\section{Introduction}

Pan-Trionychidae (see Vitek and Joyce [2015] for definition) is a highly distinctive clade of turtles characterized by a reduced shell that lacks peripherals, pygals, an ossified bridge, and scutes (Meylan 1987; Vitek and Joyce 2015). Extant trionychids have a relatively broad distribution across all tropical to warm temperate portions of Africa, Asia, New Guinea, and North America (Ernst and Barbour 1989). Although the group does not permanently inhabit any part of Europe, stray individuals of Trionyx triunguis are occasionally found in Greece, which wash in from the adjacent coasts of Asia Minor (Taskavak et al. 1999; Corsini-Foka and Masseti 2008). Because of the distinct sculpturing on the external surface of their shells, pantrionychids are readily recognized in the fossil record. The primary goal of this contribution is to document the rich fossil record of the group in the Old World from the Early Cretaceous to the
Holocene. The fossil record of the group from the New World was recently documented elsewhere (Vitek and Joyce 2015).

The first description of fossil pan-trionychids from the Old World was made by Cuvier (1812, 1821-1824, 1835-1836) on the basis of fragmentary remains found throughout France. Soon after, fossil pan-trionychids were also reported from Germany (Meyer 1832; Kaupp 1834; Fitzinger 1836) and Italy (Sismonda 1836, 1839) and later from Austria (Hörnes 1848; Peters 1855), England (Owen in Owen and Bell 1849), Spain (Ezquerra del Bayo 1850), Switzerland (Pictet and Humbert 1856), Croatia (Peters 1859), and Hungary (Peters 1859). Over the course of the second half of the 19th century and the beginning of the 20th century, almost every new find from Europe was treated as a new taxon (e.g., Laube 1900; Reinach 1900; Lörenthey 1903; Heritsch 1909; Teppner 1913, 1914c). This proliferation of names is well exemplified by the Italian record. The fossil localities 
of Monte Bolca and Monteviale in this country yielded a series of pan-trionychid specimens that were unusual for the time by being well preserved and often complete (including skulls, shells, and limb elements). However, strict application of typological species concepts prompted early workers to name a plethora of taxa, most of which occurred sympatrically in these two localities (Schauroth 1865; Negri 1892, 1893; Sacco 1894, 1895). We show here, however, that lineage-based species concepts coupled with a better understanding of intraspecific variation (Meylan 1987; Gardner and Russell 1994; Vitek and Joyce 2015) reveal that these localities only document the presence of a single lineage. Hummel $(1929,1932)$ provided the first complete lists of all fossil pan-trionychids named to date and a first indication that many species, especially those based on fragments, should be considered dubious, but that did not stop Bergounioux (1933, 1934b, 1935, 1936, 1938, $1953,1954)$ from naming many more fossil taxa based on fragmentary remains from localities across France, Italy, and Spain. Of the taxa established by the latter author, we here recognize all as nomina dubia or junior synonyms of others.

Over the course of the second half of the 20th century, only few additional taxa were named from Europe (e.g., Hernández Sampelayo and Bataller 1944; Gramann 1956; Moody and Walker 1970; Walker and Moody 1974; Broin 1977; Rieppel 1979; Gemel 2002). Instead, most new finds were referred to already known species or recognized as not being diagnostic at the species level (Kuss 1958; Mottl 1967; Kotsakis 1977; Barbera and Leuci 1980; Böhme 1995). The fossil record of European pan-trionychids was partially or fully summarized by Kuhn (1964), Młynarski (1976), Broin (1977), Lapparent de Broin (2001), and Danilov (2005), but these workers did not try to elucidate the interrelationships or the validity of all named taxa, perhaps because of the daunting nature of this task. This contrasts with a series of papers provided by Karl (1993, 1998, 1999b), who strongly simplified the taxonomy of European pan-trionychids through explicit synonymies, often with extant taxa.

The first fossil pan-trionychids from Asia were reported by Clift (1828), followed by Falconer (1831, 1859), Cautley (1836), Falconer and Cautley (1837), Meyer (1865), Lydekker (1885, 1889b), and Pilgrim (1912), all based on abundant material from British India, now India and Pakistan. This region has since yielded additional pan-trionychid remains (Prasad 1974; West et al. 1978, 1991; Sahni et al. 1981, 1984; Corvinus and Schleich 1994; Head et al. 1999; Srivastava and Patnaik 2002), but most are fragmentary. Jaekel (1911) reported new material from Indonesia and erected new Quaternary taxa from Java. Matsumoto (1918) described the first fossil pan-trionychids from Japan, and additional finds have since been reported from this country on a regular basis (Chitani 1925; Otsuka 1969, 1970; Okazaki and Yoshida 1977; Miura and Uyama 1987; Hasegawa et al. 2007), including what may be the remains of the most basal known pantrionychids (Hirayama et al. 2013). Gilmore (1931, 1934) reported the first fossil pan-trionychids from deposits near the Chinese-Mongolian border, and a wealth of new material has been unearthed and described ever since from these two countries (Chow and Yeh 1957, 1958; Yeh 1962, 1963, 1965, 1974; Khosatzky 1976; Shuvalov and Chkhikvadze 1979; Lei and Ye 1985; Chkhikvadze and Shuvalov 1988; Li, Joyce, and Liu 2015; Li, Tong et al. 2015). In parallel, fossiliferous localities in Kazakhstan, Kyrgyzstan, and Uzbekistan have yielded abundant pan-trionychid material that resulted also in an array of new taxa (e.g., Prinada 1927; Riabinin 1938; Khosatzky 1957; Chkhikvadze 1971, 1973, 2008a; Kuznetsov 1978; Nessov 1986, 1995b; Kuznetsov and Chkhikvadze 1987). Most named taxa from the Asian mainland lack adequate figuring and rigorous description and the systematics of these fossils therefore remains poorly understood. The situation has improved dramatically over the course of the last few years through a series of papers (Vitek and Danilov 2010, 2012, 2013, 2014, 2015; Danilov and Vitek 2012, 2013; Danilov et al. 2014; Danilov, Sukhanov et al. 2015; Danilov, Vitek et al. 2015) that revised many pan-trionychid faunas from this region and established several new taxa that are based on more complete material.

The fossil record of Afro-Arabian pan-trionychids remains obscured to date as most of the finds are only poorly documented. The stage was already set by Lydekker (1889a) who reported a large pantrionychid specimen from the Eastern Arabian Desert but did not figure the remains. Additional finds have since been reported from Arabia and the Middle East by Bate (1934), Thomas et al. (1980), Roger et al. (1994), Lapparent de Broin and van Dijk (1999), and Beech and Hellyer (2005), but 
fossils remain both scarce and poorly documented. The first pan-trionychid remains from Africa per se were reported by Andrews (1902, 1906), Reinach (1903), and Dacqué (1912). Whereas relatively rich material has since been documented from Kenya that serves as the basis several pan-cyclanorbine taxa (e.g., Andrews 1914; Broin 1979; Pickford 1986; Meylan et al. 1990), most new pan-trionychid material from the remainder of that continent is relatively fragmentary (Broin 1979; Wood 1987, 2013; Hirayama 1992) or just listed as a side note (Arambourg 1947; Bishop and Pickford 1975; Pickford 1975, 1986, 2008; Vignaud et al. 2002).

Australia has a scarce pan-trionychid fossil record. As early as 1869, Clarke already reported fossil pan-trionychids from that continent, but these cannot be reevaluated, as they were not described, figured, or deposited in a collection. Verifiable pan-trionychids were otherwise reported by De Vis (1894) and more recently by Gaffney and Bartholomai (1979), White (2001), and Louys and Price (2015). It is characteristic of the scarcity of remains that only two taxa have been named from Australia (De Vis 1894; White 2001), of which we here consider only one to be valid.

Some groups of fossil vertebrates have trionychid-like sculpturing and it is therefore not surprising that several fossils were historically attributed to this group in error. Among fossil turtles, these include Aspideretes planicostatus Riabinin, 1930, which has since been reassigned to lindholmemydids (recombined as Lindholmemys planicostata; Danilov et al. 2002); Trionyx bakewelli Mantell, 1833, a helochelydrid (now recombined as "Helochelydra" bakewelli; Joyce 2017); Trionyx mantelli Gray 1831, a nomen nudum that is likely "senior synonym" of the previously listed species; Trionyx bellunensis Misuri, 1911, a cheloniid (junior synonym of Trachyaspis lardyi; Chesi et al. 2007); Castresia munieri De Stefano, 1902 and T. granosa Pomel 1847, now known to be pan-carettochelyids (the former a junior synonym of Allaeochelys parayrei; Joyce 2014; the other a nomen nudum); Trionyx sansaniensis Bergounioux, 1935, a chelydrid (junior synonym of Chelydropsis murchisoni; Joyce 2016); Trionyx schlotheimii Fitzinger, 1836, most probably an emydid (junior synonym of Emys orbicularis; Geinitz 1877); and Kappachelys okurai Hirayama et al., 2013, which was recently shown to be an indeterminate pan-trionychian that lacks unambiguous pan-trionychid characteristics (Nakajima et al. in press). We here add Trionyx melitensis Lydekker, 1891, to this list. This middle Miocene turtle was initially described as the best documented pan-trionychid remain from Malta and was even reassigned to the cyclanorbine lineage (Lapparent de Broin and Van Dijk 1999), but the unique sculpturing of the holotype combined with the presence of scute sulci clearly reveal that this is a marine turtle reminiscent of Trachyaspis spp. Of special mention here are furthermore Trionyx impressus, Trionyx miliaris, Trionyx spinosus, and Trionyx sulcatus, which were named by Kutorga $(1835,1837)$ based on fragmentary material from the Devonian of Estonia but have since been shown to be dermocranial fragments of psammosteid heterostracans and placoderms (Halstead Tarlo 1965; Denison 1978).

We here provide the first global overview of the taxonomy and fossil record of pan-trionychids from the Old World, which is complementary to the review of Vitek and Joyce (2015) regarding the taxonomy and fossil record of the group from the New World. The enormity of the task prompts us to be as succinct as possible. To accomplish this, we firstly keep our taxonomic justifications to a minimum, especially for the long list of taxa we conclude to be nomina nuda and nomina dubia, as lengthily discussions would be endlessly repetitive, given that we decline the validity of most taxa for the same reasons. We here openly acknowledge that many of the fossil taxa we here deem to be valid do not display unique apomorphic features and therefore cannot be justified globally, but rather only within a particular temporal and regional context. We therefore keep our diagnoses to a bare minimum by only highlighting characters that are relevant within a certain context (i.e., Paleogene pan-trionychids from Europe), instead of providing long lists of unique character combinations that overlap greatly with those of other taxa. We finally do not discuss two names that have been noted in the literature briefly, but that only exist on museum labels, in particular Trionyx gaudini, a name mentioned by Lawley (1876) for material housed in Siena, Italy, and T. miocenicus, a name mentioned by Broin (1977) for specimens housed at MHNT (see Appendix 1 for institutional abbreviations).

It is not unusual among fossil turtles that phylogenetic relationships remain poorly resolved, but pan-trionychids are notable in that it is difficult to group fossil species into genera. Therefore, 
according to Vitek and Joyce (2015), we place most of the valid taxa we recognize in the wastebasket genus "Trionyx," instead of maintaining a plethora of monotypic genera. We here only make exception for (1) fossil taxa that can be grouped into genera (e.g., Khunnuchelys spp.), (2) fossil taxa from the Mesozoic that most certainly will never be assigned to any extant genus, (3) a selected number of Cenozoic taxa with particularly unique morphologies (e.g., Murgonemys braithwaitei), and (4) fossil taxa that can be assigned clearly to extant genera (e.g., Pelodiscus gracilia). Although the usage of a wastebasket taxon is suboptimal, we find this approach preferable to the extensive use of monotypic genera, as these do not encode additional information.

For institutional abbreviations, see Appendix 1. Named Old World pan-trionychid genera are listed in Appendix 2.

\section{Skeletal Morphology of Pan-Trionychids}

The bizarre nature of the shell of pan-trionychids makes them readily distinguishable from other turtles, a condition that has also rendered their monophyly as "de facto." Moreover, the highly distinctive shell sculpturing preserved in almost all fossil specimens of the group renders them easily identifiable among fossil remains even as fragments. The large amount of variation that is apparent in this sculpturing unfortunately prompted many early chelonian workers to diagnose many species on the basis of shell sculpturing pattern only, but this character has since been shown to be highly variable, although some species can be recognized regionally using their sculpturing (Vitek and Joyce 2015). For the skeletal morphology of Pan-Trionychidae, including descriptions of the cranium, carapace, plastron, and the postcranium, we here refer the reader to the recent summary of Vitek and Joyce (2015).

Among fossil taxa from the Old World, meaningful cranial descriptions are available for Axestemys vittata (Walker and Moody 1985), Kuhnemys orlovi (Danilov et al. 2014), Khunnuchelys erinhotensis (Brinkman et al. 1993), Khunnuchelys kizylkumensis (Brinkman et al. 1993), Khunnuchelys lophorhothon (Danilov, Vitek et al. 2015), Perochelys lamadongensis (Li, Joyce, and Liu 2015), “Trionyx" gregarius (Gilmore 1934), "T." ikoviensis (Danilov et al. 2011), “T.” messelianus (Cadena
2016), “T.” silvestris (Walker and Moody 1974; Broin 1977), and T. vindobonensis (Broin 1977).

Important descriptions of the shells of fossil Old World taxa are available for Kuhnemys breviplastra (Danilov et al. 2014), Kuhnemys orlovi (Danilov et al. 2014), Kuhnemys palaeocenica (Danilov, Sukhanov et al. 2015), Perochelys lamadongensis (Li, Joyce, and Liu 2015), Rafetus bohemicus (Liebus 1930), “Trionyx" capellinii (Kotsakis 1977), “T." gregarius (Gilmore 1934), “T." kansaiensis (Vitek and Danilov 2010), “T.” messelianus (Hummel 1927; Cadena 2016), “T.” ninae (Vitek and Danilov 2015), " $T$." riabinini (Vitek and Danilov 2010), and “T." shiluutulensis (Danilov et al. 2014).

Useful descriptions pertaining to ontogenetic variation have finally been provided for Kuhnemys spp. (Danilov et al. 2014), "Trionyx" gregarius (Gilmore 1934), and “T." riabinini (Vitek and Danilov 2010).

\section{Phylogenetic Relationships}

The phylogenetic relationships of pan-trionychids were recently discussed in detail by Vitek and Joyce (2015). Under the absence of a phylogenetic analysis that includes most of the taxa listed as valid herein, we only presume that valid genera are monophyletic and that fossil taxa related with extant trionychids concur with topologies retrieved from phylogenetic analyses based on molecular data (Engstrom et al. 2002; Le et al. 2014; Figure 1).

\section{Paleoecology}

Extant pan-trionychids occur globally today in all suitable tropical to temperate regions. Although we are unaware of studies explicitly exploring this issue, it seems that the northern distribution of the group is not necessarily limited by winter temperatures, but rather by the availability of suitable nonfrozen habitat for hibernating in combination with summers of sufficient length to allow the hatchlings to emerge prior to the winter, as exemplified by pan-trionychids naturally occurring in cold continental regions of North American and Asia today (Ernst and Barbour 1989). The presence of pan-trionychids in the fossil record therefore does not reveal much about the paleoenvironment in which they occur beyond the presence of permanent bodies of water. Some Old World fossil 


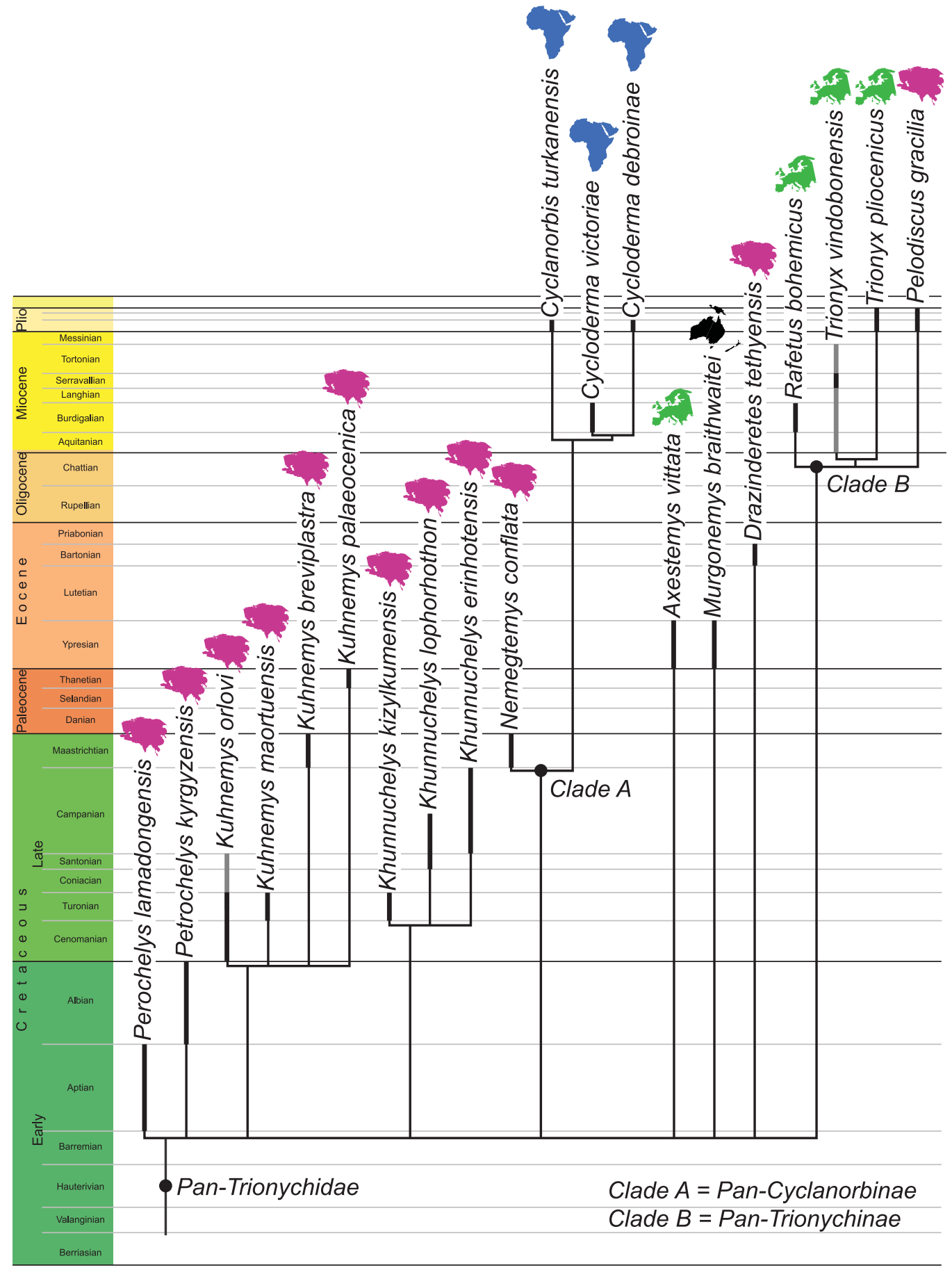

FIGURE 1. The phylogenetic relationships and stratigraphic and biogeographic distribution of valid pan-trionychid taxa. Black lines indicate temporal distribution based on type material. Gray lines indicate temporal distribution based on referred material. The topology presumes that genera are monophyletic and that fossil taxa referable to extant genera follow the molecular topology of Engstrom et al. (2002) and Le et al. (2014). 
trionychids have been inferred to have been marine tolerant or marine adapted, such as the Eocene Drazinderetes tethyensis (Head et al. 1999), but mostly because they were found in estuarine to marine sediments. Although this is a reasonable speculation given that some extant trionychids are known to venture into the marine realm, in particular Trionyx triunguis (Taskavak et al. 1999; Corsini-Foka and Masseti 2008) and Pelochelys cantorii (Fritz et al. 2014), only geochemical evidence should be able to distinguish rigorously if any fossil taxon genuinely lived in marine habitat, instead of being occasionally washed into the sea pre- or postmortem.

Gilmore (1934) suggested that the Eocene "Trionyx" gregarius was gregarious, as more than a dozens individuals were found in a single block of matrix, but it seems more likely to us that these individuals were brought together by a drought (Wings et al. 2012), as no extant turtle displays herding behavior. Taking into account their cranial anatomy, Brinkman et al. (1993) assumed that the large Khunnuchelys spp. from the Cretaceous of Asia may have preyed on mollusks or even dinosaur eggs. Sacco (1895) and Kotsakis (1977) speculated that the Eocene "T." capellinii may have preyed on juvenile crocodilians and been preyed on by the adults, but under the absence of positive evidence that would support either hypothesis, such as the bite marks reported by Wood (1987) for trionychid material from the Miocene of Africa, such ideas are purely speculative.

The eggs of pan-trionychids are rigid shelled (Lawver and Jackson 2014), and fossil eggs tentatively attributed to this clade have been recovered from the Miocene of Germany (Meyer 1860, 1867 ) and questionably from the Cretaceous of Japan (Obata et al. 1972).

\section{Paleobiogeography}

The oldest unequivocal pan-trionychid fossils are known from the Early Cretaceous of Asia (Nessov 1995b; Hirayama et al. 2013; Li, Joyce, and Liu 2015; Li, Tong et al. 2015), and an Asiatic origin for the group seems to be all but certain (Joyce et al. 2013). Even older pan-trionychid remains had previously been reported in the form of Trionyx primoevus Bergounioux, 1937 from the Late Jurassic of France and Sinaspideretes wimani Young and Chow, 1953 from the Late Jurassic or
Early Cretaceous of China, but these have since been shown to lack trionychid characteristics (Meylan and Gaffney 1992; Tong et al. 2014). At present, the Early Cretaceous record consists of Perochelys lamadongensis from the Aptian of Liaoning, China, (Li, Joyce, and Liu 2015); “T.” jixiensis from the Aptian/Albian (slashes used herein connote "or") of Heilongjiang, China (Li, Tong et al. 2015); and Petrochelys kyrgyzensis from the Albian of Kyrgyzstan (Nessov 1995b; Danilov and Vitek 2013). Additional, indeterminate material has furthermore been reported from the Early Cretaceous of Inner Mongolia, China (Gilmore 1931), Japan (Hirayama et al. 2013; Nakajima et al. in press), Mongolia (Shuvalov and Chkhikvadze 1979; Khosatzky 1999; Suzuki and Narmandakh 2004; Scheyer et al. 2017), and Uzbekistan (Nessov 1977, 1984), revealing that the group was widely distributed across the continent early in its history, though notably absent from its southern rim. We recognize in the Late Cretaceous 15 distinct species across central Asia, in particular Kazakhstan, Mongolia, Uzbekistan, and Inner Mongolia, China, (Figures 1 and 2), with additional, fragmentary material being reported from Japan, Kazakhstan, Mongolia, Uzbekistan, and Inner Mongolia, Fujian Province, and Jilin Province, China (Figure 3; see Appendix 3 for complete summary of localities and references). Notably high levels of diversity are apparent by the end of the Late Cretaceous, as is documented by the presence of at least five distinct forms in the Maastrichtian of Mongolia (Danilov et al. 2014), a phenomenon reminiscent of the high diversity observed in the late Late Cretaceous of North America (Vitek and Joyce 2015). The phylogenetic position of many fossil pan-trionychids remains unresolved, and it is therefore unclear if most of the Cretaceous forms represent the trionychid stem or crown (Li, Joyce, and Liu 2015; Vitek and Joyce 2015), although a potential assignment to the crown is consistent with molecular dating analyses (Joyce et al. 2013).

It is unclear how well pan-trionychids survived the Cretaceous-Tertiary $(\mathrm{K} / \mathrm{T})$ extinction event in Asia, as only a single reliable fossil, the type of Kuhnemys palaeocenica, has been described from the Paleocene of this continent (Danilov, Sukhanov et al. 2015). Significantly richer material has been reported from the Eocene and Oligocene of the Asian main continent, but we are here only 


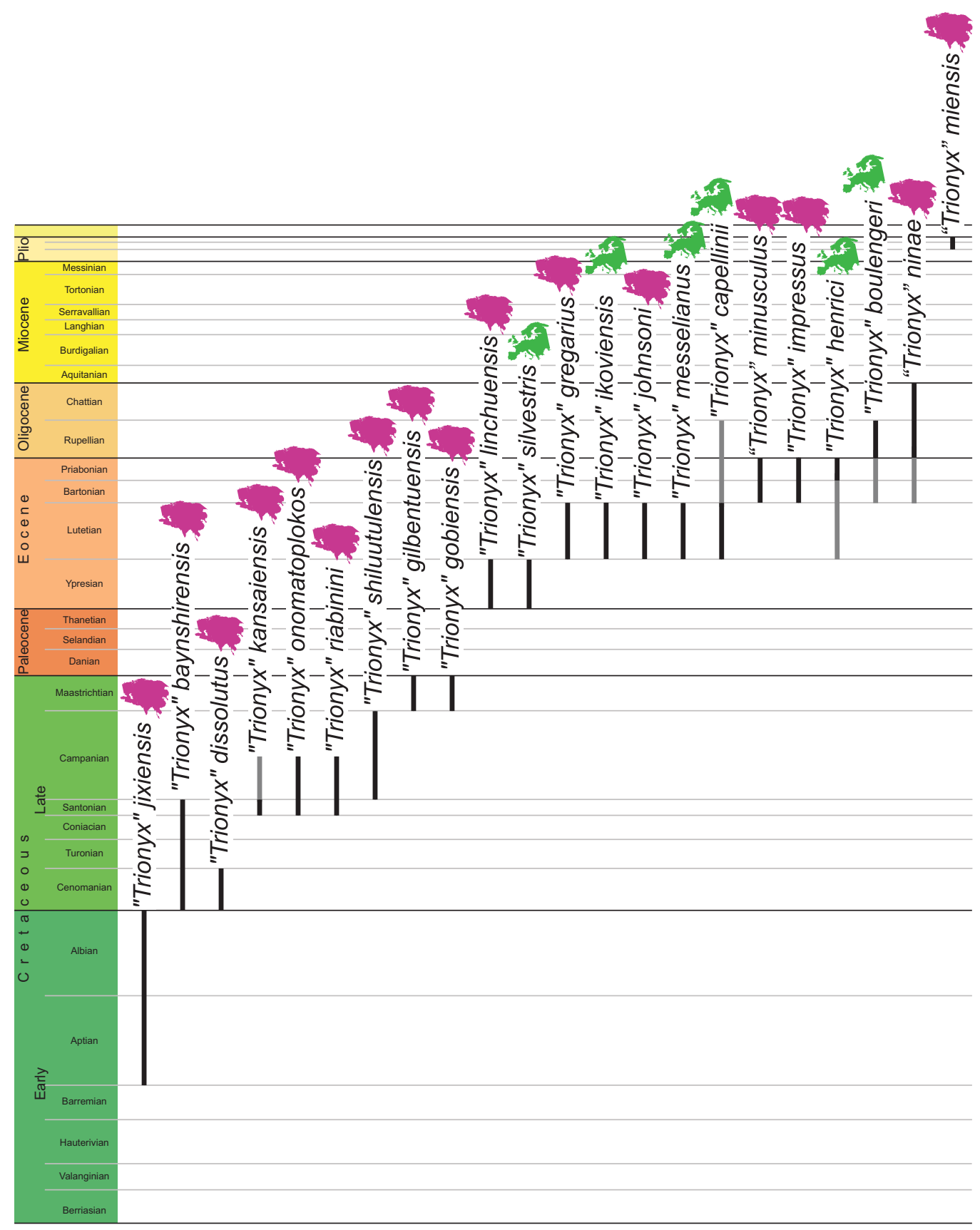

FIGURE 2. The stratigraphic and biogeographic distribution of valid pan-trionychid taxa herein referred to the wastebasket taxon "Trionyx." Black lines indicate temporal distribution based on type material, including select extant taxa for reference. Gray lines indicate temporal distribution based on referred material.

able to recognize the validity of six, in particular "Trionyx" linchuensis from the early Eocene of Shandong Province, China (Yeh 1962); “T." gregarius and "T". johnsoni from the middle Eocene of Inner Mongolia, China (Gilmore 1934; Yeh
1965); “T." impressus from the late Eocene of Guangdong Province, China (Yeh 1963); and "T." minusculus and "T." ninae from the late Eocene to early Oligocene of Kazakhstan (Chkhikvadze 1973; Vitek and Danilov 2015). Often rich, 


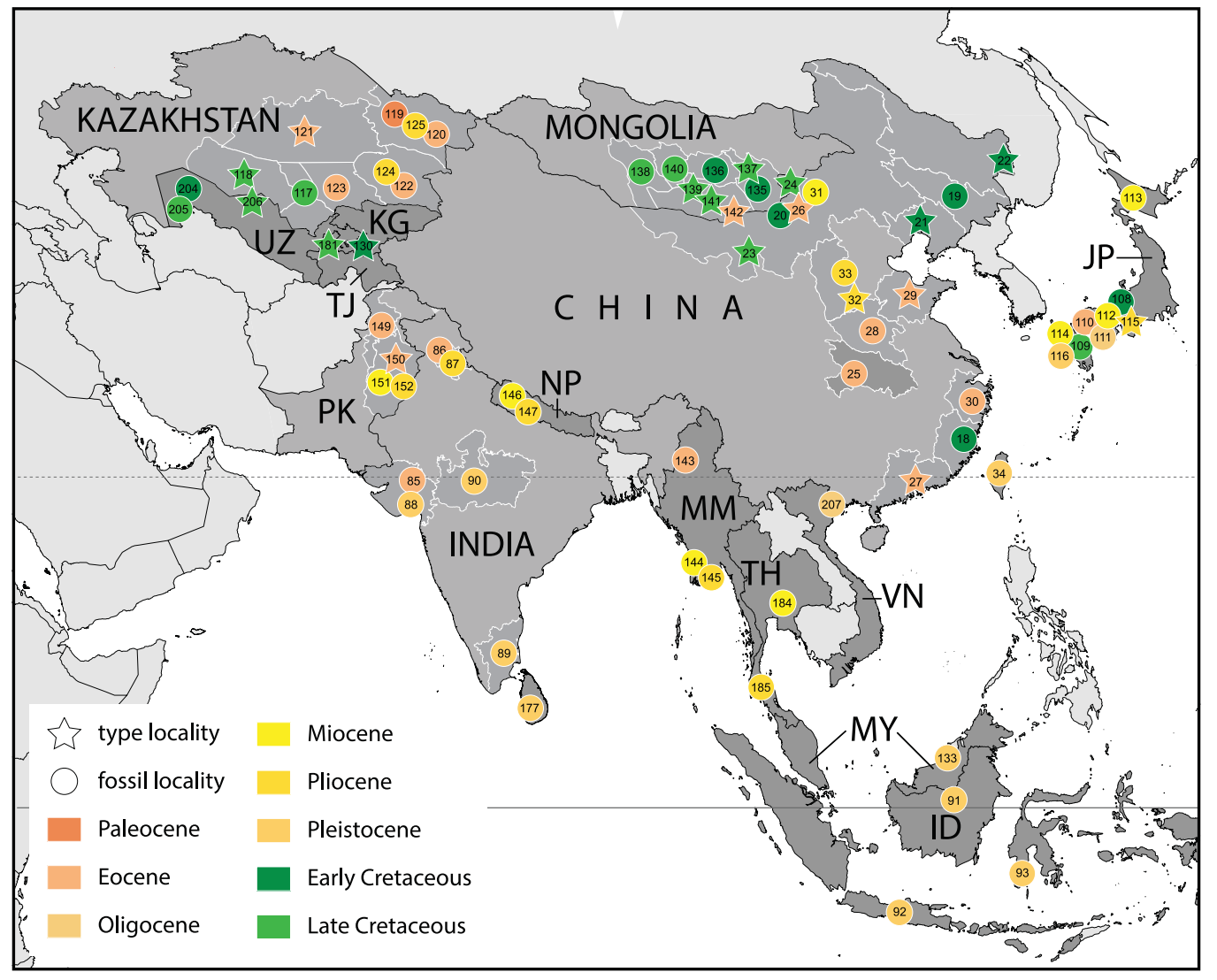

FIGURE 3. The geographic distribution of fossil pan-trionychids from the Cretaceous to the Neogene of the southeastern portions of Asia. Stars mark the type localities of valid taxa. Locality numbers are cross listed in Appendix 3. Abbreviations: ID, Indonesia; JP, Japan; KG, Kyrgyzstan; MM, Myanmar; MY, Malaysia; NP, Nepal; PK, Pakistan; TH, Thailand; TJ, Tajikistan; UZ, Uzbekistan; VN, Vietnam.

fragmentary material has otherwise been reported from the Eocene and Oligocene of Kazakhstan (Bazhanov and Kostenko 1961; Chkhikvadze 1970, 1971, 1973, 1984, 1999b, 2007, 2008a, 2008b; Kordikova 1994b; Kordikova and Mavrin 1996; Kuznetsov and Chkhikvadze 1987); the Eocene of Inner Mongolia (Gilmore 1934; Yeh 1965) and Guangdong (Yeh 1965), Henan (Chow and Yeh 1957), Hubei (Lei and Ye 1985), Shandong (Yeh 1962), and Zhejiang Provinces (Yeh 1962), China; and the Oligocene of Japan (Hasegawa et al. 2007) and Vietnam (Böhme et al. 2011). In concert with its collision with the Asian mainland, the first trionychids also appear on the Indian subcontinent, but with the exception of Drazinderetes tethyensis from Pakistan (Head et al. 1999), most of the material from India (Sahni and Mishra 1975; Sahni et al. 1981, 1984; Smith et al. 2016), Myanmar (Hutchison et al. 2004), and Pakistan (Broin 1987) is fragmentary.

Although pan-trionychids are most speciose in Asia today (Ernst and Barbour 1989), only few remains have been reported from the Neogene of that continent. We here only recognize two valid species, "Trionyx" miensis from the Pliocene of Japan (Okazaki and Yoshida 1977) and Pelodiscus gracilia from the Pliocene of Shanxi Province, China (Yeh 1963). Fragmentary remains are otherwise documented from the Neogene of India (Tripathi 1964; Prasad 1974; Srivastava and Patnaik 2002), Indonesia (Lydekker 1889a; Jaekel 1911; Hooijer 1954), Kazakhstan (Bazhanov and Kostenko 1961; Chkhikvadze 1989), Malaysia (Pritchard et al. 2009), Myanmar (Chhibber 1934; Jaeger et al. 2011), Nepal (West et al. 1978, 1991; Corvinus and Schleich 1994), Pakistan (Lydekker 
1885, 1889a, 1889b; Pilgrim 1912), Sri Lanka (Deraniyagala 1953), Thailand (Mudar and Anderson 2007; Claude et al. 2011), and Inner Mongolia, Shanxi, and Taiwan, China (Gilmore 1931; Chow and Yeh 1958; Tao 1986). For simplicity, the Georgian and Turkish record will be discussed below together with that of Europe. The Asian record of Pan-Cyclanorbinae is restricted to the Indian subcontinent, which mirrors its extant distribution completely.

Pan-trionychids are absent from Europe in the Mesozoic, with the exception of a recently found indeterminate form from the Late Cretaceous (Campanian) of southern Sweden (Scheyer et al. 2012). This find refutes the until recently prevailing theory that pan-trionychids dispersed to Europe no earlier than the Paleocene (e.g., Lapparent de Broin 2001), a conclusion previously supported by the notable absence of pan-trionychids in the richly sampled vertebrate faunas of France, Spain, Hungary, and Romania. Given the fragmentary nature of the Campanian material, however, it unfortunately remains unclear if the group dispersed to Europe from Asia or North America and if this early find is the precursor of later forms (Scheyer et al. 2012).

Fragmentary pan-trionychid remains have been reported from the early Paleocene of Denmark (Rosenkrantz 1923; Karl and Lindow 2012) and from the late Paleocene of Belgium (Broin 1977; Groessens van Dyck and Schleich 1988), France (Bergounioux 1932; Smith et al. 2014), and the United Kingdom (White 1931), but these are too fragmentary to allow rigorous attribution to any particular species or lineage. The situation improves dramatically in the Eocene and Oligocene. Although a long list of taxa have been named from these time periods (see Systematic Paleontology), we here only recognize seven as valid, in particular the early Eocene Axestemys vittata (Pomel 1847; Moody and Walker 1970; Broin 1977) and "Trionyx" silvestris (Walker and Moody 1974; Broin 1977) from Belgium, France, and the United Kingdom; the middle Eocene "T." messelianus from Germany (Reinach 1900; Cadena 2016) and "T." ikoviensis from Ukraine (Danilov et al. 2011); the middle Eocene to early Oligocene “T." capellinii from Italy (Negri 1893; Sacco 1895; Bergounioux 1954; Kotsakis 1977; Barbera and Leuci 1980); the middle to late Eocene " $T$." henrici from France and the United Kingdom (Owen and
Bell 1849; Lydekker 1889a; Boulenger 1891; Lapparent de Broin et al. 1993); and "T." boulengeri from the late Eocene to early Oligocene of Germany and Romania (Reinach 1900; Lörenthey 1903). Of these, the largest one, Axestemys vittata, is notable, as it is clearly referable to the North American taxon Axestemys, thereby revealing a positive faunal link between North American and Europe during the early Paleogene, similarly to the case suggested for several coeval continental squamates (Rage 2013), mammals (Rose 2006), and birds (Mayr 2009). Fragmentary remains are otherwise known from the Eocene and Oligocene of Austria, Belgium, Bulgaria, Croatia, Czechia, France, Germany, Hungary, Italy, Romania, Slovenia, Spain, Switzerland, and nearby Turkey (Figure 4; see Appendix 3 for extensive list of localities and citations). Several fragmentary finds from the Oligocene of Kaliningrad, Russia (Koken 1892; Dames 1894), were never figured or adequately described, and their pan-trionychid affinities are of dubious status.

Over the course of the Neogene, the distribution of pan-trionychids contracts southward (Karl 1999a), perhaps because of climatic cooling (Kotsakis 1980), and the clade is now extinct in Europe, with the exception of Trionyx triunguis, which occasionally reaches some of the Dodecanese Islands in Greece near the coast of Asia Minor (Taskavak et al. 1999; Corsini-Foka and Masseti 2008). Although an enormous number of taxa were named from this time interval, we only recognize in the Neogene two lineages that are referable to the extant Trionyx and Rafetus, much as partially proposed by Karl (1999a) and Chkhikvadze (1999b). The first lineage includes the species T. vindobonensis from the Miocene of Austria (e.g., Peters 1855, 1859; Hoernes 1881; Arthaber 1898; Heritsch 1909), Germany (Winkler 1869a; Reinach 1900), and France (Broin 1977) and T. pliocenicus from the Pliocene of Italy (Fucini 1912), whereas the other is only represented by $R$. bohemicus from the Miocene of Czechia (Liebus 1930) but may have been more widely distributed (see Systematic Paleontology). The above-mentioned contraction of the range is well documented by fragmentary remains from the Miocene of Austria, Cyprus, Czechia, France, Georgia, Greece, Hungary, Italy, Moldova, Portugal, Romania, western Russia, Slovakia, Slovenia, Spain, Switzerland, Turkey, and Ukraine, whereas 


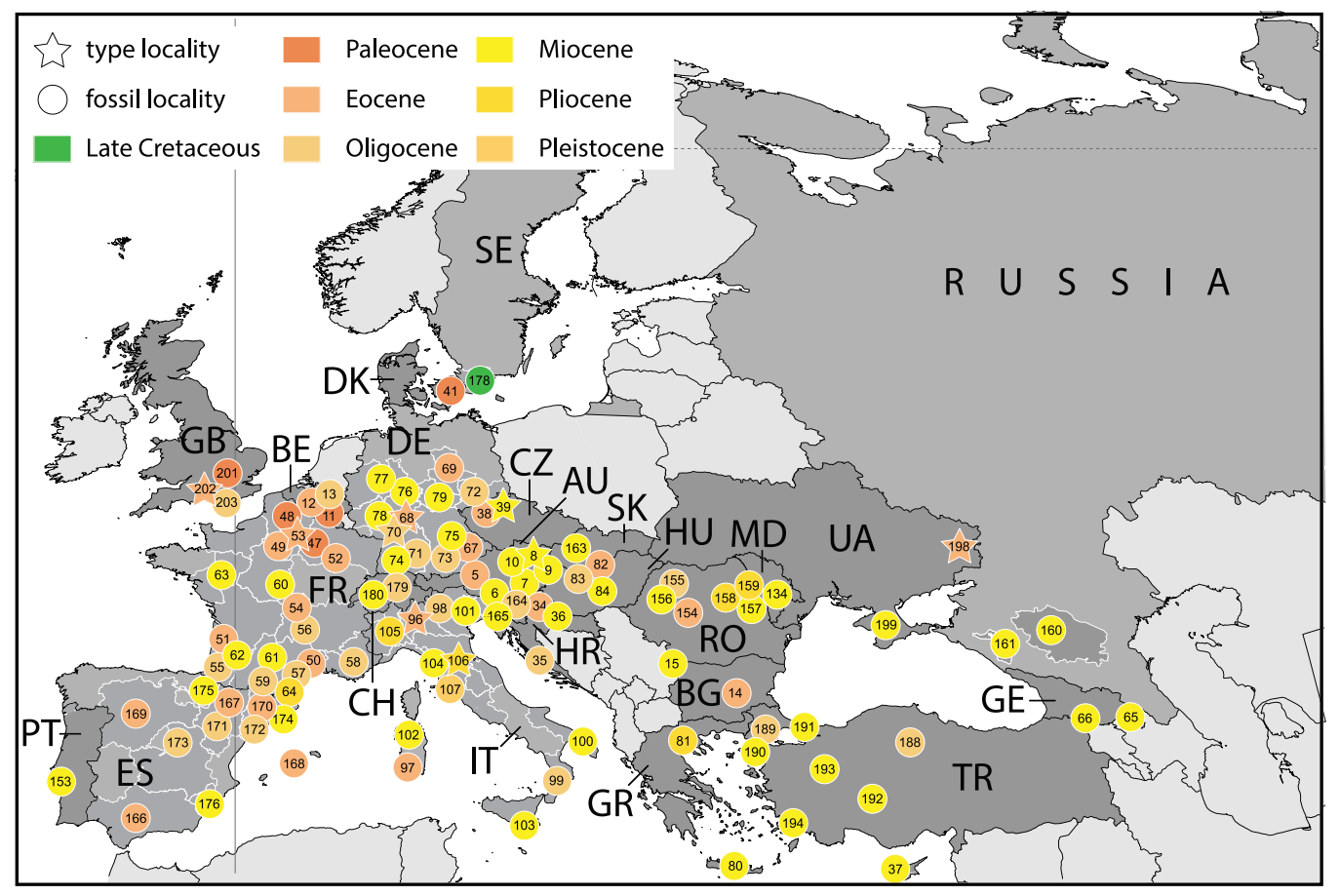

FIGURE 4. The geographic distribution of fossil pan-trionychids from the Cretaceous to the Neogene of Europe and adjacent portions of Asia. Stars mark the type localities of valid taxa. Locality numbers are cross listed in Appendix 3. Abbreviations: AU, Austria; BE, Belgium; BG, Bulgaria; CH, Switzerland; CZ, Czechia; DE, Germany; DK, Denmark; ES, Spain; FR, France; GB, United Kingdom; GE, Georgia; GR, Greece; HR, Croatia; HU, Hungary; IT, Italy; MD, Moldova; PT, Portugal; RO, Romania; SE, Sweden; SK, Slovakia; TR, Turkey; UA, Ukraine.

Pliocene remains are restricted to Greece, Italy, France, and Romania (Figure 4; see Appendix 3 for extensive list of localities and literature). We here ignore fossils reported from the Miocene of Malta as these either remain poorly figured or not figured at all (Gulia 1843; Cooke 1890) or do not represent pan-trionychids (contra Lydekker 1891; also Introduction). The last fossil occurrence in Europe is known from the early Pleistocene of Italy (Portis 1890; Kotsakis 1980).

The presence of pan-trionychids on the Australian continent is not well documented, mostly because of a lack of fossiliferous localities. The oldest Australian pan-trionychid is the bizarre and highly autapomorphic Murgonemys braithwaitei from the early Eocene of southeastern Queensland (White 2001; Figure 5) that shows no clear relationships with any other group of pan-trionychids, despite being well preserved. Although pan-trionychids are now restricted to Papua (Ernst and Barbour 1989), fragmentary finds are known from Queensland, Australia, from as recently as the Plio-Pleistocene (Gaffney and Bartholomai 1979), thereby indicating that their local extirpation occurred relatively recently. Pantrionychids have not been recovered from neighboring Antarctica and New Zealand, although connections were available with these landmasses during the Paleogene (Scanlon 1993; Hand et al. 2015).

Fossil pan-trionychids have been reported from Neogene sediments from across Africa and Arabia (Lapparent de Broin 2000), but many of the finds have not been figured, and it is therefore difficult to rigorously assess most such claims. Fossil pan-trionychids are notably absent from the Paleogene of that continent, with the notable exception of a single carapace fragment that questionably originated from the Eocene Fayum deposits of Egypt, but more likely is Holocene (Wood 1979), an assertion supported by more than one century of intensive collecting in the Fayum that otherwise did not yield a single bona fide pan-trionychid. This lack of Paleogene 


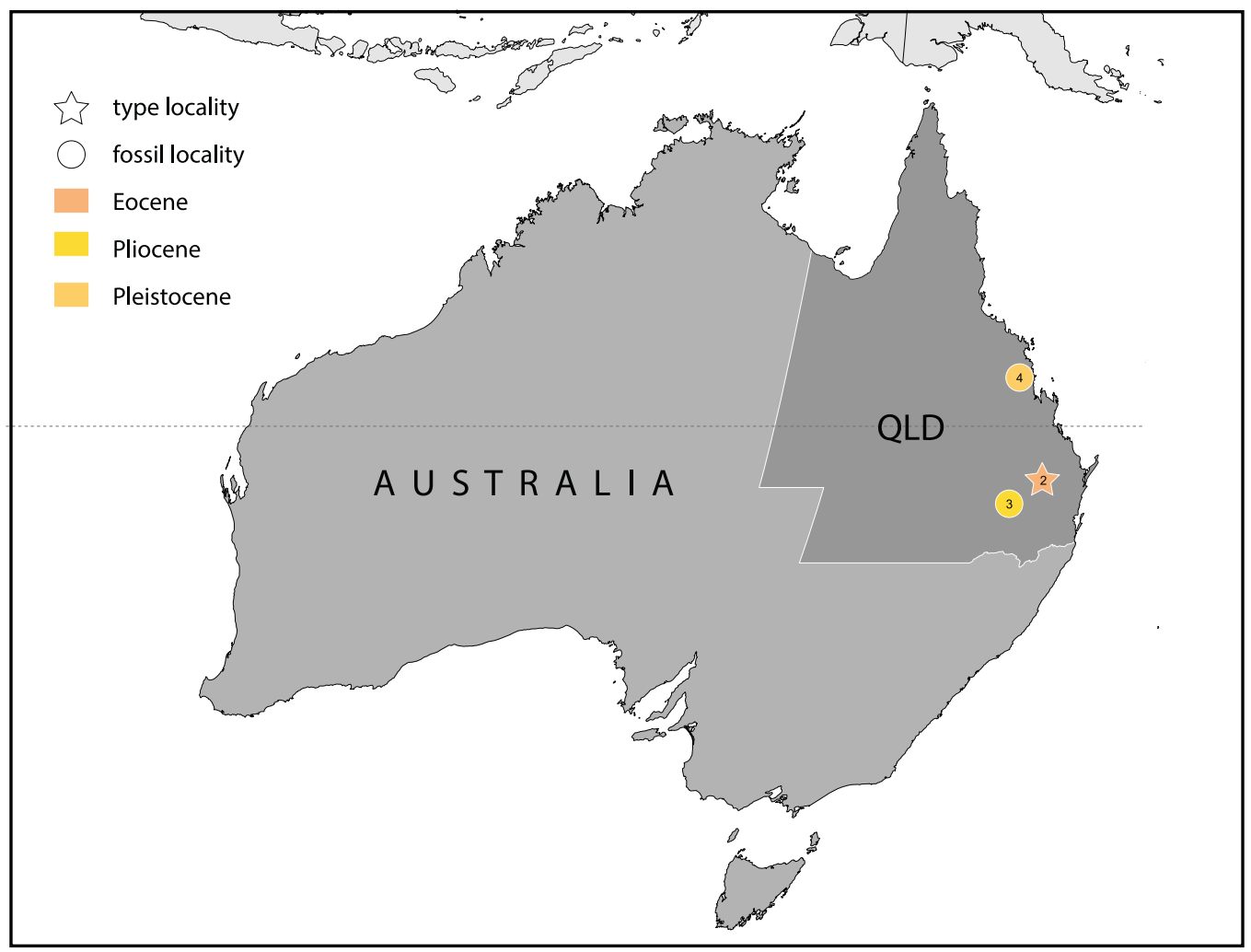

FIGURE 5. The geographic distribution of fossil pan-trionychids from the Tertiary of Australia. Stars mark the type localities of valid taxa. Locality numbers are cross listed in Appendix 3. Abbreviation: QLD, Queensland.

material contradicts the prediction of Le et al. (2014) that cyclanorbines should have migrated to that continent in the Eocene. Instead, we suggest that Le et al. (2014) overinterpreted their data by conflating the likely divergence date between African and Asian cyclanorbines with a possible dispersal date, but we readily admit that the Paleogene record from Africa is highly incomplete. We here recognize three valid species from Africa that are all based on well-preserved material from the Rift Valley of Kenya, in particular the early Miocene Cycloderma victoriae and the early Pliocene Cyclanorbis turkanensis and Cycloderma debroinae (Andrews 1914; Broin 1987; Lapparent de Broin 2000; Meylan et al. 1990). Including also the Arabian Peninsula and the Middle East, we here otherwise recognize fragmentary remains from Algeria, Chad, the Democratic Republic of Congo, Egypt, Ethiopia, Iraq, Israel, Kenya, Libya, Malawi, Oman, Saudi Arabia, Tanzania, Tunisia, Uganda, and the United Arab Emirates (Figure 6; see Appendix 3 for extensive list of localities and literature). There is no indication that pan-trionychids ever colonized nearby Madagascar.

\section{Systematic Paleontology}

\section{Valid Taxa}

See Appendix 4 for the hierarchical taxonomy of Old World Pan-Trionychidae used in this work.

\section{Pan-Trionychidae Joyce et al., 2004}

Phylogenetic definition. In accordance with Joyce et al. (2004), the name Pan-Trionychidae is herein referred to the total-clade of Trionychidae, which, in return, is defined as the crown clade that includes all extant turtles that are more closely related to Trionyx triunguis (Forskål, 1775) than Carettochelys insculpta Ramsay, 1887.

Diagnosis. Representatives of Pan-Trionychidae are currently diagnosed relative to other turtles, among others, by a reduced quadratojugal that does not contact the postorbital or maxilla, exclusion of the fused premaxillae from the apertura narium externa, the presence of sculpturing that covers all metaplastic portions of the shell bones, the absence of peripherals, pygals, 


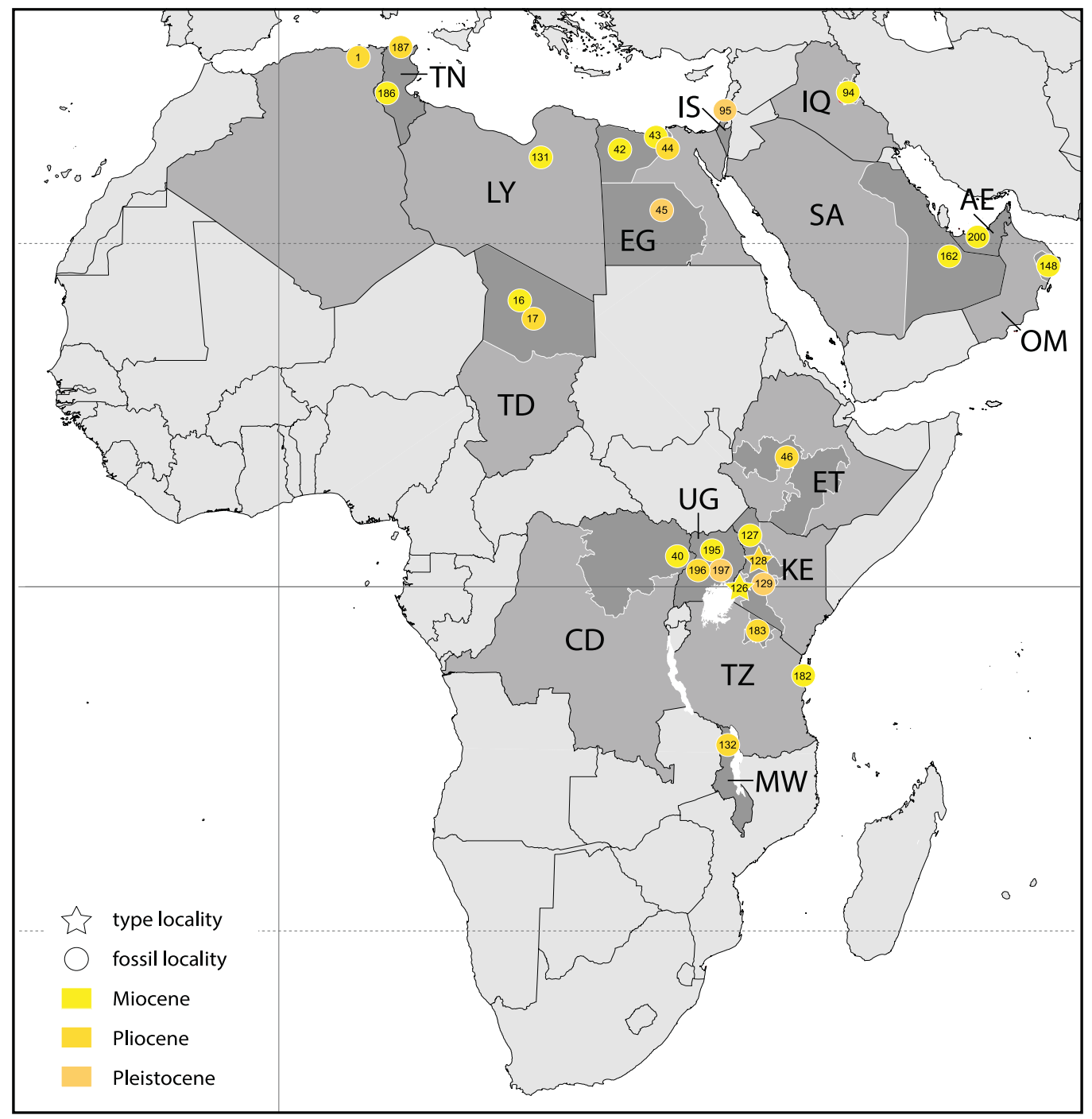

FIGURE 6. The geographic distribution of fossil pan-trionychids from the Neogene of Africa and Arabia. Stars mark the type localities of valid taxa. Locality numbers are cross listed in Appendix 3. Abbreviations: AE, United Arab Emirates; CD, Democratic Republic of the Congo; EG, Egypt; ET, Ethiopia; IQ, Iraq; IS, Israel; KE, Kenya; LY, Libya; MW, Malawi; OM, Oman; SA, Saudi Arabia; TD, Chad; TN, Tunisia; TZ, Tanzania; UG, Uganda.

suprapygals, and shell scutes, a boomerang-shaped entoplastron, a plywood-like micro-structure in the metaplastic portions of the shell, absence of central articulation between the eighth cervical and the first thoracic vertebra, hyperphalangy, and the presence of three claws in the manus and pes.

\section{Axestemys Hay, 1899}

Type species. Axestemys byssinus (Cope, 1872).

Diagnosis. Axestemys can be diagnosed as a representative of Pan-Trionychidae by the full list of characters provided for that clade above. Axestemys is currently differentiated from other pan-trionychids by large size, sculpturing on the skull roof, presence of a preneural, and a single lateral hyoplastral process.

Axestemys vittata (Pomel, 1847), comb. nov. (= Eurycephalochelys fowleri Moody and Walker, 1970)

Taxonomic history. Trionyx vittatus Pomel, 1847 (new species); Palaeotrionyx vittatus $=[$ T. erquelinnensis $]$ Broin 1977 (new combination, incorrect spelling of genus name, and senior synonym); Eurycephalochelys vittatus Augé et al. 1997 (new combination). 
Type material. MNHN (holotype), a carapace (Gervais 1859, pl. 52), now lost (Broin 1977).

Type locality. Muirancourt, Oise, France (Pomel 1847; Figure 4); Muirancourt Lignites, Paris Basin, early Ypresian, early Eocene (Broin 1977).

Referred material and range. Early Eocene (early Ypresian), Hainaut, Belgium (material of Trionyx erquelinnensis Dollo 1909; referred material of Broin 1977); early Eocene (early Ypresian), Trieu de Leval, Hainaut, Belgium (material of T. levalensis Dollo 1909); early Eocene (early Ypresian), Île-de-France, France (referred material of Broin 1977); early Eocene (early Ypresian), Champagne-Ardenne, France (referred material of Broin 1977); early Eocene (late Ypresian), West Sussex, United Kingdom (hypodigm of Eurycephalochelys fowleri Walker and Moody 1985); early Eocene (late Ypresian), Prémontré, Aisne, Hauts-de-France (referred material of Augé et al. 1997).

Diagnosis. Axestemys vittata can be diagnosed as a member of Pan-Trionychidae and Axestemys by the full list of characters provided above for those clades. At present, biogeographic considerations most clearly differentiate the European Axestemys vittata from all North American representatives of this clade (see comments below).

Comments. Four names are associated with the remains of large-bodied pan-trionychids from early Eocene deposits throughout Belgium, southern England, and northern France, in particular Trionyx vittatus Pomel, 1847, T. erquelinnensis Dollo 1909, T. levalensis Dollo 1909, and Eurycephalochelys fowleri Moody and Walker, 1970. Although T. erquelinnensis and T. levalensis are based on beautifully preserved specimens, we agree with Moody and Walker (1970) and Broin (1977) that these are nomina nuda (see below), and we therefore disregard them from consideration. Broin (1977) already noted that all European material is closely related and that it shows great similarities with Paleotrionyx quinni Schmidt, 1945, a large-bodied pan-trionychid from the late Paleocene of North America, but she nevertheless maintained two valid species, Axestemys (her Palaeotrionyx) vittata and Eurycephalochelys fowleri. Augé et al (1997) preferred synonymy within the available European material and therefore attributed vittata to Eurycephalochelys.

Vitek (2012) recently concluded that several large-bodied trionychids from the Late Cretaceous to Eocene of North America form a monophyletic lineage referable to Axestemys Hay, 1899. Earlier representatives of this lineage from the Late Cretaceous generally resemble other pan-trionychines, but the Paleocene and Eocene representatives acquire a peculiar shell that is characterized most notably by presence of a preneural, poorly developed carapacial callosities that often only cover the proximal two-thirds of the rib, carapacial ornamentation that is restricted to the proximal third of the costals, suprascapular fontanelles, plastra almost completely devoid of surficial sculpturing, and single lateral hyo- and hypoplastral processes. The skull, on the other side, is characterized by being notably short snouted and by often showing an expanded triturating surface. In all regards, the shell and skull material from Europe correspond to these derived representatives of Axestemys from North America, and we therefore refer all to Axestemys with confidence, but additional work is needed to render a meaningful diagnosis.
Broin (1977) believed that two species are apparent among the European assemblages, but we find that all described material only shows variation sufficient to warrant one species. We therefore here synonymize vittatus with fowleri but await a more detailed analysis of all material, perhaps that from Belgium. The type material of Axestemys vittata has been reported to be lost (Broin 1977), but we find the figures provided by Gervais (1859) to be informative, and a cast of the holotype is held at MNHN. We therefore see no need either to declare Axestemys vittata a nomen dubium or to designate a neotype specimen. Furthermore, the original spelling of the species epithet "vittatus" is herein emended to "vittata" in order to conform with the feminine gender of the genus name Axestemys.

Shell fragments of a large pan-trionychid originating from the late Paleocene (MP 6) of Rivecourt-Petit Pâtis, Oise, Hautsde-France, Paris Basin, France (Smith et al. 2014), could eventually belong to Axestemys vittata as well. However, this material was not figured and was only preliminarily described. Therefore, conspecificity with Axestemys vittata, although possible, cannot be confirmed.

\section{Drazinderetes tethyensis Head et al., 1999}

Taxonomic history. Drazinderetes tethyensis Head et al., 1999 (new species).

Type material. GSP UM3195 (holotype), a nearly complete carapace (Head et al. 1999, figs. 3-5).

Type locality. Bari Nadi, west of Satta Post, Punjab, Pakistan (Figure 3); Drazinda Formation, middle Bartonian, middle Eocene (Head et al. 1999).

Referred material and range. No specimens have been referred to date.

Diagnosis. Drazinderetes tethyensis can be diagnosed as a member of Pan-Trionychidae by the absence of central articulation between the eighth cervical and first thoracic vertebra and the full list of carapacial characters provided for that clade above. Drazinderetes tethyensis can be differentiated from all remaining representatives of Pan-Trionychidae by rather large size, presence of a preneural, a single pair of costiform processes, and anteriorly oriented costals I.

Comments. Drazinderetes tethyensis is based on a large, nearly complete carapace from the Eocene of Pakistan, which Head et al. (1999) reconstructed as originating from an individual that may have reached a shell length of up to $150 \mathrm{~cm}$. In addition to the type, Head et al. (1999) also reported from the type locality an isolated carapace fragment, an incomplete right hypoplastron, and a gigantic entoplastron with a lateral length of $57.3 \mathrm{~cm}$ that they estimated to have originated from an individual with a shell length of up to $220 \mathrm{~cm}$, which reveals this specimen to be not only the largest known pan-trionychid, but also among the largest known turtles. These size estimates, however, must be viewed with caution as they were calculated by direct comparison to the North American Apalone spinifera, which is notable by having a relatively small carapace relative to a large nonossified flap. Although the presence of two sympatric giant pan-trionychids in the same sedimentary basin seems improbable, we 
agree that it is prudent not to refer all to one taxon pending the discovery of more complete material. Head et al. (1999) discussed possible affinities of Drazinderetes tethyensis with the extant Nilssonia (their Aspideretes) on the basis of geographic proximity and the presence of a preneural and several other characters, but we note that the posterior constriction of the carapace combined with the poor development of the free rib ends furthermore show similarities with pan-cyclanorbines. As it seems clear that Drazinderetes tethyensis is not nested within either of these clades, we here make an exception and maintain the monotypic genus to which it was referred.

The type of Drazinderetes tethyensis was recovered from marine sediments, and Head et al. (1999) therefore suggested that this animal may have been fully adapted to marine environments. Although it is true that some extant trionychids venture into the marine realm from nearby freshwater to brackish habitats (Taskavak et al. 1999), we note that these excursions seem to be short lived, as sightings are relatively rare. We therefore believe it to be more likely that this animal was washed into the sea from the nearby coast.

\section{Khunnuchelys Brinkman et al., 1993}

Type species. Khunnuchelys erinhotensis Brinkman et al., 1993.

Diagnosis. Khunnuchelys can be diagnosed as a member of PanTrionychidae by the presence of a reduced quadratojugal that does not contact the postorbital or maxilla and exclusion of the fused premaxillae from the apertura narium externa. Khunnuchelys can be differentiated most notably from other pan-trionychids by having a thick skull roof, an external narial opening that is located ventral to the orbits, anteriorly oriented orbits, high maxillae, a vaulted palate, maxillae that meet at the midline of the palate to form a midventral ridge and secondary palate, a large contribution of palatines to the triturating surface, and an exclusion of the jugal from the margin of the orbit.

Comments. Khunnuchelys is a strange pan-trionychid taxon that has been suggested to bear affinities, among others, with the large Paleocene North American taxon "Trionyx" admirabilis, the Eocene European Axestemys vittata, or even PanCyclanorbinae (Brinkman et al. 1993; Vitek and Danilov 2013; Danilov, Vitek et al. 2015), but a rigorous phylogenetic analysis is still not available that would clarify its affinities. Brinkman et al. (1993) hypothesized that the highly vaulted palate was consistent with a durophagous diet and that the rugose middorsal ridge formed by the maxillae may have served as a pressure point for crushing shells. Along those lines, hard-shelled invertebrates, such as snails, clams, or even dinosaur eggs, have been suggested as prey items for Khunnuchelys (Brinkman et al. 1993).

\section{Khunnuchelys erinhotensis Brinkman et al., 1993}

Taxonomic history. Khunnuchelys erinhotensis Brinkman et al., 1993 (new species); Kunhuchelys erinhotensis Kordikova 2002 (incorrect spelling of genus name).

Type material. IVPP V9535 (holotype), partial skull missing ventral margin of maxilla and jugal, posterior portion of cheek region, and supraoccipital crest (Brinkman et al. 1993, figs.
1-3; Brinkman et al. 2008, fig. 79; Danilov and Vitek 2013, fig. 23.2h).

Type locality. $13 \mathrm{~km}$ northeast of Erinhot, Xilin Gol, Inner Mongolia, China (Figure 3); Iren Dabasu Formation (Brinkman et al. 1993), Campanian, Late Cretaceous (Xing et al. 2012).

Referred material and range. No specimens have been referred to date.

Diagnosis. Khunnuchelys erinhotensis can be diagnosed as a member of Khunnuchelys based on the full list of characters provided for that clade above. Khunnuchelys erinhotensis can be differentiated most readily from other members of Khunnuchelys by the presence of a formed posterior jugular foramen.

Comments. Khunnuchelys erinhotensis is known only from a single, highly distinctive skull from the Late Cretaceous (Campanian) of China (Brinkman et al. 1993; Danilov and Vitek 2013). Similar skulls have since been described from other Late Cretaceous deposits, but these have all been diagnosed as other species (see Khunnuchelys kizylkumensis and Khunnuchelys lophorhothon below). Although the postcranial anatomy of this species remains uncertain, its taxonomic validity is uncontroversial.

\section{Khunnuchelys kizylkumensis Brinkman et al., 1993}

Taxonomic history. Khunnuchelys kizylkumensis Brinkman et al., 1993 (new species).

Type material. CCMGE 8/12458 (holotype), a braincase and skull roof (Nessov 1986, pl. 1.9; Brinkman et al. 1993, figs. 4-8; Nessov 1997, pl. 13.18; Danilov and Vitek 2013, fig. 23.2i).

Type locality. Site CBI-28, Dzharakuduk (= Dzharakuduk II of Nessov 1997), $35 \mathrm{~km}$ southwest of Mynbulak, Navoiy Region, Uzbekistan (Brinkman et al. 1993; Figure 3); Bissekty Formation, late Turonian, Late Cretaceous (Brinkman et al. 1993; Vitek and Danilov 2013).

Referred material and range. Late Cretaceous (late Turonian) of type area, Navoiy Region, Uzbekistan (Vitek and Danilov 2013).

Diagnosis. Khunnuchelys kizylkumensis can be diagnosed as a member of Khunnuchelys on the basis of all characters listed for that taxon above. Khunnuchelys kizylkumensis can be differentiated from Khunnuchelys erinhotensis by the presence of an open foramen jugulare posterius and from Khunnuchelys lophorhothon by lacking a flooring of the internal nares that is formed by the palatines.

Comments. Khunnuchelys kizylkumensis is based on a partial skull from the Late Cretaceous (late Turonian) of Uzbekistan that was estimated to have exceeded $20 \mathrm{~cm}$ in length (Brinkman et al. 1993; Vitek and Danilov 2013). The type locality also yielded fragmentary shell remains of a large trionychid that may reasonably be referred to this species as well (Brinkman et al. 1993; Vitek and Danilov 2013), but an actual association is still 
lacking. Another distinct but indeterminate skull-based taxon has been described from the same locality (Trionychini indet. of Vitek and Danilov 2013).

\section{Khunnuchelys lophorhothon \\ Danilov, Vitek et al., 2015}

Taxonomic history. Khunnuchelys lophorhothon Danilov, Vitek et al., 2015 (new species); Khunnuchelys lorhophoton Li, Tong et al. 2015 (incorrect spelling of species epithet).

Type material. ZIN PH 5/55 (holotype), a partial skull (Danilov, Vitek et al. 2015, fig. 2; Averianov et al. 2016, fig. 4i).

Type locality. Baybishe, Kyzylorda Region, Kazakhstan (Figure 3); Bostobe Formation, Santonian or early Campanian, Late Cretaceous (Danilov, Vitek et al. 2015).

Referred material and range. Late Cretaceous (Santonian-early Campanian), Bostobe Formation, Baykhozha, Kyzylorda Region, Kazakhstan (referred material of Danilov, Vitek et al. 2015).

Diagnosis. Khunnuchelys lophorhothon can be diagnosed as a member of Khunnuchelys on the basis of the full list of characters provided for that clade above. Khunnuchelys lophorhothon can be differentiated from Khunnuchelys erinhotensis by the presence of an open foramen jugulare posterius and from Khunnuchelys kizylkumensis by showing a flooring of the internal nares that is formed by the palatines.

Comments. The holotype of Khunnuchelys lophorhothon, a partial skull from the Late Cretaceous of Kazakhstan, was initially identified as perhaps representing Lophorhothon, an ornithopod dinosaur otherwise known from the USA (Nessov 1995a), but actually represents the skull of a pan-trionychid (Danilov, Vitek et al. 2015). Khunnuchelys lophorhothon may perhaps be synonymous with the shell based taxon "Trionyx" kansaiensis, which also occurs in the Bostobe Formation (Vitek and Danilov 2010; Danilov, Vitek et al. 2015). If correct, the species name should be combined as Khunnuchelys kansaiensis. However, pending the discovery of associated material, "T." kansaiensis and Khunnuchelys lophorhothon are herein treated as distinct, valid species.

\section{Kuhnemys Chkhikvadze, 1999b}

Type species. Aspideretes maortuensis Yeh, 1965.

Diagnosis. Kuhnemys can be diagnosed as a member of PanTrionychidae by the full list of characters provided for that clade above. Kuhnemys can be differentiated from other Cretaceous to Paleogene pan-trionychids by the unique combination of shell characters: absence of a preneural, ratio of nuchal width to length greater than four, small or absent costals VIII, unfused hyo-hypoplastra, and two lateral hyoplastral processes.

Comments. Danilov et al. (2014) recently grouped three Late Cretaceous to Paleocene trionychids from Asia into a clade that they fittingly named Gobiapalone. We here confirm that the type of Trionyx maortuensis, as described, does not fit the diagnosis of Gobiapalone (Danilov et al. 2014), but personal observations of this specimen lead us to conclude that it should be placed in
Gobiapalone as well. As described, T. maortuensis has a complete row of eight neurals that potentially separate the costal series completely, but our observations reveal the presence of only seven neurals and a midline contact of costals VII and VIII, as in Gobiapalone. Trionyx maortuensis furthermore resembles Gobiapalone by having greatly reduced costals VIII (damage to the posterior margin is only minor), open suprascapular fontanelles, and poorly developed plastral callosities. New insights into the age of T. maortuensis reveals that it is likely Late Cretaceous (Turonian) in age, not late Early Cretaceous (Aptian/Albian), and therefore the same age as Gobiapalone orlovi. These species greatly resemble one another, but we nevertheless confirm their validity herein.

Trionyx maortuensis is the type species of Kuhnemys Chkhikvadze, 1999b, which has priority over Gobiapalone Danilov et al., 2014. This is somewhat unfortunate, because the name Kuhnemys is similar to Khunnuchelys, the other valid genus we use herein, and because we find Gobiapalone to be more euphonious. We are nevertheless forced to propose new combinations for all taxa previously assigned to Gobiapalone.

Kuhnemys breviplastra (Danilov et al., 2014), comb. nov.

Taxonomic history. Gobiapalone breviplastra Danilov et al., 2014 (new species).

Type material. PIN 4694-3 (holotype), a partial shell (Danilov et al. 2014, fig. 10f, g).

Type locality. Ulan Khushu (= Ulan Bulak), Ömnögovi (= Umunugovi) Aimag, Mongolia (Figure 3); Nemegt Formation, Maastrichtian, Late Cretaceous (Danilov et al. 2014).

Referred material and range. Late Cretaceous (Campanian), Barungoyot Formation, Nogon Tsav and Bugin Tsav, Bayankhongor and Ömnögovi Aimag, respectively, Mongolia (referred material of Danilov et al. 2014); Late Cretaceous (Maastrichtian), Nemegt Formation, Bugin Tsav, Ömnögovi Aimag, Mongolia (referred material of Danilov et al. 2014).

Diagnosis. Kuhnemys breviplastra can be diagnosed as a member of Pan-Trionychidae and Kuhnemys by the full list of characters provided for those clades above. Kuhnemys breviplastra can be differentiated from Kuhnemys orlovi and Kuhnemys maortuensis by having open suprascapular fontanelles in large specimens, more massive epiplastra, entoplastron, and xiphiplastra, an angle of more than $80^{\circ}$ between the arms of the entoplastron, and a reduced count of medial hyoplastral processes. It can be differentiated from Kuhnemys palaeocenica by having a square neural $\mathrm{V}$ and shorter anterior epiplastral processes.

Comments. Kuhnemys breviplastra is known from several carapaces, plastra, and postcranial elements from the Late Cretaceous of Mongolia (Danilov et al. 2014). The availability of adult and juvenile individuals enables the study of intraspecific and ontogenetic variation for this taxon. Given the high quality of the available material, the validity of this species is not controversial. 


\section{Kuhnemys maortuensis (Yeh, 1965) $(=$ Trionyx alashanensis Yeh, 1965)}

Taxonomic history. Aspideretes maortuensis Yeh, 1965 (new species); Axestemys maortuensis Kordikova 1994a (new combination); Kuhnemys maortuensis Chkhikvadze 1999b (new combination); Dogania maortuensis Karl 1999b (new combination).

Type material. IVPP V2864 (holotype), incomplete postcranium with parts of carapace, plastron, and girdles, two cervical vertebrae, and the right pes (Yeh 1965, fig. 1, pls. I-II).

Type locality. Dashukou, Maortu (= Maorty), Alxa (= Alashan), Inner Mongolia, China (Yeh 1965; Brinkman et al. 2008; Figure 3); Ulansuhai Formation, Turonian, Late Cretaceous (Brusatte et al. 2009).

Referred material and range. Late Cretaceous (Turonian) of the type locality, Inner Mongolia, China (type material of Aspideretes alashanensis; Yeh 1965).

Diagnosis. Kuhnemys maortuensis can be diagnosed as a member of Pan-Trionychidae by the full list of shell characters provided for that clade above and of Kuhnemys by absence of a preneural, small costals VIII, and unfused hyo-hypoplastra. Kuhnemys maortuensis can be differentiated from Kuhnemys breviplastra by having an angle of less than $100^{\circ}$ between the arms of the entoplastron and from Kuhnemys palaeocenica and Kuhnemys orlovi by having additional medial hyo- and hypoplastral processes and the reversal at neural VI.

Comments. Kuhnemys maortuensis is based on a partial skeleton that most notably lacks the nuchal and the lateral aspects of the plastron (Yeh 1965). The same locality also yielded the type of Trionyx alashanensis (Yeh 1965). The age of the holotype has variously been reported as Early Cretaceous or Late Cretaceous (e.g., Yeh 1965; Brinkman et al. 2008), but without much discussion. The rich dinosaur fauna from the locality of Maortu has been reported as originating from the Ulansuhai Formation, and we here presume that the holotype of Kuhnemys maortuensis was collected from that formation as well. This formation was initially believed to be Early Cretaceous (Aptian/Albian) based on the dinosaur fauna it contained, but we here concur with Brusatte et al. (2009) by accepting a Late Cretaceous (Turonian) age, as established by radiometric dating of basalt flows below the formation.

Over the course of the decades, Kuhnemys maortuensis was variously referred to Aspideretes, Axestemys, or Dogania (Yeh 1965; Kordikova 1994a; Karl 1999b). The holotype of Kuhnemys maortuensis was initially reported as having eight neurals and perhaps lacking a midline contact of the costals, but our personal observation of the type specimen reveals that this specimen shows a more usual arrangement of seven neurals and a midline contact of costals VII and VIII. Using a stratigraphic rationale, Yeh (1965) furthermore presumed that a preneural may have been present, but we see no evidence for its former presence. A thorough redescription of the type specimen would certainly help to anchor these observations into the literature. The validity of this taxon is nevertheless uncontroversial (see Kuhnemys above for additional comments). We here also synonymize Trionyx alashanensis with Kuhnemys maortuensis, as the type material corresponds in all important aspects (see T. alashanensis below)

Kuhnemys orlovi (Khosatzky, 1976), comb. nov.

Taxonomic history. Amyda orlovi Khosatzky in Sochava 1975 (nomen nudum); Amyda orlovi Khosatzky, 1976 (new species); Gobiapalone orlovi Danilov et al. 2014 (new combination).

Type material. PIN 557-132/1 (formerly PIN 557-1/1) (holotype), incomplete carapace (Khosatzky 1976, no figure; Sukhanov 2000, fig. 17.27; Danilov and Vitek 2013, fig. 23.2b1; Danilov et al. 2014, fig. 7f).

Type locality. Bayn Shire, Dornogovi Aimag, Mongolia (Khosatzky 1976; Figure 3); lower part of the Baynshire Formation, Cenomanian-early Turonian, Late Cretaceous (Danilov et al. 2014).

Referred material and range. Late Cretaceous (CenomanianSantonian), Baynshire Formation, Burkhant, Unegetu Ula, and Khongil, Dornogovi Aimag, Mongolia (referred material of Danilov et al. 2014).

Diagnosis. Kuhnemys orlovi can be diagnosed as a member of Pan-Trionychidae and Kuhnemys by the full list of characters provided for those clades above. Kuhnemys orlovi can be differentiated from Kuhnemys breviplastra and Kuhnemys palaeocenica by having closed suprascapular fontanelles in large specimens, more slender epiplastra, entoplastron, and xiphiplastra, and an angle of less than $80^{\circ}$ between the arms of the entoplastron. It can be differentiated from Kuhnemys maortuensis by possessing a square sixth neural and more pectinate medial hyo- and hypoplastral processes.

Comments. The early Late Cretaceous Baynshire Formation in Mongolia has yielded rich remains of trionychids, of which most, including nearly complete skeletons that include well-preserved crania, are referable to Kuhnemys orlovi (Danilov et al 2014). Kuhnemys orlovi is therefore well diagnosed, and the validity of this species uncontroversial.

\section{Kuhnemys palaeocenica (Danilov, Sukhanov} et al., 2015), comb. nov.

Taxonomic history. Gobiapalone palaeocenica Danilov, Sukhanov et al., 2015 (new species).

Type material. PIN 3639/13 (holotype), an incomplete articulated skeleton of a juvenile individual, including an almost complete shell, two or three posterior cervical vertebrae, limb girdles, both humeri, hind limbs, and anterior caudal vertebrae (Danilov, Sukhanov et al. 2015, fig. 1).

Type locality. Site 3, Ömnögovi (= Umunugovi) Aimag, Mongolia ( Danilov, Sukhanov et al. 2015; Figure 3); lowermost part of the Naran Member, Naranbulak Formation, late Paleocene (Danilov, Sukhanov et al. 2015).

Referred material and range. No specimens have been referred to date 
Diagnosis. Kuhnemys palaeocenica can be diagnosed as a member of Pan-Trionychidae and Kuhnemys by the full list of characters provided for those clades above. Kuhnemys palaeocenica can be differentiated from other members of Kuhnemys by a square neural IV and simplified medial hyoplastral processes.

Comments. Kuhnemys palaeocenica is based on a nearly complete skeleton from the Paleocene of Mongolia that Danilov, Sukhanov et al. (2015) speculated to be a juvenile, as it only has a CL of 12.5 $\mathrm{cm}$ and confluent suprascapular fontanelles. Although we normally discourage the use of juveniles as the basis for taxa, we make an exception here, as the specimen is well preserved. Kuhnemys palaeocenica constitutes the only valid and only reliable record of a pan-trionychid in the Paleocene of Asia, as all other occurrences from this epoch are based on indeterminate material. Furthermore, this taxon indicates the survivorship of the genus Kuhnemys across the K/T boundary ( Danilov, Sukhanov et al. 2015).

\section{Murgonemys braithwaitei White, 2001}

Taxonomic history. Murgonemys braithwaitei White, 2001 (new species).

Type material. QM F41129 (holotype), a nearly complete carapace and a left xiphiplastron (White 2001, figs. 1, 3, 5).

Type locality. Tingamarra, Murgon, Queensland, Australia (Figure 5); Oakdale Sandstone Formation, early Eocene (White 2001).

Referred material and range. Early Eocene of the type locality, Queensland, Australia (referred material of White 2001).

Diagnosis. Murgonemys braithwaitei can be diagnosed as a member of Pan-Trionychidae by the presence of sculpturing that covers all metaplastic portions of the shell bones and the absence of peripherals, pygals, suprapygals, and shell scutes. Murgonemys braithwaitei can be differentiated from other pan-trionychids by the presence of an expanded trapezoidal preneural, which is more than twice as wide as the neurals, and a xiphiplastron with a six-pronged medial flange.

Comments. Murgonemys braithwaitei is based on a well-preserved carapace and an associated left xiphiplastron from the Eocene of Australia. This is a rather bizarre taxon whose anatomy seems to be a mosaic of different pan-trionychid clades. White (2001) originally considered pan-trionychine affinities for his new species on the basis of the anterior process of the xiphiplastron being lateral to the posterior process of the hypoplastron. We note here, however, that the presence of costals that cover most of the underlying ribs, a large, unusually shaped preneural, the absence of neural series reversal, and the posterior tapering of the carapace are reminiscent of cyclanorbines, although there is no evidence of split costiform processes, large costals VIII, or well-developed plastral callosities, thereby contradicting the association with this group at the same time (Meylan 1987; Vitek and Joyce 2015). The origins of Murgonemys braithwaitei are totally unclear as all other pan-trionychids recovered from Australia, including the only other named taxon, Trionyx australiensis, are from the Plio-Pleistocene and are too fragmentary to allow rigorous identification beyond the family level (Gaffney and Bartholomai 1979). A possible origin from South America, much like coeval meiolaniids (Sterli 2015), can be ruled out, however, as pan-trionychids are not known from the Paleogene of that continent (Vitek and Joyce 2015). The validity of Murgonemys braithwaitei is uncontroversial, and its morphologically, geographically, and temporally isolated nature prompts us to retain the species within its own monotypic genus.

\section{Perochelys lamadongensis Li, Joyce, and Liu, 2015}

Taxonomic history. Perochelys lamadongensis $\mathrm{Li}$, Joyce, and Liu, 2015 (new species).

Type material. IVPP V18048 (holotype), a nearly complete skeleton, comprising cranium, carapace, plastron, vertebrae, and limb elements (Li, Joyce, and Liu 2015, figs. 1-3).

Type locality. Xiaotaizi locality, Lamadong, Jianchang County, Liaoning Province, China (Li, Joyce, and Liu 2015; Figure 3); Jiufotang Formation, Aptian, Early Cretaceous ( $\mathrm{Li}$, Joyce, and Liu 2015).

Referred material and range. No specimens have been referred to date.

Diagnosis. Perochelys lamadongensis can be diagnosed as a member of Pan-Trionychidae by the full list of shell characters provided for that clade above. Among Early Cretaceous pantrionychids, Perochelys lamadongensis can be differentiated from "Trionyx" jixiensis and Petrochelys kyrgyzensis by having a poorly developed nuchal that is only lightly attached to the remaining carapacial disk, a continuous neural series that fully separates the costals from one another, and greatly reduced costals VIII.

Comments. Perochelys lamadongensis is based on a single, nearly complete skeleton from the Early Cretaceous (Aptian) Jehol Fauna of China (Li, Joyce, and Liu 2015). Given the complete nature of the type specimen, the validity of this species is not controversial, because it can be readily distinguished from all other named pan-trionychids. Even though P. lamadongensis is one of the oldest known pan-trionychids, its skeletal morphology corresponds to that of crown trionychids in all major aspects, thereby documenting the evolutionary stasis of the group. The phylogenetic placement of Perochelys lamadongensis within Pan-Trionychidae therefore remains opaque, apparently because of the high levels of homoplasy within pan-trionychids (Meylan 1987; Li, Joyce, and Liu 2015; Vitek and Joyce 2015).

\section{Petrochelys kyrgyzensis (Nessov, 1995b)}

Taxonomic history. Trionyx kyrgyzensis Nessov, 1995b (new species); Kuhnemys kyrgyzensis Chkhikvadze 1999b (new combination); Petrochelys kyrgyzensis Vitek et al. 2017 (new combination).

Type material. CCMGE 186/12458 (holotype), an incomplete isolated xiphiplastron (Nessov 1995b, figs. 3gg; Danilov and Vitek 2013, fig. 23.3b.1). 
Type locality. Left bank of Sarykungoi Spring, Kylodzhun (= Klaudzin), Osh Province, Kyrgyzstan (Nessov 1995b; Vitek and Danilov 2010; Figure 3); Alamyshik Formation, Albian, Early Cretaceous (Danilov and Vitek 2013).

Referred material and range. Early Cretaceous (Albian) of type locality, Osh Province, Kyrgyzstan (referred material of Nessov 1995).

Diagnosis. Petrochelys kyrgyzensis can be diagnosed as a member of Pan-Trionychidae by the full list of shell characters listed for that clade above. Among Early Cretaceous pan-trionychids, Petrochelys kyrgyzensis can be differentiated from Perochelys lamadongensis by exhibiting a fully formed nuchal and enlarged costals VII and VIII that have a midline contact. Among Cretaceous pan-trionychids known from cranial material, Petrochelys kyrgyzensis can be differentiated by the presence of a single hypoglossal foramen, a confluent foramen jugulare posterius and fenestra postotica, and the presence of a triturating surface separate from the rest of the palate. Only geographic considerations allow us to distinguish "Trionyx" jixiensis from Petrochelys kyrgyzensis (see below).

Comments. Petrochelys kyrgyzensis is based on a xiphiplastron from the Albian of Kyrgyzstan and represents one of the earliest known pan-trionychids. Additional material from the type locality, including shell and appendicular elements, vertebrae, a braincase, and a lower jaw have also been referred to this taxon (Nessov 1995b). Like many other Cretaceous Asian pan-trionychids, the affinities of this taxon remain unclear (e.g., Chkhikvadze 1999b), mostly because high levels of homoplasy make it difficult to discern phylogenetic relationships in pan-trionychids, although a recent phylogenetic analysis retrieved it well within pan-trionychines (Vitek et al. 2017). The cranium of the holotype was recently described in detail (Vitek et al. 2017) but a thorough review of the postcranium is still outstanding. We nevertheless tentatively accept the validity of this taxon.

\section{Pan-Cyclanorbinae New Clade Name}

Phylogenetic definition. The name Pan-Cyclanorbinae is herein referred to the total clade of Cyclanorbinae, which in return is defined as the crown clade of all extant turtles that are more closely related with Cyclanorbis senegalensis (Duméril and Bibron, 1835) than Trionyx triunguis (Forskål, 1775).

Diagnosis. Pan-Cyclanorbinae can be diagnosed as a member of Pan-Trionychidae based on the full list of characters provided above for that clade. Pan-Cyclanorbinae can be differentiated from other pan-trionychids by the unique combination of the following shell characters: presence of concave posterolateral margin of the carapace, split costiform processes, costal ossifications that fully cover the ribs, large costals VIII, preneural, and seven large neurals, fusion of the hyo-hypoplastra soon after hatching, hypoplastra lateral to the xiphiplastra at the hypoxiphiplastral suture, and the presence of extensive epiplastral, entoplastral, and xiphiplastral callosities.

Comments. The fossil record of pan-cyclanorbines is rather poor and was restricted until recently to the Neogene of Africa and India (Lydekker 1885; Meylan et al. 1990) in an area that roughly approximates their current distribution in Africa and the Indian subcontinent (Ernst and Barbour 1989). The recent reinterpretation of North American plastomenids as potential stem cyclanorbines (Joyce and Lyson 2010a) combined with the identification of an unambiguous Late Cretaceous pancyclanorbine from Mongolia (Danilov et al. 2014) radically changed our understanding of the evolution of these turtles, implying a rather large ghost lineage and a formerly more extensive distribution. Given that pan-cyclanorbines are mostly known from shell material, we here only diagnose this taxon using shell characters. A more extensive list of characters is available in Meylan (1987).

\section{Cyclanorbis Gray, 1854}

Type species. Cyclanorbis petersii Gray, 1854 (= Cryptopus senegalensis Duméril and Bibron, 1835).

Diagnosis. Cyclanorbis can be diagnosed as a member of PanTrionychidae and Pan-Cyclanorbinae based on the full list of characters provided for those clades above. Cyclanorbis can be differentiated from other cyclanorbines by lacking split costiform processes and a variable tendency of the costals to divide the neural series by meeting along the midline.

Comments. Dacqué (1912) reported a large shell fragment from the Miocene of Egypt that he attributed to Cyclanorbis, but this fragment has since been shown to be a carettochelyid (Lapparent de Broin 2000; Joyce 2014). Meylan et al. (1990), Lapparent de Broin and Gmira (1994), and Karl (2012) reported rich remains from the Mio-Pleistocene of Kenya, Uganda, and Malawi, respectively, that they variously attributed to Cyclanorbis or the extant species Cyclanorbis elegans and Cyclanorbis senegalensis, but given that most remains are not figured and that detailed stratigraphic data are not reported for most localities, we are only able to partially confirm these identifications (Appendix 3). Lapparent de Broin (2000) listed several Cyclanorbis occurrences throughout Africa, but none of the relevant material seems to be figured, and we therefore dismiss these occurrences herein. We here once again restrict our diagnosis to characters that pertain to the shell, as only this region is relevant for the available fossil material.

\section{Cyclanorbis turkanensis Meylan et al., 1990}

Taxonomic history. Cyclanorbis turkanensis Meylan et al., 1990 (new species).

Type material. NMK KP17196 (holotype), a carapace, missing costals VIII and the lateral portions of all left costals (Meylan et al. 1990, fig. 2).

Type locality. Kanapoi, Rift Valley Province, Kenya (Figure 6); Bed E, Zanclean, early Pliocene (Meylan et al. 1990).

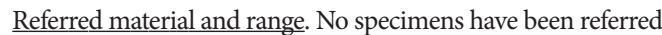
to date.

Diagnosis. Cyclanorbis turkanensis can be diagnosed as a member of Pan-Trionychidae, Pan-Cyclanorbinae, and Cyclanorbis by 
the full list of carapacial characters provided for those clades above. Cyclanorbis turkanensis can be differentiated from other Cyclanorbis species by large size (CL of about $62 \mathrm{~cm}$ ) and hypertrophied and distinctly V-shaped dorsal centra.

Comments. Cyclanorbis turkanensis is based on a partial shell from the early Pliocene of Kenya that can be easily diagnosed as a representative of Cyclanorbis by lacking subdivided costiform processes. This species convincingly documents the former distribution of the Cyclanorbis lineage outside its current range along the Ivory Coast of the African continent. The validity of this species is not controversial.

\section{Cycloderma Peters, 1854}

Type species. Cycloderma frenatum Peters, 1854

Diagnosis. Cycloderma can be diagnosed as a member of PanTrionychidae and Pan-Cyclanorbinae based on the full list of characters provided above for those clades. Cycloderma can be differentiated from other pan-cyclanorbines by the presence of I-shaped epiplastra, combined with the symplesiomorphic retention of split costiform processes and a continuous neural series.

Comments. Similarly to Cyclanorbis, several fossil specimens from the Pliocene until the Holocene of Africa have been attributed to Cycloderma (Lapparent de Broin 2000). Only a thorough redescription of these remains, along with a reevaluation of the taxonomic characters of cyclanorbines, will clarify whether these taxonomic assignments are valid. Among the most important finds that were figured and described, and can be therefore confidently assigned to Cycloderma, are the extinct taxa Cycloderma victoriae and Cycloderma debroinae from the Miocene and Pliocene, respectively, of Kenya (Meylan et al. 1990), a carapace from the Pleistocene of Uganda (Arambourg 1947), and material from the Plio-Pleistocene of Kenya and Malawi (Wood 1979; Meylan et al. 1990; Karl 2012).

\section{Cycloderma debroinae Meylan et al., 1990}

Taxonomic history. Cycloderma debroinae Meylan et al., 1990 (new species); Cycloderma debrionae Wood 2013 (incorrect spelling of species epithet).

Type material. NMK LT17200 (holotype), nearly complete skeleton including most of the carapace and plastron, complete girdles, significant portions of all four limbs, portions of the cervical and caudal vertebral columns, and fragments of the skull and hyoid (Meylan et al. 1990, figs. 9-10).

Type locality. Lothagam Hill, Turkana District, Rift Valley Province, Kenya (Figure 6); Pliocene (Meylan et al. 1990).

Referred material and range. No specimens have been referred to date.

Diagnosis. Cycloderma debroinae can be diagnosed as a member of Pan-Trionychidae, Pan-Cyclanorbinae, and Cycloderma by the full list of shell characters provided for those clades above.
Cycloderma debroinae can be differentiated from Cycloderma aubryi, by lacking well-developed entoplastral callosities, and from Cycloderma frenatum by having a deep nuchal notch and expanded distal margin of costals II. Cycloderma debroinae can currently only be distinguished from Cycloderma victoriae using temporal considerations.

Comments. Cycloderma debroinae is based on a well-preserved, nearly complete skeleton from the early Pliocene of Kenya (Meylan et al. 1990), whereas Cycloderma victoriae is based on a relatively complete carapace from the early Miocene of the same country (Andrews 1914). Phylogenetic analysis places Cycloderma debroinae and Cycloderma victoriae as sisters to the extant Cycloderma aubryi, which occurs in the same region today, though with a notably different morphology (Meylan et al. 1990). We can only distinguish Cycloderma victoriae from Cycloderma debroinae using stratigraphic arguments, as the carapaces of both taxa only show a minimal amount of variation. Given that Cycloderma debroinae differs substantially from the extant $\mathrm{Cyclo-}$ derma aubryi in the development of its plastron, however, we speculate that future finds may also reveal a unique morphology for the Miocene taxon as well, and we therefore retain both taxa for the moment.

\section{Cycloderma victoriae Andrews, 1914}

Taxonomic history. Cycloderma victoriae Andrews, 1914 (new species).

Type material. BMNH R4105 (holotype), almost complete carapace (Andrews 1914, pl. 27.1-3; Meylan et al. 1990, fig. 8).

Type locality. Bed 21 at Kachuku, adjacent to the eastern shore of Lake Victoria, Nyanza Province, Kenya (Andrews 1914; Meylan et al. 1990; Figure 6); Burdigalian, early Miocene (Drake et al. 1988; Joyce et al. 2013).

Referred material and range. No specimens have been referred to date.

Diagnosis. Cycloderma victoriae can be diagnosed as a representative of Pan-Trionychidae, Pan-Cyclanorbinae, and Cycloderma by the full list of carapacial characters provided for those clades above. Cycloderma victoriae can be differentiated from Cycloderma frenatum by having a deep nuchal notch and expanded distal margin of costals II. Cycloderma victoriae can currently only be distinguished from Cycloderma debroinae using temporal considerations.

Comments. For a brief discussion on fossil Cycloderma species, see Cycloderma debroinae above.

Nemegtemys conflata Danilov et al., 2014

Taxonomic history. Nemegtemys conflata Danilov et al., 2014 (new species).

Type material. ZIN PH 1/157 (holotype), lateral fragment of left hyo-hypoplastra (Danilov et al. 2014, figs. 3, 17f). 
Type locality. Nemegt, Ömnögovi (= Umunugovi) Aimag, Mongolia (Figure 3); Nemegt Formation, Maastrichtian, Late Cretaceous (Danilov et al. 2014).

Referred material and range. Late Cretaceous (Maastrichtian), Nemegt Formation, Bugin Tsav, Ömnögovi (= Umunugovi) Aimag, Mongolia (referred material of Danilov et al. 2014).

Diagnosis. Nemegtemys conflata can be diagnosed as a member of Pan-Trionychidae and Pan-Cyclanorbinae by all characters listed above for those clades that pertain to the hyo-hypoplastron. Nemegtemys conflata can be differentiated from other pancyclanorbines by its small size and the presence of a small hyoplastral lappet.

Comments. Nemegtemys conflata is based on a partial hyohypoplastron that represents the oldest unambiguous pancyclanorbine in the Old World. The remaining fossil record of the group in the Old World is restricted to the Neogene of Africa and the Indian subcontinent, implying a significant ghost lineage and dispersal outside the original ancestral area in central Asia (Danilov et al. 2014). The validity of this taxon is not controversial.

\section{Pan-Trionychinae New Clade Name}

Phylogenetic definition. The name Pan-Trionychinae is herein referred to the total clade of Trionychinae, which in return is defined as the crown clade arising from the common ancestor of all extant turtles more closely related to Trionyx triunguis (Forskål, 1775) than Cyclanorbis senegalensis (Duméril and Bibron, 1835)

Diagnosis. Pan-Trionychinae can be diagnosed as a member of Pan-Trionychidae based on the full list of characters provided above for that clade. Among extant trionychids, representatives of Pan-Trionychinae can be easily differentiated from representatives of Pan-Cyclanorbinae by an extensive list of characters, but it remains unclear which of these characters are derived, as opposed to plesiomorphies.

Comments. Extant trionychids form two monophyletic clades, Cyclanorbinae and Trionychinae, that are easily distinguished from one another by an extensive list of characters (Meylan 1987). If the characters that diagnose the extant groups are applied to the fossil record literally, one must conclude that nearly all known Cretaceous and Paleogene must be representatives of the trionychine lineage (with the notable exception of Nemegtemys conflata and Murgonemys braithwaitei) and that no trionychid stem lineage is apparent. Although this may be the true signal, it seems plausible that the trionychine morphotype may be ancestral to the crown (Joyce and Lyson 2010a). We herein therefore only refer those fossils to Pan-Trionychinae that are attributable to extant trionychine genera. This section therefore is mostly restricted to the Neogene.

\section{Pelodiscus Fitzinger, 1836}

Type species. Trionyx sinensis Wiegmann, 1835.

Diagnosis. Pelodiscus can be diagnosed as a member of Pan-Trionychidae by the presence of all characters listed for that clade above. Pelodiscus can be differentiated from all other pan-trionychids by small size, absence of a preneural, suprascapular fontanelles that only close in mature adults, extremely elongate anterior epiplastral processes, seven callosities, and xiphiplastra that are broader than long.

\section{Pelodiscus gracilia (Yeh, 1963), comb. nov.}

Taxonomic history. Amyda gracilia Yeh, 1963 (new species); Triony $x$ sinensis $=$ T. gracilis Mlynarski 1976 (new combination, junior synonym, incorrect spelling of species epithet).

Type material. IVPP V1038 (holotype), a carapace, with left costals I-IV, right costals I and VII, and the last two neurals damaged, seven cervical vertebrae, complete left pectoral girdle, right coracoid, complete left and right pelvic girdles, left xiphiplastron and additional fragments of the plastron (Yeh 1963, figs. 33, 34, pl. 21.1-7; Ye 1994, fig. 76).

Type locality. Yushe County, Shanxi (= Shansi) Province, China (Figure 3); Pliocene (Yeh 1963).

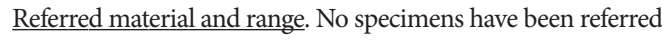
to date.

Diagnosis. Pelodiscus gracilia can be diagnosed as a member of Pan-Trionychidae by the full list of shell characters provided for that clade above and Pelodiscus by small size, absence of a preneural, suprascapular fontanelles that only close in mature adults, and xiphiplastra that are broader than long. Pelodiscus gracilia can be differentiated from Pelodiscus sinensis by larger costals VIII.

Comments. Pelodiscus gracilia is based on a partial skeleton from the Pliocene of Yushe County, China (Yeh 1963), within the current range of the extant Pelodiscus sinensis (TTWG 2014). Yeh (1963) already noted strong resemblance with Pelodiscus sinensis but nevertheless referred this species to Amyda. Mlynarski (1976), on the other side, confirmed close resemblance with Pelodiscus sinensis but suggested synonymy with it instead. We herein agree that both Pelodiscus gracilia and Pelodiscus sinensis are extremely similar by being small sized, having a broad nuchal, possessing open suprascapular fontanelles, and having broad xiphiplastra, but we note that the type of Pelodiscus gracilia possesses much larger costals VIII than the extant Pelodiscus sinensis. We therefore confirm the validity of this species. A second species with clear affinities with the Pelodiscus lineage, Trionyx sinuosus Chow and Yeh, 1958, was named from this region that could have priority over Pelodiscus gracilia, but we here disregard this taxon, as it is based on fragmentary material (see below)

\section{Rafetus Gray, 1864}

Type species. Testudo euphratica Daudin, 1801.

Diagnosis. Rafetus can be diagnosed as a representative of PanTrionychidae by the full list of characters provided for that clade above. Using shell characters, Rafetus is most readily differentiated from other pan-trionychids by the combined absence of a 
preneural, presence of seven neurals of which neural V or VI is square, highly reduced costals VIII, a reduced count of medial hyo- and hypoplastral processes, and poorly developed callosities that are restricted to the hyo-hypoplastron.

\section{Rafetus bohemicus (Liebus, 1930), comb. nov.}

Taxonomic history. Trionyx bohemicus Liebus, 1930 (new species); $T$. triunguis $=[$ Aspidonectes gergensi $]=T$. aspidiformis $=T$. bohemicus $=T$. brunhuber $=T$. croaticus $=T$. elongatus $=T . \quad$ hilberi $=T . \quad$ hoernesi $=[T . \quad$ oweni $]=[T$. partschii $]=T$. penecke $i=T$. petersi $=T$. petersi trifailensis $=$ $[T . \quad$ pliocenicus $]=T . \quad$ pontanus $=T . \quad$ preschenensis $=T$. pseudovindobonensis $=T$. senckenbergianus $=T$. septemcostatus $=T$. siegeri $=T$. sophiae $=T$. stadler $i=T$. stiriacus $=T$. teyleri $=$ T. vindobonensis Karl 1998 (junior synonym); Rafetus pontanus $=$ T. aspidiformis $=$ T. bohemicus $=T$. elongatus $=T$. preschenensis Chkhikvadze 1999b (junior synonym).

Type material. The syntype series consists of the following specimens: MMUL 633/2a/G 12908 and MMUL 633/2b/G 12941, a complete carapace with its imprint (Liebus 1930, pl. 1.1); NMP 1485, a carapace (Liebus 1930, pl. 2.1); MMUL 1444/G 12927, an entoplastron (Liebus 1930, pl. 2.2); MMUL 1447/G 12931, an epiplastron (Liebus 1930, pl. 2.3); NMP P9640, an epiplastron (Liebus 1930, pl. 2.4); MMUL 1486/G 12939, a hyoplastron (Liebus 1930, pl. 2.5); MMUL 1035/G 12915, a right hypoplastron (Liebus 1930, pl. 2.6); MMUL 1038/G 12918, a xiphiplastron (Liebus 1930, pl. 3.1); MMUL 1036/G 12916 and MMUL 1041/G 12921, a partial pelvic girdle and its imprint (Liebus 1930, pl. 3.2); MMUL 1442/G 10193, a complete skull (Liebus 1930, pl. 3.3); MMUL 631/G 12912, a partial pectoral girdle (Liebus 1930, pl. 3.4); MMUL 1451/G 12933, a cervical vertebra (Liebus 1930, pl. 3.5); MMUL 1461/G 12937, a partial epiplastron; MMUL 1037/G 12917, a xiphiplastron; MMUL 1443/G 12926, a skull; MMUL 1048/G 10194, a skull; MMUL 1037/G 12917 and MMUL 1042, a skull and xiphiplastron and their imprints; MMUL 1043/G 12923, a skull; MMUL 1045/G 12925, a mandible; MMUL 1450/G 12932, a radius and an ulna; MMUL 1453/G 12935, a fibula; MMUL 1446/G 12929 and MMUL 1445/G 12930, a tibia with and epiplastron fragment and its imprint; MMUL 1462/G 12938, a left femur.

Type locality. Břestány (= Preschen), near Bilina, Ústí nad Labem, Czechia (Liebus 1930; Figure 4); Most Formation, MN 3, Burdigalian, early Miocene (Aguilar et al. 1997).

Referred material and range. No specimens are referred herein.

Diagnosis. Rafetus bohemicus can be diagnosed as a member of Pan-Trionychidae and Rafetus by the full list of shell characters listed for those clades. Rafetus bohemicus is differentiated from Rafetus swinhoei by being significantly smaller and from Rafetus euphraticus by having a more pronounced constriction to the xiphiplastra.

Comments. Liebus (1930) established Rafetus bohemicus on the basis of abundant skeletal material from the early Miocene of Brestány, Czechia. Like most fossil trionychids, the phylogenetic affinities and taxonomic validity of this taxon were mostly ignored over the course of the subsequent decades, but Karl
(1998) more recently proposed that this species is synonymous with Trionyx triunguis, whereas Chkhikvadze (1999b) suggested junior synonymy with the coeval T. pontanus, which he referred to Rafetus.

We here conclude that the described pan-trionychid remains from the Miocene of Europe can be grouped into two morphotypes that broadly agree with the extant Trionyx triunguis and Rafetus euphraticus, but also that representatives of these two lineages can only be differentiated rigorously using plastral remains. Whereas many Miocene pan-trionychids can be attributed to the $T$. triunguis lineage, only a single find, the type material of bohemicus, can be attributed to the Rafetus euphraticus lineage with confidence based on the absence of plastral callosities on the xiphiplastra. We therefore agree with Chkhikvadze (1999b) that the Rafetus lineage was present during the Miocene in Europe but consider bohemicus to be valid, not pontanus, as the latter taxon is not represented by plastral material. The T. triunguis and Rafetus euphraticus lineages can furthermore be distinguished by the relative size of the costals VIII, but this character shows much variation and should therefore be used with caution, the primary reason why we herein disregard all Miocene taxa that are based on carapacial material alone. Along those lines, we note that the types of T. moldaviensis, T. pontanus, and T. rostratus show the reduced costals VIII more typical of the Rafetus euphraticus, thereby hinting at the possibility that this lineage may have been more widespread in the Miocene than is alluded to by the isolated type of Rafetus bohemicus. The relative scarcity of plastral material that would more rigorously document the presence of this lineage, however, may be caused by various taxonomic filters that disfavor bones with poorly developed callosities. Several skulls have been collected from the type locality of Rafetus bohemicus (Liebus 1930) that might be able to test our assertion that this taxon is referable to the Rafetus lineage, but they are poorly preserved and seem to be uninformative. We here note that three other pan-trionychid species have been established from the type locality of Rafetus bohemicus: Trionyx aspidiformis and T. preschenensis by Laube (1900) and T. elongatus by Liebus (1930). Although the former two taxa were described well before Rafetus bohemicus, we consider all of these names to be nomina dubia, as they are based on nondiagnostic material. For a more extensive discussion, see T. vindobonensis (below).

Rafetus bohemicus has otherwise been reported from the middle Miocene (Serravallian) of Viehhausen (Trionyx bohemicus jaegeri of Fuchs 1939) and Sandelzhausen (T. aff. bohemicus of Schleich 1981), Bavaria, Germany, but this material lacks plastral material and is therefore herein identified as an indeterminate pan-trionychine.

\section{Trionyx Geoffroy Saint-Hilaire, 1809}

Type species. Testudo triunguis Forskål, 1775.

Diagnosis. Trionyx can be diagnosed as a representative of Pan-Trionychidae by the full list of characters provided for that clade above. Using shell characters, Trionyx is most readily differentiated from other pan-trionychids by the combined absence of a preneural, presence of seven neurals of which neural V or VI is square, a broadly developed medial fan of hypoplastral processes, and four pairs of well-developed plastral callosities. 
Comments. We herein refer many fossil pan-trionychids to "Trionyx" as this genus has historically served as a wastebasket for fossil taxa with uncertain affiliation. However, we herein also refer two species to Trionyx as we believe that these are fossil relatives of the extant Trionyx triunguis. We highlight the two different meanings through the usage of quotation marks.

\section{Trionyx pliocenicus Fucini, 1912}

Taxonomic history. Trionyx pliocenica Lawley 1876 (nomen nudum); T. pliocenicus Fucini, 1912 (new species); T. hilberi $=$ T. pliocenicus Teppner 1914b (junior synonym); T. pliopedemontanus $=T$. blayaci $=T$. pliocenicus $=T$. pompignanensis $=T$. rotundiformis Broin 1977 (junior synonym); T. triunguis $=[T$. pliocenicus $]=24$ others Karl 1998 (junior synonym, nomen dubium, see Rafetus bohemicus for complete synonym); T. pliocaenicus Karl 1998 (incorrect spelling of species epithet).

Type material. A relatively complete skeleton, including most of skull, carapace, plastron, vertebrae, and appendicular elements (holotype) (Fucini 1912, pls. 1-5), unknown whereabouts (G. Bianucci and C. Sorbini, pers. comm., 2016).

Type locality. Mapesi (= Malpessi) near Poggio Alle Monache, Tuscany, Italy (Lawley 1876; Fucini 1912; Figure 4); Pliocene (Kotsakis 1985).

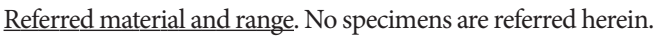

Diagnosis. Trionyx pliocenicus can be diagnosed as a representative of Pan-Trionychidae and Trionyx by the full list of characters provided for those clades above. Trionyx pliocenicus can be differentiated from $T$. triunguis and T. vindobonensis by having more extensive plastral callosities, a hypo-xiphiplastral suture outlined by callosities, and a midline contact of the xiphiplastral callosities.

Comments. Lawley (1876) provided the name Trionyx pliocenicus for beautifully preserved material from the Pliocene of Italy, but this contribution was not accompanied by a description or a definition, and Lawley's name must therefore be considered a nomen nudum (Kotsakis 1985). The specimen was much later described by Fucini (1912) and the name thereby made available. Teppner (1914b) soon after hypothesized that T. pliocenicus is conspecific with T. hilberi, but Broin (1977) and Kotsakis $(1980,1985)$ more recently argued for synonymy with the spatially and temporally close T. pliopedemontana. We herein regard both T. hilberi and T. pliopedemontana to be nomina dubia, as they are solely known by carapacial material.

The holotype of Trionyx pliocenicus is the only known partial trionychid skeleton from the northern shores of the Mediterranean Sea and therefore of particular relevance to the taxonomy and evolutionary history of Neogene trionychids. The postcranium, in particular the shell, is fully consistent with the morphology of the extant T. triunguis and notably distinct from the geographically close Rafetus euphraticus, in particular in regard to the size of the nuchal, number and arrangement of neurals, the number of lateral processes, and the number and dimensions of the plastral callosities (Meylan 1987). This specimen therefore firmly establishes the presence of the T. triunguis lineage in the Neogene of southern Europe. Given that all other known material from the same region is highly fragmentary, it is unclear to us if T. pliocenicus shared its habitat with other trionychids. The lack of quality material therefore precludes us from assuming that it is the only trionychid in the region (contra Karl 1999a). The type and only known specimen was originally deposited in the private collection of R. Lawley (Fucini 1912), a collection that was partly destroyed during WWII and now is scattered accross Italy (G. Bianucci and C. Sorbini, pers. comm., 2016). We were not able to locate the holotype of $T$. pliocenicus and therefore consider this specimen to be lost.

Trionyx vindobonensis Peters, 1855

$(=$ T. brunhuberi Ammon, $1911=$ T. gergensi

Reinach, $1900=T$. hoernesi Heritsch, $1909=$

T. peneckei Heritsch, $1909=$ T. petersi Hoernes,

$1881=T$. rostratus Arthaber, $1898=$

T. septemcostatus Hoernes, $1881=$

T. teiritzbergensis Gemel, $2002=$

T. teyleri Winkler, 1869a)

Taxonomic history. Trionyx vindobonensis Peters, 1855 (new species); T. vindibonensis Lawley 1876 (incorrect spelling of species epithet); Tryonix vindobonensis Portis 1879 (incorrect spelling of genus name); $T$. vindobonensis $=T$. partschi (sic) Glaessner 1933 (senior synonym); T. triunguis $=$ T. vindobonensis $=24$ others Karl 1998 (junior synonym, see Rafetus bohemicus for complete synonym).

Type material. NHMW 1853/0016/0003 (holotype), partial skeleton, including fragments of the carapace, plastron, and limbs (Peters 1855, pls. 1.1, 2.1, 3.1-3; Peters 1859, pl. 1).

Type locality. Hernals, Vienna, Austria (Peters 1855; Figure 4); MN 7+8, Serravallian, middle Miocene (Aguilar et al. 1997).

Referred material and range. Early Miocene (Aquitanian), Rhineland-Palatinate, Germany (type material of Trionyx gergensi; Reinach 1900); early Miocene (Burdigalian), Lower Austria, Austria (type material of T. teiritzbergensis; Gemel 2002); early Miocene (Burdigalian), Centre-Val de Loire, France (material previously referred to T. stiriacus by Broin 1977); middle Miocene (Langhian), Styria, Austria (type material of T. septemcostatus, T. hoernesi, T. petersi, and T. peneckei; Hoernes 1881; Heritsch 1909); middle Miocene (Langhian), Bavaria, Germany (type material of T. brunhuberi; Ammon 1911; referred material of Fuchs 1939); middle Miocene (Serravallian), Vienna, Austria (referred material of Peters 1859); middle Miocene (Serravallian), Baden-Württemberg, Germany (type material of T. teyleri; Winkler 1869a); late Miocene (Tortonian), Burgenland, Austria (type material of T. rostratus; Arthaber 1898); late Miocene (Tortonian), Lower Austria, Austria (referred material of Papp et al. 1953).

Diagnosis. Trionyx vindobonensis can be diagnosed as a representative of Pan-Trionychidae and Trionyx by the full list of characters provided for those clades above. Trionyx vindobonensis can be differentiated from T. triunguis and T. pliocenicus by having plastral callosities that are more extensive than T. triunguis, but less extensive than T. pliocenicus. 
Comments. For reasons beyond our comprehension, a total of 29 trionychid names were provided for specimens recovered from Miocene sediments exposed in Europe north of the Alpide belt, in particular Trionyx hilberi Hoernes, 1892, T. hoernesi Heritsch, 1909, T. partschii Peters, 1855, T. peneckei Heritsch, 1909, T. petersi Hoernes, 1881, T. rostratus Arthaber, 1898, T. septemcostatus Hoernes, 1881, T. siegeri Heritsch, 1909, T. sophiae Heritsch, 1909, T. stiriacus Peters, 1855, T. teiritzbergensis Gemel, 2002, and T. vindobonensis Peters, 1855 from Austria; T. aspidiformis Laube, 1900, T. bohemicus Liebus, 1930, T. elongatus Liebus, 1930, T. pontanus Laube, 1895, and T. preschenensis Laube, 1900 from Czechia; T. aquitanicus Delfortrie, 1869 and T. lockardi Gray 1831 from France; T. bohemicus jaegeri Fuchs, 1939, T. brunhuberi Ammon, 1911, T. gergensi Reinach, 1900, T. münzenbergensis Hummel 1927, T. oweni Reinach, 1900, and T. teyleri Winkler, 1869a from Germany; T. pseudovindobonensis Szalai, 1934 from Hungary; T. moldaviensis Khosatzky, 1986 from Moldova; T. nopcsai Szalai, 1934 from Romania; and T. reticulatus Rieppel, 1979 from Switzerland. Five additional taxa are based on poorly dated late Oligocene to early Miocene sediments exposed in France, in particular T. acutiformis Bergounioux, 1935, T. chaubeti Bergounioux, 1935, T. ciryi Bergounioux, 1935, T. manouri Gray, 1831, and T. mourieri Bergounioux, 1935, and will be discussed here for simplicity as well.

We conclude after reviewing all available shell material from Miocene localities north of the Alps that only two morphotypes are apparent that can be attributed to the stem lineages of Rafetus euphraticus and Trionyx triunguis. Extant representatives of these two species can readily be distinguished by their plastral morphology, as T. triunguis possesses four welldeveloped callosities that cover the hyo-hypoplastra and xiphiplastra, whereas $R$. euphraticus only possesses two poorly developed callosities that cover just the hyo-hypoplastra (Meylan 1987). The carapaces of both taxa resemble one another greatly by being well ossified, by having a surface texture that varies from netted to pitted, by lacking a preneural, and by typically possessing seven neurals, of which the fifth is squared and that allow for medial contact of costals VII and VIII. The primary carapacial difference between the two is that Rafetus euphraticus possesses smaller costals VIII than T. triunguis, but extensive variation makes it impractical to use this character to rigorously distinguish the two lineages.

Of the 34 taxa listed above, we immediately are able to disregard 8 from consideration, because they represent either nomina nuda or unambiguous nomina dubia. These include Trionyx aquitanicus (a nomen dubium based on two costal fragments that may well be referable to a marine turtle), T. lockardi (a nomen nudum), T. manouri (a nomen dubium based on fragmentary, now lost material), T. münzenbergensis (a nomen nudum), T. nopcsai (a nomen dubium based on a partial dentary and carapace fragment), T. oweni (a nomen dubium based on unfigured costal fragments), T. pseudovindobonensis (a nomen dubium based on a femur), and T. partschii (a nomen dubium based on two costal fragments). We similarly disregard 4 additional taxa a priori, as they are based on juvenile specimens (e.g., T. aspidiformis, T. elongatus, T. preschenensis, and T. sophiae). As we find no evidence of cyclanorbines in the Neogene north of the Alps, despite previous claims to the contrary (Portis 1901), we refer all indeterminate material from this region to Pan-Trionychinae indet.
We can confirm based on the available material that the two morphotypes we recognize cannot be distinguished rigorously using carapacial material alone, much as their recent relatives Rafetus euphraticus and Trionyx triunguis. We therefore disregard 11 further taxa from nomenclatural considerations that are based on carapacial material alone. These include T. acutiformis, T. chaubeti, T. ciryi, T. moldaviensis, T. mourieri, T. siegeri, and T. stiriacus, which are based on partial carapaces, and T. bohemicus jaegeri, T. hilberi, T. pontanus, and T. reticulatus, which are based on complete carapaces.

Of the 11 remaining taxa, 10 can be attributed to the Trionyx triunguis lineage based on the presence of four well-developed plastral callosities that broadly cover the hyo-hypoplastra and xiphiplastra. These are T. brunhuberi, T. gergensi, T. hoernesi, T. peneckei, T. petersi, T. rostratus, T. septemcostatus, T. teiritzbergensis, T. teyleri, and T. vindobonensis. Of these, T. vindobonensis was named first and therefore serves as the senior synonym. The sole remaining taxon, T. bohemicus, possesses a highly reduced plastron that lacks xiphiplastral callosities, and we therefore partially agree with Chkhikvadze (1999b) that this taxon is referable to the Rafetus lineage, but as a valid species and not a junior synonym of T. pontanus (a nomen dubium, as it is based solely on carapace material) (see Rafetus bohemicus above).

Apart from the aforementioned type specimens, we here refer material from the Miocene of Carinthia, Austria, which had previously been attributed to Trionyx petersi siegeri (Mottl 1967) to T. vindobonensis based on the presence of four welldeveloped plastral callosities. To the contrary, Miocene specimens that are known solely by carapacial material and have in the past been variously assigned to T. petersi and T. stiriacus are herein considered to be indeterminate pan-trionychines as they lack plastral remains. These include carapacial material from the middle Miocene of Carinthia (T. petersi of Wank 1977 and T. petersi siegeri of Mottl 1967), Styria (T. hilberi of Teppner 1914a; T. petersi of Heritsch 1910), and Slovakia (T. rostratus of Holec and Schlögl 2000).

The holotype of Trionyx vindobonensis does not include cranial material, but many specimens that are referred based on their plastral anatomy do. The most notable remains are a complete skull and mandible from the late Miocene of Austria (part of the type of T. rostratus, Arthaber 1898) and the anterior half of a skull from the middle Miocene of Austria (the lectotype of T. petersi, Hoernes 1881), which already show much variation, as the complete skull has a narrow palate, whereas the partial skull shows a broad palate with incipient secondary palate. Although the early Miocene locality of Artenay, France, only yielded disassociated material (T. stiriacus of Broin 1977), we find it prudent to refer all to $T$. vindobonensis, as the plastral material is diagnostic of this taxon. The beautifully preserved skulls known from Artenay (Broin 1977) once again display an extremely broad palate, much like the partial skull from Austria. On the other hand, we do not attribute the nicely preserved skull from the early Pliocene of Leobersdorf, Austria (Trionyx sp. aff. rostratus of Glaessner 1933), to $T$. vindobonensis, as it is not associated with diagnostic plastral material and because its morphology is insufficiently described to allow referral by comparison with the other skulls. Although the narrow and extremely broad skull morphotypes apparent in the available material could be used to justify the presence of two closely related taxa in the Miocene of Europe, we note that the narrow skull originates from a subadult individual, at least as inferred from its postcranium, whereas the broad skulls 
originate from larger individuals. We here therefore attribute the apparent differences to ontogenetic variation, as has otherwise been extensively documented for some extant and extinct trionychids (Dalrymple 1977; Joyce et al. 2016). A meaningful comparison with skulls likely referable to the coeval Rafetus bohemicus is not possible, as these are poorly preserved (see Rafetus bohemicus above).

The idea that most of the fossil pan-trionychids from Europe form a single lineage attributable to the extant Trionyx triunguis is not novel. Reinach (1900) was the first to propose that most Tertiary pan-trionychids from Europe form a single lineage with many concurrent species that he named the "Trionyx protriunguis succession" (die Reihe des Trionyx protriunguis in German). Teppner (1914c) went further by providing a dendrogram depicting ancestor-descendant relationships among all named taxa and by suggesting that all are representatives of a single species. However, as Hummel $(1927,1929)$ already noted, Teppner (1914c) apparently did not heed his own conclusions, as he did not formally propose any synonymies and even named yet another taxon. Hummel $(1927,1929)$ also agreed with the conclusions of Reinach (1900) as he too saw great similarities between all named pan-trionychids from the Tertiary of Europe and the extant T. triunguis, but he nevertheless felt that all named morphotypes represent true species and that the lineage is not necessary restricted to Europe and therefore does not lead only to the extant T. triunguis. According to the classification scheme of Hay (1908), he assigned all relevant taxa, including the extant T. triunguis, to the subgenus Amyda. In a series of papers, Karl (1998) partially revived Reinach's (1900) "Trionyx protriunguis succession" by explicitly synonymizing most of the Miocene to Pleistocene soft-shelled turtles from central Europe with the extant T. triunguis. Karl (1999a) soon united all known fossil pan-trionychids from the Tertiary of Europe into T. triunguis, but an explicit synonym list is lacking. Although we here arrive at the conclusion that at least two lineages are apparent in the Neogene of Europe, we agree that the T. triunguis lineage is only represented by a single morphotype at any given time interval. If one were to employ a lineage species concept, Karl (1998) would certainly be right to synonymize so many fossil taxa with T. triunguis. However, given that a rigorous phylogenetic analysis is still outstanding and that the apparent $T$. triunguis lineage shows evidence of anagenesis, we here conform to the paleontological convention of establishing chronospecies, while explicitly acknowledging that these are paraphyletic.

\section{Pan-Trionychidae Incertae Sedis}

Comments. We consider the following list of fossil pan-trionychid taxa to be valid, but given that their relationships with extant trionychids and with other fossil trionychids are unclear, we refer them to the wastebasket taxon "Trionyx." The polyphyletic nature of "Trionyx" is highlighted with the use of quotation marks, in contrast to Trionyx without quotation marks, which refers to the monophyletic group associated with the extant T. triunguis.

\section{“Trionyx” baynshirensis Danilov et al., 2014}

Taxonomic history. “Trionyx” baynshirensis Danilov et al., 2014 (new species).
Type material. PIN 557-134 (formerly PIN 557-130) (holotype), medial fragment of right hyo-hypoplastra (Danilov et al. 2014, fig. 13a, b).

Type locality. Bayn Shire, Dornogovi Aimag, Mongolia (Figure 3); Baynshire Formation, Cenomanian/Santonian, Late Cretaceous (Danilov et al. 2014).

Referred material and range. No specimens have been referred to date.

Diagnosis. "Trionyx" baynshirensis can be diagnosed as a member of Pan-Trionychidae by the presence of sculpturing that covers all metaplastic portions of the shell bones and the absence of shell scutes. "Trionyx" baynshirensis can be differentiated from all other early Late Cretaceous pan-trionychids by having a hyohypoplastral callosity with an expanded, blunt medial edge that fully covers the medial processes.

Comments. The early Late Cretaceous Baynshire Formation has yielded rich trionychid material. Danilov et al. (2014) noted that most of the specimens can be assigned to Kuhnemys orlovi (see above), but that a second, less prominent taxon is available as well that can be diagnosed easily based on a single plastral fragment that shows many similarities with the Santonian "Trionyx" kansaiensis in terms of overall shape of the hyo-hypoplastra and sculpturing pattern (Danilov et al. 2014). We provisionally accept the validity of this species herein.

\section{"Trionyx" boulengeri Reinach, 1900 \\ (= T. clavatomarginatus Lörenthey, 1903)}

Taxonomic history. Trionyx boulengeri Reinach, 1900 (new species); Amyda boulengeri $=$ T. borkenensis Karl 1993 (new combination, senior synonym); $T$. triunguis $=T$. boulengeri $=$ 24 others Karl 1998 (junior synonym, see Rafetus bohemicus for complete synonym).

Type material. BMNH 36765 (holotype), a complete carapace (Lydekker 1889a, unnumbered figure; Reinach 1900, pl. 38; Karl 2007, pl. 2).

Type locality. Alzey, Rhineland-Palatinate, Germany (Reinach 1900; Figure 4); Rupelian, early Oligocene (Karl 1999a).

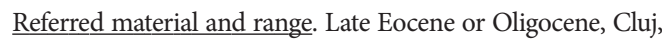
Romania (lectotype of Trionyx clavatomarginatus; Lörenthey 1903).

Diagnosis. "Trionyx" boulengeri can be diagnosed as a member of Pan-Trionychidae by the full list of carapacial characters provided for that clade above. Among Paleogene pan-trionychids from Europe, "T." boulengeri can be differentiated from Axestemys vittata by size, more extensive development of the carapacial callosities, and the absence of a preneural, and from all others by having reduced costals VIII and sinuous carapacial margins.

Comments. "Trionyx" boulengeri is based on a nearly complete carapace from the Oligocene of Alzey, Germany, that had 
originally been referred to T. gergensi (Lydekker 1889a) but was later used for the basis of a new species (Reinach 1900). The type is notable among Oligocene pan-trionychids from north of the Alps, as it is relatively complete and therefore displays at least some traits that can be considered diagnostic. However, given that " $T$." boulengeri lacks plastral material (see T. vindobonensis above for more extensive discussion), it is difficult to diagnose this taxon rigorously once temporal and biogeographic concerns are omitted. We here nevertheless recognize two valid taxa in the Oligocene of Europe, "T." boulengeri north of the Alps and "T." capellinii south of the Alps, which can be differentiated using relative nuanced characters apparent in the carapace. However, whereas "T." capellinii seems to be restricted to the Eocene to Oligocene of Italy, we here attribute the lectotype of $T$. clavatomarginatus from the late Eocene of Romania to "T". boulengeri, as this specimens also shows reduced costals VIII and sinuous carapacial margins. The future finding of more completely material, especially associated plastral remains, will allow more rigorously diagnosing the taxon " $T$ ?" boulengeri relative to other pan-trionychids from Europe.

$\operatorname{Karl}(1993,1996)$ attributed fragmentary remains from the early Eocene of Salzburg, Austria, and the Eocene and Oligocene of Germany, respectively, to Amyda cf. boulengeri, but we believe that these specimens are too fragmentary to allow identification at the species level. On the other side, we here reluctantly refer the well-preserved lectotype of T. clavatomarginatus to "T." boulengeri as it displays the sinuous carapacial margin that is diagnostic for this taxon.

“Trionyx” capellinii Negri, 1892

$(=$ T. affinis Negri, $1892=$ T. capellinii conjugens Sacco, $1894=$ T. capellinii gracilina Sacco, $1895=$ T. capellinii perexpansa Sacco, $1895=$ T. gemmellaroi Negri, $1892=T$. intermedius

Bergounioux, $1954=T$. insolitus Bergounioux, $1954=$ T. capellinii montevialensis Negri, $1892=$ T. schaurothianus Negri, 1893)

Taxonomic history. Trionyx capellinii Negri, 1892 (new species); T. capellinii $=$ T. schaurothianus Sacco 1895 (senior synonym); T. capellini Teppner 1913 (incorrect spelling of species epithet); T. c. capellinii $=$ T. c. affinis $=$ T. c. conjugens Kotsakis 1977 (senior synonym); T. c. capellinii $=T$. c. affinis $=T$. c. conjugens $=$ T. gemmellaroi $=T$. intermedius Broin 1977 (senior synonym).

Type material. MGP-PD 12883 (syntype), a partial skeleton consisting of parts of the cranium, the complete carapace, a hyohypoplastron, a humerus, and a femur (Negri 1892, pl. 2. Bergounioux 1954, fig. 9, pl. 1.7; Kotsakis 1977, fig. 3c); MGPPD 12882 (syntype), a carapace (Negri 1892, pl. 3).

Type locality. Monte Bolca (= Purga di Bolca), Veneto, Italy (Negri 1892; Figure 4); Prati Valeno Horizon, Lutetian, middle Eocene (Giusberti et al. 2014).

Referred material and range. Middle Eocene (probably Lutetian) of the type locality, Veneto, Italy (type material of Trionyx affinis, T. capellinii conjugens, T. gemmellaroi, T. intermedius; Negri 1892; Sacco 1894; Bergounioux 1954; and referred mate- rial of Kotsakis 1977); early Oligocene (early Rupelian), Veneto, Italy (type material of T. capellinii gracilina, T. capellinii montevialensis, T. capellinii perexpansa, T. insolitus, and T. schaurothianus; Negri 1893; Sacco 1895; Bergounioux 1954; material referred to T. capellinii montevialensis and T. c. schaurothianus by Barbera and Leuci 1980).

Diagnosis. "Trionyx" capellinii can be diagnosed as a member of Pan-Trionychidae by the full list of characters listed for that clade above. Among pan-trionychids from the Paleogene of Europe, "T." capellinii can be differentiated readily from Axestemys vittata by smaller size, more extensive development of all callosities, and the absence of a preneural, and from " $T$." boulengeri, "T." henrici, and "T." messelianus by having larger costals VIII. A rigorous diagnosis is not possible relative to "T." silvestris and " $T$." ikoviensis, as these are mostly based on cranial material.

Comments. The middle Eocene (Lutetian) locality of Monte Bolca and the nearby early Oligocene (early Rupelian) locality of Monteviale in the Region of Veneto, Italy, have yielded a rich pantrionychid fauna that serves as the basis of 11 taxa. For Monte Bolca, these names are Trionyx affinis Negri, 1892, T. capellinii Negri, 1892, T. capellinii conjugens Sacco, 1894, T. intermedius Bergounioux, 1954, and T. gemmellaroi Negri, 1892, and for Monteviale, T. capellinii gracilina Sacco, 1895, T. italicus Schauroth, 1865, T. capellinii montevialensis Negri, 1892, T. capellinii perexpansa Sacco, 1895, T. insolitus Bergounioux, 1954, and T. schaurothianus Negri, 1893. In contrast to similar accumulations of names from other regions in Europe, most of these names are based on partial skeletons, although crushing prohibits studying the nonshell anatomy in detail. The proliferation of names is nevertheless baffling, as there always was universal agreement that all named taxa are closely related. Indeed, four species were already named as subspecies or varieties of T. capellinii (i.e., conjugens, gracilina, montevialensis, and perexpansa), whereas two others were secondarily denoted to subspecies of T. capellinii (i.e., affinis and schaurothianus). In his review of this material, Kotsakis (1977) concluded that all material from both localities represent a single species, T. capellinii, although he retained the validity of two subspecies, one for each locality. Broin (1977), on the other hand, preferred recognizing two separate species, although she did not provide a justification for this preference. Barbera and Leuci (1980) soon after provided morphometric evidence to support the presence of one subspecies in each locality, but this study cannot be considered statistically significant, as only four specimens were used. Kotsakis (1985) nevertheless used this study to change his previous taxonomic opinion and conclude that each locality is characterized by its own species, T. capellinii for the Eocene of Monte Bolca and T. italicus for the early Oligocene of Monteviale. We were initially inclined to recognize the validity of two species as well because of stratigraphic concerns, but after our firsthand observation of all type specimens (except for the now lost holotype of Trionyx capellinii perexpansa) and several referred specimens from both Monte Bolca and Monteviale, we ultimately concluded that the differences between the two populations are so minor, while variation remains so great, that a rigorous diagnosis is impossible. We therefore only see evidence for a single taxon in this region with uncertain generic affinities. Given that we disregard T. italicus from consideration (see below), we conclude that " $T$." capellinii is the valid name for this Italian pan-trionychid. 
"Trionyx" dissolutus Vitek and Danilov, 2014

Taxonomic history. “Trionyx” dissolutus Vitek and Danilov, 2014 (new species).

Type material. ZIN PH 51/86 (holotype), external and visceral impressions of posterior part of carapace of one individual (Nessov 1984, figs. 6, 7, 9; Nessov 1997, pls. 34.17, 35.7; Vitek and Danilov 2014, fig. 5).

Type locality. Itemir locality, Central Kizylkum Desert, Navoiy Region, Uzbekistan (Figure 3); Khodzhakul Formation, Cenomanian, Late Cretaceous (Vitek and Danilov 2014).

Referred material and range. Late Cretaceous (early Cenomanian), Khodzhakul Formation, Kizylkum Desert area, Karakalpakstan, Uzbekistan (referred material of Vitek and Danilov 2014)

Diagnosis. "Trionyx" dissolutus can be diagnosed as a member of Pan-Trionychidae by the presence of sculpturing that covers all metaplastic portions of the shell bones and the absence of shell scutes. Among early Late Cretaceous pan-trionychids, "T." dissolutus can be differentiated from all by the presence of an epiplastral notch on the hyoplastron and an extensive medial contact between the hyo- and hypoplastra.

Comments. Vitek and Danilov (2014) recently described the pan-trionychid fauna from the Cenomanian Khodzhakul Formation of Uzbekistan. Although this fauna is mostly known from fragments, Vitek and Danilov (2014) were able to document the presence of two morphotypes, of which one displays a less ossified shell that resembles the slightly younger Petrochelys kyrgyzensis, whereas the other is better ossified that resembles the younger "T." kansaiensis and North American plastomenids. Vitek and Danilov (2014) provided the name "T." dissolutus for the latter morphotype and designated a partial shell as the holotype.

We generally agree that "Trionyx" dissolutus is a valid species, but we disagree on the exact interpretation of the holotype. In all trionychids that we are aware of that are known from complete shells, costals IV are the widest elements and situated at the midpoint of the specimen. As interpreted by Vitek and Danilov (2014), costals IV of the holotype of "T." dissolutus are clearly positioned at the posterior half of the shell, and the more posterior elements are unusually crowded toward the back. We are able to confirm the presence of most sutures in this specimen in high-quality photographs we were able to obtain, but we are not fully convinced that the last pair of minute costals is actually present. We therefore favor that this specimen consists of more usually proportioned costals V-VIII and that costals VIII are rather large, conclusions that are more in line with a plastomenid-like morphotype. Our assertions will hopefully be tested in the near future by additional finds.

\section{“Trionyx” gilbentuensis Danilov et al., 2014}

Taxonomic history. "Trionyx" gilbentuensis Danilov et al., 2014 (new species).
Type material. ZIN PH T/M46-2 (holotype), incomplete left hyo-hypoplastra (Danilov et al. 2014, fig. 13c, d).

Type locality. Gilbentu, Ömnögovi (= Umunugovi) Aimag Mongolia (Figure 3); Nemegt Formation, Maastrichtian, Late Cretaceous (Danilov et al. 2014).

Referred material and range. No specimens haven been referred to date.

Diagnosis. "Trionyx" gilbentuensis can be diagnosed as a member of Pan-Trionychidae by the presence of sculpturing that covers all metaplastic portions of the shell bones. Among late Late Cretaceous pan-trionychids from Asia, "T." gilbentuensis can most readily be differentiated by its large size, with an estimated $\mathrm{CL}$ of about $50 \mathrm{~cm}$.

Comments. "Trionyx" gilbentuensis is based on a partial hyohypoplastron. Although we herein generally do not support the validity of a pan-trionychid species based on a single plastral element, we feel that this species is well justified, as the rich pan-trionychid fauna of the Nemegt Formation is well described (Danilov et al. 2014) and thereby highlights the uniqueness of this taxon within this assemblage. We nevertheless hope that additional finds will soon confirm the validity of this taxon and clarify its phylogenetic relationships.

“Trionyx” gobiensis Danilov et al., 2014

Taxonomic history. "Trionyx" gobiensis Danilov et al., 2014 (new species).

Type material. PIN 4064-2 (holotype), an incomplete carapace (Danilov et al. 2014, fig. 14).

Type locality. Bamba Khuduk (= Eastern Sayr), Ömnögovi (= Umunugovi) Aimag, Mongolia (Figure 3); Nemegt Formation, Maastrichtian, Late Cretaceous (Danilov et al. 2014).

Referred material and range. Late Cretaceous (Maastrichtian), Nemegt Formation, Tsagan Khushu and Altan Ula III, Ömnögovi Aimag, Mongolia (referred material of Danilov et al. 2014).

Diagnosis. "Trionyx" gobiensis can be diagnosed as a member of Pan-Trionychidae by the full list of carapacial characters provided for that clade above. Among late Late Cretaceous pan-trionychids, "T." gobiensis can be differentiated from Kuhnemys breviplastra by having well-developed costals VIII, from "T." gilbentuensis by being much smaller, and from "T." shiluutulensis by lacking a preneural. "Trionyx" gobiensis cannot be distinguished rigorously from Nemegtemys conflata, as these taxa are not known from overlapping material.

Comments. "Trionyx" gobiensis is a rather small pan-trionychid (estimated CL only $13 \mathrm{~cm}$ ), known from several carapaces that readily distinguish this species from its contemporaries, with exception of the pan-cyclanorbine Nemegtemys conflata, which is only known from plastral material. The validity of this species is otherwise not controversial. 


\author{
"Trionyx" gregarius (Gilmore, 1934) \\ (= Rafetus gilmorei Chkhikvadze, 1999b)
}

Taxonomic history. Amyda gregaria Gilmore, 1934 (new species); Trionyx gregaria Kuhn 1964 (new combination); T. gregarius Karl 1998 (emended spelling); Amyda gregaria = Rafetus gilmorei Vitek and Danilov 2015 (senior synonym).

Type material. AMNH 6734 (holotype), carapace, plastron, and much of skeleton lacking the skull (Gilmore 1934, figs. 1, 3, 7); AMNH 6735 (paratype), skull, lower jaws, portions of carapace, plastron, and postcranial skeleton (Gilmore 1934, figs. 5-7); AMNH 6736 (paratype), a nearly complete skeleton of a juvenile individual (Gilmore 1934, figs. 2, 3, 7).

Type locality. Camp Margetts, 25 miles southwest of Iren Dabasu, Inner Mongolia, China (Gilmore 1934; Figure 3); Irdin Manha Formation, middle Eocene (Meng et al. 2007).

Referred material and range. Middle Eocene of type locality, Inner Mongolia, China (referred material of Gilmore 1934, including type material of Rafetus gilmorei; Chkhikvadze 1999b).

Diagnosis. "Trionyx" gregarius can be diagnosed as a member of Pan-Trionychidae by the full list of characters provided for that clade above. Among Paleogene pan-trionychids from Asia, " $T$." gregarius can be most readily differentiated by small size, lacking a preneural, a midline contact of the posterior costals, broad costals VIII, a finely crenulated sculpturing, and well-formed plastral callosities.

Comments. "Trionyx" gregarius is based on a large block of matrix containing an assemblage of 14 individuals in various ontogenetic stages. However, given that many mechanisms are available to concentrate turtles in a single fossil locality (Wings et al. 2012), we see no reason to infer gregarious behavior for this taxon. The type locality was initially believed to be located within the Oligocene Houldjin Formation (Gilmore 1934) but was recently reassigned to the middle Eocene Irdin Manha Formation (Meng et al. 2007). The holotype of "T." gregarius lacks cranial material, but Gilmore (1934) designated two rather complete skeletons that include skulls as the paratypes of his new species. The original attribution of this species to the genus Amyda seems to have been based on the absence of a preneural (Gilmore 1934), but this attribution is probably based on the classification scheme of Hay (1908) and does not imply that Gilmore (1934) believed this taxon to be closely related to the extant southeast Asian Amyda cartilaginea. Chkhikvadze (1999b) established a new species, Rafetus gilmorei, on the basis of two specimens that are preserved in the fossil slab of the type of "T." gregarius and that were initially considered to be juveniles by Gilmore (1934). The new species was said to differ from all other pantrionychids by the presence of suprascapular fontanelles, reduced costals VII or VIII, more elongated medial processes, and weakly sculpted hyo-hypoplastron (Chkhikvadze 1999b), but Vitek and Danilov (2015) recently affirmed that these characters are consistent with ontogenetic variation. We agree with this assessment. Given the large amount of quality material documenting the entire skeleton, the validity of this species is uncontroversial.

"Trionyx" henrici Owen in Owen and Bell, 1849 $(=$ T. barbarae Owen in Owen and Bell, $1849=$

T. circumsulcatus Owen in Owen and Bell, $1849=T$. incrassatus Owen in Owen and Bell, $1849=$ T. marginatus Owen in Owen and Bell, $1849=$ T. planus Owen in Owen and Bell, $1849=T$. rivosus Owen in Owen and Bell, 1849)

Taxonomic history. Trionyx henrici Owen in Owen and Bell, 1849 (new species); T. henrici $=T$. marginatus Lydekker 1889a (senior synonym); Rafetoides henrici $=T$. barbarae $=$ T. circumsulcatus $=T$. incrassatus $=T$. marginatus $=T$. planus $=T$. pustulatus $=T$. rivosus $=T$. silvestris Karl 1998 (new combination and senior synonym).

Type material. BMNH R30407 (holotype), a complete carapace, missing the nuchal (Owen and Bell 1849, pl. 16; Owen 1849-1884, pl. 6; Benton and Spencer 1995, fig. 9.7).

Type locality. Hordle (= Hordwell) Cliff, Hampshire, United Kingdom (Owen and Bell 1849; Figure 4); Totland Bay Member, Headon Hill Formation, Priabonian, late Eocene (Benton and Spencer 1995).

Referred material and range. Middle Eocene (late Lutetian), Guitrancourt, Yvelines, Île-de-France, France (Trionyx sp. of Lapparent de Broin et al. 1993); late Eocene (Priabonian) of type locality, Hampshire, United Kingdom (type material of T. barbarae, T. circumsulcatus, T. marginatus, T. planus, and T. rivosus; Owen and Bell 1849; referred material to T. barbarae, T. henrici, T. planus, and T. rivosus of Lydekker 1889a; referred material to T. planus of Boulenger 1891); late Eocene (Priabonian), Isle of Wight (type material of T. incrassatus; Owen and Bell 1849).

Diagnosis. "Trionyx" henrici can be diagnosed as a member of Pan-Trionychidae by the full list of shell characters listed for that clade above. Among Paleogene pan-trionychids from Europe, "T." henrici can be differentiated from others by intermediate size (CL about $30 \mathrm{~cm})$, a rounded shell margin, thick callosities, absence of a preneural, and short but broad costals VIII.

Comments. Owen (in Owen and Bell 1849) named a total of seven pan-trionychids based on rich material, including many complete carapaces, from the late Eocene of southern England, in particular Trionyx barbarae, T. circumsulcatus, T. henrici, $T$. incrassatus, T. marginatus, T. planus, and T. rivosus. Most of the type specimens were originally kept in the Museum of the Marchioness of Hastings (Owen and Bell 1849) but had since been transferred to BMNH (Lydekker 1889a). All species were originally diagnosed using characteristics, such as shell sculpturing and the size and orientation of the neurals, that are now known to be highly variable. Owen (in Owen and Bell 1849), Lydekker (1889a), and Boulenger (1891) variously referred additional material to various named taxa, including additional shell remains, two mandibles, and a partial skull, but it is difficult to reproduce their assignments, as most material was found in 
isolation and does not overlap anatomically. Along those lines, Lydekker (1889a) assigned the two mandibles to "T." henrici and T. planus even though these are not associated with any shell remains. Although some of the late Eocene English species were already synonymized by Lydekker (1889a), most were maintained as valid (e.g., Hummel 1932; Kuhn 1964), until Karl (1998) united all named English pan-trionychids, including the early Eocene skull taxon T. silvestris, into a single taxon, for which he, as the first reviser, designated T. henrici as the senior synonym and the type species of his new genus Rafetoides. Although we broadly agree with the conclusion of Karl (1998) that most of the Eocene trionychids from Europe represent a single lineage for which Rafetoides is available as a name, a rigorous phylogenetic analysis is needed to establish their monophyly relative to later taxa.

Lapparent de Broin et al. (1993) described and figured a pan-trionychid from the middle Eocene of Guitrancourt, France. Judging from the figure, we herein assign this material to "Trionyx" henrici, as the two forms share a rather enlarged nuchal, an elongated neural I, similar size, and overall a strong resemblance in terms of carapace shape and sculpturing pattern. The number of eight neurals (contra seven in the English forms) suggested for the French form in Lapparent de Broin et al. (1993) cannot be verified with certainty. If our identification of the Guitrancourt pan-trionychid as conspecific with " $T$." henrici is correct, then it represents not only a significant geographic range extension for this species, but also a stratigraphic range extension.

Karl and Lindow (2012) referred fragmentary remains from the Paleocene (Danian) of Denmark to Rafetoides cf. henrici, but we here consider these fragments to be too fragmentary to allow identification at the species level.

\section{“Trionyx” ikoviensis Danilov et al., 2011}

Taxonomic history. Trionyx ikoviensis Danilov et al., 2011 (new species).

Type material. ZIN PH 37/145 (holotype), a partial skull (Danilov et al. 2011, figs. 2-4).

Type locality. Ikovo, Luhansk Province, Ukraine (Figure 4); early Lutetian, middle Eocene (Danilov et al. 2011).

Referred material and range. Middle Eocene (early Lutetian) of type locality, Ukraine (referred material of Danilov et al. 2011).

Diagnosis. "Trionyx" ikoviensis can be diagnosed as a member of Pan-Trionychidae by the full list of characters provided for that clade above. Among Paleogene turtles from Europe, "T." ikoviensis can be differentiated by intermediate size, a broad skull with narrow contribution of the parietals to the skull roof, and short but wide costals VIII.

Comments. "Trionyx" ikoviensis was only recently described based on a large skull and associated shell elements from the middle Eocene locality of Ikovo, Ukraine (Danilov et al. 2011). Although a great resemblance is apparent with the skulls of the early Eocene " $T$ ". silvestris (including the skull of $T$. michauxi), the middle Eocene "T." messelianus, and other poorly docu- mented cranial remains of " $T$ ". henrici (skull referred to T. planus by Boulenger [1891]), we agree with Danilov et al. (2011) that the morphology of "T." ikoviensis supports the recognition of a distinct, though closely related species of pan-trionychids, although we agree that biogeographic rationales most strongly support this notion, not morphological differences.

“Trionyx” impressus (Yeh, 1963)

Taxonomic history. Aspideretes impressus Yeh, 1963 (new species); Trionyx impressus Danilov et al. 2013 (new combination).

Type material. IVPP V1036 (holotype), a negative cast of a nearly complete carapace (Yeh 1963, fig. 32, pls. 19.3, 20.1, 1a).

Type locality. Maoming, Guangdong (= Kwantung) Province, China (Yeh 1963; Figure 3); Youkanwo (= Youganwo) Formation, late Eocene (Tong et al. 2010).

Referred material and range. No specimens have been referred to date.

Diagnosis. "Trionyx" impressus can be diagnosed as a member of Pan-Trionychidae by the full list of carapacial characters that diagnose that clade. Among Paleogene pan-trionychids from East Asia, "T." impressus is provisionally differentiated by the presence of a preneural, broad costals VIII, and many longitudinal ridges that decorate the carapace.

Comments. "Trionyx" impressus is based on the external imprint of a carapace from the late Eocene of Maoming, China. Yeh (1963) initially referred this species to Nilssonia (his Aspideretes) based on the purported presence of a preneural. Judging from the published figures, we were initially skeptical that a preneural is present indeed, but low resolution photographs available to us seem to confirm the presence of a preneural that differs from the shape documented by Yeh (1963) but that resembles that of extant Nilssonia in size and shape. Given that the validity of this taxon pivots on the presence of this structure, we herein only conditionally accept the validity "T." impressus, await the redescription of the type, and retain the species in the neutral "Trionyx." It is an amusing factoid that a taxon already exists that was named T. impressus (Kutorga 1835) at one point, but this fossil is now known to be a basal vertebrate from the Paleozoic and therefore has no nomenclatural significance for turtle paleontology.

\section{“Trionyx” jixiensis Li, Tong et al., 2015}

Taxonomic history. "Trionyx" jixiensis Li, Tong et al., 2015 (new species).

Type material. GMH H2008JI20 (holotype), an almost complete carapace and the impression of its external surface (Li, Tong et al. 2015, fig. 2).

Type locality. Yufeng village, Jixi, Heilongiiang Province, China (Figure 3); Chengzihe Formation, Aptian/Albian, Early Cretaceous (Li, Tong et al. 2015). 
Referred material and range. No specimens have been referred to date.

Diagnosis. "Trionyx" jixiensis can be diagnosed as a member of Pan-Trionychidae by the full list of carapacial characters provided for that clade above. Among Early Cretaceous pan-trionychids, "T." jixiensis can be differentiated from Perochelys lamadongensis by showing a fully formed nuchal and enlarged costals VII and VIII that have a midline contact. Only geographic considerations allow us to distinguish "T." jixiensis from Petrochelys kyrgyzensis.

Comments. "Trionyx" jixiensis is based on a well-preserved, partial carapace from the Early Cretaceous of Heilongjiang Province, China (Li, Tong et al. 2015). Much like other Early Cretaceous pan-trionychids that are known from more complete material (see Perochelys lamadongensis above), this species is striking once again by greatly resembling extant pan-trionychines. However, given that the trionychine morphotype may reasonably be ancestral for Trionychidae, we are wary about attribution of this species to Trionychinae, as done by Li, Tong et al. 2015), and anticipate a more formal phylogenetic analysis. We are not able to rigorously distinguish "T?" jixiensis from the roughly coeval Petrochelys kyrgyzensis from nearby Kyrgyzstan, because the carapacial reconstruction of Nessov (1995b) must be viewed with caution, as it is based on many isolated fragments and therefore does not necessarily faithfully depict the morphology of this taxon. We therefore provisionally accept both taxa but anticipate the discovery of articulated shells of Petrochelys kyrgyzensis or plastral remains of "T." jixiensis that will allow more rigorous comparison.

\section{"Trionyx" johnsoni Gilmore, 1931 (= Amyda neimenguensis Yeh, 1965)}

Taxonomic history. Amyda johnsoni Gilmore, 1931 (new species); Trionyx johnsoni Kuhn 1964 (new combination).

Type material. AMNH 6357 (holotype), the posterior portion of a carapace (Gilmore 1931, fig. 29, pl. 11).

Type locality. Telegraph Line Camp, Irdin Manha, Inner Mongolia, China (Gilmore 1931; Figure 3); Irdin Manha Horizon, middle Eocene (Danilov, Sukhanov et al. 2015).

Referred material and range. Middle Eocene of type locality, Inner Mongolia, China (referred material of Gilmore 1931); middle Eocene, Ulan Shireh, Inner Mongolia, China (type material of Amyda neimenguensis; Yeh 1965).

Diagnosis. "Trionyx" johnsoni can be diagnosed as a member of Pan-Trionychidae by the full list of carapacial characters provided for that clade above. Among Paleogene pan-trionychids from Asia, "T." johnsoni can be differentiated by large size, greatly expanded distal margins of costals VII, reduced costals VIII, and a coarse sculpturing pattern.

Comments. "Trionyx" johnsoni is based on the partial carapace of a relatively large pan-trionychid. The type locality of "T." johnsoni was initially believed to be late Eocene (Gilmore
1931) but was more recently reallocated to the middle Eocene ( Danilov, Sukhanov et al. 2015). Gilmore (1931) was reluctant to determine the generic affinities of his new species, as the nuchal and the anterior part of the first neural were entirely missing from the holotype. Nevertheless, he provisionally assigned the species to Amyda on the basis of overall resemblance, a view that was also subsequently adhered to by Yeh (1963). In our assessment, the presence of reduced costals VIII makes a relationship with the Amyda cartilaginea lineage unlikely, and we therefore assign this species to the neutral "Trionyx." The unusually broadly developed distal margins of costals VI nevertheless prompt us to recognize the validity of this species.

\section{“Trionyx" kansaiensis Vitek and Danilov, 2010}

Taxonomic history. "Trionyx" kansaiensis Vitek and Danilov, 2010 (new species).

Type material. ZIN PH 630/64 (holotype), a partial nuchal (Vitek and Danilov 2010, fig. 6a, b; Danilov and Vitek 2013, fig. 23.3a1).

Type locality. Kansai, Khodzhent Province, Tajikistan (Figure 3); Yalovach Formation, early Santonian, Late Cretaceous (Vitek and Danilov 2010).

Referred material and range. Late Cretaceous (Santonian-early Campanian), Bostobe Formation, Kyzylorda Region, Kazakhstan; Late Cretaceous (Santonian-Campanian), Syuk-Syuk Formation and probably the lower part of the Darbaza Formation, Kyrkkuduk well $(=$ Sary-Agach = Kyrkkuduk I), South Kazakhstan Region, Kazakhstan (referred material of Vitek and Danilov 2012).

Diagnosis. "Trionyx" kansaiensis can be diagnosed as a member of Pan-Trionychidae by the full list of shell characters provided for that clade above. Among middle Late Cretaceous pan-trionychids, "T." kansaiensis can be differentiated by large size (CL up to $75 \mathrm{~cm}$ ), a deep nuchal notch, unreduced costals VIII, and well-developed hyo-hypoplastral callosities that cover most of the medial and lateral processes.

Comments. "Trionyx" kansaiensis is based on an assemblage of shell pieces that clearly document that it is distinct from all other roughly coeval forms (Vitek and Danilov 2010; Li, Joyce, and Liu 2015), but comparison with skull-based taxa is not possible. Danilov, Vitek et al. (2015) recently suggested that "T." kansaiensis may belong to the skull-based Khunnuchelys lophorhothon, because both taxa co-occur in the Bostobe Formation and are known from similarly large specimens. This conclusion is supported by the recent report of a rather similar or even conspecific form from the late Turonian of Dzharakuduk, Uzbekistan, which also happens to be the type locality of Khunnuchelys kizylkumensis (Danilov and Vitek 2013). A similar argument can be made for the type of $T$. zakhidovi, a nomen dubium that is based on an enormous femur from coeval sediments. Pending the discovery of associated material, we nevertheless maintain "T." kansaiensis as a valid species. 
“Trionyx” linchuensis (Yeh, 1962)

Taxonomic history. Amyda linchuensis Yeh, 1962 (new species); Trionyx linchuensis Kuhn 1964 (new combination).

Type material. IVPP V1050 (holotype), a partial carapace, the right coracoid, and a partial skull (Yeh 1962, pl. 1.1).

Type locality. Niushan, Linqu (= Linchu) County, Shandong (=Shantung) Province, China (Yeh 1962; Figure 3); early Eocene (Ye 1994).

Referred material and range. No specimens have been referred to date.

Diagnosis. "Trionyx" linchuensis can be diagnosed as a member of Pan-Trionychidae by the full list of carapacia characters provided for that clade above. Among Paleogene pan-trionychids from Asia, "T." linchuensis can be differentiated from all the others by small size and a complete neural column that fully separates the costals from one another.

Comments. "Trionyx" linchuensis is based on a carapace and an unfigured skull from Shandong, China, that was originally reported to be late Eocene to Oligocene (Yeh 1962), but more recently corrected to be early Eocene in age (Ye 1994). As was typical prior to the work of Meylan (1987), Yeh (1962) attempted to classify this small species (CL of $17 \mathrm{~cm}$ ) using the simplified classification key developed by Hay (1908) for fossil trionychids from North America. On the one side, Yeh (1962) reasoned that " $T$." linchuensis is not a representative of Nilssonia (his Aspideretes) as it lacks preneurals. However, he was uncertain in regard to the number of costals and therefore was not able to rigorously distinguish between Amyda (eight costals) and Apalone (his Platypeltis, seven costals). This statement is baffling, however, as the type figures clearly display a trionychid with eight pairs of costals. Yeh (1962) tentatively placed his new taxon into Amyda and further noted that it was similar overall to the late Eocene " $T$." johnsoni from nearby Inner Mongolia, especially in terms of carapace sculpturing. We herein note that costals VIII do not seem to contact each other along the carapace midline, and the specimen therefore seems to bear a complete neural column, a feature that has otherwise only been observed in a small handful of species (e.g., the early Cretaceous Perochelys lamadongensis and the extant Dogania subplana). Although we believe that the type specimen likely represents a juvenile, we nevertheless feel confident in diagnosing a valid species using this rare characteristic.

“Trionyx" messelianus Reinach, 1900

$(=$ T. messelianus lepsiusi Hummel, $1927=$ T. messelianus kochi Hummel, 1927)

Taxonomic history. Trionyx messelianus Reinach, 1900 (new species); Rafetoides austriacus $=$ T. messelianus $=$ T. messelianus kochi $=$ T. messelianus lepsiusi Karl 1998 (junior synonym); Palaeoamyda messeliana Cadena 2016 (new combination and emended spelling of species epithet).
Type material. SMF R106 (holotype), an almost complete carapace and a hyoplastron fragment (Reinach 1900, pls. 41, 42 Hummel 1927, pl. 6.24; Karl 1998, pl. 8.5).

Type locality. Messel pit fossil site, Hesse, Germany (Reinach 1900; Figure 4); MP 11, early Lutetian, middle Eocene (Joyce et al. 2012).

Referred material and range. Middle Eocene (MP 11, Lutetian) of type locality, Germany (referred material of Harrassowitz 1919; Hummel 1927; Karl 1998; Cadena 2016); middle Eocene (Lutetian), Geiseltal, Saxony-Anhalt, Germany (referred material of Cadena 2016).

Diagnosis. "Trionyx" messelianus can be diagnosed as a member of Pan-Trionychidae by the full list of characters listed for that clade above. Among Paleogene pan-trionychids from Europe, "T." messelianus can be differentiated from the others by being medium-sized and having thinner callosities, a nuchal that is only partially covered by metaplastic bone, no preneural, and relatively small, equidimensional costals VIII.

Comments. "Trionyx" messelianus is known from rich material from the middle Eocene localities of Messel and Geiseltal Germany (Reinach 1900; Harrassowitz 1919; Hummel 1927; Karl 1998; Cadena 2016), including many articulated skeletons. Three subspecies were named based on material from the type locality (e.g., T. messelianus messelianus, T. messelianus kochi, and T. messelianus lepsiusi), but we herein universally disregard varieties and subspecies and refer all material to the specific level alone. Karl (1998) suggested " $T$." messelianus to be a junior synonym of the late Eocene T. aus triacus, but we disregard that assessment, as T. austriacus is based on a partial, now lost carapace (see below) that lacks diagnostic features.

Cadena (2016) recently provided an updated description of some specimens from Messel and Geiseltal, concluded that "Trionyx" messelianus is the sister to the extant Amyda cartilaginea from Southeast Asia, and therefore assigned this taxon to a new genus, Palaeoamyda. This conclusion contradicts other recent arguments that " $T$." messelianus is an early representative of the T. triunguis lineage (e.g., Broin 1977; Karl 1999a). Although a reanalysis of this taxon is outside of the scope of this contribution, we here note that "T." messelianus was incorrectly coded for the length of the epiplastra processes (long, not short) and that many apparent differences of "T." messelianus with the Amyda lineage have not yet been encoded, in particular different developments of costal rib VIII and costal VIII, varying lengths of the intermaxillary suture, and different developments of the pterygoid muscle scar. For these reasons, we here retain messelianus in Trionyx for the moment but highlight phylogenetic ambiguity through the use of quotation marks.

“Trionyx” miensis Okazaki and Yoshida, 1977

Taxonomic history. Trionyx miensis Okazaki and Yoshida, 1977 (new species)

Type material. Aichi University (holotype), a partial cranium (Okazaki and Yoshida 1977, figs. 2, 3, pl. 1.1-4) 
Type locality. Kitakoyama, Mie Prefecture, Japan (Okazaki and Yoshida 1977; Figure 3); Kameyama Formation, late Pliocene (Hirayama 2007).

Referred material and range. No specimens have been referred to date.

Diagnosis. "Trionyx" miensis can be diagnosed as a member of Pan-Trionychidae by a quadratojugal that does not contact the postorbital or maxilla. Among Neogene to Recent pan-trionychids from Asia, "T." miensis can be differentiated by the development of broad triturating surfaces and an incipient secondary palate.

Comments. "Trionyx" miensis is based on a well-preserved, partial skull from the Pliocene of Japan. Okazaki and Yoshida (1977) noticed similarity of their new taxon with the extant Pelodiscus sinensis and differentiated their new species on the basis of skull proportions and maxillae shape, but we fully disagree, as the skull in Pelodiscus sinensis is notably slender and lacks expanded triturating surfaces or an incipient secondary palate. To our knowledge, incipient or fully formed secondary palates otherwise only occur among pan-trionychids in Late Cretaceous Khunnuchelys spp. (e.g., Brinkman et al. 1993), Late Cretaceous to Paleocene plastomenids (Joyce and Lyson 2011; Joyce et al. 2016), the Eocene "T." henrici and "T." ikoviensis (Walker and Moody 1974; Danilov et al. 2011), and the Miocene "T." vindobonensis (Broin 1977). Given that spatial and temporal arguments render close relationships with these forms unlikely, we feel confident in supporting the validity of " $T$." miensis using this character complex.

\section{“Trionyx" minusculus (Chkhikvadze, 1973), comb. nov.}

Taxonomic history. Plastomenus minusculus Chkhikvadze, 1973 (new species); Paraplastomenus minusculus Kordikova 1994a (new combination); Francedebroinella minuscula Chkhikvadze 1999a (new combination, emended spelling of species epithet).

Type material. IPGAS Z-13-1 (holotype), a partial hyohypoplastron (Chkhikvadze 1973, pl. 4.2; Chkhikvadze 2008b, fig. 5 [bottom])

Type locality. Konur-Kura $(=$ Djeman-Gora $=$ Djuva-Kara $=$ Djeman-Kara), $12 \mathrm{~km}$ south of Karabulak, Zaysan Depression, East Kazakhstan Region, Kazakhstan (Chkhikvadze 2007, 2008a, 2010; Figure 3); lower Aksyir suite, late Eocene (Kordikova 1994b; Chkhikvadze 2008a).

Referred material and range. No specimens are referred herein

Diagnosis. "Trionyx" minusculus can be diagnosed as a member of Pan-Trionychidae by the full list of plastral characters provided for that clade above. Among Paleogene pan-trionychids from Asia, "T." minusculus can be differentiated from the others by being notably small and having well-developed, thick hyohypoplastral callosities that form a relatively narrow bridge, but fully cover the lateral plastral processes.
Comments. "Trionyx" minusculus is yet another Asian pantrionychid taxon that is based on a partial hyo-hypoplastron and that has purported plastomenid affinities (Chkhikvadze 1973). The thick shell bones, which originally hinted at relationships with this North American clade, are now believed to be a widespread feature among Paleogene Asian pan-trionychids (Vitek and Danilov 2014), and their relationships with the North American clade remain unclear. Chkhikvadze (1999a) established his new monotypic genus Francedebroinella to accommodate for the unique morphology of this taxon and diagnosed it by the hyperossification of the shell. Our decision to not accept the validity of most named pan-trionychids that are based on fragmentary material is rooted on our conclusion that most of the isolated trionychid finds are not that unusual by themselves and therefore cannot diagnose a valid species. The type of "T." minusculus is the exception to the rule, as we are not aware of any other pan-trionychid globally to possess such a massive ossified hyo-hypoplastron, while maintaining a narrow bridge, and small size. We therefore here recognize the validity of this species but once again await the description of the remainders of the skeleton.

“Trionyx" ninae Chkhikvadze, 1971

(= T. turgaicus Kuznetsov and Chkhikvadze,

$1977=$ T. zaisanensis Chkhikvadze, 1973)

Taxonomic history. Trionyx ninae Chkhikvadze, 1971 (new species); Palaeotrionyx ninae Broin 1977 (new combination and incorrect spelling of genus name); Rafetus ninae Chkhikvadze 1989 (new combination); Ulutrionyx ninae Kordikova 1994a (new combination); Yuen ninae Chkhikvadze 2007 (new combination); Oscaria ninae Chkhikvadze 2008b (new combination); Ulutrionyx ninae $=T$. turgaicus $=$ T. zaisanensis Vitek and Danilov 2015 (senior synonym)

Type material. IPGAS KK-19 (holotype), a left hypoplastron (Chkhikvadze 1971, fig. 2; Chkhikvadze 2008b, fig. 1).

Type locality. Kyzyl-Kak, $60 \mathrm{~km}$ southwest of Zhezqazghan (= Jezkazgan = Dzhezgazgan), Karagandy Region, Kazakhstan (Chkhikvadze 1971; Vitek and Danilov 2015; Figure 3); Betpakdalinskaya suite (Betpakdala Formation), Oligocene (Vitek and Danilov 2015).

Referred material and range. Late Eocene-Oligocene, Chelkarnurinskaya (= Chiliktinskaya suite) and Betpakdalinskaya suite, Turgai Depression, Karagandy Region, Kazakhstan (type material of Trionyx turgaicus and referred material of Vitek and Danilov 2015); late Eocene-Oligocene, Kustovskaya suite, Zaysan Depression, East Kazakhstan Region, Kazakhstan (type material of T. zaisanensis; Chkhikvadze 1973).

Diagnosis. "Trionyx" ninae can be diagnosed as a member of Pan-Trionychidae by the full list of shell characters listed for that clade above. Among Paleogene pan-trionychids from Asia, "T." ninae can be differentiated from all taxa (except for Kuhnemys palaeocenica) by having reduced costals VIII, and from $K$. palaeocenica by being larger and having two lateral hyoplastral processes. 
Comments. Over the course of four decades, Chkhikvadze (1970, 1971, 1973, 1984, 1989, 1999b, 2008a, 2008b) and Kuznetsov and Chkhikvadze (1977) published a series of papers in which they named a total of 13 pan-trionychid taxa based on isolated fragments collected in Eocene to Miocene sediments exposed in Kazakhstan. These are, in temporal order, Plastomenus mlynarskii Chkhikvadze, 1970; Trionyx ninae Chkhikvadze, 1971; T. zaisanensis and Plastomenus minusculus Chkhikvadze, 1973; T. turgaicus Kuznetsov and Chkhikvadze, 1977; Plastomenus gabunii Chkhikvadze, 1984; T. jakhimovitchae Chkhikvadze, 1989; Zaisanonyx jimenezfuentesi Chkhikvadze, 2008b; Rafetus yexiangkuii Chkhikvadze, 1999b; Altaytrionyx burtschaki, Altaytrionyx devjatkini, and Altaytrionyx phiruzae Chkhikvadze, 2008a; and Rafetus karkhualexandri Chkhikvadze 2000b. The description of turtles based on isolated fragments was commonplace during the 19th century (see Vitek and Joyce [2015] for North American pan-trionychids), but this practice is now generally frowned on, because most modern taxonomists recognize that turtles show substantial and overlapping interspecific and intraspecific variation and that a single fragment is therefore rarely representative for a single species. The validity of fragment taxa can sometimes be "saved," if a particular stratigraphic unit yields a rich fauna that allows attribution of a type using morphology assisted by a stratigraphic rationale (e.g., Gardner et al. [1995] for pan-trionychid remains found in the Campanian of Alberta, Canada). Conversely, it is acceptable to typify a new species based on a single fragment, if the description is accompanied by a comprehensive description of the associated fauna. The extensive literature produced by Chkhikvadze unfortunately does not provide outsiders with any insights regarding the pan-trionychid fauna of Kazakhstan, and, despite many attempts, we are unaware of any taxonomist having been granted access to collections held at IPGAS. We are therefore inclined to fully disregard this assortment of names. We nevertheless make exception for "Trionyx" ninae, T. turgaicus, and T. zaisanensis, which were exonerated as each other's synonyms by the more recent work of Vitek and Danilov (2015), and "Trionyx" minusculus, which indeed reveals a highly unusually morphology diagnostic for a valid species (see above).

"Trionyx" ninae, T. turgaicus, and T. zaisanensis are based on fragmentary remains from the Oligocene Turgai and Zaisan Depressions of Kazakhstan (Chkhikvadze 1971, 1973; Kuznetsov and Chkhikvadze 1977). Trionyx turgaicus was initially differentiated from "T." ninae by lacking a suture between the nuchal and costal I, but Vitek and Danilov (2015) more recently attributed this difference to ontogenetic variation, as this suture often closes up during ontogeny. Trionyx zaisanensis was similarly differentiated from "T?" ninae by having a more massive shell and longer posteromedial process of the hypoplastron, but Vitek and Danilov (2015) recently cast doubt on the veracity or usefulness of these characters. We here agree with these assessments.

We find that none of the available type material is particularly diagnostic for a valid species of pan-trionychids, but Vitek and Danilov (2015) recently described new material from the Oligocene from Kazakhstan that is consistent in its morphology with the type of these three taxa but also documents much of the remainder of the shell. We therefore agree that it is prudent to support the validity of a single species of pan-trionychid in the Oligocene of Kazakhstan, with "T." ninae as the valid senior synonym.

\section{“Trionyx" onomatoplokos, new name}

Taxonomic history. Palaeotrionyx riabinini Kuznetsov and Chkhikvadze, 1987 (new species and incorrect spelling of genus name); "Paleotrionyx" riabinini Kordikova 1992 (emended genus spelling); Axestemys riabinini Kordikova 1994a (new combination); Khunnuchelys riabinini Chkhikvadze 2000b (new combination); Eurycephalochelys riabinini Chkhikvadze 2007 (new combination).

Etymology. The new specific epithet onomatoplokos is derived from the Greek óvo $\alpha \alpha$ (i.e., onoma) meaning "name" and the verb $\pi \lambda \varepsilon \dot{\varepsilon} \kappa \omega$ (i.e., pleko) meaning "to enfold or twist," alluding to the taxonomic confusion caused by the original specific epithet riabinini being applied to two distinct species from the same locality in the same publication.

Type material. IZK R-3920 (holotype), a nearly complete nuchal (Vitek and Danilov 2010, fig. 8; Danilov and Vitek 2013, fig. 23.2j).

Type locality. Shakh-Shakh, Kyzylorda Region, Kazakhstan (Kuznetsov and Chkhikvadze 1987; Vitek and Danilov 2010; Figure 3); Bostobe Formation, Santonian-early Campanian, Late Cretaceous (Vitek and Danilov 2010).

Referred material and range. No specimens haven been referred to date.

Diagnosis. "Trionyx" onomatoplokos can be diagnosed as a member of Pan-Trionychidae by the presence of sculpturing that covers all metaplastic portions of the shell bones and the absence of scutes. Among middle Late Cretaceous pan-trionychids " $T$." onomatoplokos can be differentiated from "T." kansaiensis by lacking a broad nuchal notch and from " $T$." riabinini by being larger and having a nuchal that is only partially covered by metaplastic bone.

Comments. "Trionyx" onomatoplokos is based on a single, large (15 cm wide) nuchal from the Late Cretaceous (Santonian or early Campanian) portions of the Bostobe Formation of Kazakhstan. We herein usually conclude that taxa based on single fragments should be considered dubious, but we here make an exception, as the pan-trionychid faunas of the Bostobe Formation are now well documented (Vitek and Danilov 2010), making it clear that the morphology being displayed by the type specimen is different from that displayed in the remainders of the fauna. We therefore here maintain this species as valid, while anticipating the discovery and description of more meaningful material.

In their review of fragmentary turtle material from the Bostobe Formation of Kazakhstan, Kuznetsov and Chkhikvadze (1987) named two new pan-trionychid species within the genera Triony $x$ and Paleotrionyx, but for reasons beyond our comprehension, they used the same species epithet twice, riabinini. From a taxonomic and nomenclatural perspective, this action is permissible, but highly confusing and impractical, because both species share the same authorship and publication date, because 
their generic affiliation remains under flux, and because both species were likely sympatric. As both taxa have unclear generic affiliations, we here assign both to "Trionyx," resulting in two homonymous species of pan-trionychids within the Bostobe Formation. We here provide the new name "T." onomatoplokos for the species originally published as Pal[a] eotrionyx riabinini. This name may be short lived, as future work may support the referral of both species to two genera once again, but could be maintained permanently, if a petition is submitted to the International Commission on Zoological Nomenclature (ICZN)

\section{"Trionyx" riabinini Kuznetsov and Chkhikvadze, 1987}

Taxonomic history. Trionyx riabinini Kuznetsov and Chkhikvadze, 1987 (new species); Plastomenus riabinini Chkhikvadze and Shuvalov 1988 (new combination); Paraplastomenus riabinini Kordikova 1994a (new combination); Crassithecachelys riabinini Chkhikvadze 2000b (new combination); Aspideretoides riabinini Vitek and Danilov 2010 (new combination).

Type material. IZK R-3919, (holotype), a partial nuchal (Vitek and Danilov 2010, fig. 5b, c; Danilov and Vitek 2013, fig. 23.2d).

Type locality. Shakh-Shakh, Kyzylorda Region, Kazakhstan (Kuznetsov and Chkhikvadze 1987; Vitek and Danilov 2010; Figure 3); Bostobe Formation, Santonian-early Campanian, Late Cretaceous (Vitek and Danilov 2010).

Referred material and range. Late Cretaceous (Santonian) Yalovach Formation, Fergana Depression, Kansai, Khodzhent Province, Tajikistan (referred material of Vitek and Danilov 2010).

Diagnosis. "Trionyx" riabinini can be diagnosed as a member of Pan-Trionychidae by the full list of shell characters listed above for that species. Among middle Late Cretaceous pan-trionychids, "T." riabinini can be differentiated from "T." kansaiensis by being smaller and lacking a broad nuchal notch, and from "T." onomatoplokos by being smaller and having a nuchal that is fully covered by metaplastic bone.

Comments. "Trionyx" riabinini is based on a partial nuchal from the Late Cretaceous (Santonian or early Campanian) of Kazakhstan, but its validity is mostly supported by a rich collection of fragmentary material that was referred by Vitek and Danilov (2010) from roughly coeval sediments exposed in Tajikistan. Vitek and Danilov (2010) considered it highly probable that " $T$." riabinini possesses a preneural, but this cannot be affirmed with certainty based on the available material. The rich Tajik material nevertheless allows reconstructing anatomical changes during ontogeny (Vitek and Danilov 2010). Over the course of the decades, "T." riabinini has variously been referred to Plastomenus (Chkhikvadze and Shuvalov 1988), Paraplastomenus (Kordikova 1994a), Crassithecachelys (Chkhikvadze 2000b), and, most recently, Aspideretoides (Vitek and Danilov 2010). However, given new insights into the phylogenetic relationships of the type species of the latter genus (Vitek and Joyce 2015; Joyce et al. 2016), we find it prudent to reassign this species to the neutral "Trionyx." See also "T." onomatoplokos above for the case of homonymy with $\mathrm{Pal}[$ a] eotrionyx riabinini.
“Trionyx" shiluutulensis Danilov et al., 2014

Taxonomic history. “Trionyx” shiluutulensis Danilov et al., 2014 (new species).

Type material. MPC 25/166 (holotype), a carapace (Danilov et al. 2014, fig. 15).

Type locality. Shiluut Ula, Ömnögovi (= Umunugovi) Aimag, Mongolia (Figure 3); unknown formation, Campanian, Late Cretaceous (Danilov et al. 2014)

Referred material and range. No specimens haven been referred to date.

Diagnosis. "Trionyx" shiluutulensis can be diagnosed as a member of Pan-Trionychidae by the complete list of carapacial characters provided for that clade above. Among late Late Cretaceous pan-trionychids from Asia, " $T$." shiluutulensis can most readily be differentiated from others by the presence of a preneural and eight neurals.

Comments. "Trionyx" shiluutulensis is based on a well-preserved, small (CL about $20 \mathrm{~cm}$ ) carapace from the Late Cretaceous (Campanian) of Mongolia (Danilov et al. 2014) that can easily be distinguished from other Late Cretaceous taxa from Asia by the presence of a preneural. This bone is otherwise known from coeval plastomenids preserved in North America (Vitek and Joyce 2015; Joyce et al. 2016), but all known representatives of this lineage only possess seven neurals and significantly larger costals VIII. Additional material will be needed to clarify the phylogenetic placement of "T." shiluutulensis, but its validity seems uncontroversial.

\section{“Trionyx" silvestris Walker and Moody, 1974 $(=$ T. michauxi Broin, 1977)}

Taxonomic history. Trionyx silvestris Walker and Moody, 1974 (new species); T. sylvestris Broin 1977 (incorrect spelling of species epithet); Rafetoides henrici $=$ T. silvestris $=7$ others Karl 1998 (junior synonym, see “T." henrici for complete synonym).

Type material. BMNH R 8567 (holotype), an almost complete cranium (Walker and Moody 1974, pl. 118.1-3; Karl 1998, pl. 6.1).

Type locality. Abbey Wood, Kent, United Kingdom (Figure 4); Blackheath Beds, early Ypresian, early Eocene (Walker and Moody 1974).

Referred material and range. Early Eocene (Ypresian), Sables à Unios et Térédines, Marne, France (type material of Trionyx michauxi; Broin 1977).

Diagnosis. "Trionyx" silvestris can be diagnosed as a member of Pan-Trionychidae by the full list of cranial characters provided for that clade above. Among Paleogene pan-trionychids from Europe known from cranial material, "T." silvestris can only be differentiated by a broader contribution of the parietals to the skull roof. 
Comments. "Trionyx" silvestris is based on a skull from the early Eocene of England (Walker and Moody 1974), which can be easily distinguished from the coeval giant pan-trionychid Axestemys vittata (see above) by its size and the development of broad anterior triturating surfaces. Early Eocene sediments in Belgium, France, and Great Britain have yielded many fragmentary remains that might be attributable to this taxon (e.g., Broin 1977), including the types of T. bowerbanki and T. pustulatus (see below), but clear associations are still lacking, and we are therefore reluctant to synonymize these taxa. Karl (1998) synonymized all medium-sized pan-trionychids from the early and late Eocene of Great Britain into "T." henrici, which is typified by late Eocene material. We generally sympathize with this idea, as we too find strong resemblance among most Eocene pan-trionychid material, but we here do not support Karl's (1998) proposed synonymy, as the only preserved late Eocene skull (Boulenger 1891) is too poorly preserved to allow meaningful comparison. We find a close relationship with "T." messelianus from the middle Eocene of Germany plausible as well, but the palate of this taxon remains undescribed, and we therefore cannot assess if meaningful similarities are apparent with the distinctive triturating surfaces of "T", silvestris. By contrast, we see overwhelming similarities between the skull of "T"' silvestris and that of the coeval skullbased taxon T. michauxi from nearby France, in that both possess expanded triturating surfaces that are formed by a broad midline contact of the maxillae. Differences are apparent to the width of the triturating surfaces, the palate of T. michauxi being wider, but this is easily referable to interspecific variation, as previously documented for other extant and fossil pantrionychids (Dalrymple 1977; Joyce et al. 2016). We therefore here synonymize these two species with confidence, though without certain generic affiliations. We are only able to differentiate "T", silvestris from the roughly coeval "T?" ikoviensis from Ukraine by nuanced differences to the development of the parietal and biogeographic concerns.

\section{Invalid and Problematic Taxa}

\section{Altaytrionyx burtschaki Chkhikvadze, 2008a nomen dubium}

Taxonomic history. Altaytrionyx burtschaki Chkhikvadze 2008b (nomen nudum); Altaytrionyx burtschaki Chkhikvadze, 2008a (new species).

Type material. IPGAS 7-1-58 (holotype), medial part of a left hypoplastron (Chkhikvadze 2008b, fig. 11; Chkhikvadze 2008a, fig. 2); IPGAS 7-1-66 (paratype), medial part of a left hypoplastron (Chkhikvadze 2008a, fig. 3).

Type locality. Treugol'nik Locality, Kalmakpay River, Zaysan Depression, East Kazakhstan Region, Kazakhstan; lower part of Obaylinskoy suite (Chkhikvadze 2008a), middle Eocene (Danilov, Sukhanov et al. 2015).

Comments. Chkhikvadze (2008b) initially introduced this name along with a figure of what would later become the holotype, but he did not provide a description, and this contribution therefore does not qualify for nomenclatural purposes (ICZN 1999).
In the same year, Chkhikvadze (2008a) formally described Altaytrionyx burtschaki and referred a partial hypoplastron to this taxon, which serves as a paratype. Chkhikvadze (2008a) considered this turtle to be the largest species of his newly established genus Altaytrionyx and diagnosed it relative to its congeners by the thickness of the shell, which is about $12 \mathrm{~mm}$ in the thickest part of the holotype, and by its sculpturing. Judging from the published figures, however, the available material bears no diagnostic characters and should rather be interpreted as an indeterminate pan-trionychid. For additional discussion, see "Trionyx" ninae (above).

\section{Altaytrionyx devjatkini Chkhikvadze, 2008a nomen dubium}

Taxonomic history. Altaytrionyx devjatkini Chkhikvadze, 2008a (new species).

Type material. IPGAS (holotype), a right hypoplastron (Chkhikvadze 2008a, fig. 4); IPGAS (paratype), fragment of the right hyoplastron of a juvenile individual (Chkhikvadze 2008a, fig. 5); IPGAS (paratype), a left hyoplastron (Chkhikvadze 2008a, fig. 6); IPGAS (paratype), fragment of the medial part of the right hypoplastron of an old individual (Chkhikvadze 2008a, fig. 7).

Type locality. Sem’kamney Locality, Kalmakpay River, Zaysan Depression, East Kazakhstan Region, Kazakhstan; basal part of the Chakpaktasskoy suite (Chkhikvadze 2008a), early Eocene (Danilov, Sukhanov et al. 2015).

Comments. Altaytrionyx devjatkini is based on fragmentary plastral material that was originally reported to be Paleocene (Chkhikvadze 2008a), but more recently corrected to be early Eocene (Danilov, Sukhanov et al. 2015). Chkhikvadze (2008a) differentiated Altaytrionyx devjatkini from the other species of his Altaytrionyx by the absence of an epiplastral notch on the hyoplastron, presence of two axillary and inguinal processes on the hyo- and hypoplastra, and prominent sculpturing of the hyoand hypoplastra, but these characters are now considered to be too general. For a discussion on the validity of pan-trionychid taxa from the Tertiary of Kazakhstan, see "Trionyx" ninae (above).

\section{Altaytrionyx phiruzae Chkhikvadze, 2008a nomen dubium}

Taxonomic history. Crassithecachelys phirusae Chkhikvadze 1995 (nomen nudum); Altaytrionyx phirusae Chkhikvadze 2008b (nomen nudum); Altaytrionyx phiruzae Chkhikvadze, 2008a (new species, with alternative spelling of species epithet).

Type material. IPGAS 7-8-1 (holotype), medial part of a right hypoplastron (Chkhikvadze 2008b, fig. 10; Chkhikvadze 2008a, fig. 1).

Type locality. Chkhikvadze Locality, Aksyir River, Zaysan Depression, East Kazakhstan Region, Kazakhstan; the lower part of Obaylinskoy or Chakpaktasskoy suites (Chkhikvadze 2008a), early-middle Eocene (Danilov, Sukhanov et al. 2015). 
Comments. Chkhikvadze (1995) initially introduced the name Crassithecachelys phirusae, but this action was not accompanied by a description, and this name therefore does not qualify for nomenclatural purposes (ICZN 1999). A few years later, Chkhikvadze (2008b) published the name Altaytrionyx phirusae together with a figure of the only known specimen, but a description was still lacking, and this name too cannot be considered for nomenclatural purposes (ICZN 1999). The name Altaytrionyx phiruzae finally became available when Chkhikvadze (2008a) published the name in concert with a brief description, although, frustratingly, two spellings were introduced, Altaytrionyx phirusae and Altaytrionyx phiruzae. We here select Altaytrionyx phiruzae as the valid spelling, as it appeared earlier in the text than the other spelling. Chkhikvadze (2008a) considered the age of Altaytrionyx phiruzae to be Paleocene, but it is now believed to be Eocene (Danilov, Sukhanov et al. 2015). Altaytrionyx phiruzae purportedly differs from the other species attributed to the same genus in terms of size, shell thickness, and the proportions of the hypoplastra (Chkhikvadze 2008a). However, judging from the published figures of the only known specimen, a hypoplastron, these differences seem to be minute and not sufficient to justify a valid trionychid taxon. For a discussion on the validity of pan-trionychid taxa from the Tertiary of Kazakhstan, see "Trionyx" ninae (above).

\section{Amyda menneri Chkhikvadze, 1988 nomen dubium}

Taxonomic history. Amyda menneri Chkhikvadze in Chkhikvadze and Shuvalov, 1988 (new species); Amyda menenri Sukhanov 2000 (incorrect spelling of species epithet); [Amyda menneri] Danilov et al. 2014 (nomen dubium).

Type material. IPGAS 11-5-1 (holotype), incomplete postcranium of a single individual, including a nuchal, the proximal part of costal I, a fragment of the right hyo-hypoplastron, a fragment of a xiphiplastron, and assorted nonshell bones (Chkhikvadze and Shuvalov 1988, fig. 1a); IPGAS 11-5-2 (paratype), nuchal fragment; IPGAS 11-5-3 (paratype), anterior part of a carapace; IPGAS 11-5-4 (paratype), distal part of right hyoplastron; IPGAS 11-5-5 (paratype), right costal VII; IPGAS 11-5-6 (paratype), right hyoplastron (Chkhikvadze and Shuvalov 1988, fig. 1c); IPGAS 11-13-11 (paratype), medial part of right hyoplastron; IPGAS 11-14-2 (paratype), left posterior part of carapace; IPGAS 11-14-3 (paratype), medial part of left hypoplastron (Chkhikvadze and Shuvalov 1988, fig. 1d); IPGAS 11-14-4 (paratype), posterior part of carapace (Chkhikvadze and Shuvalov 1988, fig. 1e); IPGAS 11-17-1 (paratype), left half of carapace.

Type locality. Gurilin Tsav, Ömnögovi (= Umunugovi) Aimag, Mongolia (Chkhikvadze in Chkhikvadze and Shuvalov 1988; Danilov et al. 2014); Nemegt Formation, Maastrichtian, Late Cretaceous (Danilov et al. 2014).

Comments. Amyda menneri was established on the basis of isolated shell fragments from several localities within the Nemegt Formation of south central Mongolia (Chkhikvadze and Shuvalov 1988). Danilov et al. (2014) concluded that the material may represent a chimera, that the holotype is not diagnostic, and that Amyda menneri is a nomen dubium (Danilov et al. 2014). We fully agree with this assessment.

Amyda neimenguensis Yeh, 1965 nomen invalidum

(junior synonym of “Trionyx" johnsoni [Gilmore, 1931])

Taxonomic history. Amyda neimenguensis Yeh, 1965 (new species).

Type material. IVPP V 2870 (holotype), posterior portions of a carapace (Yeh 1965, fig. 4, pl. 7).

Type locality. Ulan Shireh, Inner Mongolia, China (Yeh 1965); middle Eocene (Danilov, Sukhanov et al. 2015).

Comments. Amyda neimenguensis is based on a large carapace $(\mathrm{CL}$ about $50 \mathrm{~cm})$ from the middle Eocene of Inner Mongolia. The holotype was initially believed to be late Eocene in age (Yeh 1965), but was more recently reassigned to the middle Eocene. Yeh (1965) noted similarities with "Trionyx" johnsoni but nevertheless justified the recognition of a new species based on differences in carapace shape and size, shape and size of neural VI, and carapace sculpturing. Given that both Amyda neimenguensis and "T." johnsoni are now known to originate from roughly coeval sediments in the same geographic area and that both are characterized by small costals VIII combined with unusually enlarged distal margins of costals VI, we here synonymize these taxa with confidence.

\section{Aspideretes alashanensis Yeh, 1965 nomen invalidum \\ (junior synonym of Kuhnemys maortuensis} [Yeh, 1965])

Taxonomic history. Aspideretes alashanensis Yeh, 1965 (new species); Paraplastomenus alashanensis Kordikova 1994a (new combination).

Type material. IVPP V2865 (holotype), a damaged carapace (Yeh 1965, fig. 2, pl. 3; Danilov and Vitek 2013, fig. 23.2c).

Type locality. Dashukou, Maortu (= Maorty), Alxa (= Alashan), Inner Mongolia, China (Yeh 1965); Ulansuhai Formation, Turonian, Late Cretaceous (Brusatte et al. 2009).

Comments. Aspideretes alashanensis is based on a partial carapace from Inner Mongolia, China, that was recovered from the same locality as the holotype of Kuhnemys maortuensis (Yeh 1965). These specimens were long believed to be poorly dated at either late Early Cretaceous or early Late Cretaceous (Brinkman et al. 2008), but we here show that they most likely originate from the Ulansuhai Formation, which is currently dated as Late Cretaceous (Turonian). The type of Aspideretes alashanensis corresponds in all important details with that of the better-preserved type of Kuhnemys maortuensis, especially by showing highly reduced costals VIII, and we therefore synonymize the two. As both names were formed in the same publication, and 
as no rules exist that should be given preference, such as page priority, we, as primary revisers, here chose maortuensis as the senior synonym (see Kuhnemys maortuensis above for additional comments).

\section{Aspideretes jaxarticus Riabinin 1938 nomen nudum}

Material. None discussed or designated.

Locality. Kyrkkuduk well $(=$ Sary-Agach $=$ Kyrkkuduk I), South Kazakhstan Region, Kazakhstan (Riabinin 1938; Kordikova 1994b); Syuk-Syuk Formation or lower part of Darbaza Formation, Santonian or Campanian, Late Cretaceous (Kordikova 1994b; Danilov and Vitek 2013).

Comments. Riabinin (1938) briefly mentioned pan-trionychid remains from the Sary-Agach (now Kyrkkuduk well) locality as representing two new species of pan-trionychid turtles: Plastomenus jaxarticus (see below) and Aspideretes jaxarticus. It is mystifying that he assigned the same species epithet to both taxa, as this creates much confusion, even if both taxa are not available or valid (see discussion in "Trionyx" onomatoplokos about Trionyx riabinini Kuznetsov and Chkhikvadze, 1987, and Paleotrionyx riabinini Kuznetsov and Chkhikvadze, 1987, for a similar example). Riabinin (1938) did not provide descriptions, diagnoses, figures, or holotypes for either taxon, and these names can therefore be interpreted as nomina nuda (Vitek and Danilov 2012), thereby sparing the fossil turtle community additional taxonomic aggravation.

\section{Aspideretes muyuensis Lei and Ye, 1985 nomen dubium}

Taxonomic history. Aspideretes muyuensis Lei and Ye, 1985 (new species); Paleotrionyx muyuensis Chkhikvadze 1990 (new combination); Eurycephalochelys muyuensis Chkhikvadze 2007 (new combination)

Type material. YIGM V 25517 (holotype), a rather complete carapace, plastron, and parts of the pelvis (Lei and Ye 1985, figs. 2, 3; Ye 1994, fig. 69).

Type locality. Muyu, Nanzhang County, Hubei Province, China; Yangxi Formation, early Eocene (Lei and Ye 1985).

Comments. Aspideretes muyuensis is based on a relatively small, poorly documented shell from the Eocene of China (Lei and Ye 1985). The size of the holotype is unclear, as two different scale bars and the table imply different sizes, but is seems that the carapace is relatively small, likely less than $15 \mathrm{~cm}$. Lei and Ye (1985) considered this taxon to be a probable member of Nilssonia (his Aspideretes) on the basis of the presence of a preneural, but we question the veracity of this observation, as the relevant portion of the shell is not well preserved. Chkhikvadze $(1990,2007)$ saw similarities with the giant pan-trionychids of North America, but this is perhaps a misunderstanding caused by the confusing use of conflicting scale bars. Until the holotype has been redescribed in greater detail, we find this taxon to be dubious, as we cannot find characters that allow us to rigorously diagnose a valid taxon. Chkhikvadze (1990) described fragments from the middle Eocene of Kazakhstan under the name Paleotrionyx cf. muyuensis (Chkhikvadze 1990), which now serve as the holotype of Zaisanonyx jimenezfuentesi (see below). We confirm that these have no apparent similarities with the taxon from China.

\section{Aspilus cortesii Portis, 1885 nomen dubium}

Taxonomic history. Aspilus cortesii Portis, 1885 (new species); [Trionyx cortesii] Hummel 1929 (new combination, nomen dubium); Trionyx cortisii Bergounioux 1935 (incorrect spelling of species epithet).

Type material. MPP (holotype), a partial cranium with mandible (Portis 1885, pl. 11.2-3).

Type locality. Exact locality unknown (Portis 1885; Kotsakis 1985), probably Montezago, Emilia-Romagna, Italy (Broin 1977; Chesi 2009); late Miocene or Pliocene (Portis 1885; Kotsakis 1985).

Comments. Aspilus cortesii is based on a $13 \mathrm{~cm}$ long skull with uncertain provenience. Portis (1885) suggested that this specimen shows close relationship with the extant Amyda cartilaginea (his Aspilus cariniferus), thereby establishing the purported presence of this Asian group in Europe, but Hummel (1929) believed it to be an indeterminate trionychid.

The skull of Aspilus cortesii is elongated and has relatively large orbits, but it was only figured in dorsal and lateral view and shows extensive damage. As such, although this is one of the few European taxa based on cranial material, no characters are available that would rigorously diagnose this as a valid taxon. We here therefore consider Aspilus cortesii to be nomen dubium but join Kotsakis (1985) in calling for a systematic revision of the available material.

\section{Chitra minor Jaekel, 1911 nomen dubium}

Taxonomic history. Chitra minor Jaekel, 1911 (new species); [Chitra minor] Hummel 1929 (nomen dubium); Chitra indica = Chitra minor Karl 1987 (junior synonym); Pelochelys cantorii = Chitra minor Rhodin et al. 2015 (junior synonym).

Type material. MB R2496.1-2 (syntypes), a right xiphiplastron and a left hypoplastron (Jaekel 1911, pl. 15.3, 4).

Type locality. Trinil, Java, Indonesia (Jaekel 1911); Trinil Formation, Pleistocene (McCord and Pritchard 2002)

Comments. Chitra minor is based on two plastral fragments from the Pleistocene of Java, Indonesia (Jaekel 1911). Karl (1987) considered this taxon to be a junior synonym of the extant Chitra indica as he believed their morphology, at least as present, to correspond fully. McCord and Pritchard (2002), on the other had, suggested that the features presented in the available material were not sufficient to diagnose a valid species. However given the current distribution of giant soft-shelled turtles, they suggested that these fragments are not referable to Chitra, but 
rather Pelochelys, and that Chitra minor is probably a junior synonym of Pelochelys cantorii, which occurs in the extant fauna of Java. The type and only known material is fragmentary, and, judging from the original figures of Jaekel (1911), we find it insufficient to allow attribution to either Chitra or Pelochelys. We therefore suggest that Chitra minor is a nomen dubium.

Chitra selenkae Jaekel, 1911 nomen suppressum

(suppressed senior synonym of Chitra chitra Nutaphand, 1986)

Taxonomic history. Chitra selenkae Jaekel, 1911 (new species); Chitra indica $=$ Chitra selenkae Karl 1987 (junior synonym); Chitra chitra $=$ Chitra selenkae ICZN 2005 (suppressed senior synonym).

Type material. MB R2495.1-3 (syntypes), a scapula, a right xiphiplastron, and a clavicle (Jaekel 1911, pl. 15.1, 2, 11; Karl 1987, pl. 14.2).

Type locality. Trinil, Java, Indonesia (Jaekel 1911); Trinil Formation, Pleistocene (McCord and Pritchard 2002, 2003; Rhodin et al. 2015).

Comments. This species is based, among others, on a large carapace with a midline length of $64 \mathrm{~cm}$ (McCord and Pritchard 2002). Karl (1987) considered this to be a junior synonym of Chitra indica based on overall correspondence in morphology. A few years later, McCord and Pritchard (2002) noted several features that establish a close vicinity of Chitra selenkae with extant Chitra chitra, but they were reluctant to formally propose a synonymy, as such a synonymy would partially depend on the species concept being chosen and because the extinct Chitra selenkae Jaekel, 1911 would have priority over the extant Chitra chitra Nutaphand, 1986. The same authors therefore soon after made a formal petition to the ICZN (McCord and Pritchard 2003) requesting that Chitra chitra should receive priority over Chitra selenkae whenever the two are considered synonyms, a petition that was accepted by the ICZN (Opinion 2119, ICZN 2005). Rhodin et al. (2015) recently listed Chitra selenkae as a junior synonym of Chitra chitra. Although cryptic diversity in extant Chitra has been documented (Engstrom et al. 2002), the resemblance of Chitra selenkae with the extant Chitra chitra is remarkable. We agree that Chitra selenkae is the suppressed senior synonym of Chitra chitra.

Emyda lineata Lydekker, 1885 nomen dubium, designation of lectotype

Taxonomic history. Emyda lineata Lydekker, 1885 (new species); [Emyda lineata] Hummel 1929 (nomen dubium); Lissemys lineata Kuhn 1964 (new combination).

Type material. IMC E210 (lectotype), a fragmentary peripheral (Lydekker 1885, pl. 26.6); IMC E132 (paralectotype), a partial nuchal (Lydekker 1885, pl. 26.3).

Type locality. Siwaliks, Punjab, Pakistan (see comments below); Pliocene (Lydekker 1885).
Comments. Lydekker (1885) established three new pan-trionychid taxa from the Pliocene of British India on the basis of rather fragmentary material: Emyda lineata, Emyda palaeindica, and Emyda sivalensis. For all three taxa, he did not specify an explicit type locality, but rather only mentioned that the specimens originated from "the Indus Valley of Punjab," an area that more or less matches the entire Punjab, if the Indus Valley is interpreted as the Indus Valley drainage basin. After the dissolution of British India, the Punjab was divided by the newly established countries of India and Pakistan into two provinces holding this name. Given that the Punjabi portion of the Siwalik hills is almost entirely located within the Pakistani side and that most of the fossils with good provenience were collected on this side as well (e.g., Joyce and Lyson 2010b), it seems reasonable to infer that the fossils described by Lydekker (1885) were collected within the boundary of modern-day Pakistan.

Lydekker (1885) erected Emyda lineata, Emyda palaeindica, and Emyda sivalensis on the basis of three syntype series that each consist of at least one peripheral and one nuchal, and he differentiated these three taxa relative to the extant Lissemys punctata by their sculpturing pattern (Lydekker 1885). As it remains unclear if the syntypes of these taxa originate from the same locality, we here designate a peripheral for each taxon as its lectotype. Hummel (1929) thought all three taxa to be dubious, but Delfino et al. (2010) more recently suggested that they may eventually be shown to be junior synonyms of the extant Lissemys punctata. Taking into consideration the Pliocene age of Lydekker's (1885) specimens, the cryptic diversity observed among extant Lissemys (Praschag et al. 2011), and legitimate criticism regarding the identification of fragmentary fossils based on the currently existing herpetofauna (Bell et al. 2010), we here defy the synonymization of the Punjabi taxa with the extant Lissemys punctata, although assignment to the Lissemys lineage seems certain based on the presence of peripherals (Meylan 1987).

In addition to the fragmentary syntypes of Emyda lineata, Emyda palaeindica, and Emyda sivalensis, Lydekker (1885) also described a relatively complete shell from the same region that he identified as the extant Lissemys punctata (his Emyda vittata). Although we find no evidence that would contradict that conclusion, we refer this specimen to Lissemys sp. and await further preparation, description, and analysis of that specimen.

\section{Emyda palaeindica Lydekker, 1885 nomen dubium, designation of lectotype}

Taxonomic history. Emyda palaeindica Lydekker, 1885 (new species); [Emyda palaeindica] Hummel 1929 (nomen dubium); Lissemys palaeindica Kuhn 1964 (new combination).

Type material. IMC E134a (lectotype), one complete peripheral (Lydekker 1885, pl. 14.5, 5a); IMC E132a (paralectotype), one nuchal fragment (Lydekker 1885, pl. 14.10).

Type locality. Siwaliks, Punjab, Pakistan (see Emyda lineata above); Pliocene (Lydekker 1885).

Comments. See Emyda lineata above for comments. 
Emyda sivalensis Lydekker, 1885 nomen dubium, designation of lectotype

Taxonomic history. Emyda sivalensis Lydekker, 1885 (new species); [Emyda sivalensis] Hummel 1929 (nomen dubium); Lissemys sivalensis Kuhn 1964 (new combination).

Type material. IMC E134 (lectotype), fragment of a peripheral (Lydekker 1885, pl. 26.9); IMC E133 (paralectotype), right half of a nuchal (Lydekker 1885, pl. 26.2); IMC E135 (paralectotype), a partial peripheral (Lydekker 1885, pl. 26.7).

Type locality. Siwaliks, Punjab, Pakistan (see Emyda lineata above); Pliocene (Lydekker 1885).

Comments. Emyda sivalensis Lydekker, 1885 should not be confused with Trionyx hurum sivalensis Lydekker, 1889a, a probable junior synonym of the extant Nilssonia hurum (see below). See Emyda lineata above for additional comments.

\section{Eurycephalochelys fowleri \\ Moody and Walker, 1970 nomen invalidum \\ (junior synonym of Axestemys vittata}

[Pomel, 1847])

Taxonomic history. Eurycephalochelys fowleri Moody and Walker, 1970 (new species); Erycephalochelys fowleri Benton and Spencer 1995 (incorrect spelling of genus name).

Type material. BMNH R8445 (holotype), an almost complete skull, without the lower jaw (Moody and Walker 1970, figs. 1-5, pl. 102).

Type locality. East Wittering, West Sussex, United Kingdom; Wittering Formation, Bracklesham Series, late Ypresian, early Eocene (Moody and Walker 1970; Walker and Moody 1985).

Comments. Eurycephalochelys fowleri is based on a large skull with a total length of $21.5 \mathrm{~cm}$ (Moody and Walker 1970), but a much larger and better-preserved specimen was more recently described from the same formation with a $23.4 \mathrm{~cm}$ length from the premaxilla to occipital condyle only (Walker and Moody 1985). Moody and Walker (1970) and Walker and Moody (1985) repeatedly ascertained the distinctness of their taxon relative to material from the European mainland, but we here synonymize it with Axestemys vittata (see above).

Early Eocene sediments exposed at Bracklesham, England, also yielded the type specimen of Trionyx bowerbanki Lydekker, 1889 a, but we here agree that these two are not synonymous, as the holotype of T. bowerbanki, an isolated nuchal, is too small and too well ossified for a representative of the Axestemys lineage. On the other side, unpublished specimens held in the collections of the BMNH indicate the presence of plastral elements that correspond to those of Axestemys vittata by being large and by having extremely reduced callosities. We are therefore certain that T. bowerbanki is not closely related with Axestemys vittata.
Lissemys piramensis Prasad, 1974 nomen dubium

Taxonomic history. Lyssemys piramensis Prasad, 1974 (new species and incorrect spelling of genus name).

Type material. GSI 18134 (holotype), an incomplete peripheral (Prasad 1974, pl. 2.8).

Type locality. Piram (= Perim) Island, Gujarat, India; Piram Conglomerate, Pliocene (Prasad 1974).

Comments. Prasad (1974) established Lissemys piramensis on the basis of an incomplete peripheral from the Pliocene of Piram Island, India, that he differentiated relative to fossil (Lydekker 1885) and extant species of Lissemys on the basis of sculpturing pattern. Curiously, Prasad (1974) did not mention the beautiful Lissemys skull that had been described by Lydekker (1889b) from Perim Island. In any case, the type material of Lissemys piramensis is not adequate for diagnosing a specimen to the species level, and we herein therefore consider Lissemys piramensis to be a nomen dubium.

Lissemys punctata sinhaleyus Deraniyagala, 1953 nomen dubium

Taxonomic history. Lissemys punctata sinhaleyus Deraniyagala, 1953 (new subspecies).

Type material. NMC F283 (holotype), a left hypoplastron (Deraniyagala 1953, not figured).

Type locality. Sabaragamuwa Province, Sri Lanka (Deraniyagala 1953); Ratnapura Beds, Late Pleistocene (Rhodin et al. 2015).

Comments. This taxon was described on the basis of a single hypoplastron that was purported to be rather similar to the extant Sri Lankan endemic Lissemys ceylonensis, but the type was never figured (Deraniyagala 1953) making it impossible to reproduce this claim. Rhodin et al. (2015) somewhat inconsistently stated that this species is a nomen dubium but nevertheless referred it to Lissemys ceylonensis pending further analysis. Considering that the holotype was never figured, we here refrain from synonymizing this taxon with the extant form and rather consider it to be a nomen dubium.

Pelochelys taihuensis Zhang, 1984 nomen invalidum, designation of lectotype

(junior synonym of Rafetus swinhoei [Gray, 1873])

Taxonomic history. Pelochelys taihuensis Zhang, 1984 (new species); Rafetus swinhoei $=$ Pelochelys taihuensis $=$ Trionyx liupani Farkas 1992 (junior synonym); Rafetus swinhoei = Pelochelys taihuensis Chkhikvadze 1999b (junior synonym).

Type material. ZPM TNO9.5 (lectotype), a fossil skull (Zhang 1984, figs. 1.2, 3.4), probably lost (Farkas and Fritz 1998); ZPM TNO9.9 (paralectotype), a fossil left costal IV (Zhang 1984, fig. 
3.5); ZPM (paralectotypes), two extant individuals, skeletonized and stuffed (Zhang 1984, figs. 1.1, 3.1, 2,6).

Type locality. Tongxiang County, Zhejiang Province, China (Zhang 1984); Neolithic, Holocene (Farkas and Fritz 1998). The extant specimens are from Zhejiang Province, China.

Comments. Pelochelys taihuensis is based on a mixture of subfossil and extant material from Zhejiang Province, China (Zhang 1984). For the sake of taxonomic clarity, we herein designate the most complete fossil specimen, a subfossil skull, as the lectotype of this taxon. The lectotype cannot be located now (Farkas and Fritz 1998), and the available illustrations only document a skull that must have exceeded $20 \mathrm{~cm}$ in total length when it was complete in dorsal view. Farkas (1992) and Farkas and Fritz (1998) stated that this subfossil skull can be safely attributed to the extant taxon Rafetus swinhoei, which used to occur in the same region, and that both taxa are therefore synonymous. Although no quality characters evidence is available, we nevertheless support this conclusion as geographic and temporal concerns combined with the large size of the lectotype make this attribution highly likely.

Plastomenus gabunii Chkhikvadze, 1984 nomen dubium

Taxonomic history. Plastomenus gabunii Chkhikvadze, 1984 (new species); Paraplastomenus gabunii Kordikova 1994a (new combination); Amyda gabunii Chkhikvadze 1999a (new combination); Altaytrionyx gabunii Chkhikvadze 2008b (new combination)

Type material. IPGAS (holotype), a hypoplastron (Chkhikvadze 1984, pl. 11.4; Chkhikvadze 2008b, fig. 9a, b).

Type locality. Chyornyy Trioniks, Aksyir River, Zaysan Depression, East Kazakhstan Region, Kazakhstan; upper Obaylinskoy suits, middle Eocene (Chkhikvadze 1984, 2008a, 2008b).

Comments. Plastomenus gabunii has had a complex taxonomic history by being referred to multiple genera, incidentally by the same person who established the species in the first place (Chkhikvadze 1984, 1990, 2007, 2008b). In its latest combination, Plastomenus gabunii was rendered as the type species of Altaytrionyx, a poorly defined genus diagnosed by its hypoplastral morphology (Chkhikvadze 2008b). In addition to having thick shell bones, a feature first thought to link this species with the North American clade Plastomenidae, Plastomenus gabunii is also characterized by the absence of a midline contact of the hyohypoplastra, a small xiphiplastral fontanelle, thickened inguinal notch, and an estimated CL of 25 to $35 \mathrm{~cm}$. These characters are extremely general among pan-trionychids and therefore not adequate to diagnose a taxon, even in their combination. For a discussion on the validity of pan-trionychid taxa from the Tertiary of Kazakhstan, see "Trionyx" ninae (above).

Kordikova (1994b) referred several specimens from the middle Eocene of Chinzhaly, Balkhash Lake region, Kazakhstan, to this taxon, but given that we conclude that Plastomenus gabunii is a nomen dubium, we reidentify Kordikova's (1994b) material as belonging to an indeterminate pan-trionychid.

\section{Plastomenus jaxarticus Riabinin 1938 nomen nudum}

Material. None discussed or designated.

Locality. Kyrkkuduk well (= Sary-Agach = Kyrkkuduk I), South Kazakhstan Region, Kazakhstan (Riabinin 1938; Kordikova 1994b); Syuk-Syuk Formation or lower part of Darbaza Formation, Santonian or Campanian, Late Cretaceous (Kordikova 1994b; Vitek and Danilov 2012).

Comments. For a discussion on material from the Kyrkkuduk well locality, see Aspideretes jaxarticus (above).

\section{Plastomenus mlynarskii Chkhikvadze, 1970 nomen dubium}

Taxonomic history. Plastomenus mlynarskii Chkhikvadze, 1970 (new species); Paraplastomenus mlynarskii Kordikova 1994a (new combination); Crassithecachelys mlynarskii Chkhikvadze 2000a (new combination); Plastomenus mlnarskii Broin 1977 (incorrect spelling of species epithet).

Type material. IPGAS Z-1-64 (holotype), a right hypoplastron (Chkhikvadze 1970; Chkhikvadze 1973, fig. 3, pl. 3.1).

Type locality. “Trugol'nik," Kalmakpay River, East Kazakhstan Region, Kazakhstan; middle Eocene (Chkhikvadze 1970, 2000a).

Comments. Chkhikvadze (1970) established Plastomenus mlynarskii based on a hypoplastron from the middle Eocene of Kazakhstan, for which he initially only provided a plastral restoration. Three years later, the same author provided photographs of the holotype and of a referred hyoplastron and a xiphiplastron, apparently the ones he used to originally diagnose this species (Chkhikvadze 1973). Kordikova, (1994a) felt that this species is highly unusual and therefore referred it to a new genus, Paraplastomenus. Chkhikvadze (2000a) later accused Kordikova (1994a) of plagiarism, invalidated Paraplastomenus, and established a new genus, Crassithecachelys, as a replacement. However, even if the cause of Chkhikvadze (2000a) was just, it is clear according to the rules of the ICZN (1999) that Paraplastomenus has priority over Crassithecachelys. For a discussion on the validity of pan-trionychid taxa from the Tertiary of Kazakhstan, see "Trionyx" ninae (above).

Kordikova (1994b) referred fragmentary material from the early to middle Eocene of East Kazakhstan Region to this taxon. However, none of this material was figured, and we therefore refer it all to Pan-Trionychidae indet.

\section{Platypeltis subcircularis Chow and Yeh, 1957 nomen dubium}

Taxonomic history. Platypeltis subcircularis Chow and Yeh, 1957 (new species); Trionyx subcircularis Kuhn 1964 (new combination); Platypeltis subcircularus Chkhikvadze 1973 (incorrect spelling of species epithet) 
Type material. IVPP V914 (holotype), anterior two-thirds of the right part of a carapace (Chow and Yeh 1957, pl. 1.1-3).

Type locality. Lushi (= Lushih) County, Henan (= Honan) Province, China; late Eocene (Chow and Yeh 1957).

Comments. Platypeltis subcircularis is a relatively small pan-trionychid known from a single, fragmentary specimen representing the anterior right part of the carapace. Chow and Yeh (1957) assigned this taxon to the otherwise American Apalone (their Platypeltis), highlighting affinities especially with Platypeltis serialis (= Plastomenus serialis) and Platypeltis trepida, which are both now considered nomina dubia (Vitek and Joyce 2015). Platypeltis subcircularis was differentiated based on the presence of six neurals only, but this character by itself is not particularly diagnostic. Given that this species is based on what is best interpreted as a juvenile specimen, we here consider this taxon to be a nomen dubium.

\section{Procyclanorbis sardus Portis, 1901 nomen dubium}

Taxonomic history. Procyclanorbis sardus Portis, 1901 (new species); Trionyx sardus Hummel 1929 (new combination); Amyda sardus Comaschi Caria 1959 (new combination); Amyda sarda Comaschi Caria 1986 (emended spelling of species epithet).

Type material. MDLCA 14007 (holotype), a carapace and its mold (Portis 1901, pl. 1.1; Zoboli and Pillola 2016, fig. 2a, c, d).

Type locality. Is Mirrionis, Cagliari, Sardinia, Italy (Portis 1901); Calcari di Cagliari Formation, late Tortonian-Messinian, late Miocene (Kotsakis 1985).

Comments. Procyclanorbis sardus is based on a carapace from the late Miocene of Sardinia, Italy, that was described in concert with plastral material and a skull from the same locality (Portis 1901). The same author further referred an internal mold of a carapace from a different Sardinian locality (Sassari) to the same species (Portis 1901). As the name readily suggests, Portis (1901) considered his new species to have close affinities with pancyclanorbines. Hummel (1932), however, soon after defied this identification and assigned this species to Trionyx. Other specimens from Sardinia have been referred to the same species using geographic considerations (Comaschi Caria 1959; Kotsakis 1985), but none of these display diagnostic characteristics beyond Pan-Trionychinae indet.

It is unclear to us if Portis (1901) would have considered the plastron and skull to be part of the syntype series, but even a cursory glance reveals that these are not trionychid in nature. Broin (1977) already noted that the skull, which was destroyed during World War II (Kotsakis 1985), pertains to a cheloniid turtle, instead of a pan-trionychid, a view subsequently adopted by Kotsakis (1985) and also supported by us based on the published figure. Previous authors seem to have ignored the plastral material, but we find that this is also referable to a marine turtle. At best, Procyclanorbis sardus is therefore a poorly diagnosed trionychid, and, at worst, a chimera that includes trionychid and cheloniid material.
Our study of photographs available to us confirms that Procyclanorbis sardus is not a cyclanorbine, because a preneural is missing and because the nuchal, which is preserved in internal view, clearly lacks split costiform processes (Meylan 1987). Although the specimen is once again consistent with the morphology of the Trionyx triunguis lineage (Karl 1999a), it can only be diagnosed as Pan-Trionychinae indet. We therefore herein consider Procyclanorbis sardus to be a nomen dubium. Bergounioux (1935) reported the presence of Procyclanorbis (his Amyda) sardus from the Miocene of Switzerland, but this appears to be an error (Esu and Kotsakis 1983).

\section{Rafetus gilmorei Chkhikvadze, 1999b nomen invalidum \\ (junior synonym of “Trionyx" gregarius} [Gilmore, 1934])

Taxonomic history. Rafetus gilmorei Chkhikvadze, 1999b (new species); Oskaria gilmorei Chkhikvadze 2008b (new combination and incorrect spelling of genus name); Amyda gregaria = Rafetus gilmorei Vitek and Danilov 2015 (junior synonym).

Type material. AMNH 6736 and AMNH 6737 (syntypes), two complete skeletons (Gilmore 1934, figs. 2, 4; Chkhikvadze 2008b, fig. 4a-c).

Type locality. Camp Margetts, 25 miles southwest of Iren Dabasu, Inner Mongolia, China (Gilmore 1934); Irdin Manha Formation, middle Eocene (Vitek and Danilov 2015).

Comments. For a discussion on the validity of Rafetus gilmorei, see "Trionyx" gregarius above.

\section{Rafetus karkhualexandri Chkhikvadze 2000b nomen nudum}

Material. None discussed or designated.

Locality. Bulkair, Zaysan Depression, East Kazakhstan Region, Kazakhstan (Chkhikvadze 2007); Nizhnesvirsky subsuite, probably Eocene or Oligocene (Chkhikvadze 2007).

Comments. This name was only mentioned in passing by Chkhikvadze (2000b, 2007) in regard to a taxon that might be named in the future, but no specimens are either referred, listed, or described. This is therefore herein considered to be a nomen nudum.

\section{Rafetus yexiangkuii Chkhikvadze, 1999b nomen dubium}

Taxonomic history. Rafetus yexaiangkui Chkhikvadze 1999a (nomen nudum); Rafetus yexiangkuii Chkhikvadze, 1999b (new species); Yuen yexiangkuii Chkhikvadze 2007 (new combination); Oskaria yexiangkuii Chkhikvadze 2010 (new combination)

Type material. IPGAS 7-370-1 (holotype), a left hypoplastron (Chkhikvadze 1999b, not figured) 
Type locality. Mailibai, East Kazakhstan Region, Kazakhstan; Buranskaya suite, Buran Formation, early Oligocene (Chkhikvadze 1999b, 2007; Vitek and Danilov 2015).

Comments. The type description of Rafetus yexiangkuii does not include any figures, but a description and diagnosis are present (Chkhikvadze 1999b), and this name therefore fulfills the minimum requirements of the ICZN (1999) for the availability of names published prior to 2000. The holotype unfortunately remains unfigured to date making it particularly taxing to evaluate the validity of this taxon. Chkhikvadze (1999b) differentiated Rafetus yexiangkuii from all other extinct pan-trionychids by several characters that pertain to the nuchal, even though no such element was ever referred to this taxon (Chkhikvadze 1999b). We therefore here consider this taxon to be a nomen dubium (also see "Trionyx" ninae above for more extensive discussion).

\section{Trionyx acutiformis Bergounioux, 1935 nomen dubium}

Taxonomic history. Trionyx acutiformis Bergounioux, 1935 (new species).

Type material. LG-FSM (holotype), a carapace fragment (Bergounioux 1935, fig. 28, pl. 11.2), probably lost (Broin 1977).

Type locality. Armissan, Aude, France (Bergounioux 1935); Chattian or Aquitanian, late Oligocene or early Miocene (Hervet 2004).

Comments. Bergounioux (1935) named a total of four trionychid taxa, Trionyx acutiformis, T. chaubeti, T. ciryi, and T. mourieri based on fragmentary material recovered from the late Oligocene or early Miocene of Armissan, France. Broin (1977) reported the presence of carapace fragments in the collections of MNHN that bear the label "Trionyx armissansis Gervais," which apparently pertain to the pan-trionychid from Armissan described and figured by Gervais (1867-1869), but this name only appears in a museum label and does not meet the standards of ICZN (1999) for availability. Broin (1977) in additional considered all Armissan species to be probable synonyms but ultimately concluded that the material is not diagnostic. We here conclude all named specimens from Armissan to be nomina dubia, as they do not display diagnostic characters (see T. vindobonensis for more extensive discussion).

\section{Trionyx affinis Negri, 1892 nomen invalidum}

(junior synonym of “T.” capellinii Negri, 1892)

Taxonomic history. Trionyx affinis Negri, 1892 (new species); T. capellinii affinis Sacco 1894 (new combination); T.c. capellinii = T. $c$. affinis $=$ T. $c$. conjugens Kotsakis 1977 (junior synonym); T. capellinii $=T$. . . affinis $=T$. c. conjugens $=T$. gemmellaroi $=$ T. intermedius Kotsakis 1985 (junior synonym).

Type material. MGP-PD 12806 (holotype), a nearly complete carapace (Negri 1892, pl. 5.1; Bergounioux 1954, fig. 10, pl. 2; Kotsakis 1977, fig. 3e).
Type locality. Monte Bolca (= Purga di Bolca), Veneto, Italy (Negri 1892); Prati Valeno Horizon, Lutetian, middle Eocene (Giusberti et al. 2014).

Comments. For a discussion on pan-trionychid material from the middle Eocene locality of Monte Bolca, Italy, see "Trionyx" capellinii above.

Trionyx amansii Gray, 1831 nomen dubium

Taxonomic history. Trionyx amansii Gray, 1831 (new species); [T. amansii] Hummel 1929 (nomen dubium); Trionyx amansi Karl 1999a (incorrect spelling of species epithet).

Type material. MNHN (holotype), a skull fragment (Gray 1831, not figured).

Type locality. Hautesvignes, Lot-et-Garonne, France (Cuvier 1821-1824); Rupelian, early Oligocene (Broin 1977).

Comments. Trionyx amansii was erected on the basis of a cranial fragment that was originally described by Cuvier (1821-1824), but not named or figured. Gray (1831) provided a name and an indication to the description of Cuvier (1821-1824) and thus formally made this name available (ICZN 1999). Hummel $(1929,1932)$ considered this taxon to be of dubious validity, and this view was also adopted by Broin (1977). Given that the type was never figured and that the characters discussed by Cuvier (1821-1824) have no diagnostic value, we herein agree with these opinions and also regard T. amansii to be a nomen dubium.

\section{Trionyx anthracotheriorum Portis, 1883 nomen dubium}

Taxonomic history. Trionyx anthracotheriorum Portis, 1883 (new species); T. antracotheriorum Portis 1883 (incorrect spelling of species epithet); [T. anthracotheriorum] Hummel 1929 (nomen dubium); T. anthracotherium Broin 1977 (incorrect spelling of species epithet); T. anthracoteriorum Chesi 2009 (incorrect spelling of species epithet).

Type material. MGPT-PU17275 (holotype), a partial cranium, carapace, and plastron (Portis 1883, pls. 1.4, 2.3)

Type locality. Nucetto (= Nuceto), Piedmont, Italy (Portis 1883); Chattian or Aquitanian, late Oligocene or early Miocene (Chesi 2009).

Comments. Trionyx anthracotheriorum is based on a shell and associated partial cranium (Portis 1883), but the skull is badly crushed and only displays little anatomical detail. Portis (1883) originally differentiated T. anthracotheriorum from the roughly coeval Piedmontese taxon T. pedemontana on the basis of carapace size and shape and the size of costals VII and VIII, but he noted similarities with the Croatian taxon T. austriacus (Peters 1859). Kotsakis (1985) concluded that the original diagnosis of Portis (1883) was not adequate, but he provisionally regarded 
T. anthracotheriorum to be a valid species, mostly on the basis of geographic considerations. Our firsthand investigation of the holotype of this taxon revealed distinct sculpturing consisting of well-developed tubercles and ridges but additionally confirmed the bad preservation of the cranial and carapacial material. Although we acknowledge the possibility that this species could be a junior synonym of the slightly older " $T$." capellinii, which is also from Italy, the fragmentary nature of the available material prompts us to consider it to be an indeterminate pantrionychid. Trionyx anthracotheriorum is here regarded a nomen dubium.

Trionyx anthracotheriorum has been featured in the literature under an array of incorrect spellings. Indeed, Portis (1883) himself introduced two spellings in the type description: antracotheriorum and anthracotheriorum. Although the first spelling has page priority over the latter, a criterion not explicitly demanded by the ICZN (1999), we here give preference to the latter, because it is grammatically correct, appeared in the etymology section, and is also more widespread in the literature (e.g., Sacco 1889; Hummel 1929, 1932).

\section{Trionyx aquitanicus Delfortrie, 1869 nomen dubium}

Taxonomic history. Trionyx aquitanicus Delfortrie, 1869 (new species); T. girundica Lawley 1876 (incorrect spelling of species epithet); [T. aquitanicus] Hummel 1929 (nomen dubium).

Type material. MHNB (holotype), neurals, costals, and a detached nuchal (Delfortrie 1869, pl. 28.20-23).

Type locality. Léognan, Gironde, France (Delfortrie 1869); Burdigalian, early Miocene (Broin 1977).

Comments. Trionyx aquitanicus is based on the fragmentary remains of a relatively large-sized pan-trionychid (Delfortrie 1869), to which Lydekker (1889a) subsequently referred an isolated costal collected within close vicinity. Lawley (1876) explicitly referenced Delfortrie (1869) but, for inexplicable reasons, applied the name T. girundica. This is, of course, one of many strange name applications that occurred prior to the establishment of internationally recognized priority rules many decades later. Trionyx girundica could be interpreted as yet another available name, but it would be the objective junior synonym of $T$. aquitanicus as it is based on the same type material. As an alternative, T. girundica could be interpreted as a terrible misspelling, in which case this name can be disregarded. In any case, given the fragmentary nature of the type material, we here consider $T$ aquitanicus to be a nomen dubium (also see T. vindobonensis above).

Trionyx aspidiformis Laube, 1900 nomen dubium

Taxonomic history. Trionyx aspidiformis Laube, 1900 (new species); Tryonyx aspidiformis Laube 1900 (incorrect spelling of genus name); $T$. triunguis $=T$. aspidiformis $=24$ others Karl 1998 (junior synonym, see Rafetus bohemicus for complete synonym); Rafetus pontanus $=$ T. aspidiformis $=T$. bohemicus $=T$. elongatus $=T$. preschenensis Chkhikvadze 1999b (junior synonym).

Type material. NMP 36675 (holotype), external imprint of a carapace, missing the posterior left side (Laube 1900, pl. 2.2; Liebus 1930, pl. 4.1,2).

Type locality. Břestány (= Preschen), near Bilina, Ústí nad Labem, Czechia (Liebus 1930); Most Formation, MN 3, Burdigalian, early Miocene (Aguilar et al. 1997).

Comments. Trionyx aspidiformis is based on a partial carapace from the early Miocene of Břestány, Czechia, that was initially housed at the Geological Institute of the German University, Prague, but has since been transferred to NMP. We here consider this taxon to be a nomen dubium, as it is based on a juvenile specimen that lacks diagnostic characters (see $T$. vindobonensis above for more extensive discussion).

\section{Trionyx australiensis De Vis, 1894 nomen dubium}

Taxonomic history. Trionyx australiensis De Vis, 1894 (new species); T. australiensis Gaffney and Bartholomai 1979 (lectotype designation); Pelochelys australiensis Rhodin et al. 2015 (new combination).

Type material. QM F1101A (lectotype), a left costal VIII (De Vis 1894, fig. f; Gaffney and Bartholomai 1979, pl. 1.1-2); QM F1101B-G (paralectotypes), carapace elements, consisting of a neural and costal fragments (De Vis 1894, pl. 1a-e, g; Hill et al. 1970, pl. 7.8; Gaffney and Bartholomai 1979, pl. 1).

Type locality. Tara Creek, Mackay Region, Queensland, Australia (De Vis 1894); late Pliocene or Pleistocene (Gaffney and Bartholomai 1979).

Comments. Trionyx australiensis is based on rather fragmentary carapace material. The exact locality of $T$. australiensis is a matter of debate. It was originally suggested to originate from Darling Downs (De Vis 1894), but on the basis of preservation, it was later shown to have come from Tara Creek (Gaffney and Bartholomai 1979). Gaffney and Bartholomai (1979) designated a lectotype from the syntype series, compared the taxon to Pelochelys from New Guinea, the only Pleistocene or Holocene trionychid genus recorded from the region, but found that it differed significantly. We here agree with Gaffney and Bartholomai (1979) that the available material is insufficient to diagnose a valid taxon.

\section{Trionyx austriacus Peters, 1859 nomen dubium}

Taxonomic history. Trionyx austriacus Peters, 1859 (new species); Rafetoides austriacus $=$ T. messelianus $=$ T. messelianus koch $i=T$. messelianus lepsiusi Karl 1998 (new combination, senior synonym); Rafetoides austriacus $=T$. borkenensis Karl and Müller 2008 (senior synonym).

Type material. GBAW (holotype), an incomplete carapace (Peters 1859, pl. 3.1), now lost (E. Cadena, pers. comm., 2016). 
Type locality. Promina Mountain (= Siverich), Šibenik-Knin County, Croatia (Peters 1859; Hummel 1929); Priabonian, late Eocene (Karl 1998)

Comments. Trionyx austriacus was established on the basis of a large partial carapace from the late Eocene of Croatia (Peters 1859). In addition to the holotype, Peters (1859) referred a second specimen from the late Eocene of Kis-Györ (= Hisgyör), Hungary, to this species, but this find was never figured apart from a cross section in the original description depicting the thickness of the carapace (Peters 1859, pl. 3.2). The whereabouts of the type and referred material are currently unknown, and it is therefore impossible to evaluate potential affinities. The date of publication is often provided as 1858 (Szalai 1934; Kuhn 1964 Karl 1998, 1999a), but, in fact, it is 1859. Karl (1998) suggested that T. austriacus is the senior synonym of the German " $T$." messelianus, but Karl and Müller (2008) more recently proposed that it is also the senior synonym of T. borkenensis. In both cases, no sufficient justification was provided to allow reproducing these claims. Given that the holotype is fragmentary and now lost, we find it best to consider T. austriacus a nomen dubium.

\section{Trionyx bambolii Ristori, $1891 \mathrm{~b}$ nomen dubium}

Taxonomic history. Trionyx bambolii Ristori, 1891b (new species); T. bambolis Reinach 1900 (incorrect spelling of species epithet); T. bamboli Teppner 1913 (incorrect spelling of species epithet).

Type material. MUSNAF (syntype), a partial carapace and associated thoracic vertebrae (Ristori 1895, pl. 1.1, 2; Guasparri 1992 fig. 30.2); MUSNAF (syntype), a carapace fragment, one cervical vertebra, and a partial epiplastron (Ristori 1895, pl. 1.3); MSNP (syntype), a carapace fragment, consisting of right costals and neurals I and II (Ristori 1895, pl. 1.4); IGF 999V (syntype), fragment of a hyoplastron and coracoid (Ristori 1895, pl. 2.9); MUSNAF (syntype), a carapace fragment of a juvenile individual (Ristori 1895, not figured).

Type locality. Montebamboli, Tuscany, Italy (Ristori 1891b); MN 12, Tortonian, late Miocene (Chesi 2009).

Comments. The late Miocene localities of Montebamboli, Casteani, Ribolla, and Casino in Tuscany, Italy, have produced a wealth of pan-trionychid fossils (Kotsakis 1985). Ristori (1891a, 1891b) recognized four new species from these localities that he named Trionyx bambolii, T. portisi, T. senensis, and T. propinquus. Although the associated descriptions are extremely brief, they fulfill the minimum requirements of the ICZN (1999) for the creation of an available name. Later authors (e.g., Humme 1932; Kuhn 1964; Kotsakis 1985) were therefore in error by attributing authorship to Ristori (1895), where the relevant material was described in much greater detail and figured.

Ristori (1891a, 1891b, 1895) already noted that all specimens greatly overlapped in the morphology of their shells, but he nevertheless justified the creation of four species based on differences in the shape of the neurals and carapace sculpturing. Using modern standards, such minute differences in neural patterning or sculpturing cannot warrant specific distinction, as these characteristics are known to be highly variable (Meylan 1987; Vitek and Joyce 2015). Kotsakis (1985) tentatively considered these taxa to be conspecific but concluded that a second taxon may be present. We find that all material is once again consistent with an attribution to the Trionyx triunguis lineage (Karl 1999a), but modern standards only allow attribution of these fossils to Pan-Trionychinae indet. based on the presence of relatively short costals VIII. We therefore here interpret all four taxa as nomina dubia.

\section{Trionyx barbarae Owen in Owen and Bell, 1849 nomen invalidum}

(junior synonym of "Trionyx" henrici Owen in Owen and Bell, 1849)

Taxonomic history. Trionyx barbarae Owen in Owen and Bell, 1849 (new species); Rafetoides henrici $=$ T. barbarae $=7$ others Karl 1998 (junior synonym, see "T." henrici for complete synonym).

Type material. BMNH R30409 (holotype), a carapace (Owen and Bell 1849, pl. 16a; Owen 1849-1884, pl. 5).

Type locality. Hordle (= Hordwell) Cliff, Hampshire, United Kingdom (Owen and Bell 1849); Totland Bay Member, Headon Hill Formation, Priabonian, late Eocene (Benton and Spencer 1995).

Comments. For a discussion regarding pan-trionychid material from the late Eocene of England, see "Trionyx" henrici above.

\section{Trionyx blayaci Bergounioux, 1933 nomen dubium}

Taxonomic history. Trionyx blayaci Bergounioux, 1933 (new species); T. pliopedemontanus $=T$. blayaci $=T$. pliocenicus $=$ T. pompignanensis $=T$. rotundiformis Broin 1977 (junior synonym).

Type material. LG-FSM (holotype), anterior portion of a carapace (Bergounioux 1933, fig. 1, pl. 1.1).

Type locality. La Pompignane, Montpellier, Hérault, France (Bergounioux 1933); Pliocene (Broin 1977).

Comments. Bergounioux (1933) established three species of trionychids, Trionyx blayaci, T. pompignanensis, and T. rotundiformis, on the basis of carapacial fragments from the Pliocene of Montpellier, France, that he differentiated from the coeval $T$. pliopedemontana by nuanced variations in nuchal morphology and carapace sculpturing. More recently, Broin (1977) considered all three forms to be junior synonyms of T. pliopedemontana. Strictly speaking, the type of T.pompignanensis can only be identified as Pan-Trionychidae indet. as it only consists of a partial costal, whereas the more complete types of T. blayaci and $T$. rotundiformis, which only represent the anterior portions of the carapace, can only be identified as Pan-Trionychinae based on the absence of a preneural. We therefore conclude that Bergounioux's (1933) three species are nomina dubia. 
Trionyx bohemicus jaegeri Fuchs, 1939 nomen dubium

Taxonomic history. Trionyx bohemicus jaegeri Fuchs, 1939 (new subspecies).

Type material. BSPG NMR 326 (holotype), a carapace (Fuchs 1939, fig. 11, pls. 2.3, 4; Młynarski 1976, fig. 74.5).

Type locality. Viehhausen, Sinzing, Bavaria, Germany (Fuchs 1939); MN 5, Langhian, middle Miocene (Aguilar et al. 1997).

Comments. Fuchs (1939) attributed several specimens from the locality of Viehhausen to the Czech taxon Rafetus (her Trionyx) bohemicus, but she diagnosed one carapace as a new subspecies, T. bohemicus jaegeri, on the basis of the presence and shape of an eighth neural. As we do not find carapaces by themselves to be diagnostic, even if they have an unusual neural count, we here consider this taxon to be a nomen dubium (see Rafetus bohemicus and T. vindobonensis above for a more extensive discussion).

\section{Trionyx borkenensis Gramann, 1956 nomen dubium}

Taxonomic history. Trionyx borkenensis Gramann, 1956 (new species); T. borkensis Kuhn 1964 (incorrect spelling of species epithet); Amyda boulengeri $=$ T. borkenensis Karl 1993 (junior synonym); Rafetoides austriacus $=T$. borkenensis Karl and Müller 2008 (junior synonym).

Type material. UVF 6100 (holotype), a partial carapace (Gramann 1956, pl. 3.1,2).

Type locality. Gombeth, Borken, Hesse, Germany; lower "Melanian Clay" (= Melanienton), Rupelian, early Oligocene (Gramann 1956).

Comments. Trionyx borkenensis is based on a partial carapace that was originally diagnosed as a new species on the basis of an anterior convexity (Gramann 1956), a character that is now believed to be highly variable with pan-trionychids (Gardner and Russell 1994). A partial carapace from the same locality was more recently attributed to T. cf. borkenensis (Schleich 1986), likely based on biogeographic considerations. Karl (1993) synonymized T. borkenensis with "T." boulengeri, also from the Oligocene, whereas Karl and Müller (2008) synonymized it with the late Eocene T. austriacus and assigned to the same taxon further fragmentary material from the locality. As the type material does not display any diagnostic characters, we here consider T. borkenensis to be a nomen dubium.

\section{Trionyx bowerbanki Lydekker, 1889a nomen dubium}

Taxonomic history. Trionyx bowerbanki Lydekker, 1889a (new species); [T. bowerbanki] Hummel 1929 (nomen dubium); T. boweroanki Bergounioux 1954 (incorrect spelling of species epithet).

Type material. BMNH R38960 (holotype), an incomplete nuchal (Lydekker 1889a, fig. 4).
Type locality. Bracklesham, West Sussex, United Kingdom (Lydekker 1889a); Bracklesham Beds, late Ypresian, early Eocene (Moody and Walker 1970).

Comments. Lydekker (1889a) established Trionyx bowerbanki on the basis of an isolated nuchal to which he referred a right hypoplastron from the type locality. The only other pan-trionychid that has been recovered from Bracklesham, West Sussex, is Axestemys vittata (Moody and Walker 1970; Walker and Moody 1985), which is known to have a significantly different postcranial anatomy (see Axestemys vittata and Eurycephalochelys fowleri above). Some superficial similarities are apparent with slightly younger material from Germany (see "T." messelianus above), but the fragmentary nature of the available material precludes any confident assessment. We therefore agree with Hummel (1929) that T. bowerbanki should be considered a nomen dubium.

\section{Trionyx brunhuberi Ammon, 1911 nomen invalidum \\ (junior synonym of T. vindobonensis Peters, 1855)}

Taxonomic history. Trionyx brunhuberi Ammon, 1911 (new species); T. triunguis $=$ T. brunhuberi $=24$ others Karl 1998 (junior synonym, see Rafetus bohemicus for complete synonym).

Type material. BSPG 1911 I 23 (holotype), a complete carapace and right hyo-, hypo-, and xiphiplastron (Ammon 1911, pls. 2, $3.6-7,4)$.

Type locality. Dechbetten, Regensburg, Bavaria, Germany (Ammon 1911); Langhian, middle Miocene (Mottl 1967).

Comments. Trionyx brunhuberi is known from relatively wellpreserved shell material from the middle Miocene of Regensburg (Ammon 1911). The species was originally differentiated from coeval European forms by the shape of its carapace, shape and size of the neurals and costals, and details to the sculpturing of the hyo-hypoplastra, but these characteristics are now known to be highly variable (Meylan 1987; Gardner and Russell 1994). We note that the plastral material indicates the presence of four callosities, and we therefore synonymize this taxon with T. vindobonensis. We attribute apparent differences to the extent of the callosities to ontogenetic variation, with the material from Regensburg representing a more adult morphotype (see T. vin dobonensis for more extensive discussion).

\section{Trionyx bruxelliensis Winkler, 1869a nomen dubium}

Taxonomic history. Trionyx bruxelliensis Winkler, 1869a (new species); T. bruxellensis Vincent 1875 (incorrect spelling of species epithet); [T. bruxelliensis] Hummel 1929 (nomen dubium).

Type material. IRSNB 1659 (holotype), a partial carapace, along with fragments of limb elements and vertebrae (Winkler 1869a, pls. 29.73, 30.74-91; Broin 1977, pl. 9.1). 
Type locality. Brussels Capital Region, Belgium (Winkler 1869a); early Lutetian, middle Eocene (Broin 1977).

Comments. Trionyx bruxelliensis was established on the basis of a partial carapace and several isolated postcranial remains (Winkler 1869a). Winkler (1869a) briefly mentioned that he initially intended to name this taxon T. duponti, but he ended up choosing the name T. bruxelliensis. The surface of the holotype shows much damage, as the surface sculpturing is only preserved in some portions of the shell, although superficial similarities are apparent with the coeval "T." messelianus from Germany. We here therefore consider the holotype to represent an indeterminate pan-trionychid and T. bruxelliensis to be a nomen dubium, as already proposed by Hummel (1929).

Trionyx michauxi from the early Eocene of Marne, France, was initially identified as T. bruxelliensis as well (Michaux 1973) but later considered a separate, valid taxon (Broin 1977). Taking the fragmentary nature of the holotype of $T$. bruxelliensis into consideration, no further comparison with the French taxon can be made.

\section{Trionyx burdigalensis Bergounioux, 1935 nomen dubium}

Taxonomic history. Trionyx burdigalensis Bergounioux, 1935 (new species); Amyda burdigalensis Comaschi Caria 1959 (new combination)

Type material. MHNB (holotype), anterior part of a carapace (Bergounioux 1935, fig. 26, pl. 10.2).

Type locality. Saint-Vivien-de-Monségur, Gironde, France (Bergounioux 1935); Rupelian, early Oligocene (Broin 1977).

Comments. Bergounioux (1935) established Trionyx burdigalensis on the basis of the anterior portion of a rather large carapace. He originally diagnosed this taxon by the presence of a highly reduced nuchal, a widely distributed feature among pan-trionychids, and the W-shaped posterior part of neural I (Bergounioux 1935). The W-like shape in the posterior part of neural I is apparent in the drawing published by Bergounioux (1935), but not clear in the associated photograph, and it seems likely that this feature is attributable to breakage. Along those lines, Broin (1977) already considered the available material to represent an indeterminate pan-trionychid. We agree with this assessment and here consider $T$. burdigalensis to be a nomen dubium.

Comaschi Caria (1959) referred fragments of a pan-trionychid from the Miocene of Cagliari, Sardinia, to Trionyx burdigalensis. Kotsakis (1985) suggested that this material is too fragmentary to allow identification at the species level but also noted that it seemed probable that it originated from Procyclanorbis sardus. However, Zoboli and Pilolla (2016) more recently showed that this material pertains to a cheloniid. We agree with this conclusion.

\section{Trionyx capellinii bulgaricus \\ Khosatzky et al., 1983 nomen dubium}

Taxonomic history. Trionyx capellinii bulgaricus Khosatzky et al., 1983 (new subspecies)

Type material. IZ-BAS 1/1959 (holotype), an incomplete carapace (Khosatzky et al. 1983, figs. 1-3).

Type locality. Nikolaevo, Stara Zagora, Bulgaria (Khosatzky et al. 1983); Priabonian, late Eocene (Stojanov 2009).

Comments. Trionyx capellinii bulgaricus was described as a new Bulgarian subspecies of the Italian "T." capellinii (Khosatzky et al. 1983). Most of the specimen is missing, however, and much of the anatomy of the carapace can only be gleaned by observing the remaining imprint. Given that the internal morphology of turtle shells does not faithfully reflect the external arrangement of the bones, we consider this taxon to be a nomen dubium, although we do agree that the internal imprint indeed shows similarities with "T." capellinii.

\section{Trionyx capellinii conjugens Sacco, 1894 nomen invalidum (junior synonym of “T.” capellinii Negri, 1892)}

Taxonomic history. Trionyx capellinii conjugens Sacco, 1894 (new subspecies); T. c. conjungens Reinach 1900 (incorrect spelling of subspecies name); T. c. capellinii $=T$. c. conjugens Bergounioux 1954 (junior synonym); T. conjugens Kuhn 1964 (elevation to species); T. c. capellinii $=$ T. c. affinis $=$ T. c. conjugens Kotsakis 1977 (junior synonym); T. c. capellinii = T. c. affinis $=T . \quad$ c. conjugens $=T . \quad$ gemmellaroi $=T$. intermedius Kotsakis 1985 (junior synonym).

Type material. MGPT-PU 17281 (syntype), a complete carapace embedded in a slab (Sacco 1894, fig. 1; Bergounioux 1954, fig. 8; Kotsakis 1977, fig. 3d); MGPT-PU 17282 (syntype), a partial carapace (Sacco 1894, fig. 2); MGPT-PU 17283 (syntype), carapace fragments (Sacco 1894, figs. 3-5).

Type locality. Monte Bolca (= Purga di Bolca), Veneto, Italy (Sacco 1894); Prati Valeno Horizon, probably Lutetian, middle Eocene (Giusberti et al. 2014).

Comments. For a discussion on pan-trionychid material from the middle Eocene locality of Monte Bolca, Italy, see "T?" capellinii above.

\section{Trionyx capellinii gracilina Sacco, 1895 nomen invalidum} (junior synonym of “T.” capellinii Negri, 1892)

Taxonomic history. Trionyx capellinii gracilina Sacco, 1895 (new subspecies); T. c. gracillima Reinach 1900 (incorrect spelling of subspecies epithet); T. capellini gracilina Bergounioux 1933 (incorrect spelling of species epithet); T. c. montevialensis $=T$. c. gracilina $=T$. c. perexpansa $=$ T.c. schaurothianus $=$ T. insolitus $=[$ T. italicus $]$ Kotsakis 1977 (junior synonym); T. italicus $=$ T. c. montevialensis $=T$. c. schaurothianus $=$ T. c. gracilina $=T$. c. perexpansa $=T$. insolitus Kotsakis 1985 (junior synonym). 
Type material. MGPT-PU 17285 (holotype), an almost complete carapace (Sacco 1895, fig. 2; Bergounioux 1954, fig. 25; Kotsakis 1977, fig. 3j).

Type locality. Monteviale, Veneto, Italy (Sacco 1895); MP 21, early Rupelian, early Oligocene (Pandolfi et al. 2017).

Comments. For a discussion on pan-trionychid material from the early Oligocene locality of Monteviale, Italy, see "T." capellinii above.

\section{Trionyx capellinii montevialensis Negri, 1892 nomen invalidum}

(junior synonym of “T.” capellinii Negri, 1892)

Taxonomic history. Trionyx capellinii montevialensis Negri, 1892 (new subspecies); T. capellini montevialensis Teppner 1913 (incorrect spelling of species epithet); T. c. monsvialensis Fabiani 1915 (incorrect spelling of subspecies epithet); T. c. monsvialensis Bergounioux 1954 (incorrect spelling of subspecies epithet); T. c. monsilvalensis Mlynarski 1976 (incorrect spelling of subspecies epithet); T. c. montevidensis Kotsakis 1977 (incorrect spelling of subspecies epithet); T. c. montevialensis $=T$. $c$. gracilina $=T$.c. perexpansa $=$ T. c. schaurothianus $=T$. insolitus $=$ [T. italicus] Kotsakis 1977 (senior synonym); T. italicus $=$ T. $c$. montevialensis $=T . c$. schaurothianus $=T . c$. gracilina $=T . c$. perexpansa $=T$. insolitus Kotsakis 1985 (junior synonym).

Type material. MGP-PD 9273 (syntype), a rather complete carapace with associated limb elements and plastral fragments (Negri 1892, pl. 4; Bergounioux 1954, fig. 19, pl. 7; Kotsakis 1977, fig. 3g-h; Kotsakis et al. 2005, fig. 11; Pandolfi et al. 2017, fig. 7a); MGP-PD 27636 (syntype), a complete carapace in visceral view, along with plastral elements (Bergounioux 1954, pl. 11); MGP-PD 27637 (syntype), a partial carapace, two complete limb elements, and fragments of the plastron (Bergounioux 1954, figs. 20, 21, pls. 8, 9).

Type locality. Monteviale, Veneto, Italy (Negri 1892); MP 21, early Rupelian, early Oligocene (Pandolfi et al. 2017).

Comments. The type series of Trionyx capellinii montevialensis includes some of the most complete fossil pan-trionychids known to date. For a discussion on pan-trionychid material from the early Oligocene locality of Monteviale, Italy, see " $T$." capellinii above.

\section{Trionyx capellinii perexpansa Sacco, 1895 nomen invalidum}

(junior synonym of “T.” capellinii Negri, 1892)

Taxonomic history. Trionyx capellinii perexpansa Sacco, 1895 (new subspecies); T. c. montevialensis $=T$. c. gracilina $=T$. $c$. perexpansa $=T$. c. schaurothianus $=T$. insolitus $=[$ T. italicus $]$ Kotsakis 1977 (junior synonym); T. italicus $=$ T.c. montevialensis $=T$. c. schaurothianus $=T$. c. gracilina $=T$. c. perexpansa $=$ T. insolitus Kotsakis 1985 (junior synonym).

Type material. A complete carapace with fragmentary imprints of the skull (holotype) (Sacco 1895, fig. 1;
Bergounioux 1954, fig. 26; Kotsakis 1977, fig. 3k), now lost (Bergounioux 1954).

Type locality. Monteviale, Veneto, Italy (Sacco 1895); MP21, early Rupelian, early Oligocene (Pandolfi et al. 2017).

Comments. Trionyx capellinii perexpansa is one of many pan-trionychid taxa named from Monteviale, Italy (Kotsakis 1977, 1985). Its type and only known specimen is among the largest pan-trionychids (CL of $31 \mathrm{~cm}$ ) from that locality, and it was differentiated from other purportedly sympatric taxa by larger size, size and shape of neurals, and, most notably, the distal expansion of costals I and II, features that are now attributed to individual variation (Gardner and Russell 1994). For a discussion on pantrionychid material from this locality, see "T." capellinii above.

\section{Trionyx chaubeti Bergounioux, 1935 nomen dubium}

Taxonomic history. Trionyx chaubeti Bergounioux, 1935 (new species); T. chauberti Kuhn 1964 (incorrect spelling of species epithet).

Type material. LG-FSM (holotype), left part of a carapace (Gervais 1867-1869, pl. 40.2; Bergounioux 1935, fig. 30, pl. 12.1).

Type locality. Armissan, Aude, France (Bergounioux 1935); Chattian or Aquitanian, late Oligocene or early Miocene (Hervet 2004).

Comments. Bergounioux (1935) diagnosed his new species Trionyx chaubeti on the basis of its small size (CL of $18 \mathrm{~cm}$ ), reduced size of nuchal, shape of neurals, and shape of the anterior portion of the carapace. For a discussion on Bergounioux's (1935) material from Armissan, France, see T. acutiformis and T. vindobonensis above.

\section{Trionyx circumsulcatus Owen in Owen and Bell, 1849 nomen invalidum} (junior synonym of “ $T$." henrici Owen in Owen and Bell, 1849)

Taxonomic history. Trionyx circumsulcatus Owen in Owen and Bell, 1849 (new species); Aulacochelys circumsulcata Lydekker 1889a (new combination); [T. circumsulcatus] Hummel 1929 (nomen dubium); Rafetoides henrici $=T$. circumsulcatus $=7$ others Karl 1998 (junior synonym, see "T." henrici for complete synonym).

Type material. BMNH R30404 (holotype), a costal III (Owen and Bell 1849, pl. 19b.1-3; Owen 1849-1884, pl. 31.1-3).

Type locality. Hordle (= Hordwell) Cliff, Hampshire, United Kingdom (Owen and Bell 1849); Totland Bay Member, Headon Hill Formation, Priabonian, late Eocene (Benton and Spencer 1995).

Comments. Trionyx circumsulcatus is based on a single costal that was diagnosed based on the presence of a deep groove along 
its distal margin (Owen and Bell 1849:59). Lydekker (1889a) later tentatively assigned a right hypoplastral fragment from the same locality to this species and placed it in a new, monotypic genus, Aulacochelys, as he felt its morphology to be so distinct. A deep groove traversing the thickened distal margin of the costals is now known to be highly variable among pan-trionychids (Gardner and Russell 1994), but is nevertheless diagnostic for North American plastomenids (Vitek and Joyce 2015). Given the apparent lack of plastomenids in the European fossil record, we here attribute T. circumsulcatus to the coeval "T." henrici and attribute apparent differences to ontogenetic variation. For more detail regarding pan-trionychid material from the late Eocene of England, see "T?" henrici above.

\section{Trionyx ciryi Bergounioux, 1935 nomen dubium}

Taxonomic history. Trionyx ciryi Bergounioux, 1935 (new species).

Type material. LGB-UD (syntype), a carapace fragment (Bergounioux 1935, not figured), now lost (Broin 1977); LBG-UD (syntype), a partial carapace (Bergounioux 1935, fig. 27, pl. 11.1).

Type locality. Armissan, Aude, France (Bergounioux 1935); Chattian or Aquitanian, late Oligocene or early Miocene (Hervet 2004).

Comments. Bergounioux originally diagnosed his new species Trionyx ciryi on the basis of the shape and size of neurals, characters that are now known to be variable with trionychids (Meylan 1987). For a discussion on Bergounioux's (1935) material from Armissan, France, see T. acutiformis and T. vindobonensis above.

Trionyx clavatomarginatus Lörenthey, 1903 nomen invalidum, designation of lectotype

(junior synonym of " $T$." boulengeri Reinach, 1900)

Taxonomic history. Trionyx clavatomarginatus Lörenthey, 1903 (new species).

Type material. MTB 15982H (not MTB 15983, as stated in Farkas [1995]) (lectotype), a complete carapace (Lörenthey 1903, pl. 6.1-3); MTB 15983 (paralectotype), posterior carapace fragment (Farkas 1995, fig. 4); MTB 15984 (paralectotype), a partial carapace of a juvenile individual (Lörenthey 1903, pl. 5.1).

Type locality. Cluj-Mănăştur (= Kolozsmonostor), near ClujNapoja (= Kolozsvár), Cluj County, Romania (Lörenthey 1903; Myynarski 1966; Farkas 1995); Priabonian, late Eocene (Vremir 2004). The paralectotypes originate from late Eocene to early Oligocene quarries in the broader vicinity of Cluj-Napoja, Romania (Mlynarski 1966; Farkas 1995; Vremir et al. 1997).

Comments. The original type material of Trionyx clavatomar ginatus includes the remains of several individuals found in three different sites within the broader vicinity of Cluj-Napoja, Romania. Given that these cites are not synchronous, it is not surprising that the age of this taxon has variously been reported as being late Eocene (Lörenthey 1903; Vremir et al. 1997) or early Oligocene (Młynarski 1966). As it is highly undesirable to have a taxon being based on nonsynchronous material, we here render the best-preserved specimen as the lectotype of this species, which, to the best of our knowledge, was collected in late Eocene sediments (Vremir et al. 1997).

We consider the paralectotypes to be identifiable only to the level of Pan-Trionychidae indet., as they are too fragmentary to allow identification at the species level. However, we agree with Farkas (1995) that the lectotype of Trionyx clavatomarginatus greatly resembles " $T$." boulengeri in having greatly reduced costals VIII, and we further note the sinuous lateral margins of the carapace. We therefore formally synonymize these two taxa herein, thereby temporally and geographically extending the range of " $T$." boulengeri (also see above).

\section{Trionyx cliftii Fitzinger 1836 nomen nudum}

Type material. None discussed or designated.

\section{Locality. None specified.}

Comments. Fitzinger (1836) did not describe or figure this species, but rather just mentioned a name in his classic work. Fitzinger (1836) furthermore did not mention a locality where this taxon was collected or the probable age or the available material. It is therefore apparent that Trionyx cliftii does not fulfill the minimum requirements of the ICZN (1999) for names published prior to 1931, and it must therefore be considered a nomen nudum.

\section{Trionyx croaticus Koch, 1915 nomen dubium}

Taxonomic history. Trionyx croaticus Koch, 1915 (new species); T. stadleri croaticus Paunović 1986 (referral to subspecies level); T. triunguis $=T$. croaticus $=24$ others Karl 1998 (junior synonym, see Rafetus bohemicus for complete synonym).

Type material. CNHM 25.1-1-(1.485) and CNHM 25.1-2(1486) (holotype), an almost complete carapace and its mold, with traces of the nuchal, costals, and neurals (Koch 1915, pls. 1.1, 1.2, 1.3; Paunović 1986, fig. 1).

Type locality. Voča, Varaždin County, Croatia (Koch 1915; Paunović 1986); Langhian, middle Miocene (Paunović 1986; Vremir et al. 1997).

Comments. This species is known from a single, at least $37 \mathrm{~cm}$ long, well-preserved carapace (Koch 1915) from the Miocene of Croatia. At the time of its discovery, most pan-trionychids from the neighboring regions in Austria and Slovenia had been treated as distinct taxa (Peters 1855; Hoernes 1881; Heritsch 1909; Teppner 1913, 1914c). Accordingly, Koch (1915) established the new species Trionyx croaticus and differentiated it from other coeval pan-trionychids on the basis of carapace size, 
shape and size of costals, and sculpturing pattern. Paunović (1986) regarded this taxon simply as a variety of the geographically proximal but older taxon T. stadleri from the late Oligocene of Slovenia. Much like most of the coeval pan-trionychids from north of the Alps, we here conclude that the available material is too fragmentary to allow rigorously attributing it to any of the lineages apparent in Europe at that time (see T. vindobonensis for more extensive discussion above). We therefore regard this taxon as a nomen dubium.

\section{Trionyx danovi Chkhikvadze, 1989 nomen dubium}

Taxonomic history. Trionyx danovi Chkhikvadze, 1989 (new species); Rafetus danovi Chkhikvadze 2010 (new combination).

Type material. IPGAS 3-10-1 (holotype), a nuchal (Chkhikvadze 1989, fig. 6); IPGAS (paratypes), three costal fragments (Chkhikvadze 1989, not figured).

Type locality. Belomechetskaya (= Bjelometscheska), Stavropol Territory, Russia; Langhian, middle Miocene (Chkhikvadze 1989, 2010).

Comments. This species is based on a nuchal and three costals. Chkhikvadze (1989) differentiated his taxon by carapace size, nuchal morphology, and costals shape. He originally noted affinities of his new taxon with Trionyx stiriacus (Chkhikvadze 1989) but later reallocated it to Rafetus (Chkhikvadze 2010). The sole figure of the holotype nuchal is of poor quality (Chkhikvadze 1989), and the paratypes were never figured. We therefore identify this material as an indeterminate pan-trionychid and declare T. danovi to be a nomen dubium. This species has sometimes been reported as having been named in 1988 (Chkhikvadze 2007, 2010), but in fact was named in 1989.

\section{Trionyx desmostyli Matsumoto, 1918 nomen dubium}

Taxonomic history. Trionyx desmostyli Matsumoto, 1918 (new species).

Type material. TU (holotype), a partial carapace (Matsumoto 1918, pl. 21).

Type locality. Teshio, Hokkaido, Japan (Matsumoto 1918); Kawabata series, early Miocene (Otsuka 1970).

Comments. Trionyx desmostyli is based on a partial carapace from the Miocene of Hokkaido, Japan. Matsumoto (1918) noted in the type description that this taxon shares many similarities with the extant Pelodiscus sinensis and even hinted at the possibility that the former could be the ancestor of the latter, but these statements were likely made without access to much comparative material from the recent and past. Judging from the presence of at least one reversal in the neural series, the type specimen can be diagnosed as a pan-trionychine, but this specimen otherwise lacks diagnostic traits. We therefore regard $T$. desmostyli to be a nomen dubium.
Otsuka (1970) more recently referred the posterior margin of a carapace from the middle Miocene of Sasebo, Nagasaki, Japan, to Trionyx sp. aff. desmostyli, based on the presence of a pair of rather prolonged costals VIII and a straight posterior carapacial border, but these features occur broadly across PanTrionychidae. We therefore believe this fragment to be an indeterminate pan-trionychid.

\section{Trionyx dieupentalensis Bergounioux, 1935 nomen dubium}

Taxonomic history. Trionyx dieupentalensis Bergounioux, 1935 (new species); T. deupentalensis Karl 1999a (incorrect spelling of species epithet).

Type material. MHNT PAL2010.0.137 (holotype), an incomplete carapace, preserving mostly its anterior and right side (Bergounioux 1935, fig. 25, pl. 10.1).

Type locality. Dieupentale, Tarn-et-Garonne, France (Bergounioux 1935); Chattian, late Oligocene (Broin 1977).

Comments. Trionyx dieupentalensis is based on a single, incomplete carapace, but only the anterior portions are well preserved, and most of the neurals are damaged (Bergounioux 1935). Bergounioux (1935) diagnosed his new taxon on the basis of nuances in the shape of the nuchal and neurals. Given the highly fragmentary nature of the type specimen and its poor preservation, however, we judge this specimen to be an indeterminate pan-trionychine. Trionyx dieupentalensis is therefore herein considered to be a nomen dubium.

\section{Trionyx dodunii Gray 1831 nomen nudum}

Material. MNHN 8330, a costal fragment (not figured); MNHN 8373, an indeterminate fragment (not figured) (Broin 1977).

Locality. Castelnaudary, Aude, France (Gray 1831); late Lutetian, middle Eocene (Broin 1977).

Comments. Cuvier (1821-1824) briefly mentioned the presence of a pan-trionychid at Castelnaudary, France, but he did not describe or figure this material but rather simply mentioned that it could be identified as pan-trionychid costal fragments on the basis of its sculpturing. Gray (1831) suggested the name Trionyx dodunii for the material described by Cuvier (1821-1824). However, given that Gray (1831) provided neither a description nor a definition nor an indication (i.e., a reference to a description or definition), Trionyx dodunii must be considered to be a nomen nudum (ICZN 1999). According to Broin (1977), the material from Castelnaudary includes not only an indeterminate pantrionychid but possibly also fragments of a pan-carettochelyid. Auffenberg (1974) listed the species Testudo doduni (sic) Gray, 1831 as a representative of Testudinidae, but this seems to be an error.

Trionyx elongatus Liebus, 1930 nomen dubium 
Taxonomic history. Trionyx elongatus Liebus, 1930 (new species); T. triunguis $=$ T. elongatus $=24$ others Karl 1998 (junior synonym, see Rafetus bohemicus for complete synonym); Rafetus pontanus $=T$. aspidiformis $=T$. bohemicus $=$ T. elongatus $=$ T.preschenensis Chkhikvadze 1999b (junior synonym).

Type material. NMP 1488 (syntype), a carapace (Liebus 1930, pl. 3.6; Nečas et al. 1997, fig. p.17); MMUL 129/G12911 (syntype), a nuchal (Liebus 1930, pl. 3.7).

Type locality. Břestány (= Preschen), near Bilina, Ústí nad Labem, Czechia (Liebus 1930); Most Formation, MN 3, Burdigalian, early Miocene (Aguilar et al. 1997).

Comments. Trionyx elongatus is known from a rather small and elongated carapace of a juvenile individual and an isolated nuchal (Liebus 1930) that was initially characterized by a reduced number of neurals (Liebus 1930), thus prompting Hummel (1932) to tentatively include it in the North American Apalone (his Platypeltis). It is now known that the number of neurals is a variable character within pan-trionychids (Meylan 1987). Given that T. elongatus is based on a juvenile specimen (CL of $11 \mathrm{~cm}$ ), we herein consider it to be a nomen dubium (see T. vindobonensis and Rafetus bohemicus for more extensive discussions).

\section{Trionyx erquelinnensis Dollo 1909 nomen nudum}

Material. IRSNB 3908, a carapace (Broin 1977, pl. 9.2).

Locality. Erquelinnes, Hainaut, Belgium (Dollo 1909); Tienen Formation, MP 7, early Ypresian, early Eocene (Delfino and Smith 2009).

Comments. Similarly to Trionyx levalensis, the other Belgian pan-trionychid named by Dollo (1909), the name T. erquelinnensis was simply provided in a list of taxa and was not accompanied by a description of material, a diagnosis, or reference to a prior published description or definition. Dollo (1909) therefore did not make this name available. Broin (1977) much later described and figured the original material of Dollo (1909) under the name T. erquelinnensis, but nevertheless concluded that the name is not available, because it would be the junior synonym of Axestemys (her Palaeotrionyx $[$ sic]) vittata even if it were available. We here concur with this assessment and consider T. erquelinnensis to be a nomen nudum, but on the basis of Broin's (1977) description and figures, we refer all material to Axestemys vittata (see above).

\section{Trionyx fuchienensis (Yeh, 1974) nomen dubium}

Taxonomic history. Trionyx fuchienensis Yeh, 1974 (new species); Aspideretes fuchienensis Ye 1994 (new combination); Sinamyda fuchienensis Chkhikvadze 2000a (new combination); Aspideretes fuchiensis Brinkman et al. 2008 (incorrect spelling of species epithet); Synamyda fuchienensis Li, Tong et al. 2015 (incorrect spelling of genus name).
Type material. IVPP V4708 (holotype), an incomplete carapace (Yeh 1974, pl. 1).

Type locality. Hekou, Ninghua County, Fujian (= Fuchien) Province, China (Yeh 1974; Brinkman et al. 2008; Figure 4); unknown Formation, Cretaceous (epoch and age unclear) (Brinkman et al. 2008; Danilov and Vitek 2013).

Comments. Trionyx fuchienensis is based on a complete, but poorly preserved carapace with vague stratigraphic provenience that documents the purported presence of a trionychid with a carapace that is more than twice as long as wide, an unusual morphology otherwise not seen in any other pan-trionychid. According to personal observations by one of us (W.G.J.), we conclude that the holotype shows extensive repair, is heavily crushed, and displays an unusual surface texture that is not necessarily reminiscent of a trionychid. Given that the provenience of the type is uncertain, that the morphology of the type is so highly unusual, and that the authenticity of the morphology captured in the type is doubtful, we here regard this taxon as a nomen dubium.

Trionyx gemmellaroi Negri, 1892 nomen invalidum

(junior synonym of “T.” capellinii Negri, 1892)

Taxonomic history. Trionyx gemmellaroi Negri, 1892 (new species); T. gemellarioi Sacco 1894 (incorrect spelling of species epithet); T. gemellarii Reinach 1900 (incorrect spelling of species epithet); T. gemellaroi Hummel 1932 (incorrect spelling); T. gemmelarvoi Bergounioux 1953 (incorrect spelling of species epithet); $T$. capellinii $=T$. c. affinis $=T . \quad c$. conjugens $=T$. gemmellaro $i=$ T. intermedius Kotsakis 1985 (junior synonym).

Type material. MGP-PD 5157 (holotype), almost complete skeleton, including the plastron and carapace, all limb elements, and partial skull and mandible (Negri 1892, pls. 1, 5.2-5; Bergounioux 1954, figs. 11, 12, pl. 3; Giusberti et al. 2014, fig. 4a-b).

Type locality. Monte Bolca (= Purga di Bolca), Veneto, Italy (Negri 1892); Prati Valeno Horizon, probably Lutetian, middle Eocene (Giusberti et al. 2014).

Comments. Trionyx gemmellaroi is based on a beautifully preserved specimen that is almost identical to the syntypes of "T." capellinii. Given that T. gemmellaroi and "T." capellinii were named in the same publication (Negri 1892), we here concur with Kotsakis (1985), the first revisor, by acknowledging "T." capellinii as the senior synonym. For a discussion on pan-trionychid material from the middle Eocene locality of Monte Bolca, Italy, see "T"' capellinii above.

$$
\begin{gathered}
\text { Trionyx gergensi Reinach, } 1900 \\
\text { nomen invalidum }
\end{gathered}
$$

(junior synonym of T. vindobonensis Peters, 1855)

Taxonomic history. Aspidonectes gergensii Meyer 1844 (nomen nudum); Aspidonectes gergensi Meyer 1860 (nomen nudum); 
Trionyx gergensi Reinach, 1900 (new species), Procyclanorbis gergensi Portis 1901 (new combination); T. gergensis Harrassowitz 1919 (incorrect spelling of species epithet); [T. gergensi] Hummel 1929 (nomen dubium); Aspideretes gergensi Karl 1993 (new combination); T. triunguis $=[$ Aspidonectes gergensi $]=24$ others Karl 1998 (junior synonym, see Rafetus bohemicus for complete synonym).

Type material. NMM (holotype), a fragmentary specimen consisting of partial nuchal right costal I, left hyo-hypoplastron, right xiphiplastron, and limb bones (Reinach 1900, pl. 40.1-5, 8-10).

Type locality. Hechtsheim, Mainz, Rhineland-Palatinate, Germany (Meyer 1844); Aquitanian, early Miocene (Karl 1999a).

Comments. Trionyx gergensi has a tortured nomenclatural history. Meyer (1844) reported fragments from the Miocene of Mainz, Germany, under the name Aspidonectes gergensii, but this was not accompanied by any characters, a definition, or an indication, and he therefore did not make the name available. In a later contribution (Meyer 1860, 1867), he mentioned the name again with a slightly different spelling, but once again did not make it available. Maack (1869) listed this taxon as valid but also did not make it available, by not including any characters, a definition, or an indication. Lydekker (1889a) referred an additional specimen from Mainz to this name, but we do not believe that he made the taxon available, as he explicitly refers to the type specimen, for which he lacked character evidence. Reinach (1900) figured the original material of Meyer (1844), provided a description, and only then finally made the name available, though under the combination T. gergensi. Reinach (1900) attributed additional fragments from Weisenau near Mainz to $T$. gergensi but designated Lydekker's (1889a) shell as the type of another taxon, T. boulengeri (see above). Portis (1901) believed this taxon to be a cyclanorbine, and he further considered this to represent the northernmost occurrence of this group known to that date, but we cannot reproduce his rationale.

We here conclude that all of Reinach's (1900) specimens reveal the presence of well-developed plastral callosities and we therefore synonymize Triony $x$ gergensi with T. vindobonensis. The greater extent of the callosities in the material from Mainz is attributable to ontogenetic variation, as T. vindobonensis is typified by a relatively immature specimen (see $T$. vindobonensis above for more extensive discussion).

Meyer $(1860,1867)$ described and figured fossil eggs from the Miocene of Mainz that he attributed tentatively to Trionyx gergensi (his Aspidonectes gergensii), a conclusion subsequently adopted by Hummel (1929), but challenged by Gergens (1860), who instead considered these eggs to be of cheloniid origin. If the attribution to a trionychid is correct, this find would represent the only confirmed record of pan-trionychid eggs in the fossil record (Lawver and Jackson 2014).

\section{Trionyx harmati Szalai, 1934 nomen dubium}

Taxonomic history. Trionyx harmati Szalai, 1934 (new species).

Type material. A left humerus (holotype) (Szalai 1934, pl. 4.21); now considered lost (Farkas 1995).
Type locality. Budapest, Central Hungary, Hungary; Rupelian, early Oligocene (Szalai 1934).

Comments. Szalai (1934) named Trionyx harmati on the basis of a single humerus. Pan-trionychid humeri do not bear diagnostic features at the species level, and the type specimen of $T$. harmati can therefore at best be identified as an indeterminate pan-trionychine, a conclusion previously drawn by Mlynarski (1966) and Farkas (1995). Trionyx harmati is therefore herein considered to be a nomen dubium.

\section{Trionyx hilberi Hoernes, 1892 nomen dubium}

Taxonomic history. Trionyx hilberi Hoernes, 1892 (new species); T. hilberti Kuhn 1964 (incorrect spelling of species epithet); $T$. petersi $=$ T. hilberi Mottl 1967 (junior synonym); T. hilbari Myynarski 1976 (incorrect spelling of species epithet); T. triunguis $=$ T. hilberi $=24$ others Karl 1998 (junior synonym, see Rafetus bohemicus for complete synonym)

Type material. UMJGP 200692 (holotype), a complete carapace (Heritsch 1909, pl. 9.1; Gross 2002, pl. 10.3).

Type locality. Wies, Styria, Austria (Heritsch 1909); Eibiswald Formation, MN 5, early Langhian, middle Miocene (Aguilar et al. 1997).

Comments. Trionyx hilberi is based on a well-preserved, rounded carapace (CL of $26.8 \mathrm{~cm}$ ) from the middle Miocene of Austria (Hoernes 1892). We herein nevertheless find this taxon to be a nomen dubium because we disregard taxa from that time period that are based on carapacial material alone, as this part of the body is not sufficient to diagnose a valid taxon (see T. vindobonensis above for extensive discussion).

Trionyx hoernesi Heritsch, 1909

nomen invalidum, designation of lectotype

(junior synonym of $T$. vindobonensis Peters, 1855)

Taxonomic history. Trionyx hoernesi Heritsch, 1909 (new species); . triunguis $=$ T. hoernesi $=24$ others Karl 1998 (junior synonym, see Rafetus bohemicus for complete synonym).

Type material. UMJGP 200694 (lectotype), a partial left and right hyo-hypoplastron, and a partial skull and mandible (Heritsch 1909, fig. 2; Karl 1998, pl. 5; Gross 2002, pl. 11.1); UMJGP 200708 (paralectotype), bone fragments (Gross 2002, pl. 11.2); UMJGP 200709 (paralectotype), carapace fragments (Gross 2002, pl. 11.3); UMJGP 200703 (paralectotype), a partial carapace (Heritsch 1909, pl. 9.3; Gross 2002, pl. 11. 4); UMJGP 201158 (paralectotype), a carapace (Heritsch 1909, pl. 9.4; Gross 2005, fig. 1). Some of these specimens also serve as the types for Trionyx petersi (see below).

Type locality. Großradl (= Grossradl), Styria, Austria (Heritsch 1909); Eibiswald Formation, MN 5, early Langhian, middle Miocene (Aguilar et al. 1997). 
Comments. The Miocene locality of Großradl, Austria, yielded several pan-trionychid remains in the 19th century (Hoernes 1881; Heritsch 1909). On the basis of this material, Hoernes (1881) established the species Trionyx petersi, but Heritsch (1909) later described T. hoernesi on partially overlapping specimens from the same locality. As a result, part of the type material of T. hoernesi (UMJGP 200694, UMJGP 200709, and UMJGP 201158) also serves as the type material of T. petersi. To clarify this taxonomic puzzle, we designate the same specimen for both taxa as the lectotype, thereby rending both objective synonyms. The lectotype most notably includes partial right and left hyo-hypoplastra that clearly document the presence of welldeveloped plastral callosities. We therefore confidently synonymize both $T$. hoernesi and $T$. petersi with $T$. vindobonensis. The notable differences to the extent of the ossification of the plastra are once again attributable to ontogenetic variation, as the lectotypes of T. hoernesi and T. petersi represent a skeletally mature individual, in contrast to the type of $T$. vindobonensis (also see T. vindobonensis for extended discussion, including a discussion regarding variation in cranial morphology).

Trionyx hurum sivalensis Lydekker, 1889a nomen invalidum

(junior synonym of Nilssonia hurum [Gray, 1830])

Taxonomic history. Trionyx hurum sivalensis Lydekker, 1889a (new subspecies); Nilssonia hurum $=T$. hurum sivalensis Rhodin et al. 2015 (junior synonym).

Type material. IMC E163 (holotype), a plastron and carapace fragment (Lydekker 1885, pl. 27.3, 3a; Lydekker 1889a, no figure).

Type locality. Siwaliks, Punjab (Lydekker 1889a), Pakistan (see Emyda lineata); late Pliocene-early Pleistocene (Rhodin et al. 2015).

Comments. Lydekker (1885) initially described the type material of Trionyx hurum sivalensis as an unnamed, indeterminate species of Trionyx. Four years later, Lydekker (1889a) designated the same material as a new variety of Nilssonia (his Trionyx) hurum, which he characterized by a median and two lateral ridges on the carapace (Lydekker 1889a) while noting that the new taxon is almost identical to the extant form. We here fully agree with Rhodin et al. (2015) by considering T. hurum sivalensis to be a junior synonym of Nilssonia hurum. However, as was explicitly stated by Bell et al. (2010), synonymization of Pleistocene taxa with extant representatives should only be done cautiously, as cryptic diversity and conservative skeletal morphology is widespread among extant forms.

\section{Trionyx incrassatus Owen in Owen and Bell, 1849 nomen invalidum}

(junior synonym of "Trionyx" henrici Owen in Owen and Bell, 1849)

Taxonomic history. Trionyx incrassatus Owen in Owen and Bell, 1849 (new species); T. incrassus Peters 1855 (incorrect spelling); T. incrassatum Bergounioux 1933 (incorrect spelling of species epithet); Rafetoides henrici $=T$. incrassatus $=7$ others Karl 1998 (junior synonym, see "T." henrici for complete synonym).

Type material. BMNH R1433 (syntype), a carapace (Owen and Bell 1849, pl. 17; Owen 1849-1884, pl. 26); BMNH R30403 (syntype), anterior part of a carapace (Owen and Bell 1849, pl. 18; Owen 1849-1884, pl. 27); BMNH R30508 (syntype), elements of the plastron, vertebrae, and the appendicular skeleton (Owen and Bell 1849, pl. 19; Owen 1849-1884, pl. 28).

Type locality. Isle of Wight, United Kingdom (Owen and Bell 1849); upper Headon Hill Formation, late Eocene (Benton and Spencer 1995).

Comments. Trionyx incrassatus was initially distinguished from the type of "T." henrici by the presence of a more depressed carapace, differences in nuchal and costal shape, a coarser sculpturing pattern, and slight differences in the shapes of the dorsal vertebrae (Owen and Bell 1849; Lydekker 1889a), but these differences are now attributed to individual variation (Meylan 1987). Additional material from Hordle, Hampshire, assigned to T. incrassatus (Lydekker 1889a) is here referred to "T." henrici as well. The postcranial material attributed to $T$. incrassatus enhances our understanding of the appendicular skeletal anatomy of "T." henrici. For a discussion regarding pan-trionychid material from the late Eocene of England, see " $T$." henrici above.

Trionyx insolitus Bergounioux, 1954 nomen invalidum (junior synonym of “T.” capellinii Negri, 1892)

Taxonomic history. Trionyx insolitus Bergounioux 1953 (nomen nudum); T. insolitus Bergounioux, 1954 (new species); T. capellinii montevialensis $=T$. c. gracilina $=T$. c. perexpansa $=T$. c. schaurothianus $=$ T. insolitus $=[$ T. italicus $]$ Kotsakis 1977 (junior synonym); T. italicus $=T$. $c$. montevialensis $=T$. $c$. schaurothianus $=T$. c. gracilina $=T$. c. perexpansa $=$ T. insolitus Kotsakis 1985 (junior synonym).

Type material. MGP-PD 26560 (holotype), a complete carapace in dorsal view (Bergounioux 1954, fig. 27, pl. 13; Kotsakis 1977, fig. 31; Pandolfi et al. 2017, fig. 7c).

Type locality. Monteviale, Veneto, Italy (Bergounioux 1954); MP 21, early Rupelian, early Oligocene (Pandolfi et al. 2017).

Comments. Trionyx insolitus is based on a large specimen from the Oligocene of Monteviale, Italy, that Bergounioux (1954) claimed to have a preneural, a feature that would readily differentiate it from most other pan-trionychids from the Paleogene of Europe. Whereas Kotsakis (1977) interpreted this as an anomaly or pathology, we reject the presence of a preneural based on personal observations of the type specimen. For a discussion on pan-trionychid material from the early Oligocene locality of Monteviale, Italy, see "T." capellinii above. 


\author{
Trionyx intermedius Bergounioux, 1954 \\ nomen invalidum \\ (junior synonym of “T." capellinii Negri, 1892)
}

Taxonomic history. Trionyx intermedius Bergounioux 1953 (nomen nudum); T. intermedius Bergounioux, 1954 (new species); $T$. capellinii capellinii $=T$. c. affinis $=T$. c. conjugens $=$ T. gemmellaroi $=T$. intermedius Kotsakis 1985 (junior synonym).

Type material. MGP-PD 12814 (holotype), a complete carapace (Bergounioux 1954, fig. 13, pl. 4; Kotsakis 1977, fig. 3f; Giusberti et al. 2014, fig. 4d).

Type locality. Monte Bolca (= Purga di Bolca), Veneto, Italy (Bergounioux 1954); Prati Valeno Horizon, probably Lutetian, middle Eocene (Giusberti et al. 2014).

Comments. Bergounioux (1954) differentiated Trionyx intermedius from the sympatric "T." capellinii by carapace shape, shape and size of neurals, and carapacial sculpturing. Kotsakis (1977) thought that T. intermedius is probably distinct from "T." capellinii, as the former taxon lacks a posterior carapacial truncation, but Broin (1977) and Kotsakis (1985) attributed this difference to interspecific variation, an opinion soon after adopted by Kotsakis (1985) as well. For a discussion on pan-trionychid material from the middle Eocene locality of Monte Bolca, Italy, see "T." capellinii above.

\section{Trionyx irregularis Bergounioux, 1954 nomen dubium}

Taxonomic history. Trionyx irregularis Bergounioux 1953 (nomen nudum); T. irregularis Bergounioux, 1954 (new species).

Type material. MGP-PD 26561 (holotype), a fragmentary carapace (Bergounioux 1954, fig. 28, pl. 14).

Type locality. Ignago-Zovo ( = Ignago), Veneto, Italy (Bergounioux 1954; Chesi 2009); Oligocene (Kotsakis 1985).

Comments. Trionyx irregularis is based on a rather fragmentary carapace from Ignago-Zovo, Italy, not Spain, as erroneously reported by Karl (1999a), that was originally diagnosed by reference to its carapacial sculpturing pattern and, more notably, irregularly shaped neurals (Bergounioux 1954; Kotsakis 1985). However, based on our personal observations of the holotype, we regard an assignment beyond Pan-Trionychinae implausible because this specimen is too fragmentary to allow identification at the species level. Trionyx irregularis is therefore here considered to be a nomen dubium.

\section{Trionyx ishiharaensis Miura and Uyama, 1987 nomen dubium}

Taxonomic history. Trionyx ishiharaensis Miura and Uyama, 1987 (new species); T. ishiharensis Hasegawa et al. 2007 (incorrect spelling of species epithet).
Type material. HNSM (holotype), a partial carapace (Miura and Uyama 1987, pl. 5.a, b).

Type locality. Bihoku-sôgun Kimita-son, Hiroshima, Japan (Miura and Uyama 1987; Figure 3); Bihoku Group, late Burdigalian, early Miocene (Hirayama 2007).

Comments. Trionyx ishiharaensis is based on a notably large, nearly complete carapace (CL ca. $78 \mathrm{~cm}$ ) from the Miocene of Japan. Although the type specimen is unusually complete, the type description is extremely short and the associated figures and line drawing difficult to interpret. Indeed, based on the available evidence, we cannot estimate if the type specimen is attributable to any lineage of extant giant trionychids (e.g., the Amyda, Chitra, or Pelochelys lineages) or represents a separate, evolutionary lineage. Although more detailed reanalysis may confirm its validity, we here consider this taxon to be a nomen dubium.

Trionyx italicus Schauroth, 1865 nomen dubium

Taxonomic history. Trionyx italicus Schauroth, 1865 (new species); Trionix italicus De Gregorio 1892 (incorrect spelling of genus name); $T$. capellinii montevialensis $=T$. c. gracilina $=T$. $c$. perexpansa $=T$. c. schaurothianus $=T$. insolitus $=[$ T. italicus $]$ Kotsakis 1977 (nomen oblitum, junior synonym); T. italicus = T. capellinii gracilina $=T$. capellinii montevialensis $=$ T. capellinii perexpans $a=T$. capellinii schaurothianus $=T$. insolitus Kotsakis 1985 (senior synonym).

Type material. NMCL 3897 (holotype), an incomplete carapace (Schauroth 1865, pl. 29.1), now lost (E. Mönnig, pers. comm., 2016).

Type locality. Monteviale, Veneto, Italy (Schauroth 1865; Kotsakis 1977; Figure 5); MP 21, early Rupelian, early Oligocene (Pandolfi et al. 2017)

Comments. The Oligocene locality of Monteviale, Italy has yielded several pan-trionychid specimens that serve as the basis for six named taxa. Given that all material seems to represent a single species, Kotsakis (1977) concluded that Trionyx italicus should serve as the senior synonym, as it was named first, but he also concluded that the name had been in disuse for an extended amount of time and that it actually represents a nomen oblitum. A few years later, however, Kotsakis (1985) changed his opinion and resurrected T. italicus as the senior synonym of all taxa named from Monteviale. Kotsakis's (1977) initial conclusion that T. italicus is a nomen oblitum does not fulfill the requirements of the ICZN (1999), as the name T. italicus was used as a valid nomen multiple times over the course of the 20th century (e.g., Heritsch 1909; Teppner 1913; Hummel 1929, 1932; Kuhn 1964). However, we nevertheless agree with the conclusion that $T$. italicus is not an appropriate senior synonym for material from Monteviale, as the holotype only consists of undiagnostic shell fragments and now seems to be lost (E. Mönnig, pers. comm., 2016). We therefore consider this name to be a nomen dubium. 
Trionyx jakhimovitchae Chkhikvadze, 1989 nomen dubium

Taxonomic history. Trionyx jakhimovitchae Chkhikvadze, 1989 (new species); Pelodiscus jakhimovitchae Kordikova 1994a (new combination).

Type material. IPGAS 7-63-21 (holotype), left costal I (Chkhikvadze 1989, fig. 7); IPGAS 7-63-22 (paratype), fragment of left hypoplastron (Chkhikvadze 1989, not figured); IPGAS 7-64-I (paratypes), fragment of a hypoplastron (Chkhikvadze 1989, not figured); IPGAS (paratypes), costal fragments, a frontal and an ungual phalanx (Chkhikvadze 1989, not figured)

Type locality. Sarybulak, East Kazakhstan Region, Kazakhstan (Chkhikvadze 1989, 2010); Sarybulak suite, middle Miocene (Chkhikvadze 2010).

Comments. The holotype of Trionyx jakhimovitchae is a fragmentary costal that cannot be identified beyond Pan-Trionychidae indet. The paratypes listed in the type description (Chkhikvadze 1989) were never figured, and referral can therefore not be reproduced. Trionyx jakhimovitchae is here considered a nomen dubium. Kordikova (1994b) referred additional material to this species from four additional localities across the Zaysan Basin, East Kazakhstan Region, but this referred material was neither described nor figured. As the identification of pan-trionychid remains is straightforward, we here refer these fragments to Pan-Trionychidae indet. For a more extensive discussion, see "T." ninae above.

\section{Trionyx kazusensis Otsuka, 1969 nomen dubium}

Taxonomic history. Trionyx kazusensis Otsuka, 1969 (new species).

Type material. KUL GK.M.1180-1183 (holotype), fragments of a carapace (Otsuka 1969).

Type locality. Shimabara Peninsula, Nagasaki, Japan; Kuchinotsu Group, Oya Formation, early Pleistocene (Otsuka 1969, 1970).

Comments. Trionyx kazusensis is a small trionychid taxon (CL ca. $24 \mathrm{~cm}$ ) that was established on the basis of fragmentary shell material, a scapula, and an incomplete ilium from the Pleistocene of Japan. Otsuka $(1969,1970)$ distinguished it from the extant Pelodiscus sinensis by its larger size and thicker shell with deep and wide pits and variations to the shape of neural I and the quadrate. However, as stated in Hirayama (2007), the material bears no diagnostic features and should therefore be regarded as an indeterminate pan-trionychid. We concur with this view here and consider T. kazusensis to be a nomen dubium.

\section{Trionyx khosatzkyi Chkhikvadze, 1983 nomen dubium}

Taxonomic history. Trionyx khosatzkyi Chkhikvadze, 1983 (new species); Rafetus khosatzkyi Chkhikvadze 2007 (new combination).
Type material. IPGAS 3-101-3 (holotype), a cervical vertebra VI (Chkhikvadze 1983, fig. 17; Chkhikvadze and Lungu 1984, fig. 6).

Type locality. Maykop, Adygea Republic, Russia (Chkhikvadze 1983); Serravallian, middle Miocene (Kordikova 1994b).

Comments. Trionyx khosatzkyi was established on the basis of a cervical vertebra (Chkhikvadze 1983). Two scapulae, a distal fragment of a costal, and a medial fragment of a hypoplastron from the same locality were also referred to this taxon, but these were never figured (Chkhikvadze 1983). On the basis of this material, this taxon was diagnosed by its large size (estimated CL of around $60-70 \mathrm{~cm}$ ) and a sculpturing pattern described as finely rippled ridges (Chkhikvadze 1983). However, the cervical vertebrae of pan-trionychids are not diagnostic at the species level, and the taxonomic status of the referred material cannot be verified, as it was never figured or described. We therefore consider this material to represent an indeterminate pan-trionychid and T. khosatzkyi a nomen dubium.

Shebzukhova and Tarasenko (2007) more recently referred isolated carapace fragments from the type locality of Trionyx khosatzkyi to that species, but these are here also classified as indeterminate pan-trionychids.

\section{Trionyx laurillardii Gray, 1831 nomen dubium}

Taxonomic history. Trionyx laurillardii Gray, 1831 (new species); [T. laurillardi] Hummel 1929 (nomen dubium and incorrect spelling of species epithet).

Type material. MNHN (holotype), a nuchal (Cuvier 1821-1824, pl. 15.3; Broin 1977).

Type locality. Ambarès-et-Lagrave (= La Grave), Gironde, France (Cuvier 1821-1824); Priabonian, late Eocene (Broin 1977).

Comments. Cuvier (1821-1824) figured and briefly described pan-trionychid fragments from the region surrounding Bordeaux, to which Gray (1831) soon after applied the name Trionyx laurillardii. As Gray (1831) provided an indication to a previous description, his action complies with the rules of ICZN (1999) for the availability of a new name established prior to 1931 . The validity of T. laurillardii was nevertheless challenged by Hummel $(1929,1932)$ and Broin $(1977)$ as the holotype, a nuchal, bears no diagnostic characters. We agree with this opinion and therefore consider T. laurillardii to be a nomen dubium.

\section{Trionyx levalensis Dollo 1909 nomen nudum}

Material. IRSNB 1720, a partial carapace and plastron with associated skull fragments (Broin 1977).

Locality. Trieu de Leval, Hainaut, Belgium (Dollo 1909; Moody and Walker 1970); Tienen Formation, MP 7, early Ypresian, early Eocene (Delfino and Smith 2009). 
Comments. Dollo (1909) reported on the presence of some of the oldest known pan-trionychid material from Europe under the name Trionyx levalensis, but he did not provide a description, definition, or indication, and this name must therefore be considered a nomen nudum, as already noted by Moody and Walker (1970) and Broin (1977). The specimen to which Dollo (1909) was referring has since been identified as consisting of a shell, postcranial elements, and skull fragments (Moody and Walker 1970) as it is labeled under this name in the collections of the IRSNB. We agree with these authors that $T$. levalensis must be considered a nomen nudum but conclude that the relevant specimens are referable to Axestemys vittata (see above).

\section{Trionyx liupani Tao, 1986 \\ nomen invalidum}

(junior synonym of Rafetus swinhoei [Gray, 1873])

Taxonomic history. Trionyx liupani Tao, 1986 (new species); Rafetus swinhoei $=$ Pelochelys taihuensis $=$ T. liupani Farkas 1992 (junior synonym).

Type material. Private collection in Tainan, Taiwan (syntype), a nearly complete cranium (Tao 1986, text figs. 1, 3, 5, 7 and figs. $2,4,6,9)$; private collection in Chia-Yi, Taiwan (syntype), a hyohypoplastron (Tao 1986, text fig. 9 and figs. 8, 10-12).

Type locality. Penghu (Pescadores) Channel, Taiwan (Tao 1986); Late Pleistocene (Farkas 1992).

Comments. Trionyx liupani is based on a skull and a hyohypoplastron found by fishers in the Penghu Channel, off the coast of Taiwan, at a depth of more than $150 \mathrm{~m}$. The type material is housed in two different private collections, but plaster models are kept in the Museum of Zoology in the National Taiwan University under the repository numbers NTUM 002 and NTUM 003, respectively. In the type description, this species was only compared to Pelodiscus sinensis, but nevertheless assigned to Trionyx (Tao 1986). Farkas (1992) soon after noted great similarities with Rafetus swinhoei and therefore considered T. liupani to be its junior synonym. This synonymy has since been accepted by Le and Pritchard (2009) and Rhodin et al. (2015), and we concur with this assessment herein as well.

\section{Trionyx lockardi Gray 1831 nomen nudum}

Material. MNHN 8369, a plastron fragment (Gray 1831, not figured; Broin 1977).

Type locality. Avaray, Loire, France (Gray 1831; Fitzinger 1836); Burdigalian, early Miocene (Broin 1977).

Comments. Cuvier (1821-1824) mentioned the presence of pan-trionychid remains from the Miocene of Avaray, France, but he did not provide a description of this material or the definition of a new taxon. Gray (1831) soon after provided the name Trionyx lockardi for this material, but he did not provide a description or definition as well. The name T. lockardi there- fore does not fulfill the minimum requirements of ICZN (1999), and the name is not available (see T. dodunii), much as Gervais (1859), Hummel (1929, 1932), and Broin (1977) noted before.

\section{Trionyx lorioli Portis, 1882 nomen dubium}

Taxonomic history. Trionyx lorioli Portis, 1882 (new species).

Type material. MGL 8889 (syntype), posterior part of a carapace (Portis 1882, pl. 6.2); MGL 8907 (syntype), anterior part of a carapace (Portis 1882, pl. 21); MGL 8902 (syntype), posterior part of a carapace, along with parts of the hyo-hypoplastron (Portis 1882, pls. 22, 23).

Type locality. La Rocchette (= Rochette) Locality, Belmont, Vaud, Switzerland (Portis 1882); MP 29, Chattian, late Oligocene (Berger 1998)

Comments. Trionyx lorioli is based on several fragmentary specimens from the late Oligocene of La Rocchette, Switzerland, one of which had already been described and figured by Pictet and Hubert (1856) as an indeterminate species of Trionyx. We herein consider this taxon to be a nomen dubium, as the type material is not sufficient to diagnose a valid species (see T. valdensis for more extensive discussions).

Souza Torres (1947) attributed a carapace fragment from the late Miocene of Portugal to Trionyx lorioli on the basis of sculpturing pattern, but we here consider this fossil to be an indeterminate pan-trionychine.

\section{Trionyx manouri Gray, 1831 nomen dubium}

Taxonomic history. Trionyx maunoir Cuvier 1821-1824 (nomen nudum); T. manouri Gray, 1831 (new species); T. maunoiri Fitzinger 1836 (incorrect spelling of species epithet); T. maunori Ezquerra del Bayo 1850 (incorrect spelling of species epithet); $T$. monoiri Reinach 1900 (incorrect spelling of species epithet); $T$. monoiiri Heritsch 1909 (incorrect spelling of species epithet)

Type material. A partial carapace and fragments of a plastron (Cuvier 1821-1824, pl. 15.1, 2; Cuvier 1835-1836, pl. 243.1, 2), now lost (Broin 1977).

Type locality. Aix-en-Provence, Bouches-du-Rhône, France (Gray 1831); Rupelian or early Aquitanian, early Oligocene or early Miocene (Broin 1977).

Comments. This taxon was first described under the name Trionyx maunoir by Cuvier (1821-1824), who attributed the name to an unpublished abstract by Boulet, but as he was uncertain if the material represents a valid taxon, he did not make that name available for nomenclatural purposes. Gray (1831) soon after used a slightly different spelling of that name, T. manouri, as valid and referred to the work of Cuvier (1821-1824) and thereby made that name available (ICZN 1999). For this reason, we herein attribute authorship of T. manouri to Gray (1831) and not to Boulet, as has been previously suggested (Hummel 1932; Kuhn 1964). The available material is highly fragmentary and 
now lost. We therefore consider T. manouri to be a nomen dubium (also see T. vindobonensis above).

Ezquerra del Bayo (1850) referred material from Spain to this taxon, but this attribution seems questionable (Hummel 1929). This Spanish specimen is unfortunately lost, and no further comparisons can be made (Jiménez Fuentes and Alonso Andres 1994). We therefore do not list this material in our geographic summary.

\section{Trionyx marginatus Owen in Owen and Bell, 1849 nomen invalidum}

(junior synonym of “ $T$." henrici Owen in Owen and Bell, 1849)

Taxonomic history. Trionyx marginatus Owen in Owen and Bell, 1849 (new species); T. henrici $=T$. marginatus Lydekker 1889a (junior synonym); T. marginatus Kuhn 1964 (nomen validum); Rafetoides henrici $=T$. marginatus $=7$ others Karl 1998 (junior synonym, see “T.” henrici for complete synonym).

Type material. BMNH R30406 (holotype), a complete carapace (Owen and Bell 1849, pl. 19; Owen 1849-1884, pl. 30).

Type locality. Hordle (= Hordwell) Cliff, Hampshire, United Kingdom (Owen and Bell 1849); Totland Bay Member, Headon Hill Formation, Priabonian, late Eocene (Benton and Spencer 1995).

Comments. Trionyx marginatus was established on the basis of a rather complete carapace that was solely differentiated from the other late Eocene English taxa by sculpturing pattern (Owen and Bell 1849). For a discussion regarding pan-trionychid material from the late Eocene of England, see "T." henrici above. Zigno (1889) attributed a fossil from the Eocene of Monte Zuello, Veneto, Italy, to T. cf. marginatus, but Kotsakis (1977) believed this to be closer to "T." capellinii. We find this specimen to be rather fragmentary for identification and consider it to be an indeterminate pan-trionychid.

\section{Trionyx marini Hernández Sampelayo and Bataller, 1944 nomen dubium}

Taxonomic history. Trionyx marini Hernández Sampelayo and Bataller, 1944 (new species); T. marini Jiménez Fuentes and Martín de Jesús 1991 (lectotype designation).

Type material. MG-IGME 1560N (not MG-IGME 1.101N as stated by Jiménez Fuentes and Alonso Andres [1991]) (lectotype), a nearly complete carapace (Hernández Sampelayo and Bataller 1944, figs. 1, 2; Bergounioux 1958, pl. 25.4); MMB (paralectotype), a partial epiplastron (Jiménez Fuentes and Martín de Jesús 1991).

Type locality. Lignite mines of Almatret, Lerida, Catalonia, Spain (Hernández Sampelayo and Bataller 1944; Jiménez Fuentes and Alonso Andres 1994); Rupelian, early Oligocene (Jiménez Fuentes and Martín de Jesús 1991).
Comments. Trionyx marini is based on a partial epiplastron and a small (CL of $18 \mathrm{~cm}$ ), nearly complete shell from the early Oligocene of Spain (Hernández Sampelayo and Bataller 1944), of which the latter was later designated as the lectotype (Jiménez Fuentes and Martín de Jesús 1991). Bergounioux (1958) stated that the lectotype originated from Zaragoza, Aragon, but this seems to be an error (Jiménez Fuentes and Alonso Andres 1994). Jiménez Fuentes and Martín de Jesús (1991) concluded that little could be said about the affinities of this species and that its validity was based mostly on the age and provenience of the specimen. Our firsthand observation of the material reveals that although the holotype is beautifully preserved, rib ends are mostly lacking, and the posterior carapacial margin is damaged. We therefore conclude that this taxon is a nomen dubium.

\section{Trionyx messelianus kochi Hummel, 1927 nomen invalidum \\ (junior synonym of “ $T$.” messelianus Reinach, 1900)}

Taxonomic history. Trionyx messelianus kochi Hummel, 1927 (new subspecies); Amyda messeliana kochi Karl 1993 (new combination, emended spelling of species epithet); Rafetoides austriacus $=$ T. messelianus $=$ T. messelianus koch $i=$ T. messelianus lepsiusi Karl 1998 (junior synonym).

Type material. HLMD Me4194a,b (holotype), the anterior portions of a skeleton (Hummel 1927, pl. 10)

Type locality. Messel pit fossil site, Hesse, Germany (Reinach 1900); MP 11, early Lutetian, middle Eocene (Joyce et al. 2012).

Comments. Hummel (1927) described Trionyx messelianus kochi on the basis of two specimens from Messel pit, which were supposed to represent a distinct variety relative to the nominal form "T." messelianus from the same locality. We find that varieties based on material from the same locality have no relationship to modern species concepts and therefore disregard $T$. messelianus kochi from consideration completely.

\section{Trionyx messelianus lepsiusi Hummel, 1927 nomen invalidum (junior synonym of “T." messelianus} Reinach, 1900)

Taxonomic history. Trionyx lepsii Harrassowitz 1919 (nomen nudum); T. lepsiusii Harrassowitz 1922 (nomen nudum); T. messelianus lepsiusi Hummel, 1927 (new subspecies); Rafetoides austriacus $=T$. messelianus $=T$. messelianus $k o c h i=T$. messelianus lepsiusi Karl 1998 (junior synonym).

Type material. HLMD Me1460 (holotype), a well-preserved carapace and plastron (Hummel 1927, pl. 3).

Type locality. Messel pit fossil site, Hesse, Germany (Harrassowitz 1919; Hummel 1927); MP 11, early Lutetian, middle Eocene (Joyce et al. 2012).

Comments. Harrassowitz $(1919,1922)$ introduced the names Trionyx lepsii and T. lepsiusii, but he did not provide a 
description, definition, or indication and therefore did not make either spelling available for nomenclatural considerations. The taxon was therefore only formally established by Hummel (1927), who provided a detailed description and figured several specimens. Trionyx messelianus lepsiusi was principally differentiated by its sculpturing pattern, nuchal morphology, shape of costals I, and reversal of the neural series orientation at neural VI, but we do not find this to be relevant, as we do not see any value in recognizing subspecies within material from the same locality. We therefore disregard this taxon completely.

Trionyx michauxi Broin, 1977 nomen invalidum

(junior synonym of “T." silvestris Walker and Moody, 1974)

Taxonomic history. Trionyx michauxi Broin, 1977 (new species); T. michausi Broin 1977 (incorrect spelling).

Type material. LG-FSM 3488 (MCY 1) (holotype), a skull (Michaux 1973, fig. 1; Broin 1977, fig. 72, pl. 11.1-3).

Type locality. Mancy, Marne, France; Sables à Unios et Térédines, MP 9, late Ypresian, early Eocene (Broin 1977).

Comments. Trionyx michauxi is based on a skull and nonassociated shell fragments that were initially believed to have strong affinities with T. bruxelliensis (Michaux 1973). Broin (1977) erected T. michauxi on the basis of that skull, described its anatomy, and suggested affinities with the coeval, English form "T." silvestris. Despite apparent similarities, Broin (1977) differentiated both forms on the basis of skull thickness, snout, orbit, and palatine shape. Several studies have since shown that fossil and extant trionychids can show considerable ontogenetic, geographic, or sexual variation comparable to that observed between "T." silvestris and T. michauxi (Dalrymple 1977; Joyce et al. 2016). We therefore synonymize these coeval taxa with confidence (see "T." silvestris above). Broin (1977) listed several shell elements (costal and plastral fragments and a xiphiplastron) from coeval sediments as "presumed paratypes." As this does not seem to represent the formal designation of paratype material, we do not list these specimens herein.

Jiménez Fuentes and Alonso Andres (1994) referred two hypoplastra of presumably immature specimens from the middle Eocene (Lutetian) of Castile and León, Spain, to Trionyx cf. michauxi, based on supposed similarities to the sinuous morphology of the anterior margin of the hypoplastra, a referral we cannot reproduce, as Broin (1977) did not describe the plastral material for her French taxon. Kotsakis (1985) similarly discussed similarities with material from the middle Eocene of Sardinia. In both cases, we find the available material to be too fragmentary to allow identification beyond Pan-Trionychidae indet.

\section{Trionyx moldaviensis Khosatzky, 1986 nomen dubium}

Taxonomic history. Trionyx moldaviensis Khosatzky, 1986 (new species).

Type material. NMENHM 3491 (holotype), a complete carapace (Chkhikvadze 1983, fig. 19; Chkhikvadze and Lungu 1984, fig. 5; Khosatzky 1986, pls. 1.1, 2.1-4; Khosatsky and Redkozubov 1989, figs. 7, 8).

Type locality. Mileştii Mici (= Malye Mileshty), Ialoveni, Moldova (Khosatzky 1986); Serravallian, middle Miocene (Vremir et al 1997).

Comments. The type specimen of Trionyx moldaviensis is a relatively complete, large carapace from the middle Miocene of Moldova. The type was initially referred to T. brunhuberi by Chkhikvadze (1983) but was later described as a new species by Khosatzky (1986). According to the rationale we outline herein, we here consider this taxon to be a nomen dubium, as a carapace by itself is not diagnostic (see T. vindobonensis above for more extensive discussion).

Trionyx mourieri Bergounioux, 1935 nomen dubium

Taxonomic history. Trionyx mourieri Bergounioux, 1935 (new species).

Type material. MHNT PAL2011.0.82 (holotype), the imprint of a shell (Bergounioux 1935, fig. 29, pl. 12.1).

Type locality. Armissan, Aude, France (Bergounioux 1935); Chattian or Aquitanian, late Oligocene or early Miocene (Hervet 2004).

Comments. Trionyx mourieri is based on several shell imprints from Armissan, Aude, France, of which one serves as the holotype (Bergounioux 1935). Bergounioux (1935) suggested that the neural column of the type specimen continues to the posterior margin of the carapace, but we cannot reproduce this conclusion based on high resolution photographs we obtained. For additional discussion regarding trionychid material from Armissan, France, see T. acutiformis and T. vindobonensis above.

\section{Trionyx münzenbergensis Hummel 1927 nomen nudum}

Material. SMF R260 (holotype), a carapace (Hummel 1927, pl. 11.39).

Locality. Münzenberg, Hesse, Germany (Hummel 1927); Aquitanian, early Miocene (Hummel 1927).

Comments. Hummel (1927) provided Trionyx münzenbergensis as a provisional name for a nearly complete carapace from the Miocene of Germany, but as he did not intend the name to be valid, it cannot be considered for nomenclatural purposes (Karl 1993). We therefore disregard this name as a nomen nudum. The name conversely does not need to be Latinized through the removal of the German umlaut, as required by the ICZN (1999) for available names.

Trionyx nopcsai Szalai, 1934 nomen dubium, designation of lectotype

Taxonomic history. Trionyx nopcsai Szalai, 1934 (new species); Chelydropsis nopcsai Chkhikvadze 1989 (new combination). 
Type material. MFGI Ob.3980 (lectotype), a dentary (Szalai 1934, pl. 4.22; Myynarski 1966, fig. 15; Farkas 1995, fig. 1); MFGI 3136 (paralectotype), a carapace fragment (not figured), now considered lost (Farkas 1995).

Type locality. Brusturi (= Tataros), Bihor, Romania (Szalai 1934); Serravallian-Tortonian, middle-late Miocene (Farkas 1995).

Comments. Trionyx nopcsai is based on a carapace fragment and a partial lower jaw from the Miocene of Romania (Szalai 1934). MYynarski (1966) challenged the taxonomic status of the lower jaw, which he tentatively identified as belonging to a chelydrid. This view was later adopted by Farkas (1995), Karl (1999a), and Rhodin et al. (2015), and T. nopcsai was considered to be a chimera of chelydrid and trionychid fossils. More recently, Joyce (2016) reaffirmed the original identification of the mandible as being pan-trionychid in nature, as members of this group usually have delicate, slopping mandibles, quite in contrast to the more vertically oriented mandibles of chelydrids. Our firsthand observation of this material at MFGI confirms that the dentary indeed belongs to a pan-trionychid. Given that the carapace fragment now seems to be lost (Farkas 1995), we herein designate the dentary as the lectotype of the species. However, given that it is unclear to us if it is possible to firmly identify a pan-trionychid using the dentary alone, we consider T. nopcsai to be a nomen dubium (also see T. vindobonensis above).

\section{Trionyx oligocenica Negri 1892 nomen nudum}

Material. MGPT-PU, carapacial and plastral fragments (Portis 1885 , not figured).

Locality. Agnana Calabria, Calabria, Italy (Portis 1885); Chattian, late Oligocene (Kotsakis 1985).

Comments. This name is not available, as Portis (1885:889) only used the phrase "Trionyx oligocenica di Agnana" as a heading to accompany the description of trionychid specimens from the Oligocene of Agnana, Italy, but did not include any indication that he intended to create a new scientific name. The name $T$. oligocenica appeared in the taxonomic lists of Negri (1892), Hummel (1929), Bergounioux (1934b), and Kuhn (1964), who universally considered it to be an available name, but Esu and Kotsakis (1983) and Kotsakis (1985) later clarified that the name is not available in the first place. We here concur with this assessment and consider T. oligocenica to be a nomen nudum, especially considering that neither Negri (1892) nor Hummel (1929), Bergounioux (1934b), or Kuhn (1964) made the name available according to the rules of the ICZN (1999). Given that the relevant specimen remains poorly described, we consider it only to document an indeterminate pan-trionychid in the late Oligocene of Calabria.

\section{Trionyx oweni Reinach, 1900 nomen dubium}

Taxonomic history. Trionyx oweni Reinach, 1900 (new species); [T. oweni] Hummel 1929 (nomen dubium); T. triunguis $=$
[T. oweni $]=24$ others Karl 1998 (junior synonym, see Rafetus bohemicus for complete synonym).

Type material. PUM (holotype), fragments of a carapace and plastron (Reinach 1900, not figured).

Type locality. Eppelsheim, Rhineland-Palatinate, Germany (Kaup 1834; Karl 1999a); Messinian, late Miocene (Karl 1999a).

Comments. The name Trionyx oweni first appeared in Reinach (1900), who described a pan-trionychid from Eppelsheim and attributed authorship to Kaup (1834). However, even though Kaup (1834) indeed reported trionychid material from this locality, he never used this name. As was suggested by Hummel (1929, 1932), it seems that Reinach (1900) falsely attributed authorship to Kaup on the basis of a specimen from the University of Marburg that bears the label with this species name. We nevertheless refer authorship to Reinach (1900) according to the rules of the ICZN (1999). Given the fragmentary nature of the type material, we consider this taxon to be a nomen dubium (also see T. vindobonensis above).

\section{Trionyx parisiensis Gray, 1831 nomen dubium}

Taxonomic history. Trionyx parisiensis Gray, 1831(new species); [T. parisiensis] Hummel 1929 (nomen dubium).

Type material. MNHN (holotype), a costal (Cuvier 1821-1824, pl. 76.12, 77; Gray 1831, not figured; Cuvier 1835-1836, pl. 157).

Type locality. Montmarte, Paris, France (Cuvier 1821-1824; Gray 1831); MP 19, Priabonian, late Eocene (Broin 1977).

Comments. Fossil pan-trionychids from the Paris Basin were already described and figured at the beginning of the 19th century (Cuvier 1812), and these are, in fact, the earliest descriptions and figures of fossil pan-trionychids in the chelonian literature. Trionyx parisiensis is based on a single costal that was described and discussed by Cuvier (1821-1824). This taxon, however, was only formally named a few years later by Gray (1831), who provided an indication to the previous description of Cuvier (1821-1824). We therefore attribute authorship to Gray (1831), contrary to Lydekker (1889a), Reinach (1900), Hummel (1929), Kuhn (1964), and Broin (1977), who attributed authorship to Meyer (1832). We nevertheless here concur with Hummel $(1929,1932)$ and Broin $(1977)$ by regarding $T$. parisiensis as a nomen dubium, as we do not find a single costal fragment to be sufficient to diagnose a valid taxon.

\section{Trionyx partschii Peters, 1855 nomen dubium}

Taxonomic history. Trionyx partschii Fitzinger 1836 (nomen nudum); T. partschii Peters, 1855 (new species); T. partschi Laube 1896 (incorrect spelling of species epithet); [T. partschii] Hummel 1929 (nomen dubium); T. vindobonensis $=$ T. partschi (sic) Glaessner 1933 (incorrect spelling of species epithet and junior synonym); T. triunguis $=[$ T. partschii $]=24$ others Karl 
1998 (junior synonym, see Rafetus bohemicus for complete synonym).

Type material. Two costal fragments (syntypes) with uncertain whereabouts (Peters 1855, pl. 4.4, 5).

Type locality. Loretto (= Loreto), Burgenland, Austria (Peters 1855); Tortonian, late Miocene (Karl 1999a).

Comments. Trionyx partschii was first mentioned by Fitzinger (1836), but this action was not accompanied by a description, definition, or indication and therefore does not fulfill the standards of ICZN (1999) for availability of taxonomic names. The species was only later described and figured by Peters (1855), and we consequently attribute authorship to him. Given the fragmentary nature of the type material, we here consider this taxon to be a nomen dubium (also see T. vindobonensis above).

\section{Trionyx pedemontana Portis, 1879 nomen dubium}

Taxonomic history. Tryonix pedemontana Portis, 1879 (new species and incorrect genus spelling); Trionyx pedemontana Portis 1883 (emended genus spelling); T. pedemontanus Teppner 1913 (emended spelling of species epithet); T. pedemontensis Teppner 1914c (incorrect spelling of species epithet).

Type material. An almost complete carapace, with remains of the left hyo-hypoplastron (holotype) (Portis 1879, pl. 4), unknown whereabouts.

Type locality. Ceva, Mondovi, Piedmont, Italy (Portis 1879); Chattian or Aquitanian, late Oligocene or early Miocene (Kotsakis 1985).

Comments. Trionyx pedemontana was established on the basis of a well-preserved carapace and associated plastral elements from Ceva, Italy, that Portis (1879) originally reported to be early Miocene, but Rieppel (1979) thought to be late Oligocene based on anthracotheriids found nearby. Portis (1879) referred to his new species a complete carapace from the Pliocene of nearby San Stefano Roero, which had previously been described and figured by Sismonda $(1836,1839)$ as a turtle similar to the extant T. triunguis (his T. aegyptiacus), and which subsequently became the holotype of T. pliopedemontana (Sacco 1889) (see also T. pliopedemontana below). Trionyx pedemontana was originally differentiated by the shape and size of neural I (Portis 1879), but this character has only limited diagnostic value. Moreover, as it was already noted by Portis (1879), the type specimen pertained to a young individual. Given that the whereabouts of the type are furthermore unknown, we here conclude that this taxon should be viewed as a nomen dubium.

Trionyx peneckei Heritsch, 1909 nomen invalidum

(junior synonym of T. vindobonensis Peters, 1855)

Taxonomic history. Trionyx peneckei Heritsch, 1909 (new species); [T. peneckei] Hummel 1929 (nomen dubium);
T. triunguis $=$ T. peneckei $=24$ others Karl 1998 (junior synonym, see Rafetus bohemicus for complete synonym).

Type material. UMJGP 200693 (holotype), a partial carapace and hypoplastron (Heritsch 1909, pl. 10.1-2; Gross 2002, pl. 12.1)

Type locality. Pölfing-Brunn, Styria, Austria (Heritsch 1909; Gross 2002); Eibiswald Formation, MN 5, early Langhian, middle Miocene (Aguilar et al. 1997).

Comments. Trionyx peneckei is based on a disarticulated, partial shell that fully corresponds in its morphology with $T$. vindobonensis, as it also represents a less skeletally mature individual. We therefore find the synonymy of these two taxa from equally dated sediments in Austria unproblematic (for a more extensive discussion, see T. vindobonensis).

Trionyx petersi Hoernes, 1881 nomen invalidum, lectotype designation (junior synonym of T. vindobonensis Peters, 1855)

Taxonomic history. Trionyx petersi Hoernes, 1881 (new species) T. petersi $=$ T. hilberi Mottl 1967 (senior synonym); T. triunguis $=T$. petersi $=24$ others Karl 1998 (junior synonym, see Rafetus bohemicus for complete synonym).

Type material. UMJGP 200694 (lectotype), partial hyohypoplastra and partial skull (Gross 2002, pl. 11.1); UMJGP 200708 (paralectotype), bone fragments (Gross 2002, pl. 11.2); UMJGP 200709 (paralectotype), carapace fragments (Gross 2002, pl. 11.3); UMJGP 201158 (paralectotype), a carapace (Heritsch 1909, pl. 9.4; Gross 2005, fig. 1).

Type locality. Feisternitz, Großradl, Styria, Austria (Hoernes 1881; Gross 2002); Eibiswald Formation, early Langhian (MN 5), middle Miocene (Aguilar et al. 1997)

Comments. For a discussion on material from Großradl, Austria, see Trionyx hoernesi and T. vindobonensis (above). A juvenile shell from the middle Miocene of Pölfing-Brunn (= Schönegg bei Wies), Styria, Austria, that was attributed by Heritsch (1910) to T. petersi is herein considered to pertain to an indeterminate pan-trionychid. The same is true for the partia carapace described as T. petersi, also from the middle Miocene of Carinthia, by Wank (1977)

\section{Trionyx petersi trifailensis Teppner, 1914c nomen dubium}

Taxonomic history. Trionyx petersi trifailensis Teppner, 1914c (new subspecies); T. triunguis $=$ T. petersi trifailensis $=24$ others Karl 1998 (junior synonym, see Rafetus bohemicus for complete synonym).

Type material. GIML (holotype), a carapace (Teppner 1914c).

Type locality. Trbovlje (= Trifail), Slovenia; Langhian, middle Miocene (Teppner 1914c). 
Comments. Trionyx petersi trifailensis was established on the basis of a carapace from the middle Miocene of Trbovlje, Slovenia (Teppner 1914c), but the type material was never figured. We therefore here consider this taxon to be a nomen dubium.

\section{Trionyx planus Owen in Owen and Bell, 1849 nomen invalidum \\ (junior synonym of “ $T$." henrici Owen in Owen and Bell, 1849)}

Taxonomic history. Trionyx planus Owen in Owen and Bell, 1849 (new species); T. plana Hummel 1927 (incorrect spelling of species epithet); Rafetoides henrici $=$ T. planus $=7$ others Kar 1998 (junior synonym, see “T.” henrici for complete synonym).

Type material. BMNH R30410x (holotype), posterior half of a carapace (Owen and Bell 1849, pl. 19c; Owen 1849-1884, pl. 32).

Type locality. Hordle (= Hordwell) Cliff, Hampshire, United Kingdom (Owen and Bell 1849); Totland Bay Member, Headon Hill Formation, Priabonian, late Eocene (Benton and Spencer 1995).

Comments. Trionyx planus Owen in Owen and Bell, 1849 should not be confused with its junior homonym Aspideretes planus Parks, 1933 (recombined as T. planus by Russell [1934]) from the Late Cretaceous of Canada, which is a junior synonym of Axestemys splendidus (Hay, 1908) according to Gardner et al. (1995).

Trionyx planus is known from the posterior half of a carapace from the late Eocene of Hordle, United Kingdom (Owen and Bell 1849). Lydekker (1889a) diagnosed this taxon by its rather coarse sculpturing, the narrowness of neurals V and VI, and the presence of expanded costals VIII, but we find that these characters fall within the expected range of variability displayed by other material found at Hordle. As such, we herein treat $T$. planus as a junior synonym of "T." henrici. Owen (in Owen and Bell 1849), Lydekker (1889a), and Boulenger (1891) referred a plastral fragment, a mandible, and a cranium, respectively, from the type locality to T. planus as well, using size concerns or similarities in shell sculpturing, but we here assign all of these to " $T$." henrici as well, mostly based on a geographic rationale (see " $T$." henrici above for more extensive discussion)

\section{Trionyx pliocaenicus Reinach, 1903 nomen dubium}

Taxonomic history. Trionyx pliocaenicus Reinach, 1903 (new species); [T. pliocaenicus] Dacqué 1912 (nomen dubium).

Type material. SMF R 4144 (holotype), carapacial and plastral fragments (Reinach 1903, pl. 17.1, 3, 4, 7).

Type locality. Wadi El Natrun, Beheira, Egypt; Pliocene (Reinach 1903).

Comments. Trionyx pliocaenicus Reinach, 1903, should not be confused with T. pliocenicus Fucini, 1912. Reinach (1903) mostly differentiated his new taxon, which is based on a collection of shell fragments, on the basis of the shape of the costals and carapace sculpturing pattern. The validity of T. pliocaenicus was challenged by Dacqué (1912) and Wood (1979), and we agree that the listed characters are insufficient to support a valid species. The type material thus can only be identified as an indeterminate pan-trionychid, and T. pliocaenicus is herein therefore considered to be a nomen dubium.

\section{Trionyx pliopedemontana Sacco, 1889 nomen dubium}

Taxonomic history. Trionyx pliopedemontana Sacco, 1889 (new species); Trionyx pliopedemontanus Hummel 1929 (emended spelling of species epithet); Testudo pliopedemontana Kuhn 1964 (new combination); T. pliopedemontanus $=T$. blayaci $=T$. pliocenicus $=$ T. pompignanensis $=$ T. rotundiformis Broin 1977 (senior synonym).

Type material. MGPT-PU 17276 and MGPT-PU 17276/2 (holotype), internal and external imprint of a complete carapace (Sismonda 1836, pl. 1; Sismonda 1839, pl. 2).

Type locality. San Stefano Roero, Piedmont, Italy (Sismonda 1836, 1839; Portis 1879); Piacenzian, late Pliocene (Kotsakis 1985).

Comments. Sismonda $(1836,1839)$ described and figured the first known fossil trionychid from Italy, a specimen (the internal and external imprints of a nearly complete carapace) from the late Pliocene of San Stefano Roero, Piedmont, that he tentatively assigned to the extant Trionyx triunguis (his T. aegyptiacus). Four decades later, Portis (1879) referred this specimen to his newly erected taxon $T$ pedemontana, which he typified by material from the late Oligocene or early Miocene also from Piedmont (see above). Sacco (1889) finally used the same specimen to establish T. pliopedemontana, which he differentiated from the older T. pedemontana on the basis of much larger size, shape of neurals, size and shape of neurals V-VII, and the shape of costals I. Whereas Hummel $(1929,1932)$ and Kotsakis $(1980,1985)$ considered this species to be a member of the Amyda lineage, Karl (1999a) considered it to be synonymous with T. triunguis.

Our firsthand investigation of the type specimen reveals that sutures are clear, but that the margins of the carapacial disk are universally lacking. The available material is consistent with being referable to the Trionyx triunguis lineage but can only be diagnosed as Pan-Trionychinae indet. We therefore conclude that $T$. pliopedemontana is best considered a nomen dubium, contrary to more than 100 years of nomenclatural practice. Instead, we here consider T. pliocenicus to be valid, a taxon historically synonymized with T. pliopedemontana, as this is based on a nearly complete skeleton (see above). All specimens from the Neogene of Italy (Portis 1890; Kotsakis 1980, 1985; Girotti et al. 2003), France (Depéret and Donnezan 1890-1897; Bergounioux 1933; Broin 1977), and Romania (Macarovici and Motas 1965) that were historically affiliated with T. pliopedemontana, mostly using temporal and spatial considerations, are herein referred to Pan-Trionychinae indet., given that pancyclanorbines seem to be missing in the Neogene of Europe. The same is true also for what seems to be the last European fossil 
pan-trionychid, a costal fragment and a fragmentary tibia from the early Pleistocene of Valdarno, Tuscany, Italy, which was originally described by Portis (1890) and later further described and attributed to Trionyx cf. pliopedemontana by Kotsakis (1980).

Kuhn (1964) listed pliopedemontana under Testudo, but we agree with Auffenberg (1974) that this is likely an error.

\section{Trionyx pompignanensis Bergounioux, 1933 nomen dubium}

Taxonomic history. Trionyx pompignanensis Bergounioux, 1933 (new species); $T$. pliopedemontanus $=T$. blayaci $=T$. pliocenicus $=$ T. pompignanensis $=$ T. rotundiformis Broin 1977 (junior synonym).

Type material. LG-FSM (holotype), a fragment of a costal (Bergounioux 1933, pl. 1.2).

Type locality. La Pompignane, Montpellier, Hérault, France (Bergounioux 1933); Pliocene (Broin 1977).

Comments. For a discussion on Bergounioux's (1933) material from Montpellier, France, see Trionyx blayaci above.

\section{Trionyx pontanus Laube, 1895 nomen dubium}

Taxonomic history. Trionyx pontanus Laube, 1895 (new species); Amyda pontanus Comaschi Caria 1959 (new combination); . triunguis $=T$. pontanus $=24$ others Karl 1998 (junior synonym, see Rafetus bohemicus for complete synonym).

Type material. OMM Gpa77 (syntype), a rather complete carapace and its imprint (Laube 1896, pls. 1, 2); unknown collection (syntype), a complete carapace (Laube 1896, pls. 3, 4).

Type locality. Most (= Brüx), Ústí nad Labem, Czechia (Laube 1895); Most Formation, Burdigalian, early Miocene (Aguilar et al. 1997).

Comments. Trionyx pontanus is based on two well-preserved, large (CL almost equal to $40 \mathrm{~cm}$ ) carapaces from the Miocene of Czechia that Laube (1895) only introduced briefly but soon after extensively described and figured (Laube 1896). Trionyx pontanus was originally diagnosed based on sculpturing pattern and the shape of last neurals and costals (Laube 1895, 1896). Karl $(1998,1999$ a) considered T. pontanus to be a junior synonym of the extant T. triunguis, but Chkhikvadze (1999b) considered T. pontanus to be the sole European member of Rafetus and the senior synonym of all early Miocene Czech taxa (T. aspidiformis, T. bohemicus, T. elongatus, and T. preschenensis). Given that this taxon is based on carapacial material alone, affinities with Rafetus bohemicus cannot be concluded with certainty, and we herein consider T. pontanus to be a nomen dubium (see T. vindobonensis and Rafetus bohemicus for more extensive discussions).

Bergounioux (1935) reported the presence of Trionyx pontanus from the late Miocene of Sardinia, but we believe this is be a typographic error, as it seems more likely that he intended to mean Trionyx (= Procyclanorbis) sardus (Esu and Kotsakis 1983)
Trionyx portisi Ristori, 1891b nomen dubium

Taxonomic history. Trionyx portisi Ristori, 1891b (new species).

Type material. Probably IGF (syntype), a rather complete carapace, missing only the nuchal, and parts of neural I and costals I (Ristori 1895, pl. 2.8); probably IGF (syntype), a carapace fragment (Ristori 1895, pl. 2.12); probably IGF (syntype), a carapace fragment (Ristori 1895, pl. 2.13).

Type locality. Montebamboli, Tuscany, Italy (Ristori 1891b); MN 12, Tortonian, late Miocene (Chesi 2009).

Comments. For a discussion on material named by Ristori (1891a, 1891b), from the late Miocene of Tuscany, Italy, see Trionyx bambolii above.

\section{Trionyx preschenensis Laube, 1900 nomen dubium}

Taxonomic history. Trionyx preschenensis Laube 1898 (nomen nudum); T. preschenensis Laube, 1900 (new species); Tryonyx preschensis Laube 1900 (incorrect spelling); T. preschensis Reinach 1900 (incorrect spelling of species epithet); Procyclanorbis preschenensis Portis 1901 (new combination); T. preschnensis Rieppel 1979 (incorrect spelling of species epithet); $T$. triunguis $=$ T. preschenensis $=24$ others Karl 1998 (junior synonym, see Rafetus bohemicus for complete synonym).

Type material. NMP 20205 (holotype), negative and positive imprints of an almost complete carapace, along with remains of the hyo-hypoplastron (Laube 1900, pls. 1, 2.1).

Type locality. Břestány (= Preschen), near Bilina, Ústí nad Labem, Czechia (Liebus 1930); Most Formation, MN 3, Burdigalian, early Miocene (Aguilar et al. 1997).

Comments. Laube (1898) first introduced the name Trionyx preschenensis without description or definition, but soon after formally made the name available (Laube 1900). Portis (1901) regarded this taxon as a pan-cyclanorbine and included it into his new genus Procyclanorbis. Chkhikvadze (1999b), on the other hand, more recently argued that this is a junior synonym of $T$. (his Rafetus) pontanus, the only European representative of the Rafetus lineage. We herein regard T. preschenensis to be a nomen dubium, as it is based on a juvenile specimen (see T. vindobonensis and Rafetus bohemicus for more extensive discussions).

\section{Trionyx propinquus Ristori, 1891a nomen dubium}

Taxonomic history. Trionyx propinquus Ristori, 1891a (new species); T. propinquens Bergounioux 1935 (incorrect spelling of species epithet).

Type material. Probably MSNP (syntype), fragments of a carapace (Ristori 1895, pl. 2.11); MUSNAF (syntype), a partial carapace (Ristori 1895, pl. 5.27) 
Type locality. Near Sienna, Tuscany, Italy (Ristori 1891a, 1895); Casino Clays, Messinian, late Miocene (Abbazzi et al. 2008).

Comments. For a discussion on material named by Ristori (1891a, 1891b), from the late Miocene of Tuscany, Italy, see Trionyx bambolii above.

\section{Trionyx pseudovindobonensis Szalai, 1934 nomen dubium}

Taxonomic history. Trionyx pseudovindobonensis Szalai, 1934 (new species); Testudo pseudovindobonensis Kuhn 1964 (new combination); [Trionyx pseudovindobonensis] Farkas 1995 (nomen dubium); Trionyx triunguis = Trionyx pseudovindobo nensis $=24$ others Karl 1998 (junior synonym, see Rafetus bohemicus for complete synonym).

Type material. MFGI Ob.3145 (holotype), a left femur fragment (Szalai 1934, pl. 5, fig. 23; Mlynarski 1966, fig. 13; Farkas 1995, fig. 2).

Type locality. Rákos, Budapest, Hungary (Szalai 1934; Mlynarski 1966); Serravallian, middle Miocene (Farkas 1995).

Comments. Szalai (1934) erected Trionyx pseudovindobonensis on the basis of a purported humerus from the middle Miocene of Hungary that he differentiated from that of $T$. vindobonensis from the late Miocene of Austria on the basis of the humeral morphology. The diagnosis of a species based on a humerus was heavily criticized by Glaessner (1935), but Mlynarski (1966) was nevertheless reluctant to reject the validity of this taxon. More recently, Farkas (1995) challenged the original identification of the holotype as a right humerus and instead showed that it is in fact a partial left femur, which still is insufficient to diagnose a valid taxon. After our personal investigation of the holotype at MFGI, we agree with Farkas (1995) in considering T. pseudovindobonensis to be a nomen dubium (also see T. vindobonensis above).

Kuhn (1964) listed the name Testudo pseudovindobonensi in his compendium, but it is unclear to us if this is an error or if he truly believe this taxon to be a tortoise (Testudinidae).

\section{Trionyx pustulatus Owen in \\ Owen and Bell, 1849 nomen dubium}

Taxonomic history. Trionyx pustulatus Owen in Owen and Bell, 1849 (new species); [T. pustulatus] Hummel 1929 (nomen dubium); Rafetoides henrici $=$ T. pustulatus $=7$ others Karl 1998 (junior synonym, see “T.” henrici for complete synonym).

Type material. A costal fragment (holotype) (Owen and Bell 1849, pl. 19b.7-9), whereabouts unknown.

Type locality. A costal fragment (holotype) (Owen and Bell 1849, pl. 19b.7-9; Owen 1849-1884, pl. 31.7-9), whereabouts unknown.

Comments. Trionyx pustulatus is based on a costal fragment that was characterized by its distinct, reticulate sculpturing (Owen and Bell 1849). The holotype was originally held in the collec- tions of the Marchioness of Hasting, but unlike the remainders of that collection, this fragment was not transferred to the $\mathrm{BMNH}$, and we are therefore uncertain as to its whereabouts. The reticulate sculpturing mentioned by Owen and Bell (1849) is now considered to be highly variable among pan-trionychids (Gardner and Russell 1994). Given the highly fragmentary nature of the lost type specimen, we agree with Hummel (1929) that this taxon should be regarded as a nomen dubium.

\section{Trionyx ragusensis De Gregorio, 1883} nomen dubium

Taxonomic history. Trionix ragusensis De Gregorio, 1883 (new species and incorrect spelling of genus name); [Trionyx ragusensis] Kotsakis 1985 (nomen nudum).

Type material. ITCAM (holotype), a carapace (De Gregorio 1883, not figured), probably lost (Kotsakis 1985).

Type locality. Ragusa, Sicily, Italy (De Gregorio 1883, 1892); Langhian, middle Miocene (Kotsakis 1985).

Comments. De Gregorio (1883) introduced the name Trionix ragusensis (note the incorrect spelling of the genus name) on the basis of a carapace that was kept at the Cabinetto di Scienze naturali dell'Istituto tecnico di Modica, in Modica, Sicily, Italy. The specimen was never figured and is now believed to be lost (Kotsakis 1985). In a subsequent publication, De Gregorio (1892) considered his taxon to share affinities with Trionyx melitensis (herein considered to be a marine turtle) from nearby Malta, " $T$. capellinii" (his T. italicus) from Italy, and "T." henrici from England, but he did not provide any rationale for these affinities and he only mentioned that he would describe Trionix ragusensis in detail at a later stage. This unfortunately never happened. Trionix ragusensis was strangely ignored by Hummel $(1929,1932)$ and (Kuhn 1964), but Kotsakis (1985) more recently suggested that it was never formally described and should therefore be considered to be a nomen nudum. In our opinion, De Gregorio (1883) fulfilled the minimum requirements of ICZN (1999) by listing a single character, which is the size of the holotype specimen (CL of $25 \mathrm{~cm}$ ). Given that the description of De Gregorio (1883) is not informative and that the type is now lost, it is clear that $T$. ragusensis must be considered a nomen dubium.

\section{Trionyx reticulatus Rieppel, 1979 nomen dubium}

Taxonomic history. Trionyx reticulatus Rieppel, 1979 (new species).

Type material. PIMUZ A/111 502 (holotype), a well-preserved carapace, with vertebrae and parts of the shoulder girdle (Rieppel 1979, figs. 1, 2).

Type locality. Oerlikon, Zurich, Switzerland (Rieppel 1979); Upper Freshwater Molasse (Rieppel 1979), Langhian/Serravallian, middle Miocene.

Comments. Trionyx reticulatus is based on a heavily cracked carapace from the Molasse Basin of Switzerland. Rieppel (1979) 
reported the specimen to be from the late Miocene, but the updated geological map of Switzerland provides a middle Miocene age of sediments exposed in the town of Oerlikon. This species is partially diagnosed based on the presence of an extremely elongate neural I, but we do not believe this to be factual, but rather an artifact resulting from the preparation and restoration of the type specimen. According to the rationale we developed herein, we disregard this taxon from nomenclatural consideration, as we conclude that isolated carapaces from Europe are not sufficient to diagnose a valid taxon (see T. vindobonensis above for a more extensive discussion).

\section{Trionyx rivosus Owen in Owen and Bell, 1849 nomen invalidum}

(junior synonym of "Trionyx" henrici Owen in Owen and Bell, 1849)

Taxonomic history. Trionyx rivosus Owen in Owen and Bell, 1849 (new species); Rafetoides henrici $=$ T. rivosus $=7$ others Karl 1998 (junior synonym, see "T." henrici for complete synonym).

Type material. BMNH R30405 (holotype), posterior part of a carapace of a juvenile individual (Owen and Bell 1849, pl. 18a; Owen 1849-1884, pl. 29).

Type locality. Hordle (= Hordwell) Cliff, Hampshire, United Kingdom (Owen and Bell 1849); Totland Bay Member, Headon Hill Formation, Priabonian, late Eocene (Benton and Spencer 1995).

Comments. Trionyx rivosus is known from a single, fragmentary carapace that was originally diagnosed on the basis of its distinctive carapacial sculpturing (Owen and Bell 1849). Lydekker (1889a) suggested that T. rivosus could be a junior synonym of the sympatric T. planus (herein considered a junior synonym of "T." henrici) and attributed differences to ontogeny, with the former representing a younger individual of the latter. For a more extensive discussion regarding pan-trionychid material from the late Eocene of England, see "T." henrici above.

\section{Trionyx rocchettiana Portis, 1882 nomen dubium}

Taxonomic history. Trionyx rocchettiana Portis, 1882 (new species); T. rochettianus Harrassowitz 1919 (incorrect spelling of species epithet); T. rocchettianus Hummel 1932 (emended spelling of species epithet); T. rochettiana Rieppel 1979 (incorrect spelling of species epithet).

Type material. MGL 8895 (syntype), anterior part of a carapace (Portis 1882, pl. 24); MGL 8894 (syntype), central portion of a carapace (Portis 1882, pl. 25).

Type locality. La Rocchette (= Rochette) Locality, Belmont, Vaud, Switzerland (Portis 1882); MP 29, Chattian, late Oligocene (Berger 1998).

Comments. Portis (1882) formally named three pan-trionychid taxa based on abundant fossil material from La Rocchette,
Switzerland. Of these, Trionyx rocchettiana is based on the most fragmentary material. We herein consider this taxon to be a nomen dubium, as the type material is fully insufficient to diagnose a valid species (see T. valdensis for more extensive discussion).

\section{Trionyx roncensis Harrassowitz, 1919 nomen dubium}

Taxonomic history. Trionyx roncensis Harrassowitz, 1919 (new species); [T. roncensis] Hummel 1929 (nomen dubium); Amyda roncensis Bergounioux 1934b (new combination).

Type material. MGPT-PU (holotype), a carapace fragment (Portis 1885, pl. 11.1; Harrassowitz 1919), probably lost.

Type locality. Roncà, Veneto, Italy (Harrassowitz 1919); Bartonian, middle Eocene (Kotsakis 1977, 1985).

Comments. Harrassowitz (1919) established Trionyx roncensis on the basis of a rather fragmentary specimen, which was originally figured by Portis (1885) but now seems to be lost, as we were not able to find this specimen during a recent visit to MGPT-PU. The new taxon was differentiated from other pantrionychids solely by its sculpturing pattern, despite the fact that Harrassowitz (1919) himself pointed out the dubious nature of this feature. Hummel (1929) considered this taxon to bear strong resemblance to the German "T." messelianus. Kotsakis (1977, 1985) considered the status of this species as uncertain and doubtful, noting that the remains could not be identified beyond the genus level of Trionyx. Differences with "T." capellinii in carapace sculpturing, however, lead Kotsakis (1985) to believe that T. roncensis could represent a distinct species. Such differences in sculpturing are now considered to be a character that is highly variable within species (Vitek and Joyce 2015). Given the fragmentary nature of the type specimen, we therefore regard T. roncensis to be a nomen dubium.

\section{Trionyx rostratus Arthaber, 1898 nomen invalidum \\ (junior synonym of T. vindobonensis Peters, 1855)}

Taxonomic history. Trionyx rostratus Arthaber, 1898 (new species); Amyda cartilaginea $=T$. rostratus $=T$. trinilensis Karl 1998 (junior synonym).

Type material. IPUW 1897 IV (holotype), a skeleton, including most of the skull, mandible, and carapace, a fragment of an epiplastron, the hyoids, vertebrae, and several limb elements (Arthaber 1898, pls. 25-28; Hummel 1927, pl. 2.6; Karl 1998, pls. $1.2,2,3,4.3,4.4$ )

Type locality. Au am Leithaberge (= Au am Leithagebirge), Lower Austria, Austria (Arthaber 1898); early Tortonian, late Miocene (Karl 1999a).

Comments. Among Miocene trionychids from central Europe, the holotype of Trionyx rostratus stands out by consisting of a 
relatively complete skeleton that includes a skull and mandible. Given the complete nature of the type specimen, the validity of this species remained unchallenged historically. However, Karl (1998) recently highlighted that the name T. rostratus could be considered preoccupied by Testudo rostrata Thunberg, 1787, as this is a suppressed junior synonym of the extant trionychid Pelodiscus sinensis Wiegmann, 1835. We here, however, consider this name to be available, as Thunberg's (1787) taxon is now associated with Pelodiscus, not Trionyx, its historical generic placement. Karl (1998, 1999a) furthermore referred the type specimen of T. rostratus to the extant southeast Asian taxon Amyda cartilaginea. We here nevertheless synonymize this species with T. vindobonensis (see above).

\section{Trionyx rotundiformis Bergounioux, 1933 nomen dubium}

Taxonomic history. Trionyx rotundiformis Bergounioux, 1933 (new species); T. rotondiformis Bergounioux 1958 (incorrect spelling of species epithet); . pliopedemontanus $=T$. blayaci $=$ T. pliocenicus $=T$. pompignanensis $=T$. rotundiformis Broin 1977 (junior synonym).

Type material. CPS-UL 92864 (holotype), an incomplete carapace (Bergounioux 1933, fig. 2, pl. 2.2).

Type locality. Montpellier, Hérault, France (Bergounioux 1933); MN 14, Zanclean, early Pliocene (Hervet 2004).

Comments. Bergounioux (1933) established Trionyx rotundiformis on the basis of a single, incomplete carapace from the Pliocene of Montpellier, France, that he diagnosed relative to other trionychids by minor differences in the shape of the costals, neurals, and sculpturing pattern. For a discussion on trionychid material from Montpellier, France, described by Bergounioux (1933), see T. blayaci above.

$$
\begin{gathered}
\text { Trionyx schaurothianus Negri, } 1893 \\
\text { nomen invalidum } \\
\text { (junior synonym of “T.” capellinii Negri, 1892) }
\end{gathered}
$$

Taxonomic history. Trionyx schaurothianus Negri, 1893 (new species); T. capellinii schaurothiames Bergounioux 1934b (incorrect spelling of subspecies epithet); T. capellinii schaurotianus Bergounioux 1958 (incorrect spelling of subspecies epithet); $T$. capellinii schaurothiana Kuhn 1964 (emended spelling of subspecies epithet); T.c. montevialensis $=T$. c. gracilina $=T$. c. perexpansa $=T$. $c$. schaurothianus $=T$. insolitus $=[$ T. italicus $]$ Kotsakis 1977 (junior synonym); T. italicus $=$ T.c. montevialensis $=T$. c. schaurothianus $=T$. c. gracilina $=T$. c. perexpansa $=$ T. insolitus Kotsakis 1985 (junior synonym).

Type material. MGP-PD 10818Z (holotype), a complete skeleton in dorsal view, including the skull, carapace, a hyo-hypoplastron, limb elements, and caudal vertebrae (Negri 1893, pl. 2; Bergounioux 1954, fig. 24, pl. 12; Kotsakis 1977, fig. 3i; Pandolfi et al. 2017, fig. 7b).

Type locality. Monteviale, Veneto, Italy (Negri 1893); MP 21, early Rupelian, early Oligocene (Pandolfi et al. 2017).
Comments. Negri (1893) established Trionyx schaurothianus on the basis of an unusually well-preserved fossil pan-trionychid from the early Oligocene of Monteviale, Italy. For a discussion on pan-trionychid material from this locality, see "T." capellinii above.

\section{Trionyx sculptus Gilmore, 1931 nomen dubium}

Taxonomic history. Trionyx sculptus Gilmore, 1931 (new species); Aspideretes sculptus Yeh 1963 (new combination).

Type material. AMNH 6700 (holotype), a carapace, lacking the nuchal and the distal ends of many of the costals (Gilmore 1931, pl. 10).

Type locality. Tairum Nor, Inner Mongolia, China (Gilmore 1931); Tunggur Formation, Serravallian, middle Miocene (Wang et al. 2003).

Comments. Trionyx sculptus is based on a partial carapace from Inner Mongolia, China, that was originally believed to be Pliocene (Gilmore 1931), but more recently clarified to be middle Miocene in age (Wang et al. 2003). Although the anterior portion of the carapace is missing, Gilmore (1931) believed this specimen to once have possessed a preneural, a view later adopted by Yeh (1963), who reassigned this taxon to Nilssonia (his Aspideretes). Judging from photographs of the holotype, we cannot refute nor confirm the presence of a preneural. In addition, given that the remainder of the carapace does not display a sufficient amount of character evidence to support its validity, we here consider this taxon to be a nomen dubium.

\section{Trionyx senckenbergianus Reinach, 1903 nomen dubium}

Taxonomic history. Trionyx senckenbergianus Reinach, 1903 (new species); [T. senckenbergianus] Dacqué 1912 (nomen dubium); $T$. triunguis $=T$. senckenbergianus $=24$ others Karl 1998 (junior synonym, see Rafetus bohemicus for complete synonym).

Type material. SMF R430 (syntype), a fragment of a right hyoplastron (Reinach 1903, pl. 17.6); SMF (syntype), a costal fragment (Reinach 1903, pl. 17.5); SMF (syntype), a costal fragment (Reinach 1903, pl. 17.2).

Type locality. Wadi Moghra (= Moghara), Matruh Governorate, Egypt (Reinach 1903); Burdigalian, early Miocene (Lapparent de Broin 2000)

Comments. It is notable that most of the pan-trionychid fossils from Africa either have not been identified beyond the family level or have been assigned to extant taxa, even though most of them are not subfossils (e.g., Lapparent de Broin 2000). Trionyx senckenbergianus is one of few named fossil pan-trionychid taxa from Africa. Reinach (1903) mostly differentiated his new species on the basis of shell sculpturing and the shape of the costals, but these characters are now understood to be highly variable (Meylan 1987; Gardner and Russell 1994). Indeed, soon 
after the original description of T. senckenbergianus, Dacqué (1912), Hummel (1929), and Wood (1979) doubted its validity, likely as it is based on an assortment of fragments. We fully agree with this opinion and therefore regard this taxon to be a nomen dubium.

\section{Trionyx senensis Ristori, 1891b nomen dubium}

Taxonomic history. Trionyx senensis Ristori, 1891b (new species).

Type material. IGF (syntype), an almost complete carapace (Ristori 1895, pl. 2.7); probably IGF (syntype), a carapace fragment, containing the last neurals (Ristori 1895, pls. 1.5, 2.10); probably IGF (syntype), a carapace fragment in visceral view, along with parts of vertebrae and pectoral girdle (Ristori 1895, pl. 1.6).

Type locality. Montebamboli, Tuscany, Italy (Ristori 1895; Kotsakis 1985); Tortonian, late Miocene (Chesi 2009).

Comments. For a discussion on material from the late Miocene of Tuscany named by Ristori (1891a, 1891b), see Trionyx bambolii above.

\section{Trionyx septemcostatus Hoernes, 1881 nomen invalidum \\ (junior synonym of T. vindobonensis Peters, 1855)}

Taxonomic history. Trionyx septemcostatus Hoernes, 1881 (new species); T. septemradiatus Portis 1901 (incorrect spelling of species epithet); T. septemcostata Liebus 1930 (incorrect spelling of species epithet); T. triunguis $=$ T. septemcostatus $=24$ others Karl 1998 (junior synonym, see Rafetus bohemicus for complete synonym).

Type material. UMJGP 200698 (holotype), a partial shell (Hoernes 1881, fig. 3; Heritsch 1909, fig. 1, pl. 9.2; Gross 2002, pl. 14.4).

Type locality. Eibiswald, Styria, Austria (Hoernes 1881); Eibiswald Formation, MN 5, early Langhian, middle Miocene (Aguilar et al. 1997).

Comments. Trionyx septemcostatus was established on the basis of a small (CL of $23 \mathrm{~cm}$ ), partial shell (Hoernes 1881) from the Miocene locality of Eibiswald, Austria. The same locality also produced the type series of $T$. petersi (herein considered a junior synonym of $T$. vindobonensis), which is almost identical to $T$. septemcostatus with exception of the presence of eight costals, instead of the seven apparent in T. septemcostatus. The presence of seven costals was considered to be unique among European pan-trionychids and prompted early workers to speculate affinities with the North American Platypeltis (= Apalone) (Hummel 1932), which is characterized, among others, by regularly possessing only seven costals (Hay 1908). It is now known, however, that the number of costals is variable among some extant trionychids and that a reduced number by itself is not diagnos- tic. Indeed, the most posterior pair of costals is rather large in the type specimen, and we therefore also see the possibility that the posterior two pairs of costals fused with one another. According to the rationale we outlined above, we here consider T. septemcostatus to be a junior synonym of T. vindobonensis. For a more extensive discussion, please refer to the latter taxon above.

Trionyx siegeri Heritsch, 1909

nomen dubium, designation of lectotype

Taxonomic history. Trionyx siegeri Heritsch, 1909 (new species); T. petersi siegeri Mottl 1967 (referral to subspecies level); T. triunguis $=$ T. siegeri $=24$ others Karl 1998 (junior synonym, see Rafetus bohemicus for complete synonym).

Type material. UMJGP 200710 (lectotype), a partial carapace (Heritsch 1909, pl. 11.4; Gross 2002, pl. 15.1); UMJGP 200707 (paralectotype), carapace fragments, likely a chimera (Gross 2002, pl. 15.2)

Type locality. Vordersdorf, Wies, Styria, Austria (Heritsch 1909); Eibiswald Formation, MN 5, early Langhian, middle Miocene (Aguilar et al. 1997).

Comments. Trionyx siegeri is only known from an incomplete carapace from the Miocene of Styria, Austria (Heritsch 1909). Mottl (1967) believed T. siegeri to be a subspecies of T. petersi, whereas Karl (1998) synonymized it with the extant T. triunguis. Gross (2002) noted that one of the two syntypes represents a chimera consisting of a pan-trionychid and a chelydrid. We therefore render the other specimen as the lectotype for the sake of nomenclatural clarity. We nevertheless consider T. siegeri to be a nomen dubium, as it is only based on carapacial material (see T. vindobonensis above for more extensive justification).

Mottl (1967) attributed several fossils from the middle Miocene of Carinthia, Austria, to Trionyx petersi siegeri. Of these, we refer all specimens that include plastral elements diagnostic for the T. triunguis lineage to T. vindobonensis but consider all specimens lacking plastral material as indeterminate pantrionychines.

Trionyx sinuosus Chow and Yeh, 1958 nomen dubium

Taxonomic history. Trionyx sinuosus Chow and Yeh, 1958 (new species); Aspideretes sinuosus Yeh 1963 (new combination).

Type material. IVPP V 944 (holotype), anterior two-thirds of carapace (Chow and Yeh 1958, figs. 1,2).

Type locality. Kengsiu (= Gensiu), Yushe County, Shanxi Province, China (Chow and Yeh 1958; Ye 1994); late Pliocene or early Pleistocene (Rhodin et al. 2015).

Comments. Trionyx sinuosus is based on a partial shell from the Plio-Pleistocene of Shanxi, China (Chow and Yeh 1958), a province within the current range of the extant Pelodiscus sinensis (TTWG 2014). Chow and Yeh (1958) noted a resemblance with Nilssonia (their Aspideretes) but also stated that the preneural, which is the most diagnostic character for this clade, 
cannot be clearly distinguished in this specimen. Judging from the figures, we cannot confirm the presence of a preneural either but instead note that the specimen is consistent with the morphology of the Pelodiscus lineage by being relatively small and by showing open suprascapular fontanelles (Meylan 1987). However, the specimen is too fragmentary to allow rigorously distinguishing it from the extant Pelodiscus sinensis and the Pliocene Pelodiscus gracilia (see above). We therefore consider the type to be an indeterminate representative of the Pelodiscus lineage and the taxon to be a nomen dubium.

\section{Trionyx sophiae Heritsch, 1909 nomen dubium}

Taxonomic history. Trionyx sophiae Heritsch, 1909 (new species); . triunguis $=$ T. sophiae $=24$ others Karl 1998 (junior synonym, see Rafetus bohemicus for complete synonym).

Type material. UMJGP 200700 (holotype), the carapace of a juvenile and associated plastral fragments (Heritsch 1909, pl. 11.3; Gross 2002, pl. 15.3).

Type locality. Eibiswald, Styria, Austria (Heritsch 1909); Eibiswald Formation, MN 5, early Langhian, middle Miocene (Aguilar et al. 1997).

Comments. Triony x sophiae is known from a single, oval-shaped carapace, which is only $14.3 \mathrm{~cm}$ long and $11.5 \mathrm{~cm}$ wide (Heritsch 1909), that Mottl (1967) suggested to be a juvenile form of T. petersi, which is herein considered to be a junior synonym of T. vindobonensis. We conclude here, however, that T. sophiae is a nomen dubium, as it is both a juvenile and consists only of carapacial material (see T. vindobonensis for a more extensive discussion).

\section{Trionyx stadleri Teppner, 1913 nomen dubium}

Taxonomic history. Trionyx stadleri Teppner, 1913 (new species); . triunguis $=$ T. stadleri $=24$ others Karl 1998 (junior synonym, see Rafetus bohemicus for complete synonym).

Type material. UMJGP 11831 (holotype), a nearly complete carapace (Teppner 1913, fig. 1; Jurkovšek and Kolar-Jurkovšek 1994, pl. 1.1; Ramovš 1974, fig. 417; Paunović 1986, fig. 1; Gross 2002, pl. 16.1; Karl 2007, pl. 3.1).

Type locality. Trbovlje (formerly known as Trifail), Central Sava, Slovenia (Hoernes 1882; Teppner 1913); Trbovlje Formation, late Chattian, late Oligocene (Gross 2002).

Comments. Trionyx stadleri is based on a carapace from the late Oligocene of Slovenia (Teppner 1913) that was initially diagnosed based on characters now known to be highly variable within extant trionychids, such as the shape of the nuchal, neurals, and costals and the sculpturing of the shell. Given that the posterior margin of the shells seems to be damaged, we here conclude that this specimen can be identified as an indeterminate pan-trionychine at best. We therefore consider this taxon to be a nomen dubium.
Trionyx stiriacus Peters, 1855

nomen dubium, designation of lectotype

Taxonomic history. Trionyx stiriacus Peters, 1855 (new species); Tryonix stiriacus Portis 1879 (incorrect spelling of genus name); T. styriacus Hoernes 1881, Peters 1881 (incorrect spelling of species epithet); T. stiriaca Toula 1882 (incorrect spelling of species epithet); . triunguis $=$ T. stiriacus $=24$ others Karl 1998 (junior synonym, see Rafetus bohemicus for complete synonym).

Type material. UMJGP 5847 (lectotype), a partial carapace (Peters 1855, pl. 4.1, 3; Gross 2002, pl. 16.2); UMJGP 1776 (paralectotype), carapace and plastral fragments, counterpart of UMJGP 1777 (Peters 1855, pl. 6.2, 4, 6; Gemel 2002, pl. 2.d; Gross 2002, pl. 16.3); UMJGP 1777 (paralectotype), carapace and plastral fragments, counterpart of UMJGP 1776 (Peters 1855, pl. 6.1, 3, 5; Gross 2002, pl. 16.4).

Type locality. Schönegg, Pölfing-Brunn, Styria, Austria (Peters 1855; Gross 2002); Eibiswald Formation, MN 5, early Langhian, middle Miocene (Aguilar et al. 1997).

Comments. Trionyx stiriacus is one of the first named trionychids from the Miocene of central Europe. It has therefore been extensively discussed in the literature, though often using the wrong spelling "styriacus" (Peters 1881; Hoernes 1881, 1882; Depéret and Donnezan 1890-1897; Negri 1892; Laube 1895; Ristori 1895; Arthaber 1898; Reinach 1900; Heritsch 1909; Ammon 1911; Liebus 1930; Bergounioux 1935; Kuhn 1964; Tuna 1988; Lapparent de Broin 2001; Danilov et al. 2011), probably because Peters (1855) himself used the spelling "styriacus" in the plate accompanying the original publication. Given the central importance of T. stiriacus to the taxonomy of Miocene trionychids, we here designate one of the three syntypes as the lectotype, because the syntype material consists of dissociated specimens that well may represent a chimera. As a result, however, T. stiriacus is rendered a nomen dubium, because we conclude the lectotype is insufficient to diagnose a taxon, as it is only a partial carapace. The lectotype and both paralectotypes are herein identified as indeterminate pan-trionychines. For a more extensive discussion regarding our rationale, see $T$. vindobonensis above.

\section{Trionyx stormsi Delheid, 1899 nomen dubium}

Taxonomic history. Trionyx stormsi Delheid, 1899 (new species); [T. stormsi] Hummel 1929 (nomen dubium).

Type material. IRSNB R 354a-c (holotype), four costal fragments (Delheid 1899, not figured).

Type locality. Boom clay, Boom or Terhaegen, Antwerp, Belgium (Delheid 1899); Boom Formation, Rupelian, early Oligocene (Mayr and Smith 2012).

Comments. Trionyx stormsi is based on four costal fragments that were never figured, but briefly described (Delheid 1899), and this action therefore fulfills the minimum requirements of the ICZN (1999) for the availability of names published prior to 1931. There was no indication about where the material was 
housed, but we were able to locate carapace fragments from Boom in the collections of IRSNB that are labeled T. stormsi and that correspond to the brief description of Delheid (1899), although repair to the specimens resulted in a different count of bones (T. Smith and A. Folie, pers. comm., 2016). We consider this material to be the holotype of T. stormsi. Although the material without doubt pertains to an indeterminate pan-trionychid, we here consider T. stormsi to be a nomen dubium.

\section{Trionyx subangularis Bergounioux, 1954 nomen dubium}

Taxonomic history. Trionyx subangularis Bergounioux 1953 (nomen nudum); T. subangularis Bergounioux, 1954 (new species).

Type material. MGP-PD 26565 (holotype), a partial carapace and its imprint (Bergounioux 1954, figs. 35, 36, pls. 18, 19)

Type locality. Bolzano Bellunense, Veneto, Italy (Bergounioux 1954); Burdigalian, early Miocene (Kotsakis 1985).

Comments. Trionyx subangularis is based on a moderately sized specimen (CL of $29 \mathrm{~cm}$ ) that was initially diagnosed as a new taxon by the shape of its carapace and the number, shape, and size of the neurals and costals (Bergounioux 1954). Kotsakis (1985) tentatively considered this taxon to be valid and distinguished it from other pan-trionychids on the basis of shell ornamentation and the number and morphology of the neurals. However, these characters have since been shown to be highly variable within many extant trionychid species (Meylan 1987; Vitek and Joyce 2015). Our firsthand observation of the holotype reveals that it lacks characters that would allow identifying it beyond Pan-Trionychinae indet. We therefore here consider $T$. subangularis to be a nomen dubium.

\section{Trionyx teiritzbergensis Gemel, 2002 nomen invalidum \\ (junior synonym of T. vindobonensis Peters, 1855)}

Taxonomic history. Trionyx teiritzbergensis Gemel, 2002 (new species).

Type material. NOLM F/4972 (holotype), an almost complete hypoplastron (Gemel 2002, pls. 1.2, 2.a, 3.1).

Type locality. Teiritzberg, Lower Austria, Austria; Burdigalian, early Miocene (Gemel 2002).

Comments. Trionyx teiritzbergensis was only recently established on the basis of a single hypoplastron from the early Miocene of Austria that was thought to show an unusually low angle between the processus lateralis and the longitudinal axis of the hypoplastron (Gemel 2002). We do not find this characteristic to be either particularly apparent or of any systematic value and therefore attribute this material to T. vindobonensis, which is typified on slightly younger material from the same basin. For a more extensive discussion, see T. vindobonensis above.

\author{
Trionyx teyleri Winkler, 1869a \\ nomen invalidum \\ (junior synonym of T. vindobonensis \\ Peters, 1855)
}

Taxonomic history. Trionyx teyleri Winkler, 1869a (new species); Tryonix teyleri Portis 1879 (incorrect spelling of genus name); $T$. tayleri Laube 1896 (incorrect spelling of species epithet); T. triunguis $=$ T. teyleri $=24$ others Karl 1998 (junior synonym, see Rafetus bohemicus for complete synonym).

Type material. TM 8446 (holotype), fragments of a skull, mandible, hyoids, plastron, limbs, and cervical vertebrae (Winkler 1869a, pl. 15.51, 51a).

Type locality. Öhningen (= Oeningen or Oehningen), BadenWürttemberg, Germany (Winkler 1869a); MN 7+8, Serravallian, middle Miocene (Aguilar et al. 1997).

Comments. Trionyx teyleri is based on a single, incomplete skeleton that was characterized by its prominent plastral sculpturing, hyo-hypoplastron morphology, a pointed, triangular skull, and long cervical vertebrae (Winkler 1869a). However, the listed shell characters are now known to be highly variable (Meylan 1987; Gardner and Russell 1994), whereas the skull is badly crushed and therefore not informative. Trionyx teyleri is notable in that it possesses a single lateral hyoplastral process, at least judging from the figures (Winkler 1869a), which is typical for North American pan-trionychids (Vitek and Joyce 2015) but has never been described in European forms. However, inaccuracies credited to the fantasy of 19th-century lithographers have been documented repeatedly for turtles (e.g., Anquetin and Joyce 2014) and snakes (e.g., Georgalis et al. 2016a), among others, and we therefore are skeptical about the accuracy of this observation. We therefore attribute this material to T. vindobonensis (also see T. vindobonensis above).

\section{Trionyx trinilensis Jaekel, 1911 nomen invalidum \\ (junior synonym of Amyda cartilaginea [Boddaert, 1770])}

Taxonomic history. Trionyx trinilensis Jaekel, 1911 (new species); [T. trinilensis] Hummel 1929 (nomen dubium); T. cartilagineus $=$ T. trinilensis Karl 1987 (junior synonym); Amyda cartilaginea $=T$. rostratus $=T$. trinilensis Karl 1998 (junior synonym).

Type material. MB R.2754.1-2 (holotype), an epiplastron and entoplastron (Jaekel 1911, pl. 15.12, 13).

Type locality. Trinil, Java, Indonesia (Jaekel 1911); Pithecanthropus Trinil Beds, Pleistocene (Rhodin et al. 2015).

Comments. Jaekel (1911) based Trionyx trinilensis on an epiplastron and entoplastron but furthermore referred cervical vertebrae, two scapulae, and tibial fragments to this species. All elements show strong resemblance with the extant Amyda cartilaginea, and the nuanced characters that were used by Jaekel 
(1911) to distinguish this taxon can be attributed to intraspecific variation. As such, T. trinilensis is herein considered a junior synonym of the extant Amyda cartilaginea, as was initially proposed by Karl (1987) and more recently confirmed by Rhodin et al. (2015). It is worth noting that the extant populations of Amyda were recently shown to be genetically diverse. As a result, the type species Amyda cartilaginea is now confined to the islands of Indonesia, whereas the name Amyda ornata was resurrected from synonymy for the populations on the Asian mainland (Fritz et al. 2014). In light of these new insights, we here still support the synonymy of T. trinilensis with Amyda cartilaginea but note that this decision is based on geographic concerns.

\section{Trionyx tshelkarensis Chkhikvadze 1973 nomen nudum}

Material. None discussed or designated.

Locality. Chelkar-Teniz Lake (= Tshelkar), Karagandy Region, Kazakhstan (Chkhikvadze 1973); Chelkarnurinskaya suite, late Eocene to Oligocene (Vitek and Danilov 2015).

Comments. Trionyx tshelkarensis was simply mentioned by Chkhikvadze (1973) in a taxonomic list of Asian trionychids citing his unpublished thesis of 1972. The name has otherwise not appeared again in the chelonian literature and therefore must be considered a nomen nudum.

\section{Trionyx turgaicus Kuznetsov and Chkhikvadze, 1977 nomen invalidum (junior synonym of “T." ninae [Chkhikvadze, 1971])}

Taxonomic history. Trionyx turgaicus Kuznetsov and Chkhikvadze, 1977 (new species); T. turgaica Kuznetsov 1978 (unjustified emendation of spelling of species epithet); Palaeotrionyx turgaicus Chkhikvadze and Shuvalov 1988 (new combination and incorrect spelling of genus name); Rafetus turgaicus Chkhikvadze 1989 (new combination); Ulutrionyx turgaicus Kordikova 1994a (new combination); Yuen turgaicus Chkhikvadze 2007 (new combination); Oscaria turgaicus Chkhikvadze 2010 (new combination); Ulutrionyx ninae $=$ T. turgaicus $=$ T. zaisanensis Vitek and Danilov 2015 (junior synonym).

Type material. IPGAS C-5-3 (holotype), an almost complete shell, skull fragments, and limb elements of one individual (Kuznetsov and Chkhikvadze 1977, pls. 1.1-10, 2.1-5; Kuznetsov 1978, pl. 4.1, 2, 4, 6-10).

Type locality. Donguz Tau, Karagandy Region, Kazakhstan (Kuznetsov and Chkhikvadze 1977; Vitek and Danilov 2015); Chelkarnurinskaya suite, late Eocene to Oligocene (Vitek and Danilov 2015).

Comments. Trionyx turgaicus is based on a partial skeleton from the Paleogene of Kazakhstan. This is yet another Asian taxon with a complicated nomenclatural history, as it was initially referred to Trionyx (Kuznetsov and Chkhikvadze 1977) but later variously referred to Paleotrionyx (Palaeotrionyx of Chkhikvadze and Shuvalov 1988), Rafetus (Chkhikvadze 1989), Ulutrionyx (Kordikova 1994a), Yuen (Chkhikvadze 2007), and Oscaria (Chkhikvadze 2010).

Trionyx turgaicus is overall similar to the temporally and spatially close "T." ninae but notably lacks a suture between the nuchal and costals. Vitek and Danilov (2015) more recently noted that this is an ontogenetic feature typical of juvenile individuals. Moreover, given that the type of T. turgaicus belongs to a small individual, Vitek and Danilov (2015) concluded that this taxon is an ontogenetic variant of "T." ninae and therefore its junior synonym (also see "T." ninae above). We here agree with that assessment.

\section{Trionyx ubeensis Chitani, 1925} nomen dubium

Taxonomic history. Trionyx ubeensis Chitani, 1925 (new species).

Type material. GSJ (holotype), a partial carapace (Chitani 1925, unnumbered figure), destroyed by fire (Hirayama 2007).

Type locality. Ube coal mine, Yamaguchi, Japan (Chitani 1925); Ube Group, Priabonian, late Eocene (Hirayama 2007).

Comments. Trionyx ubeensis is known from a fragmentary carapace (CL approximately $40 \mathrm{~cm}$ ), consisting of the nuchal, neurals I and II, right costals I-III and VI-VIII, and fragments of the left side of the shell (Chitani 1925). According to the type description, this taxon can be differentiated from $T$. desmostyli from the Miocene of Japan and T. hilberi from the Miocene of Europe, both of which are herein considered to be nomina dubia, by having an anteriorly convex shell and variations to the shape and contacts of the neurals and costals. All of these characters are now considered to be highly variable within pan-trionychids (Meylan 1987; Gardner and Russell 1994). Moreover, the type and only known specimen is now destroyed (Hirayama 2007). All of these factors prompt us to regard this as an indeterminate pan-trionychid and T. ubeensis as a nomen dubium.

\section{Trionyx valdensis Portis, 1882 nomen dubium}

Taxonomic history. Trionyx valdensis Portis, 1882 (new species).

Type material. MGL 8898 (holotype), a carapace (Portis 1882, pl. 26).

Type locality. La Rocchette (= Rochette) Locality, Belmont, Vaud, Switzerland (Portis 1882); MP 29, Chattian, late Oligocene (Berger 1998).

Comments. A significant number of pan-trionychid fossils have been unearthed from the late Oligocene locality of La Rocchette, Switzerland (Portis 1882). Among these, Portis (1882) described three supposedly distinct species, namely Trionyx lorioli, T. rocchettiana, and T. valdensis, which he differentiated from one another by the shape of the nuchal, the shape of neural I, the number of costals, and carapacial sculpturing. In our assessment, the posterior region of the type of T. valdensis is damaged, and we 
therefore doubt that this specimen shows a reduced costal count, whereas all other listed differences are now known to be variable within extant pan-trionychid species (Meylan 1987; Gardner and Russell 1994). We therefore treat the La Rocchette pan-trionychid fauna as a monospecific assemblage. We nevertheless consider all material from Rochette to be undiagnostic at the species level, because all specimens lack plastral elements or the posterior margin of the carapace. We therefore refer all to Pan-Trionychidae indet. and declare all three taxa to be nomina dubia.

\section{Trionyx zaisanensis Chkhikvadze, 1973 nomen invalidum (junior synonym of "T." ninae [Chkhikvadze, 1971])}

Taxonomic history. Trionyx zaisanensis Chkhikvadze, 1973 (new species); Palaeotrionyx zaisanensis Chkhikvadze and Shuvalov 1988 (new combination and incorrect spelling of genus name); Rafetus zaisanensis Chkhikvadze 1989 (new combination); Eurycephalochelys zaisanensis Kordikova and Chkhikvadze 1990 (new combination); Ulutrionyx zaisanensis Kordikova 1994a (new combination); Yuen zaisanensis Chkhikvadze 2007 (new combination); Oskaria zaisanensis Chkhikvadze $2008 \mathrm{~b}$ (new combination and incorrect spelling of genus name); Ulutrionyx ninae $=T$. turgaicus $=T$. zaisanensis Vitek and Danilov 2015 (junior synonym).

Type material. IPGAS Z-34-6 (holotype), a medial half of a hypoplastron (Chkhikvadze 1973, fig. 4, pl. 5; Kuznetsov 1978, pl. 14.5; Kordikova 1994a, fig. 2; Chkhikvadze 2008a, figs. 2, 3).

Type locality. Kiin-Kerish, East Kazakhstan Region, Kazakhstan (Chkhikvadze 1973; Vitek and Danilov 2015); Kustovskaya suite, Kusto Formation, late Eocene-Oligocene (Vitek and Danilov 2015)

Comments. Trionyx zaisanensis is based on the medial half of a hypoplastron from the Paleogene of Kazakhstan (Chkhikvadze 1973). According to its type description, T. zaisanensis differs from the temporally and spatially close " $T$." ninae by having a more massive shell and longer posteromedial processes of the hypoplastron (Chkhikvadze 1973). Vitek and Danilov (2015) more recently casted doubt on the usefulness of these characters, noting that it was in fact " $T$." ninae that possesses the larger carapace, but they nevertheless considered the apparent difference to be of dubious utility and both taxa to be synonyms. We acknowledge that the available material of T. zaisanensis is fragmentary, but the close resemblance and the stratigraphic and geographic proximity with the type of Ulutrionyx ninae prompt us to concur with the assessment of Vitek and Danilov (2015; see Ulutrionyx ninae above). We therefore agree that T. zaisanensis is a junior synonym of "T." ninae.

\section{Trionyx zakhidovi Khosatzky, 1966 nomen dubium}

Taxonomic history. Trionyx zakhidovi Khosatzky, 1966 (new species); Paleotrionyx riabinini $=$ T. zakhidovi Chkhikvadze 2007 (junior synonym); [T. zakhidovi] Vitek and Danilov 2010 (nomen dubium).
Type material. CCMGE 411/1341 (holotype), a right femur (Khosatzky 1966, fig. 2; Danilov and Vitek 2013, fig. 23.3i).

Type locality. Kyrkkuduk well (= Sary-Agach = KyrkkudukI), South Kazakhstan Region, Kazakhstan (Khosatzky 1966; Vitek and Danilov 2010); Syuk-Syuk Formation or lower part of the Darbaza Formation, Santonian or Campanian, Late Cretaceous (Vitek and Danilov 2010).

Comments. Trionyx zakhidovi is based on a large, isolated femur about $20 \mathrm{~cm}$ in length from the Late Cretaceous (Santonian or Campanian) of Kazakhstan (Khosatzky 1966). Kordikova (1994a) and Chkhikvadze (2007) considered T. zakhidovi to be a possible synonym of one of the two other contemporaneous taxa from Kazakhstan (“T.” onomatoplokos [their Palaeotrionyx riabinini] or "T." riabinini) or simply an indeterminate pan-trionychid. However, given that isolated pan-trionychid limb bones are undiagnostic below the family level, we agree with Vitek and Danilov (2010) that this taxon is a nomen dubium.

Khosatzky (1966) referred the caudal part of a large pan-trionychid carapace with an estimated shell length of about $70 \mathrm{~cm}$ from the type locality to Trionyx zakhidovi, probably using a geographic rationale. Given that T. zakhidovi must be considered a nomen dubium, we agree with Vitek and Danilov (2010) and Danilov and Vitek (2012) that it is best to refer this specimen to the roughly coeval "T." kansaiensis using the diagnostic characters it displays.

Zaisanonyx jimenezfuentesi Chkhikvadze, 2008b nomen dubium

Taxonomic history. Paleotrionyx jimenezfuentesi Chkhikvadze 1995 (nomen nudum); Eurycephalochelys jimenezfuentesi Chkhikvadze 2007 (nomen nudum); Zaisanonyx jimenezfuentesi Chkhikvadze, 2008b (new species).

Type material. IPGAS 7-1-137 (holotype), a partial nuchal (Chkhikvadze 2008b, fig. 8a, b).

Type locality. Treugol'nik Locality, Kalmakpay River, Zaysan Depression, East Kazakhstan Region, Kazakhstan; Obayla suite, middle Eocene (Chkhikvadze 2008b, 2010).

Comments. Zaisanonyx jimenezfuentesi was established on the basis of a partial nuchal, which was initially tentatively referred to Paleotrionyx muyuensis (Chkhikvadze 1990). The full nuchal can be inferred to have been about $20 \mathrm{~cm}$ wide. Chkhikvadze (2007) discussed possible affinities of this fragment with the European giant form Axestemys vittata, assigning it to Eurycephalochelys, but finally used it for the basis of a new species (Chkhikvadze 2008b). We find the type material to be too fragmentary to diagnose a valid taxon and therefore consider Zaisanonyx jimenezfuentesi to be a nomen dubium.

\section{Acknowledgments}

We would like to thank an extensive list of people, who provided us with information or photographs of specimens or access to literature or collections. 
In partial alphabetical order, these include Jaroslav Bažant and Pavel Dvořák (OMM), Giovanni Bianucci and Chiara Sorbini (University of Pisa), Edwin Cadena (Yachay Tech), Marta CalvoRevuelta (MNCN), Andrej Čerňanský and Jozef Klembara (Comenius University of Bratislava), Elisabetta Cioppi (IGF), Massimo Delfino and Márton Rabi (University of Turin), Boris Ekrt (NMP), Letizia Del Favero and Mariagabriella Fornasiero (MGP-PD), Annelise Folie and Thierry Smith (IRSNB), Rafaella Garbin and Halim Zinaoui (University of Fribourg), Richard Gemel and Ursula Göhlich (NHMW), Martin Gross (UMJGP), Ren Hirayama (Waseda University, Tokyo), Dražen Japundžić (CNHM), Tassos Kotsakis (University of Rome 3), Yves Laurent (MHNT), László Makádi (MFGI), Robin Marchant (MGL), Silvia Menéndez (MG-IGME), Eckhard Mönnig (NMCL), Daniele Ormezzano (MGPT-PU), David Reese (Yale University), Lorenzo Rook (Università di Firenze), Liana Sasaran (MTB), Daniela Schwarz (MB), Zuzana Vařilová (MMUL), Stefan Vasile (University of Bucharest), Judit Vörös (Hungarian Natural History Museum), Matyas Vremir (Transylvanian Museum Society), and Daniel Zoboli (University of Cagliari). Massimo Delfino (University of Turin), Natasha Vitek (University of Florida), and Igor Danilov (ZIN PH) provided us with many valuable comments before, during, and after the review process. We would like also to thank Igor Danilov (ZIN PH), Massimo Delfino and Márton Rabi (University of Turin), Juliana Sterli (Museo Egidio Feruglio), and Madalina Bonta and Virginie Volpato (University of Fribourg) for spell-checking literature in their native tongues. This project was supported by SYNTHESYS ES-TAF-5910, SYNTHESYS AT-TAF-5911, and SYNTHESYS HU-TAF-6145, as well as travel funding from the Universities of Fribourg and Turin to G.L.G.

Received 15 April 2016; revised and accepted 19 December 2016.

\section{Appendix 1 Institutional Abbreviations}

AMNH

American Museum of Natural History,

$\mathrm{BMNH}$ New York, New York, USA

BSPG

CCMGE

CNHM

CPS-UL

GBAW

GIML

$\mathrm{GMH}$

GSI

GSJ

GSP

HLMD

HNSM

IGF

IMC

IPGAS

IPUW

IRSNB

ITCAM

IVPP

IZ-BAS

IZK

KUL

LBG-UD

LG-FSM

$\mathrm{MB}$

Natural History Museum, London, MDLCA United Kingdom
Bayerische Staatssammlung für Paläontologie und historische Geologie, Munich, Germany

Chernyshev's Central Museum of Geological Exploration, St. Petersburg, Russia

Croatian Natural History Museum, Zagreb, Croatia

Centre de paléontologie stratigraphique et paléoécologie, Université de Lyon 1, Villeurbanne, France

Geologische Bundesanstalt Wien, Vienna, Austria

Department für angewandte Geowissenschaften und Geophysik, Montanuniversität Leoben, Leoben, Austria

Geological Museum of Heilongjiang, Harbin, China

Geological Society of India, Bengaluru, India

Geological Survey of Japan, Tsukuba, Japan

Geological Survey of Pakistan, Islamabad, Pakistan

Hessisches Landesmuseum Darmstadt, Darmstadt, Germany

Hiwa Natural Sciences Museum, Hiwa, Japan

Museo di Storia Naturale, Università degli Studi di Firenze, Florence, Italy

Indian Museum of Kolkata, Kolkata, India

Institute of Paleobiology, Georgian Academy of Sciences, Tbilisi, Georgia

Institut für Paläontologie, University of Vienna, Austria

Institut royal des Sciences naturelles de Belgique, Brussels, Belgium

Istituto Tecnico Commerciale Archimede, Modica, Italy

Institute of Vertebrate Paleontology and Paleoanthropology, Beijing, China

Institute of Zoology, Bulgarian Academy of Sciences, Sofia, Bulgaria

Institute of Zoology, Academy of Sciences of Kazakhstan, Almaty, Kazakhstan

Kyushu University Library, Kyushu, Japan

Laboratoire Biogéosciences, Université de Bourgogne, Dijon, France

Laboratoire de Geologie, Université de Montpellier, Montpellier, France

Museum für Naturkunde Berlin, Berlin, Germany

Museo Sardo di Geologia e Paleontologia "Domenico Lovisato," Cagliari, Italy 


\begin{tabular}{|c|c|c|}
\hline MFGI & $\begin{array}{l}\text { Magyar Földtani és Geofizikai Intézet, } \\
\text { Budapest, Hungary }\end{array}$ & \multirow{2}{*}{$\begin{array}{l}\text { PIMUZ Paläontologisches Institut und Museum } \\
\text { der Universität Zürich, Zurich, } \\
\text { Switzerland }\end{array}$} \\
\hline MFM & $\begin{array}{l}\text { Mizunami Fossil Museum, Mizunami, } \\
\text { Japan }\end{array}$ & \\
\hline MG-IGME & $\begin{array}{l}\text { Museo Geominero, Instituto Geológico } \\
\text { y Minero de España, Madrid, Spain }\end{array}$ & $\begin{array}{l}\text { Paleontological Institute, Russian Acad- } \\
\text { emy of Sciences, Moscow, Russia }\end{array}$ \\
\hline MGL & $\begin{array}{l}\text { Musée cantonal de Géologie, Lausanne, } \\
\text { Switzerland }\end{array}$ & $\begin{array}{l}\text { Philipps-Universität Marburg, Mar- } \\
\text { burg, Germany }\end{array}$ \\
\hline MGP-PD & $\begin{array}{l}\text { Museo di Geologia e Paleontologia } \\
\text { dell'Università di Padova, Padua, }\end{array}$ & $\begin{array}{l}\text { Queensland Museum, Brisbane, Aus- } \\
\text { tralia }\end{array}$ \\
\hline \multirow[t]{2}{*}{ MGPT-PU } & $\begin{array}{l}\text { Italy } \\
\text { Museo di Geologia e Paleontologia, } \\
\text { Università degli Studi di Torino, }\end{array}$ & $\begin{array}{l}\text { Senckenberg Forschungsinstitut und } \\
\text { Naturmuseum, Frankfurt am Main, } \\
\text { Germany }\end{array}$ \\
\hline & Turin, Italy & Teylers Museum, Haarlem, The Nether- \\
\hline MHNB & $\begin{array}{l}\text { Museum d'histoire naturelle de Bor- } \\
\text { deaux, Bordeaux, France }\end{array}$ & Tohoku University, Tohoku, Japan \\
\hline MHNF & $\begin{array}{l}\text { Musée d'histoire naturelle Fribourg, } \\
\text { Switzerland }\end{array}$ & $\begin{array}{l}\text { Universalmuseum Joanneum, Geologie } \\
\text { und Paläontologie, Graz, Austria }\end{array}$ \\
\hline MHNT & $\begin{array}{l}\text { Museum d'histoire naturelle de } \\
\text { Toulouse, Toulouse, France }\end{array}$ & $\begin{array}{l}\text { Ur- und Vorgeschichtsmuseum Fritzlar, } \\
\text { Fritzlar, Germany }\end{array}$ \\
\hline MMB & $\begin{array}{l}\text { Museo Municipal de Barcelona, Barcelona, } \\
\text { Spain }\end{array}$ & $\begin{array}{l}\text { Yichang Institute of Geology and Min- } \\
\text { eral Resources, Wuhan, China }\end{array}$ \\
\hline MMUL & $\begin{array}{l}\text { Municipal Museum of Ústí nad Labem, } \\
\text { Ústí, Czechia }\end{array}$ & $\begin{array}{l}\text { Paleoherpetological Collection, Zoolog- } \\
\text { ical Institute of the Russian Academy }\end{array}$ \\
\hline MNHN & Muséum national d'Histoire naturelle, & \multirow[b]{2}{*}{$\mathrm{ZPM}$} \\
\hline MPC & $\begin{array}{l}\text { Paris, France } \\
\text { Mongolian Palaeontological Centre, } \\
\text { Ulaanbaatar, Mongolia }\end{array}$ & \\
\hline MPP & $\begin{array}{l}\text { Museo Paleontologico Parmense, Parma, } \\
\text { Italy }\end{array}$ & \multirow{4}{*}{$\begin{array}{l}\text { Altaytrionyx Chkhikvadze, 2008b (type species: Plas- } \\
\text { tomenus gabunii Chkhikvadze, 1984) }\end{array}$} \\
\hline MSNP & $\begin{array}{l}\text { Museo di Storia Naturale di Pisa, Pisa, } \\
\text { Italy }\end{array}$ & \\
\hline MTB & $\begin{array}{l}\text { Museum of the Transylvanian Basin, Uni- } \\
\text { versity of Cluj, Cluj-Napoca, Romania }\end{array}$ & \\
\hline MUSNAF & $\begin{array}{l}\text { Museo di Storia Naturale dell'Accade- } \\
\text { mia dei Fisiocritici, Siena, Italy }\end{array}$ & \\
\hline NHMW & $\begin{array}{l}\text { Naturhistorisches Museum Wien, } \\
\text { Vienna, Austria }\end{array}$ & \multirow{2}{*}{$\begin{array}{l}\text { Crassithecachelys Chkhikvadze, 2000a (type species: } \\
\text { Plastomenus mlynarskii Chkhikvadze, 1970) }\end{array}$} \\
\hline NMC & $\begin{array}{l}\text { National Museum of Colombo, } \\
\text { Colombo, Sri Lanka }\end{array}$ & \\
\hline NMCL & $\begin{array}{l}\text { Naturkundemuseum Coburg, Coburg, } \\
\text { Germany }\end{array}$ & $\begin{array}{l}\text { Drazinderetes Head et al., } 1999 \text { (type species: Drazin- } \\
\text { deretes tethyensis Head et al., 1999) }\end{array}$ \\
\hline NMENHM & $\begin{array}{l}\text { National Museum of Ethnography and } \\
\text { Natural History of Moldova, } \\
\text { Chișinau, Moldova }\end{array}$ & $\begin{array}{l}\text { Eurycephalochelys Moody and Walker, } 1970 \text { (type } \\
\text { species: Eurycephalochelys fowleri Moody and Walker, } \\
\text { 1970) }\end{array}$ \\
\hline NMK & $\begin{array}{l}\text { National Museum of Kenya, Nairobi, } \\
\text { Kenya }\end{array}$ & $\begin{array}{l}\text { Francedebroinella Chkhikvadze, 1999a (type species: } \\
\text { Plastomenus minusculus Chkhikvadze, 1973) }\end{array}$ \\
\hline NMM & $\begin{array}{l}\text { Naturhistorisches Museum Mainz, } \\
\text { Mainz, Germany }\end{array}$ & $\begin{array}{l}\text { Gobiapalone Danilov et al., } 2014 \text { (type species: Amyda } \\
\text { orlovi Khosatzky, 1976) }\end{array}$ \\
\hline NMP & $\begin{array}{l}\text { Národní Muzeum Praha, Prague, } \\
\text { Czechia }\end{array}$ & $\begin{array}{l}\text { Khunnuchelys Brinkman et al., } 1993 \text { (type species: Khun- } \\
\text { nuchelys erinhotensis Brinkman et al., 1993) }\end{array}$ \\
\hline NMR & $\begin{array}{l}\text { Naturkundemuseum } \\
\text { Regensburg, Germany }\end{array}$ & $\begin{array}{l}\text { Kuhnemys Chkhikvadze, 1999b (type species Aspideretes } \\
\text { maortuensis Yeh, 1965) }\end{array}$ \\
\hline NOLM & Landesmuseum Niederösterreich, St. & $\begin{array}{l}\text { Murgonemys White, } 2001 \text { (type species: Murgonemys } \\
\text { braithwaitei White, 2001) }\end{array}$ \\
\hline NTUM & National Taiwan University, Taipei, China & $\begin{array}{l}\text { Nemegtemys Danilov et al., } 2014 \text { (type species: Nemegte- } \\
\text { mys conflata Danilov et al., 2014) }\end{array}$ \\
\hline
\end{tabular}


Palaeoamyda Cadena, 2016 (type species: Trionyx messelianus Reinach, 1900)

Paraplastomenus Kordikova, 1994a (type species: Plastomenus mlynarskii Chkhikvadze, 1970)

Perochelys Li, Joyce, and Liu, 2015 (type species: Perochelys lamadongensis Li, Joyce, and Liu 2015)

Petrochelys Vitek et al., 2017 (type species: Trionyx kyrgyzensis Nessov, 1995b)

Procyclanorbis Portis, 1901 (type species: Procyclanorbis sardus Portis, 1901)

Rafetoides Karl, 1998 (type species: Trionyx henrici Owen in Owen and Bell, 1849)

Sinamyda Chkhikvadze, 2000a (type species: Trionyx fuchienensis Yeh, 1974)

Ulutrionyx Kordikova, 1994a (type species: Trionyx ninae Chkhikvadze, 1971)

Zaisanonyx Chkhikvadze, 2008b (type species: Zaisanonyx jimenezfuentesi Chkhikvadze, 2008b)

\section{Appendix 3 \\ Biogeographical Summary of Old World Pan-Trionychid Turtles}

Numbers in brackets reference Figures 3 to 6 . Literature lacking catalogued or described or figured specimens is omitted, as also all fossil Holocene records. Abbreviations: T., Trionyx; TL, type locality.

\section{Algeria}

[1] Pliocene, Zanclean-early Piacenzian; Constantine Province; Pan-Trionychidae indet. (Arambourg 1956)

\section{Australia}

[2] Early Eocene; Murgon, Queensland; Murgonemys braithwaitei (TL) (White 2001; Trionychidae indet. of Gaffney and Bartholomai 1979)

[3] Pliocene; Darling Downs, Queensland; Pan-Trionychidae indet. (Louys and Price 2015)

[4] Pleistocene; Queensland; Pan-Trionychidae indet. (T. australiensis of De Vis 1894; Trionychidae indet. of Gaffney and Bartholomai 1979)

\section{Austria}

[5] Early Eocene, late Ypresian; Salzburg; Pan-Trionychidae indet. (Trionyx sp. of Schleich 1988; Amyda cf. boulengeri of Karl 1996)

[6] Middle Miocene; Carinthia; T. vindobonensis (T. petersi siegeri of Mottl 1967), Pan-Trionychinae indet. (T. petersi siegeri of Mottl 1967; T. petersi of Wank 1977)

[7] Miocene; Styria; middle Miocene, Langhian: T. vindobonensis (Peters 1855, 1859; T. petersi and T. septemcostatus of Hoernes 1881; T. hoernesi, T. peneckei, and T. siegeri of Heritsch 1909), Pan-Trionychinae indet. (T. stiriacus of Peters 1855, 1859, 1869; T. sophiae of Heritsch 1909; T. petersi of
Heritsch 1910; T. hilberi of Teppner 1914a); middle Miocene, Langhian-Serravallian: Pan-Trionychinae indet. (T. hilberi of Hoernes 1892); late Miocene: PanTrionychinae indet. (Trionyx sp. of Toula 1882)

[8] Miocene; Vienna; middle Miocene, Serravallian: T. vindobonensis (TL) (Peters 1855, 1859); late Miocene, Tortonian: Pan-Trionychidae indet. (Trionyx sp. of Bachmayer 1966)

[9] Late Miocene, Tortonian; Burgenland; T. vindobonensis (T. rostratus of Arthaber 1898), Pan-Trionychinae indet. (T. partschii of Peters 1855)

[10] Mio/Pliocene; Lower Austria; early Miocene, Burdigalian: T. vindobonensis (T. teiritzbergensis of Gemel 2002), Pan-Trionychinae indet. (Trionychidae indet. of Depéret 1895); late Miocene, Tortonian: T. vindobonensis (Papp et al. 1953), Pan-Trionychidae indet. (Trionyx sp. of Delfino and Göhlich 2009); Early Pliocene; Pan-Trionychinae indet. (Trionyx sp. aff. rostratus of Glaessner 1933)

\section{Belgium}

[11] Late Paleocene, Thanetian; Walloon Brabant; PanTrionychidae indet. (Broin 1977; Groessens van Dyck and Schleich 1988)

[12] Eocene; early Eocene, Ypresian, Flemish Brabant: Pan-Trionychidae indet. (Trionyx sp. of Groessens van Dyck and Schleich 1988); early Eocene, Ypresian, Hainaut: Axestemys vittata (T. erquelinnensis and T. levalensis of Dollo 1909; Broin 1977); middle Eocene, Lutetian, Brussels Capital Region: Pan-Trionychidae indet. (T. bruxelliensis of Winkler 1869a, 1869b); middle Eocene, Lutetian, East Flanders: Pan-Trionychidae indet. (Groessens van Dyck and Schleich 1988); middle Eocene, Lutetian, Flemish Brabant: Pan-Trionychidae indet. (Groessens van Dyck and Schleich 1988); middle Eocene, Lutetian, Walloon Brabant: Pan-Trionychidae indet. (Trionyx sp. of Groessens van Dyck and Schleich 1988)

[13] Early Oligocene, Rupelian; Antwerp; Pan-Trionychidae indet. (T. stormsi of Delheid 1899)

\section{Bulgaria}

[14] Late Eocene, Priabonian; Stara Zagora; Trionychidae indet. (T. capellinii bulgaricus of Khosatzky et al. 1983)

[15] Miocene; Vidin; Pan-Trionychinae indet. (Trionyx sp. of Pamouktchiev et al. 1998)

\section{Chad}

[16] Late Miocene, Tortonian; Borkou; Pan-Trionychidae indet. (Trionychidae indet. of Vignaud et al. 2002)

[17] Late Pliocene, Piacenzian; Borkou; Pan-Trionychidae indet. (Trionyx sp. of Priem 1914)

\section{China}

[18] Cretaceous, state uncertain; Fujian Province; PanTrionychidae indet. (Sinamyda fuchienensis of Yeh 1974) 
[19] Cretaceous, stage uncertain; Jilin (= Chilin) Province; Pan-Trionychidae indet. (Yeh 1963)

[20] Early Cretaceous, stage uncertain; Inner Mongolia; Pan-Trionychidae indet. (Gilmore 1931)

[21] Early Cretaceous, Aptian; Liaoning Province; Perochelys lamadongensis (TL) (Li, Joyce, and Liu 2015)

[22] Early Cretaceous, Aptian/Albian; Heilongjiang Province; "T." jixiensis (TL) (Li, Tong et al. 2015)

[23] Late Cretaceous, Turonian; Alxa (= Alashan), Inner Mongolia; Kuhnemys maortuensis (TL) (including T. alashanensis of Yeh 1965)

[24] Late Cretaceous, Campanian; Xilin Gol, Inner Mongolia; Khunnuchelys erinhotensis (TL) (Brinkman et al. 1993)

[25] Early Eocene; Hubei Province; Pan-Trionychidae indet. (Aspideretes muyuensis of Lei and Ye 1985)

[26] Eocene; Inner Mongolia; early Eocene: Pan-Trionychidae indet. (Gilmore 1934); middle Eocene: “T." gregarius (TL) (Gilmore 1934; including Rafetus gilmorei of Chkhikvadze 1999b), "T." johnsoni (TL) (Gilmore 1931, 1934; including "T." neimenguensis of Yeh 1965)

[27] Late Eocene; Guangdong Province; “T.” impressus (TL) (Yeh 1965)

[28] Late Eocene; Henan Province; Pan-Trionychidae indet. (Platypeltis subcircularis of Chow and Yeh 1957)

[29] Early Eocene; Shandong Province; "T." linchuensis (TL) (Yeh 1962)

[30] Late Eocene-early Oligocene; Zhejiang Province; Pan-Trionychidae indet. (= Amyda sp. of Yeh 1962)

[31] Middle Miocene, Serravallian; Inner Mongolia; Pan-Trionychidae indet. (T. sculptus of Gilmore 1931)

[32] Pliocene; Shanxi Province; Pelodiscus gracilia (TL), Pan-Trionychidae indet. (including Pelodiscus cf. sinensis of Yeh 1963)

[33] Late Pliocene or early Pleistocene; Shanxi Province; Pelodiscus indet. (T. sinuosus of Chow and Yeh 1958)

[34] Late Pleistocene; Taiwan Island; Rafetus swinhoei (T. liupani of Tao 1986)

\section{Croatia}

[35] Late Eocene-early Oligocene, PriabonianRupelian; Šibenik-Knin; Pan-Trionychidae indet. (T. austriacus of Peters 1859; T. cf. capellinii of Paunovic 1984)

[36] Middle Miocene, Langhian; Varaždin; Pan-Trionychinae indet. (T. croaticus of Koch 1915)

\section{Cyprus}

[37] Miocene; Pan-Trionychidae indet. (Reed 1932; Hadjisterkotis et al. 2000)

\section{Czechia}

[38] Late Eocene; Ústí nad Labem (= Ústecký); Pan-Trionychidae indet. (Trionyx sp. of Laube 1882 and Kvaček 2002)
[39] Early Miocene, Burdigalian; Ústí nad Labem (= Ústecký); Rafetus bohemicus (TL) (Liebus 1930), PanTrionychinae indet. (Trionyx sp. of Stur 1874; T. pontanus of Laube 1895, 1896; T. aspidiformis and T. preschenensis of Laube 1898, 1900; T. elongatus of Liebus 1930)

\section{Democratic Republic of Congo}

[40] Late Miocene-early Pliocene; Orientale Province; Pan-Trionychidae indet. (Hirayama 1992)

\section{Denmark}

[41] Early Paleocene, Danian; Capital Region of Denmark; Pan-Trionychidae indet. (Trionyx sp. of Rosenkrantz 1923; Rafetoides cf. henrici of Karl and Lindow 2012)

\section{Egypt}

[42] Early Miocene, Burdigalian; Matruh Governorate; Pan-Trionychidae indet. (T. senckenbergianus of Reinach 1903; Trionyx sp. of Dacqué 1912)

[43] Late Miocene, Messinian; Beheira Governorate; Pan-Trionychidae indet. (Dacqué 1912).

[44] Pliocene; Beheira Governorate; Pan-Trionychidae indet. (Andrews 1902; T. pliocaenicus of Reinach 1903)

[45] Middle Pleistocene; New Valley Governorate; PanTrionychidae indet. (Churcher et al. 1999)

\section{Ethiopia}

[46] Pliocene-Pleistocene; Oromia Region; Pan-Trionychidae indet. (Broin 1979)

\section{France}

[47] Late Paleocene, late Thanetian; Grand Est; Pan-Trionychidae indet. (Trionyx sp. of Bergounioux 1932)

[48] Late Paleocene, late Thanetian; Hauts-de-France; Pan-Trionychidae indet. (Palaeotrionyx [sic] sp. and Trionychidae indet. of Smith et al. 2014)

[49] Eocene; Île-de-France; early Eocene, early Ypresian: Axestemys vittata (Palaeotrionyx [sic] vittatus of Broin 1977); middle Eocene, late Lutetian: "T." henrici (Trionyx sp. of Lapparent de Broin et al. 1993); late Eocene, Priabonian: Pan-Trionychidae indet. (Trionyx sp. of Cuvier 1821-1824; T. parisiensis of Gray 1831, Meyer 1832, and Lydekker 1889a)

[50] Eocene; Occitanie; early Eocene, Ypresian: Pan-Trionychidae indet. (Broin 1977; Trionyx sp. of Laurent et al. 2010); middle Eocene, Lutetian: Pan-Trionychidae indet. (Trionyx sp. of Cuvier 1821-1824; T. dodunii of Gray 1831; Fitzinger 1836)

[51] Eocene; Nouvelle-Aquitaine; middle Eocene, Bartonian: Pan-Trionychidae indet. (Broin 1977); late Eocene, Priabonian: Pan-Trionychidae indet. (Trionyx sp. Cuvier 1821-1824; T. laurillardii of Gray 1831; Bergounioux 1935) 
[52] Early Eocene, Ypresian; Grand-Est; “T.” silvestris (T. michauxi of Broin 1977), Axestemys vittata, Pan-Trionychidae indet. (Palaeotrionyx [sic] vittatus of Broin 1977)

[53] Early Eocene, Ypresian; Hauts-de-France; Axestemys vittata (TL) (T. vittatus of Pomel 1847; Palaeotrionyx [sic] vittatus of Broin 1977; Eurycephalochelys aff. vittatus of Augé et al. 1997), Pan-Trionychidae indet. (Trionyx sp. of Augé et al. 1997)

[54] Late Eocene; Auvergne-Rhône-Alpes; Pan-Trionychidae indet. (Trionyx sp. of Bergounioux 1936)

[55] Early Oligocene, Rupelian; Nouvelle-Aquitaine; Pan-Trionychidae indet. (T. burdigalensis of Bergounioux 1935; Trionyx sp. of Broin 1977)

[56] Early Oligocene, Rupelian; Auvergne-Rhône-Alpes; Pan-Trionychidae indet. (Tryonix [sic] sp. of Pomel 1846)

[57] Oligocene; Occitanie; early Oligocene, Rupelian: PanTrionychidae indet. (Broin 1977); late Oligocene, Chattian: Pan-Trionychidae indet. (Trionyx sp. of Cuvier 1821-1824; T. amansii of Gray 1831; T. dieupentalensis of Bergounioux 1935; Trionyx sp. of Broin 1977)

[58] Early Oligocene or early Miocene, Rupelian or Aquitanian; Provence-Alpes-Côte d'Azur; Pan-Trionychidae indet. (T. manouri of Cuvier 1821-1824 and Gray 1831)

[59] Late Oligocene or early Miocene, Chattian or Aquitanian; Occitanie; Pan-Trionychidae indet. (Trionyx sp. of Gervais 1867-1869; T. acutiformis, T. chaubeti, T. ciryi, and T. mourieri of Bergounioux 1935; Trionyx sp. of Broin 1977)

[60] Miocene; Centre-Val de Loire; early Miocene, Burdigalian: T. vindobonensis (T. stiriacus of Broin 1977), Pan-Trionychinae indet. (Trionyx sp. of Cuvier 1821-1824; T. lockardi of Gray 1831); middle Miocene, Langhian: Pan-Trionychinae indet. (Broin 1977; Gobé et al. 1980; Trionyx sp. of Augé et al. 2002; Trionyx sp. of Gagnaison et al. 2012)

[61] Miocene; Occitanie; early Miocene, Burdigalian: Pan-Trionychidae indet. (Broin 1977); middle Miocene, Langhian: Pan-Trionychidae indet. (Broin 1977); late Miocene, Tortonian: Pan-Trionychidae indet. (Broin 1977)

[62] Early Miocene; Nouvelle-Aquitaine; Aquitanian: Pan-Trionychidae indet. (Broin 1977); Burdigalian: Pan-Trionychinae indet. (T. aquitanicus of Delfortrie 1869 and Lydekker 1889a)

[63] Middle Miocene, Langhian; Pays de la Loire; PanTrionychinae indet. (Broin 1977)

[64] Pliocene; Occitanie; Trionychinae indet. (Trionyx sp. of Gervais 1867-1869; Trionyx pliopedemontana of Depéret and Donnezan 1890-1897; T. blayaci, T. pliopedemontana, T. pompignanensis, T. rotundiformis, and Trionyx sp. of Bergounioux 1933, 1935; T. pliopedemontanus of Broin 1977)

\section{Georgia}

[65] Middle Miocene, Serravallian; Kakheti Region; Pan-Trionychidae indet. (Bakradze and Chkhikvadze 1988)
[66] Middle Miocene, Serravallian; Kvemo Kartli Region; Pan-Trionychidae indet. (Bakradze and Chkhikvadze 1988)

\section{Germany}

[67] Middle Eocene, Lutetian; Bavaria; Pan-Trionychidae indet. (Rafetoides cf. austriacus of Karl 2002)

[68] Middle Eocene; Upper Rhine Basin (Hesse and Rhineland-Palatinate); "T." messelianus (TL) (Reinach 1900; Harrassowitz 1919; Hummel 1927; Palaeoamyda messeliana of Cadena 2016), Pan-Trionychidae indet. (Schleich 1994; Gröning and Brauckmann 1996)

[69] Middle Eocene, Lutetian; Saxony-Anhalt; “T.” messelianus (Palaeoamyda messeliana of Cadena 2016), Pan-Trionychidae indet. (Trionyx sp. of Barnes 1927; Trionyx sp. of Hummel 1935; Krumbiegel 1963; Amyda boulengeri of Karl 1993)

[70] Oligocene; Upper Rhine Basin; early Oligocene, Rupelian, Hesse: Pan-Trionychidae indet. (T. borkenensis of Gramann 1956; T. aff. borkenensis of Schleich 1986; Schleich 1994; Rafetoides austriacus of Karl and Müller 2008); early Oligocene, Rupelian, Rhineland-Palatinate: "T." boulengeri (TL) (T. gergensi of Lydekker 1889a; Reinach 1900); late Oligocene, Chattian, Rhineland-Palatinate: Pan-Trionychidae indet. (Mörs 1998)

[71] Early Oligocene, Rupelian; Baden-Württemberg; Pan-Trionychidae indet. (Trionychidae indet. of Maxwell et al. 2016)

[72] Early Oligocene, Rupelian; Saxony; Pan-Trionychidae indet. (Karl 1993; T. triunguis of Karl 2007)

[73] Late Oligocene, Chattian; Bavaria; Pan-Trionychidae indet. (Schleich 1985; Trionyx sp. of Darga et al. 1999; Trionyx sp. of Böhme 2008; Trionyx cf. triunguis of Karl et al. 2011)

[74] Miocene; Baden-Württemberg; early Miocene, Aquitanian: Pan-Trionychinae indet. (Schleich 1985); early Miocene, Burdigalian: Pan-Trionychinae indet. (Schleich 1985); early to middle Miocene, Burdigalian-Langhian: Pan-Trionychinae indet. (T. triunguis of Karl 2013); middle Miocene, Serravallian: $T$. vindobonensis (T. teyleri of Winkler 1869a, 1869b); middle-late Miocene, Serravallian-Tortonian: PanTrionychinae indet. (T. triunguis of Karl 2013); late Miocene, Tortonian: Pan-Trionychinae indet. (Schleich 1985)

[75] Miocene; Bavaria; early Miocene, Aquitanian: PanTrionychinae indet. (Trionyx sp. of Kuss 1958); early Miocene, Burdigalian: Pan-Trionychinae indet. (Schleich 1985); middle Miocene, Langhian: T. vindobonensis (T. brunhuberi of Ammon 1911 and Fuchs 1939); Trionychinae indet. (T. bohemicus, T. bohemicus jaegeri, and Trionyx sp. of Fuchs 1939), Pan-Trionychidae indet. (Trionyx aff. bohemicus of Schleich 1981, 1985; Groessens-van Dyck and Schleich 1985); middle Miocene, Serravallian: Pan-Trionychidae indet. (Schleich 1985; Karl 1993); late Miocene, Tortonian: Pan-Trionychinae indet. (Schleich 1985) 
[76] Miocene; Hesse; early Miocene, Aquitanian: PanTrionychinae indet. (T. münzenbergensis of Hummel 1927); late Miocene (Tortonian): Pan-Trionychidae indet. (Trionychidae of Eikamp 1978)

[77] Miocene; North Rhine-Westphalia; early Miocene, Burdigalian: Pan-Trionychinae indet. (Schleich 1985); middle Miocene: Pan-Trionychinae indet. (Trionyx sp. of Klein and Mörs 2003)

[78] Miocene; Rhineland-Palatinate; early Miocene, Aquitanian: T. vindobonensis (Aspidonectes/T. gergensi of Meyer 1844, Lydekker 1889a, and Reinach 1900); late Miocene, Messinian: Pan-Trionychinae indet. (T. oweni of Reinach 1900)

[79] Miocene; Thuringia; early Miocene, Burdigalian: Pan-Trionychinae indet. (Böhme 1995); early to middle Miocene, Burdigalian-Langhian: Pan-Trionychinae indet. (Karl 1993)

\section{Greece}

[80] Late Miocene, Tortonian; Crete; Pan-Trionychidae indet. (Georgalis et al. 2016b)

[81] Late Pliocene, Piacenzian; Central Macedonia; PanTrionychidae indet. (Vlachos et al. 2015)

\section{Hungary}

[82] Eocene; Northern Hungary: Pan-Trionychidae indet. (T. austriacus of Peters 1859); middle Eocene, Central Transdanubia: Pan-Trionychidae indet. (Ösi 2001); late Eocene, Central Hungary: Pan-Trionychidae indet. (Mlynarski 1966)

[83] Oligocene; Early Oligocene, Rupelian, Central Hungary: Pan-Trionychidae indet. (Szalai 1934; Młynarski 1966); Oligocene, Central Transdanubia: Pan-Trionychidae indet. (Mlynarski 1966; Rabi and Botfalvai 2008)

[84] Miocene; early Miocene, Burdigalian, Central Hungary: Pan-Trionychinae indet. (Szalai 1934; Mlynarski 1966); middle Miocene, Serravallian, Central Hungary: Pan-Trionychinae indet. (T. pseudovindobonensis of Szalai 1934); late Miocene, early Messinian, Central Hungary: Pan-Trionychinae indet. (Szalai 1934; Mlynarski 1966); late Miocene, Northern Hungary: Pan-Trionychinae indet. (MYynarski 1966); late Miocene, Tortonian, Southern Transdanubia: PanTrionychinae indet. (Mlynarski 1966)

\section{India}

[85] Eocene Gujarat; early Eocene, Ypresian: Pan-Trionychidae indet. (Trionychidae indet. of Smith et al. 2016); middle Eocene: Pan-Trionychidae indet. (Trionyx sp. of Sahni and Mishra 1975)

[86] Middle Eocene; Himachal Pradesh; Pan-Trionychidae indet. (Trionyx sp. of Sahni et al. 1981, 1984)

[87] Late Pliocene; Himachal Pradesh; Chitra indet., Nilssonia indet. (Aspideretes cf. gangeticus and Chitra cf. indica of Srivastava and Patnaik 2002)
[88] Pliocene; Piram (= Perim) Island, Gujarat; Lissemys indet. (Emyda cf. vittata of Lydekker 1889a; Emyda cf. granosa of Lydekker 1889b; Lyssemys [sic] piramensis of Prasad 1974)

[89] Pleistocene; Tamil Nadu; Lissemys indet. (Lissemys punctata of Tripathi 1964)

[90] Pleistocene; Madhya Pradesh; Nilssonia gangetica, Pan-Trionychidae indet. (T. gangeticus and Trionyx sp. of Lydekker 1889b)

\section{Indonesia}

[91] Late Pleistocene; Borneo; Pan-Trionychidae indet. (T. phayrei of Lydekker 1889a)

[92] Pleistocene; Java; Amyda cartilaginea (T. trinilensis of Jaekel 1911; T. cartilagineus of Karl 1987), Chitra chitra (Chitra selenkae of Jaekel 1911; Chitra indica of Karl 1987), Pelochelys cantorii, Pan-Trionychinae indet. (Chitra minor of Jaekel 1911)

[93] Pleistocene; Sulawesi (= Celebes); Pan-Trionychidae indet. (Hooijer 1954)

\section{Iraq}

[94] Late Miocene, Tortonian; Diyala Governorate; PanTrionychidae indet. (Trionyx sp. of Thomas et al. 1980)

\section{Israel}

[95] Pleistocene; Haifa; Pan-Trionychidae indet. (Trionyx sp. of Bate 1934)

\section{Italy}

[96] Eocene; Prealpine Basin; middle Eocene, Piedmont: Pan-Trionychidae indet. (Sacco 1889); middle Eocene, Lutetian, Veneto: "T." capellinii (TL) (including T. affinis and T. gemmellaroi of Negri 1892, T. c. conjugens of Sacco 1894, T. intermedius of Bergounioux 1954 and T. c. capellinii of Kotsakis 1977), Pan-Trionychidae indet. (T. marginatus of Zigno 1889); middle Eocene, Bartonian, Veneto: Pan-Trionychinae indet. (Portis 1885; T. roncensis of Harrassowitz 1919)

[97] Middle Eocene, early Lutetian; Sardinia; Pan-Trionychidae indet. (Trionyx sp. of Kotsakis 1985)

[98] Oligocene; Prealpine Basin; late Oligocene, Chattian, Liguria: Pan-Trionychidae indet. (Issel 1892); Oligocene, Piedmont: Pan-Trionychidae indet. (T. pedemontana of Portis 1879); late Oligocene or early Miocene, Piedmont: Pan-Trionychidae indet. (T. pedemontana of Portis 1879; T. anthracotheriorum of Portis 1883; Trionyx sp. of Chesi 2009); early Oligocene, early Rupelian, Veneto: "T." capellinii (T. italicus of Schauroth 1865; T. c. montevialensis of Negri 1892 and Fabiani 1915; T. schaurothianus of Negri 1893; T. c. gracilina and T. c. perexpansa of Sacco 1895; T. insolitus of Bergounioux 1954; T. c. montevialensis and T. c. schaurothianus of Barbera and Leuci 1980); Oligocene, Veneto: Pan-Trionychinae indet. (T irregularis of Bergounioux 1954) 
[99] Late Oligocene, Chattian; Calabria; Pan-Trionychinae indet. (Tryonix $[$ sic] sp. of Gastaldi 1863; T. oligocenica of Portis 1885)

[100] Early to middle Miocene, Burdigalian-Langhian; Apulia; Pan-Trionychidae indet. (Chesi 2009); Miocene; Apulia; Pan-Trionychidae indet. (Capellini 1878)

[101] Miocene; Prealpine Basin; late Miocene, Messinian, Emilia-Romagna: Pan-Trionychidae indet. (Trionyx sp. of Kotsakis 1989); late Miocene or Pliocene, Emilia-Romagna: Pan-Trionychinae indet. (Aspilus cortesii of Portis 1885); middle Miocene, Serravallian, Friuli-Venezia Giulia: Pan-Trionychidae indet. (Dalla Vecchia 2007); early Miocene, Piedmont: Pan-Trionychidae indet. (Negri 1892); early Miocene, Burdigalian, Veneto: Pan-Trionychinae indet. (T. subangularis of Bergounioux 1954)

[102] Miocene; Sardinia; early Miocene: Pan-Trionychidae indet. (Trionyx sp. of Chesi 2009; Zoboli and Pillola 2017); late Miocene, Tortonian-Messinian; Pan-Trionychinae indet. (Procyclanorbis sardus of Portis 1901; Amyda sardus of Comaschi Caria 1959)

[103] Middle Miocene (Langhian); Sicily; Pan-Trionychidae indet. (Trionix ragusensis of De Gregorio 1883)

[104] Late Miocene, Tortonian; Tuscany; Pan-Trionychinae indet. (T. bambolii, T. portisi, T. senensis, T. propinquus, and Trionyx sp. of Ristori 1891a, 1891b, 1895; Trionyx sp. of Merciai 1907)

[105] Pliocene; Piedmont; Pan-Trionychidae indet. (T. aegypticus of Sismonda 1836, 1839; T. pedemontana of Portis 1879; T. pliopedemontana of Sacco 1889; Delfino 2002; Chesi 2009)

[106] Pliocene; early Pliocene, Zanclean, Tuscany: PanTrionychinae indet. (T. propinquus of Ristori 1891a, 1895); Pliocene, indeterminate stage, Tuscany: $T$. pliocenicus (TL) (Lawley 1876; Fucini 1912); late Pliocene-early Pleistocene, late Zanclean-Piacenzian, Tuscany: Pan-Trionychinae indet. (Trionyx sp. of Portis 1890; T. cf. pliopedemontanus of Kotsakis 1980); late Pliocene-early Pleistocene, Zanclean-Piacenzian, Umbria: Pan-Trionychidae indet. (Trionyx sp. of Girotti et al. 2003)

[107] Early Pleistocene (Gelasian); Tuscany; Pan-Trionychinae indet. (Trionyx sp. of Portis 1890; T. cf. pliopedemontanus of Kotsakis 1980)

\section{Japan}

[108] Early Cretaceous, Barremian/Aptian; Fukui; PanTrionychidae indet. (Hirayama 1998; Hirayama et al. 2013; Nakajima et al. in press)

[109] Late Cretaceous, Coniacian/Santonian; Kumamoto; Pan-Trionychidae indet. (Hirayama 1998)

[110] Late Eocene, Priabonian; Yamaguchi; Pan-Trionychidae indet. (T. ubeensis of Chitani 1925)

[111] Late Oligocene; Yamaguchi; Pan-Trionychidae indet. (Trionychinae gen. et sp. indet. of Hasegawa et al. 2007)
[112] Early Miocene, Burdigalian; Hiroshima; Pan-Trionychidae indet. (T. ishiharaensis of Miura and Uyama 1987)

[113] Middle Miocene; Hokkaidō; Pan-Trionychidae indet. (T. desmostyli of Matsumoto 1918)

[114] Middle Miocene; Nagasaki; Pan-Trionychidae indet. (Trionyx sp. aff. desmostyli of Otsuka 1970)

[115] Late Pliocene; Mie; “T.” miensis (TL) (Okazaki and Yoshida 1977)

[116] Early Pleistocene; Nagasaki; Pan-Trionychidae indet. (T. kazusensis of Otsuka 1969)

\section{Kazakhstan}

[117] Late Cretaceous, Santonian/early Campanian; South Kazakhstan Region; "T." kansaiensis (Vitek and Danilov 2012), Pan-Trionychidae indet. (Prinada 1927; including Aspideretes jaxarticus and Plastomenus jaxarticus of Riabinin 1938 and T. zakhidovi of Khosatzky 1966)

[118] Late Cretaceous, Santonian/early Campanian; Kyzylorda Region; Khunnuchelys lophorhothon (TL), "T." kansaiensis, "T." onomatoplokos (TL), "T." riabinini (TL), Pan-Trionychidae indet. (Khosatzky 1957; Kuznetsov 1976; Kuznetsov and Shilin 1983; Nessov 1984; Kuznetsov and Chkhikvadze 1987; Vitek and Danilov 2010; Danilov, Vitek et al. 2015)

[119] Eocene; East Kazakhstan Region; early Eocene: Pan-Trionychidae indet. (Chkhikvadze 1970; Kordikova 1994b; Altaytrionyx devjatkini and Altaytrionyx phiruzae of Chkhikvadze 2008a; Plastomenus mlynarskii of Chkhikvadze 1970); middle Eocene: Pan-Trionychidae indet. (Chkhikvadze 1973; Plastomenus gabunii of Chkhikvadze 1984; Zaisanonyx jimenezfuentesi of Chkhikvadze 2008b; Altaytrionyx burtschaki of Chkhikvadze 2008a; Trionychidae indet. of Scheyer et al. 2017); late Eocene: "T." ninae (T. zaisanensis of Chkhikvadze 1973; Vitek and Danilov 2015), "T." minusculus (TL) (Plastomenus minusculus of Chkhikvadze 1973; Paraplastomenus minusculus of Kordikova 1994b)

[120] Early Oligocene; East Kazakhstan Region; PanTrionychidae indet. (Rafetus yexiangkuii of Chkhikvadze 1999b, 2007)

[121] Oligocene; Karagandy Region; “T." ninae (TL) (Chkhikvadze 1971; T. turgaicus of Kuznetsov and Chkhikvadze 1987; Vitek and Danilov 2015)

[122] Oligocene; Almaty Region; early Oligocene: Pan-Trionychidae indet. (Bazhanov and Kostenko 1961; Kordikova and Mavrin 1996); late Oligocene: Pan-Trionychidae indet. (Bazhanov and Kostenko 1961)

[123] Oligocene; Jambyl Region; Pan-Trionychidae indet. (Chkhikvadze 1971; Kordikova 1994b)

[124] Early to middle Miocene, late Burdigalian-early Langhian; Almaty Region; Pan-Trionychidae indet. (Bazhanov and Kostenko 1961) 
[125] middle Miocene; East Kazakhstan Region; PanTrionychidae indet. (T. jakhimovitchae of Chkhikvadze 1989)

\section{Kenya}

[126] Early Miocene, Burdigalian; Nyanza; Cycloderma victoriae (TL), Pan-Cyclanorbinae indet. (Andrews 1914; Broin 1979; Pickford 1986)

[127] Miocene; Rift Valley; middle Miocene, Serravallian: Pan-Cyclanorbinae indet. (Bishop and Pickford 1975); late Miocene: Pan-Trionychidae indet. (Pickford 1975; Wood 2013)

[128] Pliocene; Rift Valley; early Pliocene: Cycloderma debroinae (TL), Cyclanorbis turkanensis (TL), PanCyclanorbinae indet. (Meylan et al. 1990); Pliocene (indeterminate stage): Pan-Cyclanorbinae indet., PanTrionychidae indet. (Pickford 1986; Meylan et al. 1990); Plio/Pleistocene: Cyclanorbis elegans (Meylan et al. 1990)

[129] Pleistocene; Rift Valley; early Pleistocene: Trionyx sp. (T. cf. triunguis of Wood 1979); Middle Pleistocene, Calabrian; Rift Valley; Pan-Cyclanorbinae indet. (Bishop, Pickford, and Hill 1975)

\section{Kyrgyzstan}

[130] Early Cretaceous, Albian; Osh Province; Petrochelys kyrgyzensis (TL) (Vitek et al. 2017; "T." kyrgyzensis of Nessov 1995b; Danilov and Vitek 2013)

\section{Libya}

[131] Late Miocene, late Messinian; Benghazi Governorate; Pan-Trionychidae indet. (Trionyx sp. of D' Erasmo 1933; T. cf. triunguis of Wood 1987)

\section{Malawi}

[132] Pliocene; Northern Region; Pliocene, indeterminate stage: Cycloderma sp. (Wood 1979; Meylan et al. 1990); late Pliocene-early Pleistocene: Cyclanorbis sp., Cycloderma sp. (including Cycloderma senegalensis of Karl 2012)

\section{Malaysia}

[133] Late Pleistocene; Sarawak, Borneo Island; Amyda cartilaginea, Dogania subplana (Pritchard et al. 2009)

\section{Moldova}

[134] Miocene; middle Miocene, Serravallian, Anenii Noi: Pan-Trionychidae indet. (Khosatzky and Tofan 1970; Chkhikvadze 1983); middle Miocene, Serravallian, Ialoveni: Trionyx sp. (Khosatzky and Tofan 1970; Chkhikvadze 1983; T. moldaviensis of Khosatzky 1986); middle Miocene, Chişinau: Pan-Trionychidae indet. (Khosatzky and Tofan 1970)

\section{Mongolia}

[135] Early Cretaceous; Dornogovi Aimag; Pan-Trionychidae indet. (Suzuki and Narmandakh 2004)

[136] Early Cretaceous, Aptian-Albian; Dundgovi Aimag; Pan-Trionychidae indet. (Trionychidae indet. of Scheyer et al. 2017)

[137] Late Cretaceous, Cenomanian-early Turonian Dornogovi Aimag; Kuhnemys orlovi (TL), “T.” baynshirensis (TL) (Khosatzky 1976; Danilov et al. 2014)

[138] Late Cretaceous, Campanian; Bayankhongor Aimag; Kuhnemys breviplastra (Danilov et al. 2014)

[139] Late Cretaceous, Campanian; Ömnögovi Aimag; Kuhnemys breviplastra, "T." shiluutulensis (TL), PanTrionychidae indet. (Khosatzky 1999; Danilov et al. 2014)

[140] Late Cretaceous, Campanian; Övörkhangai Aimag; Pan-Trionychidae indet. (Danilov et al. 2014)

[141] Late Cretaceous, Maastrichtian; Ömnögovi Aimag; Kuhnemys breviplastra (TL), Nemegtemys conflata (TL), "T." gilbentuensis (TL), "T." gobiensis (TL), Pan-Trionychidae indet. (Khosatzky and Mlynarski 1971; Trionyx sp. of Mlynarski and Narmandach 1972; Shuvalov and Chkhikvadze 1975, 1979; Merkulova 1978; Chkhikvadze and Shuvalov 1988; Danilov et al. 2014; including Amyda menneri of Chkhikvadze in Chkhikvadze and Shuvalov 1988)

[142] Late Paleocene; Ömnögovi Aimag; Kuhnemys palaeocenica (TL) (Danilov, Sukhanov et al. 2015)

\section{Myanmar}

[143] Late middle Eocene; Sagaing Region; Pan-Trionychidae indet. (Trionychinae indet. of Hutchison et al. 2004)

[144] Late Miocene; Ayeyarwady Region; Pan-Trionychidae indet. (Trionyx sp. of Jaeger et al. 2011)

[145] Pliocene-Pleistocene; Ayeyarwady Region; PanTrionychidae indet. (Chhibber 1934)

\section{Nepal}

[146] Late Miocene; Province 5; Pan-Cyclanorbinae indet. (Lissemys punctata of West et al. 1991), PanTrionychinae indet. (West et al. 1978; Chitra cf. C. indica and Trionychinae indet. of West et al. 1991)

[147] Pliocene-early Pleistocene; Province 5; Lissemys sp. (Lissemys cf. punctata of Corvinus and Schleich 1994), Pan-Trionychinae indet. (Aspideretes sp. vel Chitra sp. of Corvinus and Schleich 1994)

\section{Oman}

[148] Early Miocene; Ash Sharqiyah; Pan-Trionychidae indet. (aff. Cycloderma sp. of Roger et al. 1994)

\section{Pakistan}

[149] Early to middle Eocene; Khyber Pakhtunkhwa; Pan-Trionychidae indet. (Broin 1987) 
[150] Middle Eocene, middle Bartonian; Punjab; Drazinderetes tethyensis (TL), Pan-Trionychidae indet. (Head et al. 1999)

[151] Early Miocene; Punjab; Pan-Trionychidae indet. (Pilgrim 1912)

[152] Pliocene-Pleistocene; Punjab; Nilssonia hurum (T. hurum sivalensis of Lydekker 1889a), Chitra sp., PanCyclanorbinae indet. (Emyda lineata, Emyda palaeindica, Emyda sivalensis, and Emyda vittata of Lydekker 1885), Pan-Trionychidae indet. (Lydekker $1885,1889 \mathrm{a}, 1889 \mathrm{~b})$

\section{Portugal}

[153] Miocene; Lisbon; Early Miocene, Burdigalian: Pan-Trionychidae indet. (Zbyszewsky 1949); late Miocene, Tortonian: Pan-Trionychidae indet. (T. lorioli of Souza Torres 1947)

\section{Romania}

[154] Eocene; Early Eocene, Ypresian, Argeş County: Pan-Trionychidae indet. (Vremir 2013); middle Eocene, Sibiu County: Pan-Trionychidae indet. (Trionyx sp. of Peters 1855); late Eocene, Cluj County: Pan-Trionychidae indet. (Trionyx sp. of Koch 1894); late Eocene (Priabonian) or Oligocene, Cluj County: " $T$." boulengeri ( $T$. clavatomarginatus of Lörenthey 1903)

[155] Oligocene; early Oligocene (Rupelian), Cluj County: Pan-Trionychidae indet. (Vang-Lauridsen 1998); late Oligocene (Chattian); Hunedoara County: Pan-Trionychinae indet. (Trionyx sp. of Poporogu 1972)

[156] Miocene; Early Miocene, Cluj County: Pan-Trionychinae indet. (Trionyx sp. of Fuchs 1962; Trionyx sp. of Vremir and Codrea 1997); middle Miocene, Serravallian, Arad County: Pan-Trionychinae indet. (T. stiriacus of Vremir et al. 1997); middle-late Miocene, Serravallian-Tortonian, Bihor County: Pan-Trionychinae indet. (T. harmati and T. nopcsai of Szalai 1934)

[157] Late Miocene, Tortonian; Vrancea County; PanTrionychidae indet. (T. cf. pliopedemontana of Macarovici and Motas 1965)

[158] Pliocene; Harghita County; Pan-Trionychidae indet. (Trionyx sp. of Mlynarski 1966)

[159] Pliocene; Vaslui County; Pan-Trionychidae indet. (Trionyx sp. of Simionescu 1930)

\section{Russia}

[160] Middle Miocene, Langhian; Stavropol Territory; Pan-Trionychidae indet. (T. danovi of Chkhikvadze 1989)

[161] Middle Miocene, Serravallian; Adygea Republic; Pan-Trionychidae indet. (T. khosatzkyi of Chkhikvadze 1983, 1989, and Shebzukhova and Tarasenko 2007)

\section{Saudi Arabia}

[162] Early Miocene, Burdigalian; Eastern Province; Pan-Cyclanorbinae indet. (aff. Cycloderma sp. of Thomas et al. 1982)

\section{Slovakia}

[163] Miocene; early Miocene, middle Burdigalian, Banská Bystrica: Pan-Trionychinae indet. (?Trionychidae indet. of Čerňanský et al. 2012); middle Miocene, late Langhian, Bratislava: Pan-Trionychinae indet. (T. rostratus of Holec and Schlögl 2000), Pan-Trionychidae indet. (Trionyx sp. of Hörnes 1848; Trionyx sp. of Młynarski 1966; Trionyx sp. of Holec 2006; Trionyx sp. of Danilov et al. 2012); late Miocene, Tortonian, Trnava: Pan-Trionychinae indet. (Trionychidae indet. of Danilov et al. 2012)

\section{Slovenia}

[164] Late Oligocene, Chattian; Central Sava; Pan-Trionychinae indet. (T. stadleri of Teppner 1913; T. styriacus [sic] of Bergounioux 1934a)

[165] Miocene; Central Sava; early Miocene, Aquitanian: Pan-Trionychidae indet. (Jurkovšek and KolarJurkovšek 1994); middle Miocene, Langhian: Pan-Trionychidae indet. (T. petersi trifailensis of Teppner 1914c)

\section{Spain}

[166] Middle Eocene, Lutetian; Andalusia; Pan-Trionychidae indet. (Jiménez Fuentes and Alonso Andres 1994)

[167] Middle Eocene, Lutetian; Aragon; Pan-Trionychidae indet. (Trionyx sp. of Pérez-García et al. 2013)

[168] Middle Eocene, ?Bartonian; Balearic Islands; PanTrionychidae indet. (Jiménez Fuentes et al. 1990)

[169] Eocene; Castile and León; middle Eocene, Lutetian: Pan-Trionychidae indet. (T. cf. michauxi of Jiménez Fuentes and Alonso Andres 1994; Jiménez Fuentes 2003); middle Eocene, Bartonian: Pan-Trionychidae indet. (Jiménez Fuentes and Alonso Andres 1994); late Eocene, Priabonian: Pan-Trionychidae indet. (Jiménez Fuentes and Alonso Andres 1994)

[170] Middle Eocene, Lutetian; Catalonia; Pan-Trionychidae indet. (Crusafont and Villalta 1954; Bergounioux 1958)

[171] Early Oligocene; Aragon; Pan-Trionychidae indet. (Jiménez Fuentes and Alonso Andres 1994)

[172] Early Oligocene; Catalonia; Pan-Trionychidae indet. (Vidal and Depéret 1906; T. marini of Hernández Sampelayo and Bataller 1944, Crusafont and Villalta 1954, Bataller 1956, and Bergounioux 1958)

[173] Oligocene; Guadalajara, Castile-La Mancha; early Oligocene, Rupelian: Pan-Trionychidae indet. (Crusafont et al. 1960); Oligocene (undetermined stage): Pan-Trionychidae indet. (Trionyx sp. of Jiménez Fuentes 2003) 
[174] Early Miocene, Burdigalian; Catalonia; Pan-Trionychidae indet. (Pérez García et al. 2011)

[175] Early Miocene, Aquitanian; Navarre; Pan-Trionychidae indet. (Trionyx cf. maunori [sic] of Ezquerra del Bayo 1850; Trionychinae indet. of Murelaga et al. 2002)

[176] Late Miocene, Messinian; Murcia; Pan-Trionychidae indet. (Pérez García et al. 2011)

\section{Sri Lanka}

[177] Late Pleistocene; Sabaragamuwa Province; PanTrionychidae indet. (Lissemys punctata sinhaleyus of Deraniyagala 1953)

\section{Sweden}

[178] Late Cretaceous, Campanian; Skåne; Pan-Trionychidae indet. (Trionychidae indet. of Scheyer et al. 2012)

\section{Switzerland}

[179] Oligocene; early Oligocene, Rupelian, Fribourg: Pan-Trionychinae indet. (MHNF); late Oligocene, Chattian; Vaud; Pan-Trionychinae indet. (T. lorioli, T. rocchettiana, and T. valdensis of Portis 1882)

[180] Miocene; early Miocene, Aquitanian, Aargau: PanTrionychidae indet. (Meyer 1839); early Miocene, Aquitanian, Vaud: Pan-Trionychidae indet. (Pictet and Humbert 1856); middle Miocene, Serravallian, Neuchâtel: Pan-Trionychidae indet. (Jaccard 1888); late Miocene, Zurich: Pan-Trionychinae indet. (T. reticulatus and T. cf. stiriacus of Rieppel 1979)

\section{Tajikistan}

[181] Late Cretaceous, early Santonian; Khodzhent Province; "T." kansaiensis (TL) "T." riabinini, Pan-Trionychidae indet. (Khosatzky and Nessov 1979; Nessov 1984; Kordikova 1994b; Vitek and Danilov 2010)

\section{Tanzania}

[182] Middle Miocene; Zanzibar; Pan-Trionychidae indet. (Trionychidae indet. of Pickford 2008)

[183] Pleistocene; Arusha Region; Trionyx sp. (Leakey 1965)

\section{Thailand}

[184] Middle Miocene-Pleistocene; Nakhon Ratchasima Province; Pan-Trionychidae indet. (Amyda sp., Chitra sp. of Claude et al. 2011)

[185] Late Pleistocene; Krabi Province; Pan-Trionychidae indet. (Mudar and Anderson 2007)

\section{Tunisia}

[186] Late Miocene, Tortonian; Gafsa Governorate; PanTrionychidae indet. (Trionyx sp. of Robinson and Black 1974)

[187] Late Pliocene, Piacenzian; Bizerte Governorate; Pan-Trionychidae indet. (Arambourg 1979)

\section{Turkey}

[188] ?Oligocene; Çorum; Pan-Trionychidae indet. (Staesche 1975)

[189] Oligocene; Tekirdağ; Pan-Trionychidae indet. (Trionix [sic] sp. of Lebküchner 1974; Staesche 1975)

[190] Miocene; Çanakkale; middle Miocene, Serravallian: Pan-Trionychidae indet. (Trionyx sp. of Calvert and Neumayr 1880); late Miocene: Pan-Trionychidae indet. (Trionyx sp. of Tuna 1988)

[191] Late Miocene; İstanbul; Pan-Trionychidae indet. (Trionyx sp. of Malik and Nafiz 1933; Trionyx sp. of Rückert-Ülkümen 1963; Staesche 1975)

[192] Late Miocene, middle Tortonian; Konya; Pan-Trionychinae indet. (T. triunguis of Staesche et al. 2007)

[193] Late middle-early late Miocene, Serravallian-early Tortonian; Kütahya; Pan-Trionychinae indet. (T. triunguis of Staesche et al. 2007)

[194] Middle Miocene, Serravallian; Mugla; Pan-Trionychinae indet. (Staesche et al. 2007)

\section{Uganda}

[195] Late Miocene, Messinian; Central Region; PanCyclanorbinae indet. (Cyclanorbis sp. of Lapparent de Broin and Gmira 1994)

[196] Pliocene; Central Region; early Pliocene, Zanclean: Cyclanorbis indet. (Lapparent de Broin and Gmira 1994); late Pliocene, Piacenzian: Cyclanorbis indet. (Lapparent de Broin and Gmira 1994)

[197] Early Pleistocene, Gelasian; Central Region; Cycloderma sp. (Cycloderma frenatum of Arambourg 1947), Pan-Cyclanorbinae indet. (Swinton 1926; Lapparent de Broin and Gmira 1994)

\section{Ukraine}

[198] Middle Eocene, early Lutetian; Luhansk Province; “T." ikoviensis (TL) (Danilov et al. 2011)

[199] Middle Miocene, Serravallian; Crimea Province (currently administered by Russia); Pan-Trionychidae indet. (Trionyx sp. of Khosatzky 1948; Chkhikvadze 1989)

\section{United Arab Emirates}

[200] late Miocene, Tortonian; Abu Dhabi; Pan-Trionychinae indet. (Trionyx sp. of Lapparent de Broin and van Dijk 1999; Beech and Hellyer 2005)

\section{United Kingdom}

[201] Late Paleocene, ?Thanetian; London; Pan-Trionychidae indet. (White 1931)

[202] Eocene; middle Eocene, Bartonian, Dorset: PanTrionychidae indet. (Burton 1933); middle Eocene, Lutetian, Hampshire: Pan-Trionychidae indet. (Benton and Spencer 1995); late Eocene, Priabonian, Hampshire: "T." henrici (TL) (including T. barbarae, T. [or Aulacochelys] circumsulcatus, T. marginatus, T. planus, and T. rivosus of Owen in Owen and Bell 1849, Lydekker 1889a, and Boulenger 1891); late 
Eocene, Isle of Wight: "T." henrici (T. incrassatus of Owen in Owen and Bell 1849); early Eocene, Ypresian, Kent: "T." silvestris (TL) (Walker and Moody 1974), Pan-Trionychinae indet. (T. pustulatus of Owen in Owen and Bell 1849); early Eocene, late Ypresian, West Sussex: Axestemys vittata (Eurycephalochelys fowleri of Moody and Walker 1970 and Walker and Moody 1985), Pan-Trionychinae indet. (Trionyx sp. of Owen in Owen and Bell 1849; T. bowerbanki of Lydekker 1889a)

[203] Oligocene; Isle of Wight; early Oligocene, Rupelian: Pan-Trionychidae indet. (Hooker and Ward 1980); late Oligocene-early Miocene: Pan-Trionychidae indet. (Lydekker 1889a)

\section{Uzbekistan}

[204] Early Cretaceous, early Albian; Karakalpakstan; Pan-Trionychidae indet. (Nessov 1977, 1984)

[205] Late Cretaceous; Karakalpakstan; early Cenomanian: “T." dissolutus, Pan-Trionychidae indet. (“T." cf. kyrgyzensis of Vitek and Danilov 2014); late Turonian: Pan-Trionychidae indet. (Nessov 1984, 1987)

[206] Late Cretaceous; Navoiy Region; Cenomanian: "T." dissolutus (TL), Pan-Trionychidae indet. (“T." cf. kyrgyzensis of Vitek and Danilov 2014); late Turonian: Khunnuchelys kizylkumensis (TL) (Brinkman et al. 1993; Vitek and Danilov 2013), Pan-Trionychidae indet. (Nessov 1984, 1987, 1997; Brinkman et al. 1993; Aspideretoides cf. riabinini and "T." cf. kansaiensis of Danilov and Vitek 2013)

\section{Vietnam}

[207] Oligocene; Ląng Son Province; Pan-Trionychidae indet. (Böhme et al. 2011)

\section{Appendix 4 \\ Hierarchical Taxonomy of Old World Pan-Trionychidae}

Pan-Trionychidae Joyce et al., 2004

Axestemys vittata (Pomel, 1847), comb. nov.

Drazinderetes tethyensis Head et al., 1999

Khunnuchelys Brinkman et al., 1993

Khunnuchelys erinhotensis Brinkman et al., 1993

Khunnuchelys kizylkumensis Brinkman et al., 1993

Khunnuchelys lophorhothon Danilov, Vitek et al., 2015

Kuhnemys Chkhikvadze, 1999b

Kuhnemys breviplastra (Danilov et al., 2014), comb. nov.

Kuhnemys maortuensis (Yeh, 1965)

Kuhnemys orlovi (Khosatzky, 1976), comb. nov.
Kuhnemys palaeocenica (Danilov, Sukhanov et al., 2015), comb. nov.

Murgonemys braithwaitei White, 2001

Perochelys lamadongensis Li, Joyce, and Liu, 2015

Petrochelys kyrgyzensis (Nessov, 1995b)

Pan-Cyclanorbinae New Clade Name

Cyclanorbis turkanensis Meylan et al., 1990

Cycloderma Peters, 1854

Cycloderma debroinae Meylan et al., 1990

Cycloderma victoriae Andrews, 1914

Nemegtemys conflata Danilov et al., 2014

Pan-Trionychinae New Clade Name

Pelodiscus gracilia (Yeh, 1963), comb. nov.

Rafetus bohemicus (Liebus, 1930), comb. nov.

Trionyx Geoffroy Saint-Hilaire, 1809

Trionyx pliocenicus Fucini, 1912

Trionyx vindobonensis Peters, 1855

Pan-Trionychidae Incertae Sedis

Trionyx Geoffroy Saint-Hilaire, 1809

"Trionyx" baynshirensis Danilov et al., 2014

"Trionyx" boulengeri Reinach, 1900

"Trionyx" capellinii Negri, 1892

"Trionyx" dissolutus Vitek and Danilov, 2014

"Trionyx" gilbentuensis Danilov et al., 2014

“Trionyx" gobiensis Danilov et al., 2014

“Trionyx" gregarius (Gilmore, 1934)

"Trionyx" henrici Owen in Owen and Bell, 1849

"Trionyx" impressus (Yeh, 1963)

"Trionyx" ikoviensis Danilov et al., 2011

“Trionyx" jixiensis Li, Tong et al., 2015

"Trionyx" johnsoni Gilmore, 1931

"Trionyx" kansaiensis Vitek and Danilov, 2010

"Trionyx" linchuensis (Yeh, 1962)

"Trionyx" messelianus Reinach, 1900

"Trionyx" miensis Okazaki and Yoshida, 1977

"Trionyx" minusculus (Chkhikvadze, 1973), comb. nov.

"Trionyx" ninae Chkhikvadze, 1971

"Trionyx" onomatoplokos, new name

"Trionyx" riabinini Kuznetsov and Chkhikvadze, 1987

"Trionyx" shiluutulensis Danilov et al., 2014

"Trionyx" silvestris Walker and Moody, 1974 


\section{Literature Cited}

Abbazzi, L., M. Benvenuti, M.E. Ceci, D. Esu, C. Faranda, L. RoOK AND F. TANGOCCI. 2008. The end of the Lago-Mare time in the SE Valdelsa Basin (Central Italy): interference between local tectonism and regional sea-level rise. Geodiversitas 30:611-639.

Aguilar, J.-P., S. Legendre And J. Mechaux, Eds. 1997. Actes du Congrès BiochroM'97, Montpellier, 14-17 avril: biochronologie mammalienne du cénozoïque en Europe et domaines reliés. Mémoires et travaux de l'Institut de Montpellier, no. 21. Montpellier, France: Ecole pratique des hautes études, Institut de Montpellier. 817 pp.

AMMON, L. VON. 1911. Schildkröten aus dem Regensburger Braunkohlenton. Jahresbericht des Naturwissenschaftlichen Vereins zu Regensburg 12:1-35.

ANDREWs, C.W. 1902. I.-Note on a Pliocene vertebrate fauna from the Wadi-Natrun, Egypt. Geological Magazine 9:433-439.

-1906. Order Chelonia. In: C.W. Andrews, ed. A Descriptive Catalogue of the Tertiary Vertebrata of the Fayum, Egypt. London: Trustees of the British Museum Editions. pp. 275-306.

-1914. Appendix II. On the Lower Miocene vertebrates from British East Africa, collected by Dr. Felix Oswald. Quarterly Journal of the Geological Society of London 70:163-186.

ANQUETIN, J. AND W.G. JoYCE. 2014. A reassessment of the Late Jurassic turtle Eurysternum wagleri (Eucryptodira, Eurysternidae). Journal of Vertebrate Paleontology 34:1317-1328.

Arambourg, C. 1947. Contribution à létude géologique et paléontologique du bassin du Lac Rodolphe et de la basse vallée de l'Omo. In: C. Arambourg, ed. Mission scientifique de I’Omo 1932-1933. Tome I. Géologie-Anthropologie. Fascicule III, 2ème partie, Paléontologie. Paris: Museum national d'Histoire naturelle. pp. 231-562.

-1956. Nouvelles recherches dans le gisement de l'Ain Hanech. In: G.A. Blanc, ed. Actes du IV Congrès International du Quaternaire; 1953 Aug-Sep; Rome-Pise, Italy. Rome: Istituto Italiano di Paleontologia Umana. p. 4.

-1979. Vertébrés villafranchiens d’Afrique du Nord (Artiodactyles, Carnivores, Primates, Reptiles, Oiseaux). Paris: Fondation Singer-Polignac. $141 \mathrm{pp}$.

Arthaber, G. von. 1898. Über Trionyx rostratus n. sp. von Au am Leithagebirge. Beiträge zur Palaeontologie und Geologie Oesterreich-Ungarns und des Orients 21:179-198.

AuffenberG, W. 1974. Checklist of fossil land tortoises (Testudinidae). Bulletin of the Florida State Museum, Biological Sciences Series 18:121-251.

Augé, M., S. Duffaud, F. de Lapparent de Broin, J.-C. Rage AND D. VASSE. 1997. Les amphibiens et les reptiles de Prémontré (Cuisien, Bassin parisien): une herpétofaune de référence pour l'Eocène inférieur. Géologie de la France 1:23-33.

Augé, M., L. Ginsburg, F. De Lapparent de Broin, M. MakinSKY, C. Mourer, D. PoutT AND S. SEN. 2002. Les vertébrés du Miocène moyen de Contres (Loir-et-Cher, France). Revue de Paléobiologie, Genève 21:819-852.

Averianov, A.O., I.G. Danilov, P.P. SkUtschas, I.T. KuZMin, H.-D. SuES AND G. DyKe. 2016. The Late Cretaceous vertebrate assemblages of western Kazakhstan. New Mexico Museum of Natural History and Science Bulletin 71:5-18.
BACHMAYER, F. 1966. Ein bemerkenswerter Schildkrötenfund aus dem Ober-Pannon der Schottergrube "Heidfeld" beim Flughafen Schwechat (Wien). Annalen des Naturhistorischen Museums in Wien 69:101-103.

BAKRADZE, M.A. AND V.M. CHKHIKVADZE. 1988. [Materials on the Tertiary history of the herpetofauna of the Caucasus and adjoining regions]. Vestnik Gosudarstvennogo Muzeya Gruzii 34:176-193. [in Russian]

BARBERA, C. AND G. LeUCI. 1980. I trionicidi di Monteviale presenti presso il Museo di Paleontologia dell' Universita di Napoli. Atti dell'Accademia Pontaniana 29:37-52.

BARNES, B. 1927. Eine eozäne Wirbeltierfauna aus der Braunkohle des Geiseltals. Jahrbuch des Halleschen Verbandes für die Erforschung der mitteldeutschen Bodenschätze 6:5-24.

BATALLER, J.R. 1956. Contribución al conocimiento de los Vertebrados terciarios de España. Cursillos y conferencias del Instituto Lucas Mallada del Consejo Superior de Investigaciones Científicas 3:11-28.

Bate, D.M.A. 1934. Two additions to the Pleistocene cavefauna of Palestine (Trionyx and Crocodilus). Annals and Magazine of Natural History 14:474-478.

BazHAnov, V.S. And N.N. KostenKo. 1961. [Geological section of Dzhungarian Alatau and its paleontological basis]. Materialy po istorii fauny i flory Kazakhstana 3:47-52. [in Russian]

Beech, M. And P. Hellyer. 2005. Abu Dhabi-8 Million Years Ago: Late Miocene Fossils from the Western Region. Abu Dhabi, United Arab Emirates: Abu Dhabi Islands Archaeological Survey. $92 \mathrm{pp}$.

Bell, C.J., J.A. GAUTHIER AND G.S. Bever. 2010. Covert biases, circularity, and apomorphies: a critical look at the North American Quaternary herpetofaunal stability hypothesis. Quaternary International 217:30-36.

Benton, M.J. ANd P.S. SPEnCER. 1995. Fossil Reptiles of Great Britain, Geological Conservation Review Series 10. London: Chapman and Hall. 386 pp.

Berger, J.-P. 1998. 'Rochette' (Upper Oligocene, Swiss Molasse): a strange example of a fossil assemblage. Review of Palaeobotany and Palynology 101:95-110.

BergouniouX, F.-M. 1932. Chéloniens fossiles conservés au Museum d'Histoire Naturelle de Munich. Bulletin de la Société d'histoire naturelle de Toulouse 64:523-544.

-1933. Monographie paléontologique de la faune de vertébrés des sables de Montpellier. 2. Chéloniens fossiles des sables Pliocènes astiens de Montpellier. Travaux du Laboratoire de Géologie de la Faculté des sciences de Lyon 23:1-32.

-1934a. Catalogue des chéloniens fossiles conservés à Vienne (Autriche). Bulletin de la Société d'Histoire Naturelle de Toulouse 66:369-376.

-1934b. Sur quelques Chéloniens fossiles du Nord de l'Italie. Bulletin de la Société d'Histoire Naturelle de Toulouse 66:271-280.

-1935. Contribution à létude paléontologique des chéloniens: chéloniens fossiles du bassin d'Aquitaine. Mémoires de la Société Géologique de France (nouvelle série) 25:1-215.

-1936. Chéloniens fossiles conservés au laboratoire de géologie de la faculté des sciences de Clermont-Ferrand. Bulletin de la Société d'Histoire Naturelle de Toulouse 69:50-58.

-1937. Chéloniens fossiles du Kimméridgien du Cap de la Hève. Bulletin de la Société d'Histoire Naturelle de Toulouse 71:180-191. 
-1938. Chéloniens fossiles d'Espagne. Bulletin de la Société d'Histoire Naturelle de Toulouse 72:257-288.

-1953. Chéloniens fossiles des terrains tertiaires de la Vénétie. Comptes rendus hebdomadaires des séances de l'Académie des sciences de Paris 236:222-224.

-1954. Les chéloniens fossiles des terrains tertiaires de la Vénétie. Memorie degli Istituti di geologia e mineralogia dell'Università di Padova 18:1-115.

-1958. Les reptiles fossiles du Tertiaire de la Catalogne. Estudios Geológicos 14:129-219.

BISHOP, W.W. AND M.H.L. PICKFORD. 1975. Geology, fauna and palaeoenvironments of the Ngorora Formation, Kenya Rift Valley. Nature 254:185-192.

BISHOP, W.W., M. PICKFORD AND A. HiLL. 1975. New evidence regarding the Quaternary geology, archaeology and hominids of Chesowanja, Kenya. Nature 258:204-208.

BODDAERT, P. 1770. Brief van de kraakbeenige schildpad. Epistola de testudine cartilaginea. Amsterdam: Kornelis van Tongerlo. $39 \mathrm{pp}$.

BöHME, M. 1995. Eine Weichschildkröte (Trionychidae) aus dem Untermiozän vom Dietrichsberg bei Vacha (Rhön). Mauritania (Altenburg) 15:357-366.

-2008. Ectothermic vertebrates (Teleostei, Allocaudata, Urodela, Anura, Testudines, Choristodera, Crocodylia, Squamata) from the Upper Oligocene of Oberleichtersbach (Northern Bavaria, Germany). Courier Forschungsinstitut Senckenberg 260:161-183.

BÖHME, M., J. PRIETO, S. SCHNEIDER, N.V. Hung, D.D. QUANG and D.N. TRan. 2011. The Cenozoic on-shore basins of northern Vietnam: biostratigraphy, vertebrate and invertebrate faunas. Journal of Asian Earth Sciences 40: 672-687.

BOULENGER, G.A. 1891. On some chelonian remains preserved in the Museum of the Royal College of Surgeons. Proceedings of the Zoological Society of London 1891:4-8.

BRINKMAN, D.B., J. Li AND X. YE. 2008. Order Testudines. In: J. $\mathrm{Li}, \mathrm{X}$. Wu and F. Zhang, eds. The Chinese Fossil Reptiles and Their Kin. Beijing: Science Press. pp. 35-102.

Brinkman, D.B., L.A. Nessov and J.-H. Peng. 1993. Khunnuchelys gen. nov., a new trionychid (Testudines: Trionychidae) from the Late Cretaceous of Inner Mongolia and Uzbekistan. Canadian Journal of Earth Sciences 30:2214-2223

BroIN, F. DE. 1977. Contribution à létude des Chéloniens: Chéloniens continentaux du Crétacé et du Tertiaire de France. Mémoires du Muséum National d'Histoire Naturelle, Série C 38:1-366.

-1979. Chéloniens du Miocène et du Plio-Pléistocène d'Afrique orientale. Bulletin de la Société Géologique de France 21:323-327.

-1987. Lower vertebrates from the early-Middle Eocene Kuldana Formation of Kohat (Pakistan): Chelonia. Contribution from the Museum of Paleontology, the University of Michigan 27:169-185.

Brusatte, S.L., R.B.J. Benson, D.J. Chure, X. Xu, C. Sullivan AND D.W.E. HoNE. 2009. The first definitive carcharodontosaurid (Dinosauria: Theropoda) from Asia and the delayed ascent of tyrannosaurids. Naturwissenschaften 96:1051-1058.

BURTON, E.S.J. 1933. Faunal horizons in the Barton Beds in Hampshire. Proceedings of the Geologists' Association 44:131-167.
CADENA, E. 2016. Palaeoamyda messeliana nov. comb. (Testudines, Pan-Trionychidae) from the Eocene Messel Pit and Geiseltal localities, Germany, taxonomic and phylogenetic insights. PeerJ 4:e2647. doi: 10.7717/peerj.2647

Calvert, F. AND M. Neumayr. 1880. Die jungen Ablagerungen am Hellespont. Akademie der Wissenschaften, Vienna. Denkschriften der kaiserlichen Akademie der Wissenschaften/Mathematisch-Naturwissenschaftliche Classe 40:357-378.

CAPellini, G. 1878. Della Pietra Leccese e di alcuni suoi fossili. Memorie dell'Accademia delle Scienze dell'Istituto di Bologna 9:225-258.

CAUTLEY, P.T. 1836. On the structure of the Siwalik Hills, and the organic remains found in them. Transactions of the Geological Society of London 5:267-278.

ČERŇANSKÝ, A., T. CSABA AND J. ŠURKA. 2012. Crocodylian and turtle finds from the Early Miocene of the Baňa Dolina Mine in Vel'krý Krtíš (Slovakia). Acta Geologica Slovaca 4:113-123.

CHESI, F. 2009. Il registro fossile italiano dei cheloni [dissertation]. Florence, Italy: Università di Firenze. 178 pp.

Chesi, F., M. Delfino, A. Varola and L. Rook. 2007. Fossil sea turtles (Chelonii, Dermochelyidae and Cheloniidae) from the Miocene of Pietra Leccese (late Burdigalian-early Messinian), southern Italy. Geodiversitas 29:321-333.

CHHiBBER, H.L. 1934. Geology of Burma. London: Macmillan. $538 \mathrm{pp}$.

CHITANI, Y. 1925. On a new fossil Trionyx from the Yamaguchi Prefecture. Journal of the Geological Society of Japan 32(387):28-33.

Chrhikvadze, V.M. 1970. [The oldest Cenozoic turtles of the U.S.S.R.]. Soobshcheniya Akademii Nauk Gruzinskoi SSR 60:749-752. [in Russian]

-1971. [New turtles from the Oligocene of Kazakhstan and the systematic position of some species in Mongolia]. Soobshcheniya Akademii Nauk Gruzinskoi SSR 62:489-492. [in Russian]

-1973. [Tertiary Turtles of the Zaisan Depression]. Tbilisi, Georgia: Metsniereba. 100 pp. [in Russian]

-1983. [Fossil Turtles of the Caucasus and the northern Black Sea region]. Tbilisi, Georgia: Metsniereba. 149 pp. [in Russian] -1984. [Early Paleogene Turtles from Zaisan]. In: [Flora and fauna of the Zaisan Depression]. Tbilisi, Georgia: Metsniereba. pp. 128-139. [in Russian]

-1988. [New data on turtles of the Miocene and Pliocene of Cis-Caucasus]. In: [Animal World of Ciscaucasia and Adjacent Territories]. Stavropol, Russia: Stavropol' State Pedagogical Institute. pp. 128-139. [in Russian]

-1989. [Neogene Turtles of the USSR]. Tbilisi, Georgia: Metsniereba. 102 pp. [in Russian]

-1990. [Paleogene Turtles of the USSR]. Tbilisi, Georgia: Metsniereba. 96 pp. [in Russian]

-1995. [New data on Paleogene turtles of Zaisan]. In: Nauchnaya sessiya Instituta paleobiologii Gruzii. Tbilisi, Georgia: Metsniereba. p. 21 [in Russian]

-1999 a. [The history of the development of the Paleogene herpetofauna of the CIS]. Problems of Paleobiology, Tbilisi 1:259-279. [in Russian]

-1999b. [Some fossil soft-shelled turtles of Asia (Rafetini trib. nov.)]. Trudy Tbilisskogo Gosudarstvennogo Pedagogicheskogo Universiteta 5:215-225. [in Russian]

$-2000 \mathrm{a}$. [About the systematic positions of some extinct softshelled turtles of North America and Asia]. Trudy Tbilis- 
skogo Gosudarstvennogo Pedagogicheskogo Universiteta 7:199-213. [in Russian]

$-2000 \mathrm{~b}$. Fossil trionychid turtles from the territory of the former Soviet Union. In: Fourth Asian Herpetological Conference; 2000 Jul 16-20; Chengdu, China. Chengdu: Chengdu Institute of Biology. p. 56.

-2007. [A short catalogue of fossil turtles of northern Eurasia]. Problems of Paleobiology, Tbilisi 2:126-137. [in Russian with English summary]

-2008a. [New trionychids and current problems of biostratigraphy of the Early Paleogene of Zaysan depression]. In: [Paleontological Monuments of Nature-Natural Heritage: Studying, Research Prospect and Conservation Problems]; Pavlodar, Kazakhstan: Pavlodarian State University. pp. 117-122. [in Russian]

-2008b. [Soft-shell turtles (Trionychidae) of Asia and North America: Morphology, phylogeny, systematics, terminology of elements of carapace]. Problems of Paleobiology, Tbilisi 3:85-95. [in Russian]

-2010. [An annotated catalogue of Paleogene, Neogene, and modern turtles of northern Eurasia]. Georgian National Museum. Proceedings of the Natural and Prehistoric Section 2:96-113. [in Russian]

ChKHIKVADZE, V.M. AND A.N. LuNGU. 1984. [New data on the Miocene herpetofauna of Moldavia and the Caucasus.]. In: A.N. Lungu, ed. [Palaeobiological research on the Mesozoic and Caenozoic of the Dnestr and Transnistria-Prut interfluve]. Kishinev: Ştiințsa. pp. 72-86. [in Russian]

ChKHIKVADZE, V.M. AND V.F. SHuvalov. 1988. [A new species of a trionychid from the Upper Cretaceous deposits of Mongolia]. Izvestiya Akademii Nauk Gruzinskoi SSR 14:198-204. [in Russian]

Chow, M.M. AND S.K. Yeh. 1957. A new Eocene Platypeltis from Lushih, Honan. Vertebrata Palasiatica 1:261-262.

-1958. A new species of Trionyx from Yushe, Shansi. Vertebrata Palasiatica 2:55-56.

ChURCHER, C.S., M.R. KLEINDIENST AND H.P. SCHWARCZ. 1999. Faunal remains from a Middle Pleistocene lacustrine marl in Dakhleh Oasis, Egypt: palaeoenvironmental reconstructions. Palaeogeography, Palaeoclimatology, Palaeoecology 154:301-312.

ClaRKE, W.B. 1869. Dinornis an Australian genus. Geological Magazine 6:383-384.

Claude, J., W. Naksri, N. Boonchai, E. Buffetaut, J. DUANGKRAYOM, C. LAOJUMPON, P. JiNTASAKUL, K. LAUPRASERT, J. MARTin, V. SuteETHORn AND H. Tong. 2011. Neogene reptiles of northeastern Thailand and their paleogeographical significance. Annales de Paléontologie 97:113-131.

Clift, W. 1828. On the fossil remains of two new species of Mastodon and of other vertebrate animals, found on the left bank of the Irawaddi. Transactions of the Geological Society of London 2:369-374.

COMASCHI CARIA, J. 1959. Nuovi resti di cheloni nel Miocene della Sardegna. Bollettino della Società Geologica Italiana 78:37-44.

-1986. Animali e piante fossili della Sardegna. Cagliari, Italy: Edizioni della Torre. $107 \mathrm{pp}$.

COOKE, J.H. 1890. Notes on the fossil reptiles of Malta. Il Naturalista Maltese 1:18-20.

COPE, E.D. 1872. Descriptions of some new Vertebrata from the Bridger Group of the Eocene. Palaeontological Bulletin $1: 1-6$.
Corsini-FoKA, M. AND M. MASSETI. 2008. On the oldest record of the Nile soft-shelled turtle, Trionyx triunguis (Forskål, 1775), in the Eastern Aegean islands (Greece). Zoology in the Middle East 43:108-110.

Corvinus, G. AND H.H. Schleich. 1994. An Upper Siwalik reptile fauna from Nepal. Courier Forschungsinstitut Senckenberg 173:239-259.

Crusafont, M., B. Meléndez and J. Truyols Santonja. 1960. El yacimiento de Huérmeces del Cerro y su significado cronoestratigráfico. Estudios Geológicos 16:243-254.

CRusafont, M. AND J.F. Villalta. 1954. "Almogáver", un nuevo primate del Eoceno pirenaico. Estudios Geológicos 22:165-176.

CUvier, G. 1812. Recherches sur les ossements fossiles de quadrupèdes, où l'on rétablit les caractères de plusieurs espèces d’animaux que les révolutions du globe paraissent avoir détruites. Paris: Déterville.

-1821-1824. Recherches sur les ossements fossiles, où lon rétablit les caractères de plusieurs animaux, dont les révolutions du globe ont détruits les espèces. Nouvelle édition. Paris: Dufour and D’Ocagne.

-1835-1836. Recherches sur les ossements fossiles, où l'on rétablit les caractères de plusieurs animaux, dont les révolutions du globe ont détruits les espèces. Quatrième édition. Paris: Dufour and D'Ocagne.

DACQUÉ, E. 1912. Die fossilen Schildkröten Aegyptens. Geologische und Paläontologische Abhandlungen 14:275-337.

DALLA VeCChIA, F.M. 2007. 300 milioni di anni di evoluzione. In: Salvaguardia dell'Erpetofauna nel Territorio di AlpeAdria. Un contributo della Regione Friuli Venezia Giulia a favore della Biodiversità. Udine, Italy: Regione Friuli Venezia Giulia. pp. 11-25.

DALRYMPLE, G.H. 1977. Intraspecific variation in the cranial feeding mechanism of turtles of the genus Trionyx (Reptilia, Testudines, Trionychidae). Journal of Herpetology 11:255285.

DAMES, W. 1894. Die Chelonier der norddeutschen Tertiärformation. Palaeontologische Abhandlungen 6:197-220.

DANILOV, I.G. 2005. Die fossilen Schildkröten Europas. In: U. Fritz, ed. Handbuch der Reptilien und Amphibien Europas, Part 3/IIIB: Schildkröten (Testudines) II. Wiebelsheim, Germany: Aula-Verlag. pp. 329-448.

Danilov, I.G., Y. Bolotsky, A.O. AVERIANov and I.V. DONCHENKO. 2002. A new genus of lindholmemydid turtle (Testudines: Testudinoidea) from the Late Cretaceous of the Amur River Region, Russia. Russian Journal of Herpetology 9:155-168.

DANILOV, I.G., A. ČERŇ́ANSKÝ, E.V. SyROMYATNIKOVA AND P. JONIAK. 2012. Fossil turtles of Slovakia: new material and a review of the previous record. Amphibia-Reptilia 33:423-442.

Danilov, I.G., R. Hirayama, V.B. Sukhanov, S. Suzuki, M. WATABE AND N.S. VITEK. 2014. Cretaceous soft-shelled turtles (Trionychidae) of Mongolia: new diversity, records and a revision. Journal of Systematic Paleontology 12:799-832.

Danilov, I.G., V.B. SuKhanov, E.M. ObRATZOVA AND N.S VITEK. 2015. The first reliable record of trionychid turtles in the Paleocene of Asia. Paleontological Journal 49:407-412. Danilov, I.G., E.V. SyromyatniKova, P.P. SKutschas, T.M Kodrul and J. JIN. 2013. The first 'true' Adocus (Testudines, Adocidae) from the Paleogene of Asia. Journal of Vertebrate Paleontology 33:1071-1080. 
DANILOV, I.G. AND N.S. VITEK. 2012. Soft-shelled turtles (Trionychidae) from the Bissekty Formation (Late Cretaceous: late Turonian) of Uzbekistan: Shell-based taxa. Cretaceous Research 41:55-64.

-2013. Cretaceous trionychids of Asia: an expanded review of their record and biogeography. In: D.B. Brinkman, P.A. Holroyd and J.D. Gardner, eds. Morphology and Evolution of Turtles. Dordrecht, The Netherlands: Springer. pp. 419-438.

Danilov, I.G., N.S. ViteK, A.O. Averianov and V.N. GlinSKIY. 2015. A new softshelled trionychid turtle of the genus Khunnuchelys from the Upper Cretaceous Bostobe Formation of Kazakhstan. Acta Palaeontologica Polonica 60: 155-161.

Danilov, I.G., E.A. Zvonok, E.V. Syromyatnikova AND N.I. UdOVICHENKo. 2011. A new species of soft-shelled turtle (Trionychidae) from the middle Eocene of Ukraine. Proceedings of the Zoological Institute of the Russian Academy of Sciences 315:399-411.

DARga, R., M. BöHme, U. GÖHLICH ANd G. RÖSSNER. 1999. Reste höherer Wirbeltiere aus dem Alttertiär des Alpenvorlandes bei Siegsdorf/Oberbayern. Mitteilungen der Bayerischen Staatssammlung für Paläontologie und historische Geologie 39:91-114.

DAUDIN, F.M. 1801. Histoire naturelle, générale et particulière des reptiles. Tome second. Paris: Imprimerie F. Dufart. 432 pp.

De GrEgorio, A. 1883. Nuovi fossili terziari (vertebrati e invertebrati). Palermo, Italy. $4 \mathrm{pp}$.

-1892. Sulla Trionix ragusensis, De Greg. e la Tr. Melitensis Lyd. Il Naturalista Siciliano 11:182-183.

DELFINO, M. 2002. Erpetofaune italiane del Neogene e del Quaternario [dissertation]. Modena and Reggio Emilia, Italy: University of Modena and Reggio Emilia. 382 pp.

Delfino, M. AND U.B. GöHLICH. 2009. The early Vallesian vertebrates of Atzelsdorf (Late Miocene, Austria). 4. Testudines. Annalen des Naturhistorischen Museums in Wien 111A:499 508.

DELFINO, M., T.M. SChEYER, U. FrITZ AND M.R. SÁNCHEZ-VILLAGRA. 2010. An integrative approach to examining homology question: shell structures in soft-shell turtles. Biological Journal of the Linnean Society 99:462-476.

Delfino, M. AND T. Smith. 2009. A reassessment of the morphology and taxonomic status of 'Crocodylus' depressifrons Blainville, 1855 (Crocodylia, Crocodyloidea) based on the early Eocene remains from Belgium. Zoological Journal of the Linnean Society 156:140-167.

DelForTRIE, E. 1869. Les chéloniens du Miocène supérieur de la Gironde. Actes de la Société linnéenne de Bordeaux 27:399-440.

DelheID, E. 1899. Un Trionyx de l'argile de Boom (Oligocène moyen). Annales de la Société Zoologique de Belgique 33:76-77.

Denison, R. 1978. Handbook of Paleoichthyology, Volume 2: Placodermi. Stuttgart, Germany: Gustav Fischer Verlag. 71 pp.

DEPÉRET, C. 1895. Über die Fauna von miocänen Wirbelthieren aus der ersten Mediterranstufe von Eggenburg. Sitzungs berichte der Akademie der Wissenschaften in Wien 104:395-416.

Depéret, C. AND A. DonneZan. 1890-1897. Classe des reptiles. In: C. Depéret, ed. Les animaux Pliocènes du Roussillon.
Mémoires de la Société Géologique de France, Paléontologie 3:140-194

Deraniyagala, P.E.P. 1953. A Colored Atlas of Some Vertebrates from Ceylon, Volume 2: Tetrapod Reptilia. Colombo, Sri Lanka: Ceylon Natural History Museum. 101 pp.

D’ERASMO, G. 1933. Sui resti di vertebrati terziari raccolti nella Sirtica dalla missione della Reale Accademia d'Italia (1931). Atti Reale Accademia Nazionale dei Lincei. Rendiconti Classe di Scienze Fisiche, Matematiche e Naturali 17:656658.

De Stefano, G. 1902. Un nuovo Chelonide della Famiglia Trionychidae appartenente all'Eocene francese. Bollettino della Società Geologica Italiana e del Servizio Geologico d'Italia 21:389-397.

DE VIS, C.W. 1894. The lesser chelonians of the Nototherian drifts. Proceedings of the Royal Society of Queensland 10:123-127.

DolLo, L. 1909. The fossil vertebrates of Belgium. Annals of the New York Academy of Sciences 19:99-119.

Drake, R.E., J.A. VAn COUvering, M.H. PickFord, G.H. CuRTIS AND J.A. HARRIS. 1988. New chronology for the Early Miocene mammalian faunas of Kisingiri, western Kenya. Journal of the Geological Society 145:479-491.

DuMÉRIL, A.M.C. AND G. BiBRON. 1835. Erpétologie générale ou histoire naturelle complète des reptiles, Tome 2. Paris: Roret. 680 pp.

EIKAMP, H. 1978. Zur obermiozänen Kieselgurlagerstätte von Beuern (Kreis Giessen) und ihrer ehemaligen Flora und Fauna. Jahresberichte der Wetterauischen Gesellschaft für die Gesamte Naturkunde zu Hanau 129-130:91-103.

Engstrom, T.N., H.B. SHAFFer AND W.P. McCord. 2002. Phylogenetic diversity of endangered and critically endangered Southeast Asian softshell turtles (Trionychidae: Chitra). Biological Conservation 104:173-179.

ERnst, C.H. AND R.W. Barbour. 1989. Turtles of the World. Washington, DC: Smithsonian Institution Press. 313 pp. Esu, D. AND T. KotsakIs. 1983. Les vertébrés et les mollusques continentaux du Tertiaire de la Sardaigne: paléobiogéographie et biostratigraphie. Geologia Romana 22:177-206.

EZQUERRA DEL BAYO, J. 1850. Ensayo de una descripción general de la estructura geológica del terreno de España en la Península. Memorias de la Real Academia de Ciencias 1:35-65.

FABIANI, R. 1915. Il Paleogene del Veneto. Memorie dell'Istituto di Geologia dell'Università di Padova 3:1-336.

FALCONER, H. 1831. Note on certain specimens of animal remains from Ava. Gleanings in Science 3:167-170.

-1859. Descriptive Catalogue of the Fossil Remains of Vertebrata from the Sewalik Hills, the Nerbudda, Perim Island, \&c. in the Museum of the Asiatic Society of Bengal. Calcutta, India: Asiatic Society of Bengal. 261 pp.

FALCONER, H. AND P.T. CAUTLEY. 1837. Notice on the remains of a fossil monkey from the Tertiary strata of the Siwalik Hills in the north of Hindustan. Transactions of the Geological Society of London 5:499-504.

FARKAS, B.L. 1992. Wiederentdeckung eines Exemplars von Rafetus swinhoei (Gray, 1873) im Naturhistorischen Museum Wien. Salamandra 28:145-152.

-1995. Fossil trionychid turtle types in Hungarian collections-a preliminary review (Reptilia, Testudines). Annales Historico-Naturales Musei Nationalis Hungarici 87:57-62. 
FARKAS, B. AND U. FRITZ. 1998. On the identity of Rafetus swinhoei (Gray, 1873) and Pelochelys maculatus (Heude, 1880). Zoologische Abhandlungen des Museums für Tierkunde, Dresden 50:59-75.

FITZINGER, L. 1836. Entwurf einer systematischen Anordnung der Schildkröten nach den Grundsätzen der natürlichen Methode. Annalen des Wiener Museums der Naturgeschichte 1:104-128.

FORSKÅL, P. 1775. Descriptiones Animalium. Avium, Amphibiorum, Piscium, Insectorum, Vermium. Quae in Itinere Oriental Observavit. Haunia, Denmark: Mölleri. 12 pp.

Fritz, U., R. Gemel, C. Kehlmaier, M. Vamberger and P. PRASCHAG. 2014. Phylogeography of the Asian softshell turtle Amyda cartilaginea (Boddaert, 1770): evidence for a species complex. Vertebrate Zoology 64:229-243.

FuCHS, E. 1939. Die Schildkrötenreste aus dem Oberpfälzer Braunkohlentertiär. Palaeontographica Abteilung A 89:57104.

FuCHS, H. 1962. Adatok a kóródi rétegek ősállatvilágának fontosabb ismeretéhez. Földtani Közlöny 91:448-449.

FuCINI, A. 1912. Trionyx pliocenicus Law. Paleontographia Italica $18: 1-28$.

GAFFNEY, E.S. AND A. BARTHOLOMAI. 1979. Fossil trionychids of Australia. Journal of Paleontology 53:1354-1360.

Gagnaison, C., B. Guevel, S. Xerri, J.-L. Sicot, J.-M. VilLENEUVE AND B. CosSARD. 2012. La falunière du Tourrelet (Thenay, Loir-et-Cher, France): nouvelles données sur les vertébrés des sables continentaux du Miocène moyen (Orléanien supérieur: MN5). Revue de Paléobiologie, Genève 31:219-234

GARDNER, J.D. AND A.P. RUSSELL. 1994. Carapacial variation among soft-shelled turtles (Testudines: Trionychidae), and its relevance to taxonomic and systematic studies of fossil taxa. Neues Jahrbuch für Geologie und Paläontologie, Abhandlungen 193:209-244.

GARDNER, J.D., A.P. Russell AND D.B. BRINKMAN. 1995. Systematics and taxonomy of soft-shelled turtles (Family Trionychidae) from the Judith River Group (mid-Campanian) of North America. Canadian Journal of Earth Sciences 32:631-643

GASTALDI, E. 1863. Antracoterio di Agnana, balenottera di Cà Lunga presso S. Damiano e mastodonte di Mongrosso. Atti della Società Italiana di Scienze Naturali 5:88-91.

GeINITZ, E. 1877. Die angebliche Trionyx schlotheimii im diluvialen Kalktuff von Burgtonna ist eine Cistudo europaea. Neues Jahrbuch für Mineralogie, Geognosie, Geologie und Petrefaktenkunde, Stuttgart 1877:278-279.

GEMEL, R. 2002. Weichschildkrötenreste aus dem Karpatium des Korneuburger Beckens (Untermiozän; Niederösterreich). Beiträge zur Paläontologie 27:355-371.

Geoffroy Saint-Hilaire, E.F. 1809. Mémoire sur les tortues molles, nouveau genre sous le nom de Trionyx, et sur la formation des carapaces. Annales du Muséum d'Histoire Naturelle 14:1-20.

Georgalis, G.L., Z. Szyndlar, B.P. Kear and M. Delfino. 2016a. New material of Laophis crotaloides, an enigmatic giant snake from Greece, with an overview of the largest fossil European vipers. Swiss Journal of Geosciences 109:103-116.

Georgalis, G.L., A. Villa, E. Vlachos and M. Delfino. 2016b. Fossil amphibians and reptiles from Plakias, Crete: a glimpse into the earliest late Miocene herpetofaunas of southeastern Europe. Geobios 49:433-444.

Gergens, F. 1860. Mitteilung an Geheimrat v. Leonhard gerichtet. Jahrbuch fur Mineralogie, Geologie und Palaeontologie 1860:554-555.

GERVAIS, P. 1859. Zoologie et paléontologie française. 2nd ed. Paris: Arthus Bertrand. 544 pp.

-1867-1869. Zoologie et paléontologie générales (animaux vertébrés): ou nouvelles recherches sur les animaux vivants et fossiles. Paris: Arthus Bertrand. 263 pp.

GILMORE, C.W. 1931. Fossil turtles of Mongolia. Bulletin of the American Museum of Natural History 59:1-14.

-1934. Fossil turtles of Mongolia: second contribution. American Museum of Natural History Novitates 689:1-14.

Girotti, O., L. Capasso Barbato, D. Esu, E. Gliozzi, T. KotSakis, E. Martinetto, C. Petronio, R. Sardella and E. SQUAZZINI. 2003. The section of Torre di Picchio (Terni, Umbria, Central Italy): a Villafranchian site rich in vertebrates, molluscs, ostracods and plants. Rivista Italiana di Paleontologia e Stratigrafia 109:77-98.

Giusberti, L., L. Del Favero and G. Roghi. 2014. The Purga di Bolca-Vegroni sites. Rendiconti della Società Paleontologica Italiana 4:95-103.

GlaEsSNER, M.F. 1933. Die Tertiärschildkröten Niederösterreichs. Neues Jahrbuch für Mineralogie, Geologie, und Paläontologie, Abteilung B 69:353-387.

-1935. Bemerkungen zur tertiären Schildkrötenfauna Ungarns. Zentralblatt für Mineralogie, Geologie und Paläontologie, Abteilung B 1:124-127.

Gobé, J.-F., J. Mornand AND D. Pouit. 1980. Les restes des reptiles des faluns de l'Anjou-Touraine (et supplément Poissons). Mémoires de la Société d'Etudes scientifiques de l'Anjou, Angers 5:1-40.

GramanN, F. 1956. Schildkröten aus dem Malnienton von Borken (Niederhessische Senke) (Trionyx, Anosteira). Notizblatt des Hessischen Landesamtes für Bodenforschung zu Wiesbaden 84:16-20.

GraY, J.E. 1830. A synopsis of the species of the class Reptilia. In: E. Griffith and E. Pidgeon, eds. The Class Reptilia arranged by the Baron Cuvier, with specific descriptions. In: E. Griffith, ed. The Animal Kingdom arranged in conformity with its organization, by the Baron Cuvier, with additional descriptions of all the species hitherto named, and of many not before noticed, Volume 9: Reptilia. Supplement. London: Whittaker, Treacher, and Co. pp. 75-76.

-1831. Synopsis Reptilium. Part I. Cataphracta. Tortoises, Crocodiles, Enaliosauria. London: G.B. Sowerby. 85 pp.

-1854. Description of a new genus and some new species of tortoises. Proceedings of the Zoological Society of London 1852:133-135.

-1864. Revision of the species of Trionychidae found in Asia and Africa, with the description of some new species. Proceedings of the Zoological Society of London 1864:76-98.

-1873 . Notes on the tortoises of the 'Zoology of Mexico' of MM. A. Duméril and Bocourt. Annals and Magazine of Natural History, Series 4 12:109-114.

Groessens-van Dyck, M.-C. AND H.H. SchleICH. 1985. New reptile material from the German Tertiary. 5. Fossil turtle remains (Chelydropsis, Trionyx) from the Miocene fissure filling of Appertshofen/N-Ingolstadt. Bulletin de la Société Belge de Géologie 94:101-112. 
Groessens van Dyck, M.-C. AND H.H. SCHLeICH. 1988. Zur Verbreitung tertiärer und quartärer Reptilien und Amphibien Europas. Belgien, Dänemark, Niederlande, Schweden. Studia Geologica Salmanticensia, Volume Especial 3:113-147.

GRÖNING, E. AND C. BRAUCKMANN. 1996. Schildkröten-Reste (Testudines) aus dem Mittel-Eozän des Eckfelder Maares (SW-Eifel, Deutschland). Mainzer Naturwissenschaftliches Archiv 34:45-53.

Gross, M. 2002. Aus der paläontologischen Sammlung des Landesmuseums Joanneum - Die fossilen Schildkröten (Testudines). Joannea Geologie und Paläontologie 4:5-68.

-2005. Nachtrag zum Katalog der fossilen Schildkröten am Landesmuseums Joanneum. Joannea Geologie und Paläontologie 6:61-64.

GuASPARRI, G. 1992. L'Accademia dei Fisiocritici di Siena: Guida ai Musei. San Quirico d'Orcia, Italy: Editoriale Donchisciotte. 166 pp.

GuliA, G. 1843. Guscio di testuggine fossile trovato a Malta. Repertorio di Conoscenze Utile, Zoologia Fossile 27: 77-78.

HADJISTERKOTIS, E., I. KASSAPIS AND N. KLERIDES. 2000. Paleontological evidence for the presence of Trionyx sp. on Cyprus, with new information on living and alien species of terrapins. Newsletter, Hellenic Zoological Society 33:8-10.

Halstead TARLO, L.B. 1965. Psammosteiformes (Agnatha)-a review with descriptions of new material from the Lower Devonian of Poland, II: Systematic part. Palaeontologia Polonica 15:1-167.

Hand, S.J., D.E. LeE, T.H. Worthy, M. Archer, J.P. Worthy, A.J.D. Tennyson, S.W. Salisbury, R.R. Scofield, D.C. Mildenhall, E.M. Kennedy And J.K. LindQVist. 2015 Miocene fossils reveal ancient roots for New Zealand's endemic Mystacina (Chiroptera) and its rainforest habitat. PLoS ONE 10:e0128871. doi: 10.1371/journal.pone.0128871

HARRASSOWITZ, H.L.F. 1919. Eocäne Schildkröten von Messe bei Darmstadt. Zentralblatt für Mineralogie, Geologie und Paläontologie, Abteilung B 9/10:147-154.

-1922. Die Schildkrötengattung Anosteira von Messel bei Darmstadt und ihre stammesgeschichtliche Bedeutung. Abhandlungen der Hessische Geologische Landesanstalt 6:137-238.

Hasegawa, Y., Y. SuYAma AND A. KameYama. 2007. Fossil turtle from the Upper Oligocene, Taoyama Formation, Hioki Group, in Tobou-cho, Shimonoseki, Yamaguchi, Japan. Bulletin of the Gunma Museum of Natural History 11:29-36.

HAY, O.P. 1899. Notes on the nomenclature of some North American fossil vertebrates. Science 10:253-254.

-1908. The fossil turtles of North America. Carnegie Institute of Washington Publication 75:1-568.

HEAD, J.J., S.M. RaZa AND P.D. GINGERICH. 1999. Drazinderetes tethyensis, a new large trionychid (Reptilia: Testudines) from the marine Eocene Drazinda Formation of the Sulaiman Range, Punjab (Pakistan). Contributions from the Museum of Paleontology of the University of Michigan 30:199-214.

HerITSCH, F. 1909. Jungtertiäre Trionyxreste aus Mittelsteiermark. Jahrbuch der Kaiserlich Königlichen Geologischen Reichsanstalt 59:333-382

-1910. Ein Jugendexemplar von Trionyx Petersi R. Hoernes aus Schönegg bei Wies. Mitteilungen des Naturwissenschaftlichen Vereines für Steiermark 46:348-355.

Hernández Sampelayo, P.H. and J.R. Bataller. 1944. Trionyx marini, tortuga nueva del Oligoceno leridano. Notas y
Comunicaciones del Instituto Geológico y Minero de España 13:9-19.

HERVET, S. 2004. Systématique du groupe $<<$ Palaeochelys sensu lato-Mauremys $>>$ (Chelonii, Testudinoidea) du Tertiaire d'Europe occidentale: principaux résultats. Annales de Paléontologie 90:13-78.

Hill, D., G. Playford and J.T. Woods. 1970. Cainozoic Fossils of Queensland. Brisbane, Australia: Queensland Palaeontographical Society. $36 \mathrm{pp}$.

Hirayama, R. 1992. Fossil Turtles from the Neogene strata in the Sinda Basin, eastern Zaire. African Study Monographs 17:49-65.

-1998. Fossil turtles from the Mifune Group (Late Cretaceous) of Kumamoto Prefecture, western Japan. In: Dinosaurs from the Mifune Group, Kumamoto Prefecture, Japan. Mifune, Japan: Mifune Town Education Board. pp. 85-99. [in Japanese with English abstract]

-2007. Revision of the systematics of the fossil turtles from Japan. In: N. Inuzuka, ed. Jubilee Publication in Commemoration of Professor Kamei Tadao's 80th Birthday. pp. 145-153.

Hirayama, R., S. IsajI AND T. Hibino. 2013. Kappachelys okurai gen. et sp. nov., a new stem soft-shelled turtle from the Early Cretaceous of Japan. In: D.B. Brinkman, P.A. Holroyd and J.D. Gardner, eds. Morphology and Evolution of Turtles. Dordrecht, The Netherlands: Springer. pp. 179-185.

HoERNES, R. 1881. Zur Kenntnis der mittelmiozänen Trionyxformen. Jahrbuch der Kaiserlich Königlichen Geologischen Reichsanstalt 31:479-482.

-1882. Trionyx-Reste des Klagenfurter Museums von Trifail in Steiermark. Verhandlungen der Kaiserlich-Königlichen Geologischen Reichsanstalt 1882:39-40.

-1892. Neue Schildkrötenreste aus steirischen Tertiärablagerungen. Verhandlungen der Kaiserlich-Königlichen Geologischen Bundesanstalt 1892:242-246.

HolEc, P. 2006. Remnants of the turtles genus Trionyx sp. from Miocene sediments of Devinska Kobyla hill near Bratislava. Mineralia Slovaca 38:67-70. [in Slovakian, with English abstract]

Holec, P. AND J. SCHLÖGL. 2000. Find of Trionyx rostratus Arth. in the upper Badenian deposits of the Malé Karpaty Mts., western Carpathians. Slovak Geological Magazine 6:106-109.

Hooljer, D.A. 1954. Pleistocene vertebrates from Celebes. X Testudinata. Proceedings of the Koninklijke Nederlandsche Akademie van Wetenschappen, Series B 57:486-489.

HOOKER, J.J. AND D.J. WARD. 1980. List of localities. Tertiary Research 3:3-12.

HÖRNES, M. 1848. Verzeichnis der Fossil-Reste aus 135 Fundorten des Tertiär-Beckens von Wien. In: J. Czjzek, ed. Erläuterungen zur geognostischen Karte der Umgebung Wiens. Vienna: Braumüller. pp. 1-43.

Hummel, K. 1927. Die Schildkrötengattung Trionyx im Eozän von Messel bei Darmstadt und im aquitanischen Bättersandstein vom Münzenberg in der Wetterau. Abhandlungen der Hessische Geologische Landesanstalt 8:5-96.

-1929. Die fossilen Weichschildkröten (Trionychia): eine morphologisch-systematische und stammesgeschichtliche Studie. Geologische und Paläontologische Abhandlungen 16:359-487. -1932. Pars 52: Trionychia fossilia. In: W. Quenstedt, ed. Fossilium Catalogus. I: Animalia. Berlin: W. Junk. 106 pp.

-1935. Schildkröten aus der mitteleozänen Braunkohle des Geiseltales. Nova Acta Leopoldina 2:457-483. 
Hutchison, J.H., P.A. Holroyd and R.L. Ciochon. 2004. A preliminary report on Southeast Asia's oldest Cenozoic turtle fauna from the late Middle Eocene Pondaung Formation, Myanmar. Asiatic Herpetological Research 10:38-52.

[ICZN] INTERNATIONAL COMMISSION ON ZOOLOGICAL NOMENCLATURE. 1999. International Code of Zoological Nomenclature. 4th ed. London: International Trust for Zoological Nomenclature. 306 pp.

-2005. Opinion 2119 (case 3277). Chitra chitra Nutaphand, 1986 (Reptilia, Testudines): specific name given precedence over Chitra selenkae Jaekel, 1911. Bulletin of Zoological Nomenclature 62:118-119.

ISSEL, A. 1892. Liguria geologica e preistorica, Volume 1. Genoa, Italy: Donath Editore. 440 pp.

JACCARD, A. 1888. Sur les animaux vertébrés fossiles de létage Oeningen du Loche. Bulletin de la Société des Sciences Naturelles de Neuchâtel 16:52-57.

Jaeger, J.-J., A.N. Soe, O. Chavasseau, P. Coster, E.-G. EMONET, F. GUY, R. LEBRUN, ET AL. 2011. First hominoid from the Late Miocene of the Irrawaddy Formation (Myanmar). PLoS ONE 6:e17065. doi: 10.1371/journal.pone.0017065.

JAEKEL, O. 1911. Die fossilen Schildkröten von Trinil. In: M.L. Selenka and M. Blanckenhorn, eds. Die PithecanthropusSchichten auf Java. Geologische und Paläontologische Ergebnisse der Trinil-Expedition (1907 und 1908). Leipzig, Germany: Engelmann. pp. 75-81.

JimÉnEZ Fuentes, E. 2003. Quelonios fósiles de la Cuenca del Duero. In: E. Jiménez Fuentes and J. Civis Llovera, eds. Los vertebrados fósiles en la historia de la vida. Excavación, estudio y patrimonio. Salamanca, Spain: Universidad de Salamanca. pp. 177-195.

JiméNEZ Fuentes, E. AND L. AlONSO ANDREs. 1994. Nuevos hallazgos de Trionychidae (Chelonii) en el Eoceno de Salamanca y Zamora. Studia Geologica Salmanticensia 29:95-113.

JimÉNEZ Fuentes, E. AND S. MARTín DE JEsús. 1991. Ejemplarestipo de quelonios fósiles españoles. Revista Española de Paleontología 6:98-106.

Jiménez Fuentes, E., E. Ramos Guerrero, S. Martín De Jesús, E. Pérez Ramos and E. Mulas Alonso. 1990. Quelonios del Eoceno medio de Mallorca. Paleontologia i Evolució 23:153-156.

JoYCE, W.G. 2014. A review of the fossil record of turtles of the clade Pan-Carettochelys. Bulletin of the Peabody Museum of Natural History 55:3-33.

-2016. A review of the fossil record of turtles of the clade PanChelydridae. Bulletin of the Peabody Museum of Natural History 57:21-56.

-2017. A review of the fossil record of basal Mesozoic turtles. Bulletin of the Peabody Museum of Natural History 58(1):65-113.

JoYCE, W.G. AND T.R. LYSON. 2010a. A neglected lineage of North American turtles fills a major gap in the fossil record. Palaeontology 53:241-248.

-2010b. Pangshura tatrotia, a new species of pond turtle (Testudinoidea) from the Pliocene Siwaliks of Pakistan. Journal of Systematic Palaeontology 8:449-458.

-2011. New material of Gilmoremys lancensis nov. comb. (Testudines: Trionychidae) from the Hell Creek Formation and the diagnosis of plastomenid turtles. Journal of Paleontology 85:442-459.
Joyce, W.G., T.R. LySON AND S. Williams. 2016. New cranial material of Gilmoremys lancensis (Testudines, Trionychidae) from the Hell Creek Formation of southeastern Montana, U.S.A. Journal of Vertebrate Paleontology 36:e1225748. doi: 10.1080/02724634.2016.1225748

Joyce, W.G., N. Micklich, S.F.K. SCHAAL AND T.M. SCHEYeR. 2012. Caught in the act: the first record of copulating fossil vertebrates. Biology Letters 8:846-848.

Joyce, W.G., J.F. PARHAm AND J.A. GaUTHIER. 2004. Developing a protocol for the conversion of rank-based taxon names to phylogenetically defined clade names, as exemplified by turtles. Journal of Paleontology 78:989-1013.

Joyce, W.G., J.F. PARHAM, T.R. LYSON, R.C.M. WARNOCK AND P.C.J. Donoghue. 2013. A divergence dating analysis of turtles using fossil calibrations: an example of best practices. Journal of Paleontology 87:612-634.

JURKOVŠEK, B. AND T. KOLAR-JURKOVŠEK. 1994. Fossil turtles in Slovenia. Geologija 36:75-93.

KARL, H.-V. 1987. Revision der fossilen Schildkröten (Reptilia, Testudines) von Jawa. Gothaer Museumsheft 14:37-44.

-1993. Revision der känozoischen Weichschildkröten (Testudines, Trionychidae) Mitteldeutschlands. Mauritiana 14:115-134.

-1996. Some remarks on the fossil turtles (Reptilia, Testudines) from the federal country of Salzburg, Austria. Mitteilungen der Gesellschaft für Salzburger Landeskunde 136:389-426.

-1998. Zur Taxonomie der känozoischen Weichschildkröten Österreichs und Deutschlands (Trionychidae: Trionychinae). Mitteilungen zur Geologie und Paläontologie, Landesmuseum Joanneum 56:273-328.

-1999a. Die Zoogeographie der känozoischen Weichschildkröte Trionyx triunguis Forskål, 1775 (Testudines: Trionychidae). Joannea - Geologie und Paläontologie 1:27-60.

-1999b. Paleogeography and systematics of the genus Dogania Gray, 1844 (Testudines: Trionychidae). Studia Geologica Salmanticensia 35:3-8.

-2002. Über Reptilienreste aus dem Alttertiär des nördlichen Alpenvorlandes bei Siegsdorf/Oberbayern. Joannea - Geologie und Paläontologie 4:69-81.

-2007. The fossil reptiles (Reptilia: Chelonii, Crocodylia) from the marine Early Oligocene of the Weisselster Basin (Central Germany: Saxonia). Studia Geologica Salmanticensia 43:25-66.

-2012. Human consumption of turtles of the Homo rudolfensis site Uraha (Malawi, East Africa). Archaeofauna 21:253-264.

-2013. Die fossilen Schildkröten aus der Molasse von Oberschwaben mit taxonomischen Notizen zu "Promalacoclemmys Reinach, 1900" und Testudo antiqua Bronn, 1831 (Testudines: Cryptodira). Mainzer Naturwissenschaftliches Archiv 50:121-146.

Karl, H.-V., E. Gröning AND C. BraUCKMANn. 2011. New Oligocene turtle remains of the Oberleichtersbach doline filling (Lower Franconia, Germany) and revision of the genus Palaeomauremys (Testudines: Geoemydidae). Studia Geologica Salmanticensia 47:175-194.

KarL, H.-V. AND B.E.K. Lindow. 2012. Revision of the Palaeocene turtles (Reptilia: Testudines) of Denmark. Studia Palaeocheloniologica 4:175-192. 
KarL, H.-V. AND A. MÜlLer. 2008. New fossil reptil [sic] material (Reptilia: Chelonii, Crocodylia) from the lowe Oligocene of Borken (central Germany: Hesse). Studia Geologica Salmanticensia 44:41-58.

Kaup, J.J. 1834. Pisoodon Coleanus, ein neues Genus der Saurier aus dem tertiären Sande bey Eppelsheim. Isis 5:533-536.

KHOSATZKY, L.I. 1948. [About remains of turtles from the Sarmatian of the Crimea]. Byulleten' Moskovskogo Obshchestva Ispytateley Prirody, Otdel geologii 23:17-22 [in Russian]

-1957. [On the history of trionychids in Kazakhstan]. Izvestiya Akademii Nauk Kazakh SSR, Seriya Biologicheskaya 2:15-30. [in Russian]

-1966. [About a gigantic Mesozoic representative of trionychids and several features of the shell of these turtles]. In Pozvonochnye zhivotnye Sredney Azii. Tashkent, Uzbekistan: Fan. pp. 150-157. [in Russian]

-1976. [A new representative of trionychids from the Late Cretaceous of Mongolia]. In: Gerpetologiya, Kubanskiy Gosudarstvennyy Universitet. Nauchnye Trudy 218:3-19. [in Russian]

-1986. [A large trionychid from the Sarmatian of Moldavia]. Ezhegodnik Vsesoyuznogo Paleontologicheskogo Obshchestva 29:158-170. [in Russian]

-1999. [Turtles-trionychids of the Cretaceous of Mongolia]. Voprosy Paleontologii 11:141-149. [in Russian]

KhosatzKy, L.I., L. Christov and D. Nankinov. 1983. An Eocene soft-shelled turtle from Bulgaria. Schriftenreihe für geologische Wissenschaften 19/20:271-280.

KhosatzKy, L.I. AND M. MrynarsKi. 1971. Chelonians from the Upper Cretaceous of the Gobi Desert, Mongolia. Palaeontologia Polonica 25:131-144.

KHOSATZKY, L.I. AND L.A. Nessov. 1979. [Big turtles of the Late Cretaceous of Middle Asia]. Trudy Zoologicheskogo Instituta Akademii Nauk SSSR 89:98-108.

KHosATSKY, L.I. AND O.I. RedKOZUBOV. 1989. [The Neogene turtles of Moldova]. Chișinau, Moldova: Shtiinca. 94 pp. [in Russian]

KHOSATZKY, L.I. AND V.I. Tofan. 1970. [Past and present state of the herpetofauna of Moldavia]. Uchenye Zapiski Tiraspol'skogo Gosudarstvennogo Pedagogicheskogo Instituta 20:157-181. [in Russian]

Klein, N. AND T. Mörs. 2003. Die Schildkröten (Reptilia: Testudines) aus dem Mittel-Miozän von Hambach (Niederrheinische Bucht, NW-Deutschland). Palaeontographica Abteilung A 268:1-48.

KocH, A., 1894. Az erdélyrészi medencze harmadkori képzö dményei. 1. Paleogén csoport. Magyar Királyi Földtani Intézet Évkönyve 10:161-356.

KocH, F. 1915. Über Trionyx croaticus n. sp. aus dem Mittelmiozän von Voca in Kroatien. Glasnik Hrvatskoga prirodoslovnoga društva 27:203-211.

KOKEN, 1892. Über Wirbeltierreste der samländischen Unteroligocäns. Schriften der physikalisch-ökonomischen Gesellschaft zu Königsberg 33:42-43.

KORDIKOVA, E.G. 1992. [Review of fossil trionychid turtles of the USSR]. Izvestiya Akademii Nauk Gruzii, Seriya Biologicheskaya 18:131-141. [in Russian]

-1994a. About systematics of fossil trionychids in Kazakhstan. Selevinia 2:3-8
- 1994b. Review of fossil trionychid localities in the Soviet Union. Courier Forschungs-Institut Senckenberg 173:341358.

-2002. Heterochrony in the evolution of the shell of Chelonia. Part 1: Terminology, Cheloniidae, Dermochelyidae, Trionychidae, Cyclanorbidae and Carettochelyidae. Neues Jahrbuch für Geologie und Paläontologie 226:343-417.

Kordikova, E.G. AND V.M. CHKHIKVADZE. 1990. [Stratigraphic significance of fossil trionychids of Kazakhstan]. Materialy po istorii fauny i flory Kazakhstana 11:135-139. [in Russian]

Kordikova, E.G. AND A.V. Mavrin. 1996. Stratigraphy and Oligocene-Miocene mammalian biochronology of the Aktau Mountains, Dzhungarian Alatau Range, Kazakhstan. Palaeovertebrata 25:141-174.

KoTsakis, T. 1977. Due nuovi Trionyx capellinii Negri (Testudinata, Trionychidae) dell'Eocene di Monte Bolca (Verona, Italia). Bollettino della Società Paleontologica Italiana 16:203-228.

-1980. Révision des tortues (Emydidae, Testudinidae, Trionychidae) du Plio-Pléistocène de Valdarno supérieur (Toscane, Italie). Quaternaria 22:11-37.

-1985. Les Trionychidae (Testudinata, Reptilia) fossiles de l'Italie. Bollettino della Società Paleontologica Italiana 24:161-168.

-1989. Late Turolian amphibians and reptiles from Brisighella (northern Italy): preliminary report. Bollettino della Società Paleontologica Italiana 28:277-280.

Kotsakis, T., P. Argenti, G. Barisone, M. Delfino, M.R. Palombo, M. Pavia And P. Piras. 2005. I vertebrati continentali. Memorie del Museo Civico di Storia Naturale di Verona, Scienze della Terra 6:11-139.

Krumbiegel, G. 1963. Trionychidenfunde (Flussschildkröten) der Gattung Trionyx Geoffroy 1809 aus der eozänen Braunkohle des Geiseltales. Geologie 12:196-223.

Kunn, O. 1964. Fossilium Catalogus, Volume I: Animalia, Part 107, Testudines. The Hague, The Neatherlands: Junk. 299 pp.

KUSS, S.E. 1958. SCHILDKRÖTENRESTE (Ptychogaster buechelbergense n. sp., Ocadia malthaneri n. sp., Trionyx sp.) aus dem aquitanen Tonlager von Bichelberg in der Pfalz. Notizblatt des Hessischen Landesamtes für Bodenforschung 86:50-76.

Kutorga, S.S. 1835. Beitrag zur Geognosie und Paläontologie Dorpats und seiner nächsten Umgebungen. St. Petersburg: Mineralogische Gesellschaft. 45 pp.

-1837. Beitrag zur Geognosie und Paläontologie Dorpat's und seiner nächsten Umgebungen. St. Petersburg: Mineralogische Gesellschaft. 51 pp.

KuZneTsov, V.V. 1976. [A freshwater turtle from the Senonian deposits of the northeastern Cis-Aralia region]. Paleontologicheskii Zhurnal 4:125-127. [in Russian]

-1978. [Materials on fossil turtles of Kazakhstan]. Moscow: VINITI. 119 pp. [in Russian]

Kuznetsov, V.V. And V.M. ChKhIKVADZE. 1977. [Fossil softshelled turtles from the middle Oligocene of the Turgai Depression]. Materialy po istorii fauny i flory Kazakhstana 7:10-14. [in Russian]

-1987. [The Late Cretaceous trionychids from Shakh-Shakh locality in Kazakhstan]. Materialy po istorii fauny i flory Kazakhstana 9:33-39. [in Russian]

Kuznetsov, V.V. AND P.V. SHiLin. 1983. [Late Cretaceous turtle from Baybishe northeastern Aral Sea region]. Izvestiya 
Akademii Nauk Kazakh SSR, Seriya Biologicheskaya 6:41-44. [in Russian]

KVAČEK, Z. 2002. Late Eocene landscape, ecosystems and climate in northern Bohemia with particular reference to the locality of Kuclín near Bílina. Bulletin of Geosciences 77:217-236

LAPPARENT DE BROIN, F. DE. 2000. African chelonians from the Jurassic to the present: phases of development and preliminary catalogue of the fossil record. Paleontologia Africana 36:43-82.

-2001. The European turtle fauna from the Triassic to the Present. Dumerilia 4:155-217.

LAPPARENT DE BROIN, F. DE AND S. GMIRA. 1994. Les chéloniens dulçaquicoles du Rift occidental, Ouganda. In: M. Pickford, B. Senut and D. Hadoto, eds. Geology and Palaeobiology of the Albertine Rift Valley, Uganda-Zaire. II: Palaeobiology. Paris: Fondation CIFEG. pp. 157-186.

Lapparent de Broin, F. DE, D. Merle, M. Fontana, L. GinsBURG, P. HeRvat, Y. Le CalveZ and J. Riveline. 1993. Une faune continentale à vertébrés dans le Lutétien supérieur de Guitrancourt (Yvelines) et son environnement. Bulletin d'information des géologues du Bassin de Paris 30:3-16.

LAPPARENT DE BRoIN, F. DE AND P.P. VAN DiJK. 1999. Chelonia from the Late Miocene Baynunah Formation, Emirate of Abu Dhabi, United Arab Emirates: palaeogeographical implications. In: P.J. Whybrow and A. Hill, eds. Fossil Vertebrates of Arabia. New Haven, CT: Yale University Press. pp. 136-162.

LaUBE, G.C. 1882. Notiz über das Vorkommen von Trionyx resten im Diatomeenschiefer von Kutschlin bei Bilin. Verhandlungen der Kaiserlich-Königlichen Geologischen Reichsanstalt 1882:107-108.

-1895. Vorläufiger Bericht über Schildkrötenreste aus der böhmischen Braunkohlenformation. Verhandlungen der Geologischen Bundesanstalt 1895:391-392.

-1896. Schildkrötenreste aus der böhmischen Braunkohlenformation. Abhandlungen des Deutschen NaturwissenschaftlichMedizinischen Vereins für Böhmen "Lotos" 1:1-19.

-1898. Bericht über einen neuen Trionyx aus den aquitanischen (plastischen) Thonen von Preschen bei Bilin in Böhmen. Verhandlungen der Geologischen Bundesanstalt 1898:232-233.

-1900 . Neue Schildkröten und Fische aus der böhmischen Braunkohlenformation. Abhandlungen des Deutschen Naturwissenschaftlich-Medizinischen Vereins für Böhmen "Lotos" 2:37-56.

LaURent, Y., S. Adnet, E. Bourdon, D. Corbalan, L. Danilo, S. Duffaud, G. FleurY, ET AL. 2010. La Borie (Saint-Papoul, Aude): un gisement exceptionnel dans l'Éocène basal du Sud de la France. Bulletin de la Société d'Histoire Naturelle de Toulouse 146:89-103.

LAWLEY, R. 1876. Nuovi studi sopra ai pesci ed altri vertebrati fossili delle Colline Toscane. Florence, Italy: Tipografia dell'Arte Della Stampa. 122 pp.

LAWVER, D.R. AND F.D. JACKSON. 2014. A review of the fossil record of turtle reproduction: eggs, embryos, nests and copulating pairs. Bulletin of the Peabody Museum of Natural History 55:215-236.

Le, M., H.T. DuOnG, L.D. Dinh, T.Q. NGuYen, P.C.H. PritCHARD AND T. MCCORMACK. 2014. A phylogeny of softshell turtles (Testudines: Trionychidae) with reference to the taxonomic status of the critically endangered, giant softshell turtle, Rafetus swinhoei. Organisms, Diversity and Evolution 14:279-293.

Le, M.D. AND P. Pritchard. 2009. Genetic variability of the critically endangered softshell turtle, Rafetus swinhoei: a preliminary report. In: D.C. Ngo, H.T. Ta, N.N. Le, X.Q. Hoang, V.P. Vo, V.S. Nguyen, V.T. Nguyen, T.T. Le and Q.D. Tran, eds. Proceedings of the First Vietnamese National Symposium on Reptiles and Amphibians. Hue, Vietnam: Hue University Press. pp. 84-92.

LEAKeY, L.S.B. 1965. Olduvai Gorge, 1951-1961. A Preliminary Report on the Geology and the Fauna. Cambridge: Cambridge University Press. 109 pp.

LEBKÜCHNER, R.F. 1974. Beitrag zur Kenntnis der Geologie des Oligozäns von Mittelthrakien (Türkei). Bulletin of the Mineral Research and Exploration Institute of Turkey 83:1-30.

LEI, Y. AND X. Ye. 1985. An early Eocene trionychid from Nanzhang, Hubei. Vertebrata Palasiatica 23:19-26.

Li, L., W.G. JOYCE AND J. LiU. 2015. The first soft-shelled turtle from the Jehol Biota of China. Journal of Vertebrate Paleontology 35:e909450. doi: 10.1080/02724634.2014.909450

LI, L., H. TonG, W. GU AND J. Liv. 2015. A new trionychid turtle from the Early Cretaceous of Heilongiiang Province, northeastern China. Cretaceous Research 56:155-160.

Liebus, A. 1930. Neue Schildkröten aus den Tertiären Süsswassertonen von Preschen bei Bilin in Böhmen. Rozpravy Státního geologického ústavu Ceskoslovenské Republiky 4:1-57.

LÖRENTHEY, E. 1903. Zwei neue Schildkrötenarten aus dem Eocän von Kolozsvár. Földtani Közlöny 33:249-266.

LOUYS, J. AND G.J. PRICE. 2015. The Chinchilla local fauna: an exceptionally rich and well-preserved Pliocene vertebrate assemblage from fluviatile deposits of south-eastern Queensland, Australia. Acta Palaeontologica Polonica 60:551-572.

LYDEKKER, R. 1885. Indian Tertiary and post-Tertiary Vertebrata. Siwalik and Nerbada Chelonia. Memoirs of the Geological Survey of India 21:155-208.

-1889a. Catalogue of the Fossil Reptilia and Amphibia in the British Museum (Natural History), Part III: The Order Chelonia. London: British Museum (Natural History). 239 pp.

-1889b. Notes on Siwalik and Narbada Chelonia. Records of the Geological Survey of India 22:56-58.

-1891 . On a new species of Trionyx from the Miocene of Malta and a chelonian scapula from the London Clay. Quarterly Journal of the Geological Society of London 47:37-40.

MAACK, G.A. 1869. Die bis jetzt bekannten fossilen Schildkröten und die im oberen Jura bei Kelheim (Bayern) und Hannover neu aufgefundenen ältesten Arten derselben. Palaeontographica 18:193-336.

Macarovici, N. AND I. Motas. 1965. Asupra unui Trionyx sp. găsit în Kersonianul din Munţii Vrancei. Analele ştiințifice ale Universităţii "Alexandru Ioan Cuza" din Iaşi 11:93-96.

MALIK, A. AND H. NAFIZ. 1933. Küçükçekmece fosil fikrali hayvanlar mecmuası. Bulletin de la Faculté des sciences de l'Université d'Istanbul 8:1-119.

Mantell, G.A. 1833. The Geology of the South East of England. London: Longman. 415 pp.

Maтsumoto, H. 1918. On a new fossil Trionyx from Hokkaidō. Science Reports of the Tohoku Imperial University, Geology 3:57-60. 
Maxwell, E.E., S. Alexander, G. Bechly, K. Eck, E. Frey, K. Grimm, J. Kovar-EDER, ET AL. 2016. The Rauenberg fossi Lagerstätte (Baden-Württemberg, Germany): a window into early Oligocene marine and coastal ecosystems of Centra Europe. Palaeogeography, Palaeoclimatology, Palaeoecology 463:238-260.

MaYr, G. 2009. Paleogene Fossil Birds. Berlin: Springer-Verlag. 262 pp.

MaYr, G. AND T. SMith. 2012. Phylogenetic affinities and taxonomy of the Oligocene Diomedeoididae, and the basal divergences amongst extant procellariiform birds. Zoological Journal of the Linnean Society 166:854-875.

MCCORD, W.P. AND P.C.H. PrITCHARD. 2002. A review of the softshell turtles of the genus Chitra, with the description of new taxa from Myanmar and Indonesia (Java). Hamadryad 27:11-56.

-2003. Case 3277. Chitra chitra Nutaphand, 1986 (Reptilia, Testudines): Proposed precedence of the specific name over that of Chitra selenkae Jaekel, 1911. Bulletin of Zoological Nomenclature 60:208-210.

MenG, J., Y. WanG, X. Ni, K.C. BEARD, C. Sun, Q. LI, X. Jin AND B. BAI. 2007. New stratigraphic data from the Erlian Basin: implications for the division, correlation, and definition of Paleogene lithological units in Nei Mongol (Inner Mongolia). American Museum Novitates 3570:1-31.

MerciaI, G. 1907. Sopra alcuni resti di vertebrati miocenici delle ligniti di Ribolla. Atti della Società Toscana di Scienze Naturali, Memoire 23:79-87.

Merkulova, N.N. 1978. [A new Trionyx from the Nemegt (MPR)]. Byulleten Moskovskogo Obshchestva Ispytateley Prirody. Otdel Geologicheskiy 53:156. [in Russian]

MeYer, H. von. 1832. Paläologica zur Geschichte der Erde und ihrer Geschöpfe. Frankfurt am Main: Siegmund Schmerber 560 pp.

-1839. Die Säugetiere, Reptilien und Vögel aus den MolasseGebilden der Schweiz. Neues Jahrbuch für Mineralogie, Geognosie, Geologie und Petrefaktenkunde 1839:1-9.

-1844. Mitteilung an Prof. Bronn gerichtet. Neues Jahrbuch für Mineralogie, Geognosie, Geologie und Petrefaktenkunde 1844:564-567.

-1860. Trionyx Eier im Mainzer Becken. Jahrbuch fur Mineralogie, Geologie und Palaeontologie 1860:556-560.

-1865. Ueber die fossilen Reste von Wirbelthieren, welche die Herren von Schlagintweit von ihren Reisen in Indien und Hoch-Asien mitgebracht haben. Palaeontographica 15:140.

-1867. Ueber fossile Eier und Federn. Palaeontographica 15:223-252.

MEYLAN, P.A. 1987. The phylogenetic relationships of softshelled turtles (Family Trionychidae). Bulletin of the American Museum of Natural History 186:1-101.

MeYLAn, P.A. AND E.S. GAFFNEY. 1992. Sinaspideretes is not the oldest trionychoid turtle. Journal of Vertebrate Paleontology 12:257-259.

Meylan, P.A., B.S. Weig and R.C. WoOd. 1990. Fossil softshelled turtles (Family Trionychidae) of the Lake Turkana Basin, Africa. Copeia 1990:508-528.

Michaux, J. 1973. Description d'un crâne de Trionyx cf. bruxelliensis Winckler, 1869 (Reptilia, Chelonia) du Cuisien d'Epernay (Marne). Compte rendu sommaire des séances de la Société géologique de France 3:92-94.
Misuri, A. 1911. Sopra un nuovo trionichide dell'arenaria miocenica del Bellunese (Trionyx bellunensis Dal Piaz in sch.). Perugia, Italy: Bartelli. 11 pp.

MiURA, M. AND Y. Uyama. 1987. A new species of the fossil soft-shelled turtle Trionychidae Testudinata from the Miocene Bihoku-sogun Kimita-son, Hiroshima Prefecture. Miscellaneous Reports of the Hiwa Museum for Natural History 25:11-14.

MlynARSKI, M. 1966. Die fossilen Schildkröten in den ungarischen Sammlungen. Acta Zoologica Cracoviensa 11:223-288.

-1976. Encyclopedia of Paleoherpetology. Part 7, Testudines. Stuttgart, Germany: Gustav Fischer Verlag. 129 pp.

MrynARSKI, M. AND P. NARMANDACH. 1972. New turtle remains from the Upper Cretaceous of the Gobi Desert, Mongolia. Palaeontologia Polonica 27:95-102.

Moody, R.T.J. AND C.A. WALKER. 1970. A new trionychid turtle from the British lower Eocene. Palaeontology 13:503510.

MöRs, T., 1998. Über das Vorkommen von Trionyx s. 1. (Testudines: Trionychidae) im Oberoligozän von Rott (Rheinland). Bonner Zoologische Beiträge 48:31-34.

Motтl, M., 1967. Neue Schildkrötenreste aus dem Mittelmiozän SW-Österreichs. Carinthia 77:169-182.

MudAr, K. AND D. ANDERSON. 2007. New evidence for Southeast Asian Pleistocene foraging economies: faunal remains from the early levels of Lang Rongrien Rockshelter, Krabi, Thailand. Asian Perspectives 46:298-334.

Murelaga, X., X.P. Suberbiola, F. De Lapparent de Broin, J.C. Rage, S. Duffaud, H. Astibia and A. Badiola. 2002. Amphibians and reptiles from the Early Miocene of the Bardenas Reales of Navarre (Ebro Basin, Iberian Peninsula). Geobios 35:347-365.

Nakajima, Y., I.G. Danilov, R. Hirayama, T. Sonoda AND T. SCHEYER. Morphological and histological evidence for the oldest known softshell turtles from Japan. Journal of Vertebrate Paleontology. In Press.

Nečas, P., D. Modry and V. Zavadil. 1997. Czech Recent and Fossil Amphibians and Reptiles: An Atlas and Field Guide. Frankfurt am Main, Germany: Edition Chimaira. 94 pp.

NegRI, A. 1892. Trionici eocenici ed oligocenici del Veneto. Memorie della Società Italiana di Scienze 8:1-53.

-1893. Nuove osservazioni sopra i trionici delle ligniti di Monteviale. Padua, Italy: Prosperini. 13 pp.

Nessov, L.A. 1977. [Turtles and some other reptiles from the Cretaceous of Karakalpakia]. In: Voprosy gerpetologii. Avtoreferaty dokladov IV Vsesoyuznoi gerpetologicheskoi konferentsii. Leningrad: Nauka. pp. 155-156. [in Russian]

-1984. [Preservation of remains of organisms and conditions of their burial in Kulbike Member of Itemir]. In: V.G. Ochev, ed. Tafonomiya i Voprosy Paleogeografii. Saratov, Russia: Saratov University. pp. 62-76. [in Russian]

-1986. Some late Mesozoic and Paleocene turtles of Soviet Middle Asia. Studia Palaeocheloniologica 2:7-22.

-1987. On some Mesozoic turtles of Soviet Union, Mongolia and China, with comments on systematics. Studia Palaeocheloniologica 2:87-102.

-1995a. [Dinosaurs of northern Eurasia: new data about assemblages, ecology, and paleobiogeography]. St. Petersburg: Izdatel'stvo Sankt-Peterburgskogo Universiteta. [in Russian] 
-1995b. On some Mesozoic turtles of the Fergana Depression (Kyrgyzstan) and Dzhungar Alatau Ridge (Kazakhstan). Russian Journal of Herpetology 2:134-141.

-1997. [Cretaceous Non-marine Vertebrates of Northern Eurasia]. St. Petersburg: Saint Petersburg State University, Institute of Earth Crust. 218 pp. [in Russian]

NutAPHAND, W. 1986. [Manlai. The world's biggest softshell turtle]. Thai Zoological Magazine 1:64-70. [in Thai]

Obata, I., H. Yoshikazu and O. Hiroyuki. 1972. Preliminary report on the Cretaceous reptile fossils from Hokkaidō. Memoirs of the National Science Museum 5:213-222.

OKaZAKI, Y. AND S. Yoshida. 1977. On a new fossil Trionyx from the Pliocene age group, Mie Prefecture, west Japan. Bulletin of the Mizunami Fossil Museum 4:87-95.

ŐsI, A. 2001. Középső-eocén teknősleletek Nyires-pusztáról (Déli-Bakony). Földtani Közlöny 131:353-360.

OTsuKa, H. 1969. Pleistocene vertebrate fauna from the Kuchinotsu Group of west Kyushu (part III-V). Reports of the Faculty of Science, Kagoshima University 2:53-84.

-1970. Tertiary Chelonia from northwestern Kyushu. Reports of the Faculty of Science, Kagoshima University 3:23-28.

Owen, R. 1849-1884. A History of British Fossil Reptiles. London: Cassell and Company. 657 pp.

Owen, R. AND T. BeLl. 1849. Part I: Chelonia. In: R. Owen and T. Bell, eds. Monograph on the fossil Reptilia of the London Clay and of the Bracklesham and other Tertiary beds. London: Palaeontographical Society of London. pp. 1-76.

Pamouktchiev, A., F. de Lapparent de Broin and A. ANGUelov. 1998. Nouvelle trouvaille de tortue fossile en Bulgarie. Annuaire de l'Université de Sofia "St. Kliment Ohridski” Faculté de Géologie et Géographie, Livre 1 Geologie 90:5-8.

Pandolfi, L., G. Carnevale, L. Costeur, L. Del Favero, M Fornasiero, E. GHEZZO, L. MAIORINO, ET AL. 2017. Reassessing the earliest Oligocene vertebrate assemblage of Monteviale (Vicenza, Italy). Journal of Systematic Palaeontology 15:83-127.

Papp, V.A., E. Thenius, W. Berger and E. Weinfurter. 1953. Vösendorf-ein Lebensbild aus dem Pannon des Wiener Beckens: ein Beitrag zur Geologie und Paläontologie der unterpliozänen Congerienschichten des südlichen Wiener Beckens. Mitteilungen der Geologischen Gesellschaft in Wien 46:1-109.

PARKS, W.A. 1933. New species of dinosaurs and turtles from the Upper Cretaceous formations of Alberta. University of Toronto Studies, Geological Series 34:1-33.

PAunović, M. 1984. Süsswasserschildkrötenrest aus den Promina-Schichten bei Varoš (Siverić, Kroatien). Rod jugoslavenske Akademije Znanosti i Umjetnosti 411:7-16.

-1986. Revision of the Species Trionyx croaticus Koch, 1915. In: Z. Roček, ed. Studies in Herpetology. Prague: Charles University of Prague. pp. 183-186.

Pérez-García, A., X. Murelaga, J. Cadiel Lalueza, A. Badiola And E. Díaz-Berenguer. 2013. Presence of several clades of continental turtles in the Lutetian (Middle Eocene) of the Sobrarbe Formation (Ainsa Basin, south-central Pyrenees, northeast Spain). Geologica Belgica 16:311-319.

Pérez García, A., X. Murelaga, M.A. Mancheño and I. Fierro. 2011. Nuevos datos sobre las tortugas del Puerto de la Cadena (Mioceno superior de Murcia). Geogaceta 50:185-188.

PETERS, K.F. 1855. Schildkrötenreste aus den österreichischen Tertiär-Ablagerungen. Denkschriften der Kaiserlichen Akademie der Wissenschaften, mathematisch-naturwissenschaftliche Classe 9:1-22.

-1859. Beiträge zur Kenntniss der Schildkrötenreste aus den österreichischen Tertiärablagerungen. Beiträge zur Palaeontographie von Österreich 1:59-64.

-1869. Zur Kenntniss der Wirbelthiere aus den Miocänschichten von Eibiswald in Steiermark. 1. Die Schildkrötenreste. Denkschriften der Kaiserlichen Akademie der Wissenschaften, mathematisch-naturwissenschaftliche Classe 29:111-124.

-1881. Der Schädel von Trionyx Styriacus. Verhandlungen der Kaiserlich-Königlichen Geologischen Reichsanstalt 1881: 221-222.

Peters, W.C.H. 1854. Übersicht der auf seiner Reise nach Mossambique beobachteten Schildkröten. Monatsberichte der Akademie der Wissenschaften zu Berlin 1854:215-216.

PICKFORD, M. 1975. Late Miocene sediments and fossils from the northern Kenya Rift Valley. Nature 256:279-284.

-1986. Cainozoic paleontological sites of western Kenya. Münchner Geowissenschaftliche Abhandlungen A 8:1-151.

-2008. Middle Miocene vertebrate fauna from Pemba Island, Tanzania. South African Journal of Science 104:231-237.

Pictet, F.-J. and A. Humbert. 1856. Monographie des chéloniens de la Molasse Suisse. Matériaux pour la paléontologie suisse 1:1-71.

PILGRIM, G.E. 1912. The vertebrate fauna of the Gaj Series in the Bugti Hills and the Punjab. Memoirs of the Geological Survey of India, New Series 4:1-83.

Pomel, A. 1846. Mémoire pour servir à la géologie paléontologique des terrains tertiaires du département de l'Allier. Bulletin de la Société géologique de France 3:353-373.

-1847 . Note sur les mammiferes et reptiles fossiles des terrains éocènes de Paris, inférieurs au dépôt gypseux. Archives des Sciences Physiques et Naturelles de Genève 4:326-330.

Poporogu, E. 1972. Prezenţa unui chelonian fosil-Trionyx sp. în sedimentele orizontului 2 din bazinul Petroşani în câmpul minier Lupeni. Acta Musei Devensis, Sargetia, Series Scienta Naturae 9:211-212.

PorTIS, A. 1879. Di alcuni fossili terziarii del Piemonte e della Liguria appartenenti allordine dei chelonii. Memorie della Reale Accademia delle Scienze di Torino, serie 2 32: 113-134.

-1882. Les chéloniens de la molasse Vaudoise conservés dans le musée géologique de Lausanne. Mémoires de la Société Paléontologique Suisse 9:1-78.

-1883. Nuovi chelonii fossili del Piemonte. Memorie della Reale Accademia delle Scienze di Torino 35:369-378.

-1885 . Resti di chelonii terziarii italiani. Atti della Reale Accademia delle Scienze di Torino 20:881-896.

-1890. I rettili pliocenici del Valdarno superiore e di alcune altre località plioceniche di Toscana. Florence, Italy: Le Monnier. $32 \mathrm{pp}$.

-1901. Il Procyclanorbis sardus Port., nuovo trionychide fossile della Sardegna. Bollettino della Società Geologica Italiana 20:51-79. 
PRASAD, K.N. 1974. The vertebrate fauna from Piram Island, Gujarat, India. Memoirs of the Geological Survey of India 41:1-23.

Praschag, P., H. Stuckas, M. Päckert, J. Maran and U. FRITZ. 2011. Mitochondrial DNA sequences suggest a revised taxonomy of Asian flapshell turtles (Lissemys Smith, 1931) and the validity of previously unrecognized taxa (Testudines: Trionychidae). Vertebrate Zoology 61:147-160.

PrIEM, F. 1914. Sur des poissons fossiles et en particulier des siludires du Tertiaire supérieur et des couches récentes d'Afrique (Egypte et région du Tchad). Mémoires de la Société Géologique de France. Paléontologie 49:5-13.

PRINADA, V.D. 1927. [Report on excavation of sites, where dinosaur bones were discovered]. Izvestiya Geologicheskogo komiteta 45:453-454. [in Russian]

Pritchard, P.C.H., R.J. RabetT AND P.J. PiPer. 2009. Distinguishing species of geoemydid and trionychid turtles from shell fragments: evidence from the Pleistocene at Niah Caves, Sarawak. International Journal of Osteoarchaeology 19:531-550.

RABI, M. AND G. BOTFALVAI. 2008. A preliminary report on the Late Oligocene vertebrate fauna from Máriahalom, Hungary. Hantkeniana 6:177-185.

RAGE, J.-C. 2013. Mesozoic and Cenozoic squamates of Europe. Palaeobiodiversity and Palaeoenvironments 93:517-534.

Ramovš, A. 1974. Paleontologija. Ljubljana, Slovenia: Fakulteta za naravoslovje in tehnologijo, Univerza v Ljubljani. $304 \mathrm{pp}$.

RAMSAY, E.P. 1887. On a new genus and species of fresh water tortoise from the Fly River, New Guinea. Proceedings of the Linnean Society of New South Wales (Second Series) 1:158-162.

REED, F.R.C. 1932. New Miocene faunas from Cyprus. Geological Magazine 69:511-517.

REINACH, A. VON. 1900. Schildkrötenreste im Mainzer Tertiärbecken und in benachbarten ungefähr gleichaltrigen Ablagerungen. Abhandlungen der Senckenbergischen Naturforschenden Gesellschaft 28:1-135.

-1903. Schildkrötenreste aus dem ägyptischen Tertiär Abhandlungen Herausgegeben von der Senckenbergischen Naturforschenden Gesellschaft 29:1-64.

Rhodin, G.J.A., S. Thomson, G.L. Georgalis, H.-V. KarL, I.G. Danilov, A. Takahashi, M.S. DE la Fuente, et Al. 2015. Turtles and tortoises of the world during the rise and global spread of humanity: first checklist and review of extinct Pleistocene and Holocene chelonians. Chelonian Research Monographs 5:1-66.

Riabinin, A.N. 1930. On the fauna and age of the dinosaur beds in Amur River. Zapiski Rossiiskogo mineralogicheskogo obshchestva 59:41-51. [in Russian with English summary]

-1938. [Some results of the study of the Upper Cretaceous dinosaurian fauna from the vicinity of the station SaryAgach, South Kazakhstan]. Problemy Palaeontologii 4:130-136. [in Russian, with English summary]

Rieppel, O. 1979. Eine neue Trionyx (Reptilia, Chelonia) aus der oberen Süsswassermolasse von Oerlikon, Kanton Zürich. Vierteljahrsschrift der Naturforschende Gesellschaft in Zürich 124:141-155.

RIstoRI, G. 1891a. I cheloniani delle ligniti del Casino (Siena). Atti della Società Toscana di Scienze Naturali, Processi Verbali 7:308. -1891b. I cheloniani fossili di Montebamboli e Casteani (Maremma, Toscana). Atti della Società Toscana di Scienze Naturali, Processi Verbali 7:304-307.

-1895. Cheloniani fossili di Montebamboli e Casteani. Memoria paleontologica del prof. Giuseppe Ristori. Con appendice sui Cheloniani fossili del Casino (Siena). Pubblicazioni del Reale Istituto di Studi superiori in Firenze, lezione di scienze fisiche e naturale 21:1-104.

ROBINSON, P. AND C.C. BLACK. 1974. Vertebrate faunas from the Neogene of Tunisia. Annals of the Geological Survey of Egypt 4:319-332.

Roger, J., M. Pickford, H. Thomas, F. de Lapparent de Broin, P. TASSY, W. VAN NeER, C. Bourdillon-DE-GrissaC AND S. AL-BUSALDI. 1994. Découverte de vertébrés fossiles dans le Miocène de la région du Huqf au Sultanat d'Oman. Annales de Paléontologie 80:253-273.

Rose, K.D. 2006. The Beginning of the Age of Mammals. Baltimore, MD: Johns Hopkins University Press. 428 pp.

RosenkrantZ, A. 1923. En Trionyx fra Crania-Kalkblokke. Meddelelser fra Dansk geologisk Forening 6:3-14.

RƯCKERT-ÜLKÜMEN, N. 1963. Tertiäre Fische aus Thrakien und Dardanellen (Türkei). İstanbul Üniversitesi Fen Fakültesi mecmuas1, Series B 28:86-103.

RusSeLL, L.S. 1934. Fossil turtles from Saskatchewan and Alberta. Transactions of the Royal Society of Canada 28:101-110.

SACCO, F. 1889. I Cheloni astiani del Piemonte. Memorie della Reale Accademia delle Scienze di Torino 39:427-461.

-1894. Trionici di Monte Bolca. Atti della Reale Accademia delle Scienze di Torino 29:3-12.

-1895. Trionici di Monteviale. Atti della Reale Accademia delle Scienze di Torino 30:3-8.

SAHNI, A., R.S. BATRA AND S.B. BHATIA. 1984. Vertebrate assemblage from the Upper Subathu (middle Eocene) of the Bilaspur area, Himachal Pradesh, India. Proceedings of the Indian Colloquium on Micropalaeontology and Stratigraphy 10:357-368.

Sahni, A., S.B. Bhatia, J.-L. Hartenberger, J.-J. Jaeger, K. KUMAR, J. SUdRE AND M. ViANEY-LIAUd. 1981. Vertebrates from the Subathu formation and comments on the biogeography of Indian subcontinent during the early Paleogene. Bulletin de la Société Géologique de France 23:684-695.

SAHNI, A. AND V.P. Mishra. 1975. Lower Tertiary vertebrates from western India. Monographs of the Paleontological Society of India 3:1-48.

SCANLON, J.D. 1993. Madtsoiid snakes from the Eocene Tingamarra Fauna of eastern Queensland. Kaupia, Darmstädter Beiträge zur Naturgeschichte 3:3-8.

SCHAUROTH, C.V. 1865. Verzeichnis der Versteinerungen im Herzoglichen Naturalienkabinett zu Coburg No. 1-4328. Coburg, Germany: Dietzsche Hofdruckerei. 265 pp.

SCHEYER, T.M., T. MÖRS AND E. EINARSSON. 2012. First record of soft-shelled turtles (Cryptodira, Trionychidae) from the Late Cretaceous of Europe. Journal of Vertebrate Paleontology 32:1027-1032.

SCHEYER, T.M., E.V. SYROMYATNIKOVA AND I.G. DANILOV. 2017. Turtle shell bone and osteoderm histology of Mesozoic and Cenozoic stem-trionychian Adocidae and Nanhsiungchelyidae (Cryptodira: Adocusia) from Central Asia, Mongolia, and North America. Fossil Record 20:69-85. 
SCHLEICH, H.-H. 1981. Jungtertiäre Schildkröten Süddeutschlands unter besonderer Berücksichtigung der Fundstelle Sandelzhausen. Courier Forschungsinstitut Senckenberg 48:1-372.

-1985. Zur Verbreitung tertiärer und quartärer Reptilien und Amphibien. I. Süddeutschland. Münchner Geowissenschaftliche Abhandlungen, Series A: Geologie und Paläontologie 4:67-149.

-1986. Neue Reptilienfunde im Tertiär Deutschlands: 6. Schildkröten- und Krokodilreste aus dem Braunkohlentagebau Gombeth bei Borken (Hessen). Lippischen Mitteilungen aus Geschichte und Landeskunde 55:281-288.

-1988. Eozäne Schildkrötenreste (Reptilia, Testudines) von St. Pankraz am Haunsberg (Österreich). Studia Geologica Salmanticensia, Volume Especial 3:165-184.

-1994. Neue Reptilienfunde aus dem Tertiär Deutschlands. 13. Schildkröten- und Krokodilreste aus der eozänen Braunkohle des Untertagebaues Stolzenbach bei Borken (Hessen). Courier Forschungsinstitut Senckenberg 173:79101.

SCHMidT, K.P. 1945. A new turtle from the Paleocene of Colorado. Fieldiana Geology 10:1-4.

SHEBZUKHOVA, E.A. AND K.K. TARASENKO. 2007. [New findings of Trionyx khosatzkyi from the Middle Sarmatian sediments in the Belaya River]. Bulletin of Adyghe State University, Natural-Mathematical and Technical Sciences Series 2007:1-2. [in Russian]

Shuvalov, V.F. AND V.M. ChKHIKVADZE. 1975. [New data on the Late Cretaceous turtles of south Mongolia]. Trudy Sovmestnoy Sovetsko-Mongolskoy Paleontologicheskoy Ekspeditsii 2:214-229. [in Russian]

-1979. [On the stratigraphic and systematic position of some freshwater turtles from new Cretaceous localities in Mongolia]. Trudy Sovmestnoy Sovetsko-Mongolskoy Paleontologicheskoy Ekspeditsii 8:58-76. [in Russian]

Simionescu, I. 1930. Vertebratele Pliocene de la Măluşteni (Covurlui). Publicaţiunile Fondului Vasile Adamachi 9:83-151.

SIsmondA, A. 1836. Découverte d'une Trionix et d'un crustacé aux collines de Saint-Etienne Poevo, Province d'Alva. Bulletin de la Société Géologique de France 7:207.

-1839 . Notizie intorno a due fossili trovati nei colli di San Stefano Roero. Memorie della Reale Accademia delle Scienze di Torino 1:85-90.

Smith, T., K. Kumar, R.S. Rana, A. Folie, F. Solé, C. Noiret, T. STEEMAN, A. SAHNi AND K.D. Rose. 2016. New early Eocene vertebrate assemblage from western India reveals a mixed fauna of European and Gondwana affinities. Geoscience Frontiers 7:969-1001.

Smith, T., F. Quesnel, G. De Plöeg, D. De Franceschi, G. Métais, E. De Bast, F. Solé, et AL. 2014. First Clarkforkian equivalent Land Mammal Age in the latest Paleocene basal Sparnacian facies of Europe: fauna, flora, paleoenvironment and (bio)stratigraphy. PLoS ONE 9:e86229. doi: 10.1371/ journal.pone.0086229.

SOCHAVA, A.V. 1975. [Stratigraphy and lithology of the Upper Cretaceous deposits of southern Mongolia]. Trudy Sovmestnoy Sovetsko-Mongolskoy Nauchno-Issledovatelskoy Geologicheskoy Ekspeditsii 13:113-182. [in Russian]

SOUZA TORRES, A. 1947. Um Trionyx do Tortoniano portugués. Las Ciencias 12:535-537.
SRIVASTAVA, R. AND R. PATNAIK. 2002. Large soft-shelled turtles from the Upper Pliocene rocks of Saketi (district, Sirmaur), Himachal Pradesh, India. Journal of the Palaeontological Society of India 47:65-76.

STAESCHE, K. 1975. Die Schildkrötenreste der türkischen Fundstellen. Geologisches Jahrbuch, Series B 15:117-118.

Staesche, K., H.-V. Karl and U. Staesche. 2007. Fossile Schildkröten aus der Türkei. Geologisches Jahrbuch, Series B 98:91-149.

STERLI, J. 2015. A review of the fossil record of Gondwanan turtles of the clade Meiolaniformes. Bulletin of the Peabody Museum of Natural History 56:21-45.

Stojanov, A. 2009. Erster Nachweis einer Riesenlandschildkröte (Geochelone s.l. Gray, 1872) aus Bulgarien. Revue de Paléobiologie 28:457-470.

STUR, D. 1874. Trionyx und andere Petrefakten aus der Braunkohle von Klösterle. Verhandlungen der KaiserlichKöniglichen Geologischen Reichsanstalt 1874:225-226.

SukHANov, V.B. 2000. Mesozoic turtles of Middle and Central Asia. In: M.J. Benton, M.A. Shishkin, D.M. Unwin and E.N. Kurochkin, eds. The Age of Dinosaurs in Russia and Mongolia. Cambridge: Cambridge University Press. pp. 309-367.

SUZUKI, S. AND P. NARMANDAKH. 2004. Change of the Cretaceous turtle faunas in Mongolia. Hayashibara Museum of Natural Sciences Research Bulletin 2:7-14.

SwinTon, W.E. 1926. Fossil Reptilia. Geological Survey of Uganda Occasional Papers 2:37-44.

SZALAI, T. 1934. Die fossilen Schildkröten Ungarns. Folia Zoologica et Hydrobiologica 6:97-142.

TAO, H. 1986. Report of a new fossil soft-shelled turtle, Trionyx liupani from Taiwan, with comparative study to the living species, Trionyx sinensis (Wiegmann). Journal of the Taiwan Museum 39:21-41.

TaskavaK, E., M.J. Reimann and W.N. Polder. 1999. First record of the Nile soft-shelled Turtle, Trionyx triunguis, from Kos Island, Greece, with comments on its occurrence in the eastern Mediterranean. Chelonian Conservation and Biology 3:510-512.

TePPNER, W. 1913. Südsteirische Trionyx-Reste im Kärntner Landesmuseum in Klagenfurt. Verhandlungen der Kaiserlich-Königlichen Geologischen Reichsanstalt 1913:322-332.

-1914a. Fossile Schildkrötenreste von Göriach in Steiermark. Mitteilungen des naturwissenschaftlichen Vereins für Steiermark 50:95-98.

$-1914 \mathrm{~b}$. Trionyx pliocenicus Lawley $=$ Trionyx Hilberi $\mathrm{R}$. Hoernes. Centralblatt für Mineralogie, Geologie und Paläontologie 1914:29-31.

-1914c. Zur phylogenetischen Entwicklung der 'protriunguiden Trionychiden' des Tertiärs und Trionyx petersi var. trifailensis nov. var. aus dem Miozän von Trifail in Steiermark. Centralblatt für Mineralogie, Geologie und Paläontologie 1914:628-638.

Thomas, H., S. Sen, M. Khan, B. Battail and G. Ligabue. 1982. The lower Miocene of As Sarrar (Eastern Province, Saudi Arabia). Atlal 5:109-136.

Thomas, H., S. Sen AND G. Ligabue. 1980. La faune miocène de la Formation Agha Jari du Jebel Hamrin (Irak). Proceedings of the Koninklijke Nederlandse Akademie van Wetenschappen 83:269-287. 
Thunberg, C.P. 1787. Beskrifning på Trenne Sköld-paddor. Kongliga Vetenskaps Academiens Nya Handlingar, Stockholm 8:178-180. [in Swedish]

Tong, H., L. LI AND H. OuYang. 2014. A revision of Sinaspideretes wimani Young \& Chow, 1953 (Testudines: Cryptodira: Trionychoidae) from the Jurassic of the Sichuan Basin, China. Geological Magazine 151:600-610.

ToNG, H., J. ZHANG AND J. Li. 2010. Anosteira maomingensis (Testudines: Carettochelyidae) from the Late Eocene of Maoming, Guangdong, southern China: new material and re-description. Neues Jahrbuch für Geologie und Paläontologie, Abhandlungen 256:279-290.

ToulA, F. 1882. Einige neue Wirbelthierreste aus der Braunkohle von Göriach bei Turnau in Steiermark.Verhandlungen der Kaiserlich-Königlichen Geologischen Reichsanstalt 1882:274-279.

TRIPATHI, C. 1964. A note on the geology and vertebrate fossils of Sayamalai area, Tirunelveli district, Madras. Records of the Geological Survey of India 93:257-262.

TunA, V. 1988. The remains of a fossil soft-shelled Turtle (Trionyx) from Bayraktepe (Turkey). Zoology in the Middle East 2:63-67.

[TTWG] TURTLE TAXONOMY WORKING GROUP. 2014. Turtles of the world, 7th edition: annotated checklist of taxonomy, synonymy, distribution with maps, and conservation status. Chelonian Research Monographs 5:329-479.

VANG-LAURIDSEN, H. 1998: Tertiary Trionychidae (Reptilia; Testudines) from the Carpathian Basin [dissertation] Copenhagen, Denmark: University of Copenhagen, 130 pp.

VIDAL, L.M. AND C. DEPÉRET. 1906. Contribución al estudio de Oligoceno en Cataluña. Memorias de la Real Academia de Ciencias y Artes de Barcelona 19:1-19.

Vignaud, P., P. Duringer, H.T. Mackaye, A. Likius, C. BLONDEL, J.-R. BoISSERIE, L. DE BONIS, ET AL. 2002. Geology and palaeontology of the Upper Miocene Toros-Menalla hominid locality, Chad. Nature 418:152-155.

VINCENT, G. 1875. Note sur la faune Bruxelliense des environs de Bruxelles. Annales de la Société malacologique de Belgique 10:23-32.

VITEK, N.S. 2012. Giant fossil soft-shelled turtles of North America. Palaeontologia Electronica 15:1-43.

ViteK, N.S. AND I.G. DANILOV. 2010. New material and a reassessment of soft-shelled turtles (Trionychidae) from the Late Cretaceous of Middle Asia and Kazakhstan. Journal of Vertebrate Paleontology 30:383-393.

-2012. New data on the soft-shelled turtles from the Upper Cretaceous Kyrkkuduk I locality of southern Kazakhstan. Proceedings of the Zoological Institute of the Russian Academy of Sciences 316:50-56.

-2013. Soft-shelled turtles (Trionychidae) from the Bissekty Formation (Upper Cretaceous: Turonian) of Uzbekistan: Skull-based taxa and probable skull-shell associations. Cretaceous Research 43:48-58.

-2014. Soft-shelled turtles (Trionychidae) from the Cenomanian of Uzbekistan. Cretaceous Research 49:1-12.

-2015 . New material of Ulutrionyx ninae from the Oligocene of Kazakhstan, with a review of Oligocene trionychids of Asia. Journal of Vertebrate Paleontology 35:e973570. doi: 10.1080/02724634.2015.973570.

ViteK, N., I.G. DANILOV, Y. NAKajIMA AND R. Hirayama. 2017. Redescription of the skull of 'Trionyx' kyrgyzensis and improved phylogenetic taxon sampling of Cretaceous and Palaeogene soft-shelled turtles (Trionychidae) of Asia, including the oldest crown trionychids. Journal of Systematic Palaeontology. doi: 10.1080/14772019.2017.1283365.

VITEK, N.S. AND W.G. JOYCE. 2015. A review of the fossil record of New World turtles of the clade Pan-Trionychidae. Bulletin of the Peabody Museum of Natural History 56:185-244.

VLACHOS, E., I. CERDA AND E. Tsoukala. 2015. The first record of a soft-shelled turtle (Testudines: Pan-Trionychidae) from southern Balkans (Pliocene, Gefira, N. Greece) and new information from bone histology. Science of Nature 102:45. doi: 10.1007/s00114-015-1295-2

VREMIR, M. 2004. Fossil turtle found in Romania-overview. A Magyar Állami Földtani Intézet Évi Jelentése 2002:143-152.

-2013. An early Eocene freshwater turtle assemblage from the şimleu Basin (NW Romania): paleobiogeographic significance. Acta Musei Sabesiensis 5:597-625.

VREMIR, M. AND V. CODREA. 1997. A soft-shelled turtle (Testudines, Trionychidae) in the Eggenburgian of Coasta Mare (Cluj). Nymphaea, Folia Naturae Bihariae 23-25:69-76.

VRemir, M., V. Codrea AND B. FarKas. 1997. Trionyx stiriacus Peters, 1855 (Reptilia, Testudines) from the Sarmatian (Middle Miocene) of Minişu de Sus (Romania). Annales Historico-Naturales Musei Nationalis Hungarici 89:43-52.

WALKER, C.A. AND R.T.J. MoODY. 1974. A new trionychid turtle from the Lower Eocene of Kent. Palaeontology 17:901-907.

-1985. Redescription of Eurycephalochelys, a trionychid turtle from the lower Eocene of England. Bulletin of the British Museum, Geology 38:373-380.

WANG, X., Z. QIU AND N.D. OpdyKe. 2003. Litho-, bio-, and magnetostratigraphy and paleoenvironment of Tunggur Formation (Middle Miocene) in central Inner Mongolia, China. American Museum Novitates 3411:1-31.

WANK, M. 1977. Fischotter- und Schildkrötenfunde im Mittelmiozän von Schönweg (Lavanttal, Kärnten). Carinthia II 167:153-156.

WeSt, R.M., J.H. Hutchison AND J. MuntHe. 1991. Miocene vertebrates from the Siwalik Group, western Nepal. Journal of Vertebrate Paleontology 11:108-129.

West, R.M., J.R. LuKaCs, J. Munthe JR. AND S.T. Hussain. 1978. Vertebrate fauna from Neogene Siwalik Group, Dang Valley, western Nepal. Journal of Paleontology 52: 1015-1022.

WHITE, A.W. 2001. A new Eocene soft-shelled turtle (Trionychidae) from Murgon, south-eastern Queensland. Memoirs of the Association of Australasian Palaeontologists 25:37-43.

White, E.I. 1931. The Vertebrate Faunas of the English Eocene, Volume 1. London: British Museum (Natural History). 123 pp.

WIEGMANN, A.F.A. 1835. Beiträge zur Zoologie gesammelt auf einer Reise um die Erde von Dr. F.J.F. Meyen. Siebente Abhandlung. Amphibien. Nova Acta Physico-Medica Academia Caesarea Leopoldino-Carolina 17:185-268.

Wings, O., M. Rabi, J.W. Schneider, L. SchWermann, G. Sun, C. ZHOU AND W.G. JoYCE. 2012. An enormous Jurassic turtle bone bed from the Turpan Basin of Xinjiang, China. Naturwissenschaften 99:925-935.

WINKLER, T.C. 1869a. Des tortues fossiles conservées dans le Musée Teyler et dans quelques autres Musées. Haarlem, The Netherlands: Héritiers Loosjes. 151 pp. 
-1869b. Deux nouvelles tortues fossiles. Archives néerlandaises des sciences exactes et naturelles 4:342-358.

WooD, R.C. 1979. First record of a fossil trionychid skull from Africa. Herpetologica 35:360-364.

-1987. Fossil turtles from the Sahabi Formation. In: N.T. Boaz, A. El-Amauti, A.W. Gaziry, J. de Heinzelin and D. Dechant Boaz, eds. Neogene Palaeontology and Geology of Sahabi. New York: Alan R. Liss. pp. 107-112.

-2013. Fossil turtles from Lothagam. In: M.G. Leakey and J.M. Harris. Lothagam: The Dawn of Humanity in Eastern Africa. New York: Columbia University Press. pp. 115-136. XING, H., Y. He, L. Li AND D. XI. 2012. A review on the study of the stratigraphy, sedimentology, and paleontology of the Iren Dabasu Formation, Inner Mongolia. In: W. Dong, ed. Proceedings of the Thirteenth Annual Meeting of the Chinese Society of Vertebrate Paleontology. Beijing: China Ocean Press. pp. 1-44.

YE, X. 1994. Fossil and Recent Turtles of China. Beijing: Science Press. 112 pp.

YeH, H.-K. 1962. Note on two fossil trionychid turtles from Shantung and Chekiang. Vertebrata Palasiatica 6:384-389.

-1963. Fossil turtles of China. Palaeontologia Sinica, New Series C 150:1-113.
-1965. New materials of fossil turtles of Inner Mongolia. Vertebrata Palasiatica 9:47-69.

-1974. [A new fossil Trionyx from Fuchien]. Vertebrata Palasiatica 12:190-192. [in Chinese with English abstract]

YounG, C.-C. AND M.-C. CHOw. 1953. [New Mesozoic reptiles from Szechuan]. Palaeontologia Sinica 1:87-110. [in Chinese with English abstract]

ZBYsZEWSKY, G. 1949. Les vertébrés du Burdigalien supérieur de Lisbonne. Lisbon, Portugal: Services ge¥ologiques du Portugal. $77 \mathrm{pp}$

ZHANG, M. 1984. A new species of Pelochelys from Zhejiang, with subfossil description. Acta Herpetologica Sinica 3:71-76. [in Chinese with English summary]

Zigno, A. DE. 1889. Chelonii scoperti nei terreni Cenozoici delle Prealpi Venete: Memoria. Memorie del Regio Istituto Veneto di Scienze Lettere Arti 23:119-130.

Zoboli, D. AND G.L. Pillola. 2016. I rettili miocenici conservati nel Museo Sardo di Geologia e Paleontologia Domenico Lovisato (Cagliari, Italia). Museologia Scientifica 10:81-87.

-2017. Early Miocene insular vertebrates from Laerru (Sardinia, Italy): preliminary note. Rivista Italiana di Paleontologia e Stratigrafia 123:149-158.

Editor's note: This article is intended to be included with others in a forthcoming book being coordinated by Walter G. Joyce to elucidate the fossil record of turtles. The individual articles that will form the components of this book are being published separately in the next several volumes of the Bulletin of the Peabody Museum of Natural History. 